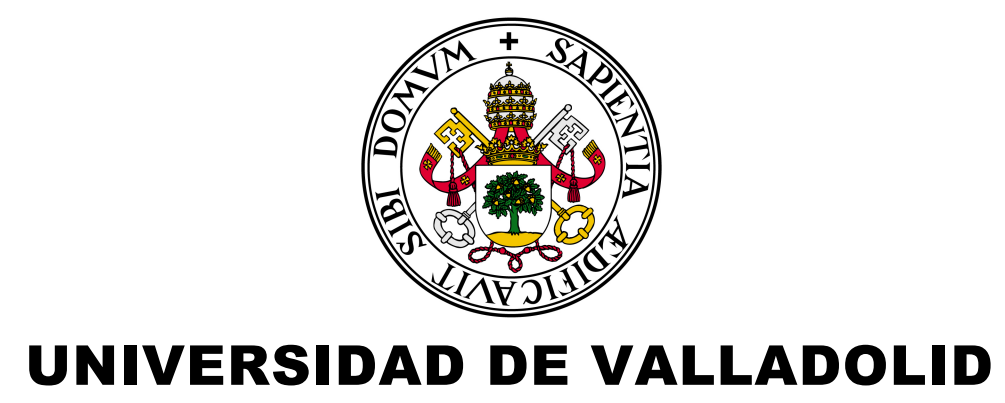

FACULTAD DE MEDICINA

DEPARTAMENTO DE CIRUGÍA, OFTALMOLOGÍA,

OTORRINOLARINGOLOGÍA Y FISIOTERAPIA

TESIS DOCTORAL

\title{
Valoración de la selección de los vasos del colgajo DIEP para la reconstrucción mamaria
}

\author{
RUBÉN ÁLVAREZ GARCÍA
}

\author{
DIRECTOR \\ PROF. DR. CARLOS VAQUERO PUERTA \\ CODIRECTORA \\ DRA. MARIA VICTORIA DIAGO SANTAMARÍA
}



A mis niños, Fer y Blanca, y a María 



\section{AGRADECIMIENTOS}

A todas las pacientes que han participado en este estudio. Gracias por confiarme vuestras esperanzas, expectativas e ilusiones.

Al Profesor Dr. Carlos Vaquero Puerta, por tus enseñanzas y consejos durante todos estos años, primero como estudiante, luego durante mi formación en microcirugía y por último en la realización de esta tesis.

A la Dra. María Victoria Diago Santamaría, por todos los momentos que hemos compartido en el quirófano y por la ayuda que me has ofrecido fuera de él. Gracias por tu comprensión y tu fe en mi, incluso en aquellos momentos en los que creí que no sería posible realizar este tabajo.

A Eva Vallejo Pascual, por tu ayuda incondicional y sobretodo tu paciencia con la estadística.

A David Robla Costales. Ha sido un verdadero placer haber trabajado todos estos años a tu lado. Empezamos con muy poquito pero con muchas ilusiones y con el tiempo y mucho esfuerzo hemos sobrepasado metas a las que no pensamos ni llegar. Sin ti, nada de esto habría sido posible.

A mis compañeros del Servicio de Cirugía Plástica del Hospital de León, Bárbara, Paco, Esperanza, Nazaret, Elena y Leticia, por hacer que ningún reto parezca imposible y por luchar cada caso hasta el final.

A Carmen y Rocío, nuestras enfermeras en el quirófano. Vuestra capacidad de trabajo y profesionalidad siempre me ha resultado encomiable. Sólo los que hemos trabajado con vosotras sabemos que teneis bastante culpa en el éxito de todas estas cirugías.

A todas los profesionales que han colaborado, y han sido muchos, en que nuestras pacientes recobren de nuevo su vida. 
A Jaume Estrada Cuxart, por todas las lecciones que me diste como cirujano y como persona. Y gracias por enseñarme a hacer "DIEPs".

A Pepe y Rosa, por estar siempre ahí.

A mi hermano Jose Miguel, a mi padre Miguel y en especial a mi madre, Maria Jesús, por apoyarme siempre y por demostrarme que merece la pena luchar por lo que quieres.

Y sobretodo a María. Esta tesis sólo ha sido posible por el sacrificio que has realizado durante todos estos años. Este éxito también es tuyo. 
ÍNDICE 

1. EL CÁNCER DE MAMA 17

1.1. EPIDEMIOLOGÍA 17

1.2. FACTORES DE RIESGO 18

1.3. CLASIFICACIÓN ANATOMOPATOLÓGICA 23

1.4. CLASIFICACIÓN TNM 26

1.5. TRATAMIENTO DEL CÁNCER DE MAMA 30

2. RECONSTRUCCIÓN MAMARIA $\quad 43$

2.1. FACTORES PSICOLÓGICOS RELACIONADOS CON EL CÁNCER DE MAMA. JUSTIFICACIÓN DE LA $\begin{array}{ll}\text { RECONSTRUCCIÓN MAMARIA } & 44\end{array}$

2.2. EVOLUCIÓN HISTÓRICA DE LA RECONSTRUCCIÓN MAMARIA 46

2.3. RECONSTRUCCIÓN MAMARIA INMEDIATA Y DIFERIDA 53

2.4. TÉCNICAS DE RECONSTRUCCIÓN MAMARIA 56

3. CONSIDERACIONES ANATÓMICAS DE LA PARED ANTERIOR DEL ABDOMEN Y DEL $\begin{array}{ll}\text { COLGAJO DIEP } & \mathbf{7 8}\end{array}$

4. ESTUDIO VASCULAR DE LA PARED ABDOMINAL CON TÉCNICAS RADIOLÓGICAS 93

4.1. ECOGRAFÍA DOPPLER COLOR 94

4.2. DOPPLER BIDIRECCIONAL 97

4.3. ANGIOGRAFÍA POR TC MULTICORTE 98

4.4. ANGIOGRAFÍA POR RESONANCIA NUCLEAR MAGNÉTICA (ANGIO RNM) 101

4.5. PROCESAMIENTO DIGITAL DE IMÁGENES 102

\section{JUSTIFICACIÓN, HIPÓTESIS Y OBJETIVOS 111}

1. JUSTIFICACIÓN 113

2. HIPÓTESIS 115

3. OBJETIVOS 116

3.1. OBJETIVO PRINCIPAL 116

3.2. OBJETIVOS SECUNDARIOS 116

MATERIAL Y MÉTODOS

1. SELECCIÓN DE PACIENTES 119

1.1. Población OBJETO de ESTUdiO 119

1.2. CRITERIOS DE INCLUSIÓN 119 
1.3. CRITERIOS DE EXCLUSIÓN 119

1.4. CRITERIOS DE INDICACIÓN QUIRÚRGICA DE COLGAJO DIEP 120

1.5. REGISTRO PREOPERATORIO DE DATOS EN LA HISTORIA CLÍNICA 121

2. ESTUDIO ANGIO TC PREOPERATORIO

3. PROCEDIMIENTO OPERATORIO 126

3.1. PROTOCOLO PREOPERATORIO 126

3.2. MARCAJE PREOPERATORIO 127

$\begin{array}{lr}\text { 3.3. TÉCNICA QUIRÚRGICA } & 129\end{array}$

3.4. PROTOCOLO POSTOPERATORIO 134

3.5. SIMETRIZACIÓN DE LA MAMA RECONSTRUIDA Y LA MAMA CONTRALATERAL 134

3.6. RECONSTRUCCIÓN DEL COMPLEJO AREOLA-PEZÓN

4. RECOGIDA DE DATOS 137

4.1. DATOS RELACIONADOS CON LA PACIENTE 137

4.2. DATOS RELACIONADOS CON EL CÁNCER DE MAMA 139

4.3. DATOS RELACIONADOS CON EL COLGAJO Y CON LA INTERVENCIÓN QUIRÚRGICA 140

4.4. DATOS RELACIONADOS CON LA VASCULARIZACIÓN DEL COLGAJO 141

4.5. DATOS RELACIONADOS CON LAS COMPLICACIONES 146

4.6. INTERVENCIONES DE SIMETRIZACIÓN Y RECONSTRUCCIÓN DEL CAP 148

5. ANÁLISIS ESTADÍSTICO 150

RESULTADOS 153

1. DESCRIPCIÓN DE LA MUESTRA

2. ANÁLISIS DE LAS COMPLICACIONES

2.1. DESCRIPCIÓN DE LAS COMPLICACIONES 156

2.2. PROBLEMAS CIRCULATORIOS DEL COLGAJO 159

2.3. REINTERVENCIONES 162

2.4. ESTANCIA HOSPITALARIA 163

3. VARIABLES EPIDEMIOLÓGICAS Y FACTORES DE RIESGO CIRCULATORIO 167

3.1. EDAD 167

3.2. ÍNDICE DE MASA CORPORAL 168

3.3. FACTORES DE RIESGO VASCULAR 170

4. VARIABLES RELACIONADAS CON EL CÁNCER DE MAMA 177

$\begin{array}{ll}\text { 4.1. Histología } & 177\end{array}$

$\begin{array}{ll}\text { 4.2. } & \text { BIOPSIA SELECTIVA DE GANGLIO CENTINELA } \\ & 177\end{array}$ 
$\begin{array}{ll}\text { 4.3. LINFADENECTOMÍA AXILAR } & 178\end{array}$

4.4. RADIOTERAPIA 179

4.5. QUIMIOTERAPIA 181

4.6. HORMONOTERAPIA 183

4.7. ANTECEDENTE DE CIRUGÍA CONSERVADORA DE MAMA 185

4.8. TIEMPO TRANSCURRIDO ENTRE LA MASTECTOMÍA Y LA RECONSTRUCCIÓN 185

4.9. RECIDIVA DEL CÁNCER 186

5. VARIABLES EN RELACIÓN CON LA INTERVENCIÓN QUIRÚRGICA 188

5.1. LATERALIDAD DE LA RECONSTRUCCIÓN MAMARIA Y DE LA DISECCIÓN DEL COLGAJO 188

5.2. FRECUENCIA DE LOS VASORRECEPTORES SELECCIONADOS 188

5.3. TIEMPO OPERATORIO 189

6. VARIABLES RELACIONADAS CON EL ANGIO TC Y LA VASCULARIZACIÓN DE LA

PARED ABDOMINAL 193

6.1. TOMÓGRAFO 193

6.2. PATRÓN DE LA ARTERIA EPIGÁSTRICA INFERIOR PROFUNDA 193

6.3. VASOS PERFORANTES 194

6.4. LOCALIZACIÓN DE LAS VENAS EPIGÁSTRICAS INFERIORES SUPERFICIALES 195

6.5. HALLAZGOS COMPLEMENTARIOS DEL ANGIO TC 196

7. VARIABLES RELACIONADAS CON LA VASCULARIZACIÓN DEL COLGAJO 199

7.1. PATRÓN DE LA AEIP 199

7.2. TRAYECTO MUSCULAR DE LA PERFORANTE 202

7.3. CARACTERÍSTICAS DEL TRAYECTO DE LA PERFORANTE 204

7.4. LÍNEA DE LA PERFORANTE 205

7.5. LOCALIZACIÓN DE LA SALIDA DE LA PERFORANTE A NIVEL DE FASCIA ABDOMINAL 207

7.6. NÚMERO DE PERFORANTES DEL COLGAJO 212

7.7. RAMIFICACIÓN DE LA PERFORANTE 213

7.8. MEJOR PERFORANTE SOBRE LA QUE BASAR EL COLGAJO 216

7.9. CONEXIÓN DE LA PERFORANTE AL SISTEMA VENOSO SUPERFICIAL 218

7.10. REALIZACIÓN DE UNA ANASTOMOSIS VENOSA SUPERFICIAL 222

8. PROCEDIMIENTOS DE SIMETRIZACIÓN MAMARIA Y RECONSTRUCCIÓN DEL COMPLEJO AREOLA-PEZÓN

8.1. SIMETRIZACIÓN DE LA MAMA CONTRALATERAL 224

8.2. PROCEDIMIENTO SOBRE LA MAMA RECONSTRUIDA 225 
1. INTRODUCCIÓN

2. ANÁLISIS DE LAS COMPLICACIONES

2.1. NECROSIS TOTAL Y PARCIAL DEL COLGAJO 232

2.2. NECROSIS GRASA DEL COLGAJO 233

2.3. PRoBlEMAS CIRCULATORIOS DEL COLGajo 235

2.4. COMPETENCIA DE LA PARED ABDOMINAL 237

2.5. OTRAS COMPLICACIONES 239

2.6. ESTANCIA HOSPITALARIA 239

3. VARIABLES EPIDEMIOLÓGICAS Y FACTORES DE RIESGO CIRCULATORIO 241

3.1. EDAD 241

3.2. ÍNDICE DE MASA CORPORAL 241

3.3. TABAQUISMO 242

3.4. Cirugía ABDOMinal 243

3.5. OTROS FACTORES DE RIESGO CIRCULATORIOS 245

4. TRATAMIENTO ONCOLÓGICO ADYUVANTE 246

4.1. RADIOTERAPIA 246

4.2. QUIMIOTERAPIA 250

4.3. HORMONOTERAPIA 251

5. VARIABLES RELACIONADAS CON LA INTERVENCIÓN 252

5.1. FRECUENCIA DE LOS VASORRECEPTORES SELECCIONADOS 252

5.2. TIEMPO OPERATORIO 253

6. CONTRIBUCIÓN DE LA ANGIO TC EN LA PLANIFICACIÓN DE COLGAJOS DE PERFORANTES ABDOMINALES $\quad 256$

6.1. ESTUDIO CIRCULATORIO DE LA PARED ABDOMINAL 261

6.2. HALLAZGOS COMPLEMENTARIOS DEL ANGIO TC 263

7. ESTUDIO DE LA ARQUITECTURA CIRCULATORIA DEL COLGAJO 265

7.1. PATRÓN DE LA AEIP 266

7.2. TRAYECTO MUSCULAR DE LA PERFORANTE 267

7.3. CARACTERÍSTICAS DEL TRAYECTO DE LA PERFORANTE 268

7.4. LÍNEA DE LA PERFORANTE 269

7.5. LOCALIZACIÓN DE LA SALIDA DE LA PERFORANTE A NIVEL DE FASCIA ABDOMINAL 272

7.6. NÚMERO DE PERFORANTES DEL COLGAJO 273

7.7. RAMIFICACIÓN DE LA PERFORANTE 276 
7.8. MEJOR PERFORANTE SOBRE LA QUE BASAR EL COLGAJO

7.9. CONEXIÓN DE LA PERFORANTE AL SISTEMA VENOSO SUPERFICIAL 278

7.10. REALIZACIÓN DE UNA ANASTOMOSIS VENOSA SUPERFICIAL 280

8. SIMETRIZACIÓN 285

9. LIMITACIONES DE ESTE ESTUDIO 287

\begin{tabular}{lr} 
CONCLUSIONES & 289 \\
\hline
\end{tabular}

\begin{tabular}{ll} 
ANEXO & 293 \\
\hline
\end{tabular}

1. PROTOCOLO DE ACTUACIÓN PARA LAS PACIENTES INTERVENIDAS DE RECONSTRUCCIÓN MAMARIA CON COLGAJO DIEP 295

2. PROTOCOLO DE ANESTESIA PARA LAS PACIENTES INTERVENIDAS DE RECONSTRUCCIÓN MAMARIA CON COLGAJO DIEP 299

3. RECONSTRUCCIÓN MAMARIA POSTMASTECTOMÍA MEDIANTE COLGAJO DIEP 301 

INTRODUCCIÓN 



\section{EL CÁNCER DE MAMA}

El cáncer de mama es uno de los tumores más importantes en el mundo occidental, debido fundamentalmente a su alta incidencia y a la importante causa de mortalidad y morbilidad que representa entre las mujeres afectadas. Las consecuencias físicas, psicológicas y sociales de esta enfermedad superan aún hoy a las estrictamente sanitarias.

En los últimos años se han adquirido nuevos conocimientos acerca de esta enfermedad lo que ha permitido un diagnóstico y tratamiento más precoz que ha conducido a una significativa disminución de la morbimortalidad. Asimismo, se han descubierto algunos genes relacionados con el desarrollo de esta enfermedad, lo que ha posibilitado rastrear a aquellas mujeres con mayor riesgo, siendo sometidas en algunos casos a técnicas de mastectomía reductoras de riesgo. La tumorectomía y la técnica del ganglio centinela han reducido la extensión de las resecciones oncológicas, permitiendo realizar cirugías con menores secuelas y contribuyendo a un mejor afrontamiento psicológico de la enfermedad. Los tratamientos ayudantes como la quimioterapia, hormonoterapia y radioterapia han contribuido globalmente a la reducción de la mortalidad. Por último, el mejor conocimiento de los factores de riesgo poblaciones ha permitido seleccionar poblaciones de riesgo elevado de padecer cáncer de mama en los que se ha puesto en marcha programas de prevención con excelentes resultados $(1,2)$.

Debido a su importancia, la investigación, el diagnóstico y el tratamiento del cáncer de mama deben ser aspectos considerados como prioritarios dentro de la política sanitaria actual.

\subsection{Epidemiología}

El cáncer de mama es el tumor más frecuente en las mujeres tanto en los países desarrollados como en los países en desarrollo (excluyéndose los cánceres cutáneos no melanomas) y constituye la principal causa de muerte por cáncer en la población femenina 
en el mundo industrializado. La incidencia de cáncer de mama está aumentando en el mundo en desarrollo debido a la mayor esperanza de vida, el aumento de la urbanización y la adopción de estilos de vida occidentales (3).

En EEUU, el riesgo relativo de padecer una neoplasia maligna de mama es de $12,2 \%$, es decir, lo padecerán una de cada ocho mujeres, y una de cada 28 fallecerá por esta enfermedad (4). Se estima que en los países de la Unión Europea, la probabilidad de desarrollar un cáncer de mama antes de los 75 años es del $8 \%$.

Anualmente en nuestro país se diagnostican unos 22.000 casos al año y produce la muerte de casi 6.000 mujeres, con una tasa de incidencia ajustada por edad en el año 2006 de 94 por 100.000, una de las más bajas de la Unión Europea $(5,6)$. La probabilidad de que una mujer española desarrolle una neoplasia maligna de mama antes de cumplir los 75 años es del 5\% aproximadamente, es decir, se estima que 1 de cada 20 mujeres desarrollará la enfermedad antes de esta edad (7).

En Castilla y León las tasas brutas de incidencia por 100.000 mujeres en el año 2000 oscilaron desde los 56,75 casos de Ávila, hasta los 99,14 casos de Burgos. En nuestra comunidad los tumores malignos de la mama constituyen la segunda causa de muerte entre las mujeres, con una tasa específica de mortalidad de 28,65 defunciones por 100.000 habitantes en el año 2.000 y de 30,52 casos por 100.000 habitantes en el caso de la provincia de León (8).

\subsection{Factores de riesgo}

En el cáncer de mama se han descrito multitud de factores de riesgo. Sin embargo, los más importantes, aquellos que pueden variar de forma sustancial su incidencia son difícilmente modificables, como por ejemplo, los factores genéticos o los antecedentes personales de patología de mama (9). Aunque individualmente los diferentes factores varían poco el riesgo, son factores no excluyentes y pueden actuar de forma sinérgica (10). Por otra parte, más del 70\% de las mujeres que desarrollan una neoplasia maligna de mama 
no presentan ningún factor de riesgo conocido. Estos factores se pueden agrupar en diferentes categorías.

\section{Factores ambientales y relacionados con el estilo de vida}

Esta categoría esta formada por un grupo heterogéneo de factores como son una ingesta elevada de alcohol (11), el consumo de tabaco, la obesidad y las dietas con alto porcentaje de grasas, las radiaciones ionizantes (12) o tóxicos ambientales como el PVC, el teflón y los pesticidas. Este último factor puede tener relación con el aumento de la incidencia de cáncer de mama en las pacientes jóvenes de los países industrializados y puede tomar gran importancia en los próximos años cuando la cohorte de pacientes expuestas aumente de edad (13).

Un factor a tener cada vez más en cuenta es la obesidad. Su efecto sobre la acción de la aromatasa periférica y el incremento de los estrógenos circulantes han hecho que la obesidad se asocie con un aumento en el riesgo de padecer cáncer de mama postmenopáusico. Se ha comprobado que la actividad física presenta un efecto protector al disminuir el número de ciclos ovulatorios, los niveles de estrógenos y prevenir la obesidad (14), aunque también se ha comprobado que disminuye el riesgo de manera independiente del IMC, sobre todo en mujeres postmenopáusicas $(15,16)$. Una alta ingesta de vegetales también muestra un efecto protector directo a la vez que confiere un beneficio indirecto al prevenir el sobrepeso (17). Existen otros factores nutricionales protectores como el consumo de ácidos omega 3 (18) debido a la toxicidad directa que ocasionan sobre las células tumorales y a que potencian el efecto quimioterápico de algunas sustancias como el paclitaxel (19) o el transtuzumab, y el consumo de fitoestrógenos (20) por el poder antiestrogénico de la soja que actúa como inhibidor de la aromatasa.

\section{Factores hormonales}

En este grupo se engloban todos aquellos factores que tienen influencia sobre el perfil hormonal de la mujer. Son factores predisponentes la menarquia precoz, la menopausia 
tardía, la nuliparidad o dar a luz al primer hijo con una edad superior a 35 años. Los anticonceptivos orales también aumentan el riesgo de manera transitoria si bien este disminuye después de unos años de haber suspendido el tratamiento $(21,22)$.

Algunos de estos factores hormonales muestran un efecto protector. El embarazo a término es un factor protector frente al cáncer de mama (23), disminuyendo el riesgo especialmente cuando el embarazo sucede a edades jóvenes y aumentando el efecto protector con el número de embarazos. Cada año de lactancia materna disminuye un 4,7\% el riesgo de padecer cáncer de mama, que se suma a la disminución del $7 \%$ que confiere cada embarazo (23-25). En cambio, aquellas pacientes portadoras de la mutación BRCA 2 sufren un aumento de riesgo después del embarazo, especialmente crítico durante los dos años siguientes al parto (26). Los abortos, sean espontáneos o inducidos no interfieren en el riesgo de cáncer de mama ni en la población general (27) ni en las portadoras de mutación BRCA 2 (25).

\section{Factores hereditarios}

Una historia familiar de cáncer de mama es un conocido factor de riesgo. La magnitud de este riesgo varía dependiendo del número de familiares con cáncer de mama, del grado de parentesco y de la edad en el momento del diagnóstico. El riesgo relativo de cáncer de mama en pacientes con familiares directos afectados es de 1,5 cuando es la abuela, 1,8 cuando es la madre, 2,3 cuando es la hermana y del 14,0 cuando es la madre y la hermana. Un $20 \%$ de mujeres diagnosticadas de cáncer de mama presentan una historia familiar de la enfermedad y solo el 5-10\% tienen una verdadera predisposición hereditaria (28).

\section{Factores genéticos (29)}

a) Cáncer de mama hereditario de inicio temprano y síndrome de cáncer mamario ovárico:

Asociado inicialmente con una anormalidad genética en el brazo largo del cromosoma 17, el locus del gen responsable fue identificado en la región cromosómica 17q21, siendo 
posteriormente clonado y secuenciado como BRCA 1 . Se han identificado gran número de mutaciones en diferentes alelos de BRCA 1, la mayor parte de las cuales (86\%) dan por resultado una terminación prematura de la proteína BRCA 1. Diferentes alelos se asocian con distintos riesgos de desarrollar cáncer de mama y ovario. Se ha demostrado que la mutación de BRCA 1 es responsable del $45 \%$ de los cánceres de mama hereditarios.

El $80 \%$ de las familias en los que hay casos múltiples de cáncer mamario y ovárico tienen mutaciones del gen BRCA 1. Las mujeres con una mutación del BRCA 1 tienen una probabilidad de desarrollar cáncer de mama de entre un 40 - 87\%, con una edad media de inicio a los 45 años y un riesgo aumentado de cáncer contralateral hasta los 70 años. Las mutaciones del gen BRCA 1 no parecen incrementar el riesgo de cáncer mamario en varones, aunque los portadores de mutaciones de BRCA 1 pueden transmitir el alelo de alto riesgo a sus descendientes.

En 1994, Wooster y cols. (30) descubrieron una mutación en una región sobre el brazo largo del cromosoma 13 presente en familias con cáncer no relacionadas con BRCA 1. La región del denominado BRCA 2 se encuentra en el mapa en 13q12-13. El gen BRCA 2 es responsable del $35 \%$ de los cánceres de mama hereditarios y se relaciona con el $70 \%$ de las familias con cáncer no vinculadas al BRCA 1.

Existen estudios que indican que la mastectomía profiláctica reduce el riesgo de cáncer de mama entre un $85 \%$ y un $100 \%$ en mujeres portadoras de mutaciones (31). Con respecto a la técnica quirúrgica de elección hay que tener en cuenta que, a mayor cantidad de tejido resecado, mayor prevención. Por otro lado, la eliminación completa de todo el tejido mamario es casi imposible, por lo que persiste la necesidad de seguimiento.

En pacientes portadoras de mutaciones en el BRCA es conveniente iniciar mamografías entre los 25 y los 30 años. Existen estudios que han demostrado que la resonancia magnética es más sensible que la mamografía y la ecografía en la detección del cáncer de mama en mujeres con predisposición hereditaria (32). 


\section{b) Sindrome de Li-Fraumeni:}

El cáncer mamario es la manifestación más frecuente de este síndrome, que a su vez también se relaciona con tumores cerebrales, laríngeos, leucemia, sarcomas de tejidos blandos, osteosarcomas, y cáncer corticosuprarrenal. El 50\% de los pacientes presenta uno de los tumores antes de los 30 años y el $90 \%$ antes de los 60 años.

Puede ser causado por una mutación en línea germinal del gen TP53, si bien no aparece en todos los individuos. TP53 codifica una fosfoproteína nuclear de cuyo funcionamiento normal depende la interrupción del ciclo celular o apoptosis ante un daño del ADN. La ausencia de este efecto inhibitorio contribuye a la acumulación de mutaciones en el ADN.

\section{c) Sindrome de Muir-Torre:}

Comprende la asociación de tumores cutáneos y adenocarcinoma de las vías gastrointestinales y genitourinarias. Su presentación en mujeres se relaciona con una probabilidad del $12 \%$ de padecer un cáncer de mama. Se piensa que este síndrome pudiera ser una variante fenotípica del síndrome de Lynch II o cáncer colorrectal hereditario no polipósico (HNPCC). En ambos se encuentran implicados genes de reparación del ADN desiguales.

\section{d) Enfermedad de Cowden:}

Es una rara enfermedad autosómica dominante que incluye cáncer de mama bilateral (50\% antes de los 50 años), triquilemomas faciales múltiples, queratosis acrales, papilomatosis bucales, poliposis gastrointestinales, tumores de las vías genitales femeninas y tumores tiroideos benignos y malignos. No se ha podido identificar el gen causante.

\section{e) Síndrome de Peutz-Jeghers:}

Es una enfermedad autosómica dominante que se manifiesta con poliposis hamartomatosa de tubo digestivo (especialmente intestino delgado) y manchas de melanina en los labios y la mucosa bucal. El cáncer de mama generalmente es bilateral y ocurre entre los 20 y 40 años. La anomalía genética responsable es desconocida. 


\section{f) Mutación del gen CHEK2:}

Se considera responsable del 5\% de los cánceres hereditarios.

Los avances en el conocimiento del sustrato genético del cáncer de mama, han planteado nuevos conceptos diagnósticos y terapéuticos. Aquellas mujeres cuyo elevado riesgo de padecer la enfermedad ha sido identificado mediante una adecuada historia familiar y confirmado a través de estudios genéticos (BRCA 1 y BRCA 2), son candidatas a nuevos protocolos de vigilancia intensiva, a su incorporación a ensayos clínicos de nuevos fármacos de quimioprevención así como a valorar indicaciones quirúrgicas como la mastectomía profiláctica.

\subsection{Clasificación anatomopatológica}

Los tumores malignos de la mama se pueden clasificar según su estirpe histológica. Los tumores más frecuentes son de estirpe epitelial, teniendo su origen en las glándulas y conductos galactóforos.

\section{Tumores malignos epiteliales}

\section{Carcinomas in situ}

Son aquellos cánceres en los que no se observa que la proliferación neoplásica invada el estroma microscópicamente. Se dividen en ductales y lobulillares. Los carcinomas ductales in situ (CDIS) están siendo diagnosticado con más frecuencia desde que se instauró el screening mamario con mamografía. Según su morfología se pueden dividir en tipo "comedo" (asociados a agresividad), tipo "cribiforme" (de pronóstico más favorable) y tipo "papilar" (su pronóstico esta asociado al grado de necrosis).

Los carcinomas lobulillares in situ (CLIS) son considerados un marcador de riesgo para el desarrollo de carcinoma invasivo de diez veces superior a la población normal 
(fig.1). El CLIS se puede desarrollar en cualquiera de las dos mamas y ser a su vez lobulillar o ductal.

\section{Carcinomas infiltrantes (33)}

Constituyen el 95\% de las neoplasias invasivas de la mama, y según su estirpe se pueden clasificar en:

a) Carcinoma ductal infiltrante (CDI)

Es el tipo histológico más frecuente (fig. 1), constituyendo el $65-80 \%$ de todas las neoplasias de mama.

b) Carcinoma lobulillar infiltrante (CLI)

Es el segundo tipo histológico en frecuencia, y en muchas ocasiones es multicéntrico y bilateral. Se asocia con frecuencia al CLIS.

c) Carcinoma tubular

Se trata de una variedad histológica de excelente pronóstico en la que más de un $90 \%$ de la tumoración forma túbulos y se asocia habitualmente a calcificaciones.

d) Carcinoma cribiforme infiltrante

e) Carcinoma medular

Es una lesión circunscrita con buen pronóstico, pero su diagnóstico requiere unos criterios diagnósticos muy estrictos pues el CDI de alto grado puede mostrar en ocasiones las mismas características representando un peor pronóstico.

f) Carcinoma productor de mucina

g) Carcinoma neuroendocrino

h) Carcinoma papilar infiltrante

i) Carcinoma micropapilar infiltrante 
j) Carcinoma apocrino

k) Carcinoma metaplásico

l) Carcinoma rico en lípidos

m) Carcinoma secretor

n) Carcinoma adenoide quístico

o) Carcinoma de células claras

p) Carcinoma sebáceo

\section{Tumores mesenquimales (34)}

Los sarcomas de mama tienen una incidencia muy baja, inferior a $1 \%$ y su pronóstico es similar al de otras localizaciones. En esta categoría se incluyen el angiosarcoma, liposarcoma, rabdomiosarcoma, leiomiosarcoma y el osteosarcoma.

\section{Tumor phyllodes maligno}

Es una lesión mixta, con un componente epitelial y otro estromal. El componente estromal muestra densidad variable y puede diferenciarse habitualmente en fibrosarcoma. En ocasiones maligniza el componente epitelial considerándose un carcinoma originado de un tumor phyllodes.

\section{Procesos linfoproliferativos}

Los procesos linfoproliferativos malignos en la mama pueden originarse en ganglios linfáticos intramamarios o constituir una afectación secundaria de un proceso generalizado. La mayoría se trata de linfomas de células B, pero cualquiera de las variedades de procesos linfoproliferativos que afectan a los ganglios linfáticos pueden observarse en la mama. De especial actualidad está el linfoma anaplásico de células grandes asociado a implantes 
mamarios (35). Se trata de un linfoma de células T que aparece en la cápsula periprotésica de pacientes portadoras de prótesis mamarias. Se especula sobre un origen multifactorial pero sin que se conozca aún con exactitud su verdadera asociación causal con los implantes. Puede que se trate de una nueva entidad que necesite categorizarse en el futuro.

\section{Metástasis}

Tienen una incidencia muy baja en la mama. Su origen más frecuentes son el melanoma y el linfoma y en menor proporción los carcinomas pulmonares, gástrico y ovárico.

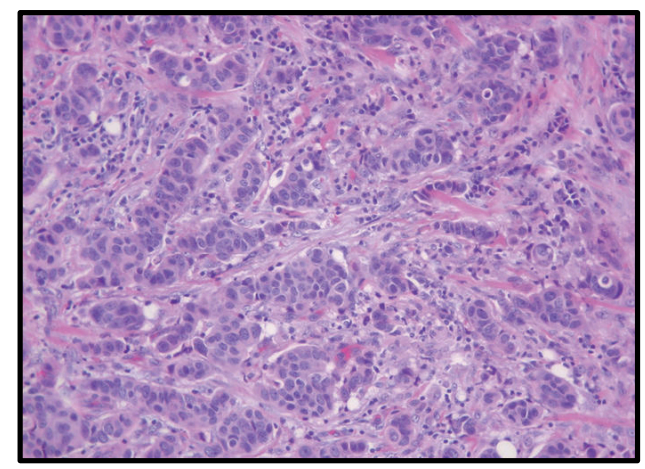

Figura 1: Carcinoma ductal infiltrante (derecha)

\subsection{Clasificación TNM}

El American Joint Committe on Cancer (AJCC) (36) establece una clasificación TNM y un estadiaje. Esta clasificación permite la agrupación de pacientes por estadios, con implicaciones terapéuticas sobre el abordaje locorregional y sistémico, permitiendo comparar los resultados de distintos centros. La estadificación se establece a partir de datos clínicos, radiológicos y de laboratorio

El sistema TNM permite clasificar a los tumores mamarios por estadios. La T corresponde al tamaño tumoral (0-4), la $\mathbf{N}$ a la afectación ganglionar (0-3) y la $\mathbf{M}$ a las metástasis a distancia (0-1). Existe una clasificación TNM clínica y otra patológica. A la 
clasificación patológica se le añade una p delante, e implica el examen microscópico del carcinoma primario. En el caso de la clasificación patológica del tumor, el tamaño tumoral sólo hace referencia a su componente invasivo, no a su componente in situ.

\section{Clasificación clínica TNM}

T: tamaño tumoral.

Tx: el tamaño del tumor primario no se puede evaluar.

T0: no hay evidencia de tumor primario.

Tis: carcinoma intraductal o lobulillar in situ, o enfermedad de Paget de la areola sin invasión asociada del tejido mamario normal.

T1: tumor de diámetro máximo $\leq 2 \mathrm{~cm}$.

T1mic: microinvasión de $0,1 \mathrm{~cm}$ de diámetro máximo.

T1a: diámetro máximo $>0,1 \mathrm{~cm}$ pero $\leq 0,5 \mathrm{~cm}$.

T1b: diámetro máximo $>0,5 \mathrm{~cm}$ pero $\leq 1 \mathrm{~cm}$.

T1c: diámetro máximo $>1 \mathrm{~cm}$ pero $\leq 2 \mathrm{~cm}$.

T2: tumor de diámetro máximo $>2 \mathrm{~cm} \mathrm{y} \leq 5 \mathrm{~cm}$.

T3: tumor de diámetro máximo $>5 \mathrm{~cm}$.

T4: tumor de cualquier tamaño con extensión directa a la pared del tórax o a la piel (la pared del tórax incluye las costillas, los músculos intercostales y el músculo serrato mayor, pero no los músculos pectorales).

T4a: extensión a la pared torácica.

T4b: edema, piel de naranja o ulceración de la piel de la mama o nódulos satélites en la piel de la misma mama.

T4c: $T 4 a+T 4 b$.

T4d: carcinoma inflamatorio.

$\mathbf{N}$ : afectación ganglionar.

Nx: los ganglios linfáticos no se pueden valorar.

N0: no hay evidencia de metástasis ganglionares regionales.

N1: metástasis móviles en ganglios axilares homolaterales. 
N2: metástasis fijas (a otros ganglios o estructuras) en ganglios axilares homolaterales, metástasis en mamaria interna homolateral detectada por métodos de imagen (excluyendo linfoscintigrafía) o por examen clínico.

N2a: metástasis en ganglios axilares homolaterales fijas entre si o a otras estructuras.

N2b: metástasis en mamaria interna homolateral detectada por métodos de imagen o exploración clínica, sin evidencia de metástasis axilares.

N3: metástasis en ganglios infraclaviculares homolaterales con o sin metástasis en ganglios axilares, o en ganglios mamarios internos detectadas por técnicas de imagen (excluyendo linfoscintigrafía), con presencia de metástasis axilares; o metástasis en ganglios supraclaviculares homolaterales con o sin afectación axilar y de cadena mamaria interna.

N3a: metástasis en ganglios infraclaviculares homolaterales.

N3b: metástasis en cadena mamaria interna homolateral y axilares.

N3c: metástasis supraclaviculares homolaterales.

M: metástasis a distancia.

Mx: no evaluable.

M0: no hay evidencia de metástasis a distancia.

M1: metástasis a distancia.

\section{Clasificación anatomopatológica pTNM}

pT: tamaño tumoral. Las categorías pT se corresponden con las categorías $\mathrm{T}$, teniendo en cuenta, como se ha comentado antes, que sólo se mide el tamaño del tumor invasivo, no el in situ.

pN: afectación ganglionar.

pNx: ganglios linfáticos no evaluables porque no fueron resecados o lo fueron previamente. 
pN0: ausencia de metástasis ganglionares.

Para valorar la existencia o no de células tumorales aisladas (acúmulo de células no mayor de $0.2 \mathrm{~mm}$ ), es preciso realizar técnicas de inmunohistoquímica (IHQ) o técnicas de biología molecular.

pN0(i-): no metástasis ganglionares detectadas histológicamente ni con IHQ.

pN0(i+): no metástasis ganglionares histológicamente detectables, IHQ+ para acúmulos celulares no mayores de $0.2 \mathrm{~mm}$.

pN0(mol-): no metástasis ganglionares histológicamente detectables, estudios de biología molecular negativos.

pN0(mol+): no metástasis histológicamente detectables, estudios de biología molecular positivos.

pN1: metástasis en 1-3 ganglios axilares y/o en ganglios de la cadena mamaria interna con enfermedad microscópica detectada por biopsia selectiva del ganglio centinela (BSGC), pero no detectada con métodos de imagen (excluida la linfogammagrafía) ni clínicamente.

pN1mi: micrometástasis $(>0,2 \mathrm{~mm} \mathrm{y} \leq 2 \mathrm{~mm})$.

pN1a: metástasis en 1-3 ganglios axilares.

pN1b: metástasis en la cadena mamaria interna con enfermedad microscópica detectada con BSGC pero no con métodos de imagen (excepto linfoscintigrafia), ni clínicamente evidentes.

pN1c: metástasis en 1-3 ganglios axilares y cadena mamaria interna con enfermedad microscópica detectada con BSGC (si la afectación de la cadena mamaria interna se acompaña de más de tres ganglios axilares afectos, se clasifica como pN3b para reflejar el incremento de carga tumoral). 


\section{Estadiaje}

\begin{tabular}{|c|c|c|c|}
\hline ESTADÍO & TUMOR & $\begin{array}{l}\text { AFECTACIÓN } \\
\text { GANGLIONAR }\end{array}$ & METÁSTASIS \\
\hline $\mathbf{0}$ & $\mathrm{T}_{\text {is }}$ & $\mathrm{N}_{0}$ & $\mathrm{M}_{0}$ \\
\hline $\mathbf{I}$ & $\mathrm{T}_{1}$ & $\mathrm{~N}_{0}$ & $\mathrm{M}_{0}$ \\
\hline \multirow{3}{*}{ IIA } & $\mathrm{T}_{0}$ & $\mathrm{~N}_{1}$ & $\mathrm{M}_{0}$ \\
\hline & $\mathrm{T}_{1}$ & $\mathrm{~N}_{1}$ & $\mathrm{M}_{0}$ \\
\hline & $\mathrm{T}_{2}$ & $\mathrm{~N}_{0}$ & $\mathrm{M}_{0}$ \\
\hline \multirow{2}{*}{ IIB } & $\mathrm{T}_{2}$ & $\mathrm{~N}_{1}$ & $\mathrm{M}_{0}$ \\
\hline & $\mathrm{T}_{3}$ & $\mathrm{~N}_{0}$ & $\mathrm{M}_{0}$ \\
\hline \multirow{5}{*}{ IIIA } & $\mathrm{T}_{0}$ & $\mathrm{~N}_{2}$ & $\mathrm{M}_{0}$ \\
\hline & $\mathrm{T}_{1}$ & $\mathrm{~N}_{2}$ & $\mathrm{M}_{0}$ \\
\hline & $\mathrm{T}_{2}$ & $\mathrm{~N}_{2}$ & $\mathrm{M}_{0}$ \\
\hline & $\mathrm{T}_{3}$ & $\mathrm{~N}_{1}$ & $\mathrm{M}_{0}$ \\
\hline & $\mathrm{T}_{3}$ & $\mathrm{~N}_{2}$ & $\mathrm{M}_{0}$ \\
\hline \multirow{3}{*}{ IIIB } & $\mathrm{T}_{4}$ & $\mathrm{~N}_{0}$ & $\mathrm{M}_{0}$ \\
\hline & $\mathrm{T}_{4}$ & $\mathrm{~N}_{1}$ & $\mathrm{M}_{0}$ \\
\hline & $\mathrm{T}_{4}$ & $\mathrm{~N}_{2}$ & $\mathrm{M}_{0}$ \\
\hline IIIC & Cualquier T & $\mathrm{N}_{3}$ & $\mathrm{M}_{0}$ \\
\hline IV & Cualquier T & Cualquier N & $\mathrm{M}_{1}$ \\
\hline
\end{tabular}

Tabla 1: Estadiaje

\subsection{Tratamiento del cáncer de mama}

Las opciones terapéuticas en las pacientes con cáncer de mama incluyen el tratamiento de la enfermedad locorregional, con tumorectomía y radioterapia o mastectomía, y el tratamiento de la enfermedad sistémica, con quimioterapia, hormonoterapia o terapia biológica. 


\section{Tratamiento quirúrgico de la mama}

A pesar del desarrollo de las terapias en las últimas décadas, a fecha de hoy el tratamiento del cáncer de mama continúa siendo eminentemente quirúrgico. Existen dos técnicas fundamentalmente: la cirugía conservadora y la mastectomía.

\section{Cirugía conservadora}

Este procedimiento tiene sus orígenes en la década de los años 70, cuando el National Cancer Institute de Milán realizó el primer gran ensayo entre 1973 y 1980, en el que comparó la mastectomía radical con la mastectomía parcial con vaciamiento axilar seguida de radioterapia para pacientes con cánceres en estadío clínico I. Los resultados no mostraron diferencias en cuanto a la supervivencia y se observaron mínimas diferencias en cuanto a la recidiva local entre los dos tratamientos $(37,38)$.

El tratamiento conservador consiste en la resección del tumor (tumorectomía) o de un cuadrante mamario (cuadrantectomía) preservando el resto de la glándula mamaria con su envoltura cutánea, al que se le asocia posteriormente un tratamiento radioterápico. La RT no aumenta la supervivencia global, pero sí disminuye el número de recidivas. El aumento del número de casos de cáncer mamario detectados en estadíos iniciales unido al desarrollo de tratamientos neoadyuvantes y la mejora de las técnicas conservadoras han hecho que sea la técnica quirúrgica más habitualmente utilizada (39).

El tratamiento conservador es de primera elección siempre y cuando se cumplan tres premisas fundamentales:

1. Cáncer de mama único y de pequeño tamaño, que puede ser extirpado con márgenes de resección libres de tumor preservando la mayor parte de la mama.

2. Es necesario que la paciente pueda recibir radioterapia externa posteriormente.

3. La paciente debe desear conservar la mama. 
Si no se cumplen estas condiciones, el tratamiento que se debe ofrecer a la paciente es la mastectomía.

En ocasiones puede ser necesario asociar técnicas de cirugía oncoplástica (fig. 2). Este concepto fue propuesto por Audretsch y cols. en $1994(40,41)$ para describir los procedimientos que permiten la resección de tumores y la reconstrucción inmediata de la mama con técnicas de restauración que aplican los principios de cirugía estética y sus variaciones según la ubicación de los tumores en los diferentes cuadrantes y la relación entre el volumen de la mama y el tamaño del tumor.

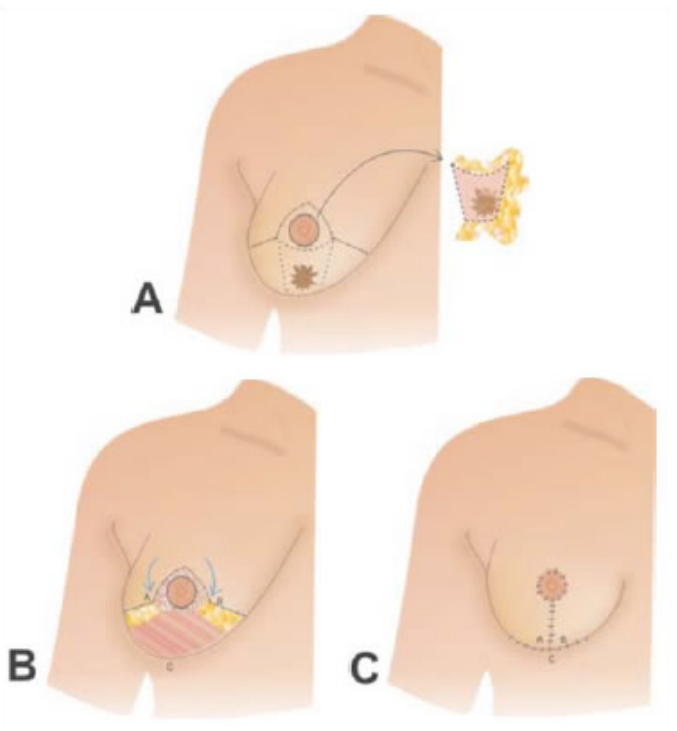

Figura 2: Cirugía Oncoplástica. Resección de un tumor en el polo inferior de la mama y reconstrucción inmediata mediante avance de ambos pilares dela mama. Ilustración tomada de Sánchez NB, Rubiano J. Oncoplastic surgery in mammary cancer. Rev Colomb Cir. 2008;23(4):217-29.

\section{Tratamiento radical: Mastectomía}

La cirugía radical de la mama incluye dos tipos de mastectomía fundamentalmente:

1. Mastectomía simple: consiste en la extirpación de la glándula mamaria, sin vaciamiento axilar. Está indicada en los siguientes casos: 
a) - Lesiones multicéntricas de carcinoma ductal.

b) - Sarcomas invasivos, cuando no están fijos a la pared torácica subyacente, fascia o músculo.

c) Debe ser valorada como profilaxis en pacientes de alto riesgo.

2. Mastectomía radical modificada tipo Madden (MRM) (fig.3): consiste en la extirpación de la glándula mamaria preservando ambos pectorales y linfadenectomía axilar de al menos los dos primeros niveles axilares de Berg. Las indicaciones para MRM incluyen una enfermedad multicéntrica (tumor presente en diferentes cuadrantes de la mama), imposibilidad de recibir radioterapia (condición necesaria para cirugía conservadora), presencia de tumores grandes en mamas pequeñas y preferencia de la paciente por este tipo de intervención. El vaciamiento axilar está indicado, más allá de la biopsia del ganglio centinela, cuando hay ganglios palpables o cuando los ganglios son positivos por biopsia.

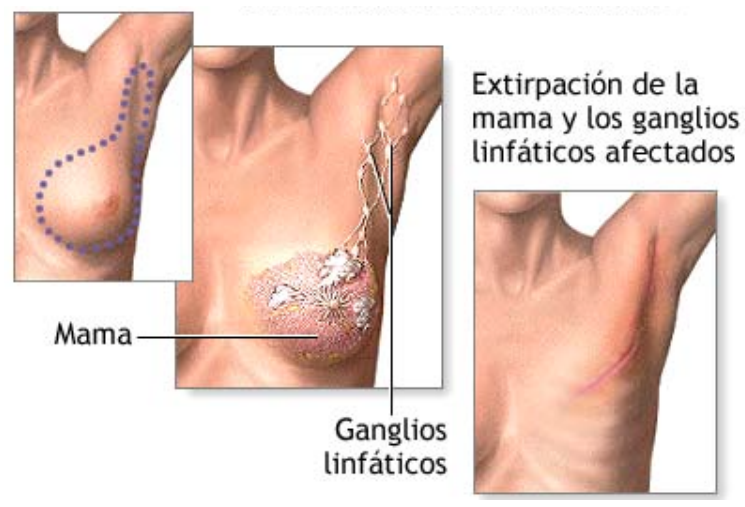

Figura 3: Mastectomía radical modificada.

\section{Tratamiento de la axila}

El estado de los ganglios axilares es el factor pronóstico más importante en el cáncer de mama. La biopsia del ganglio centinela (BSGC), técnica con mucha menor morbilidad, ha sustituido a la linfadenectomía axilar en la estadificación ganglionar, mostrándose al menos igual de eficaz en términos de intervalo libre de enfermedad y supervivencia global (9). 


\section{Biopsia selectiva de ganglio centinela}

El ganglio centinela se define como el primer ganglio de la cadena linfática que recibe el drenaje desde el tumor primario en la mama. La localización, exéresis y biopsia de los ganglios centinelas, supone la obtención de una muestra comparativamente mucho menor que la de la linfadenectomía completa, disminuyendo la morbilidad de la intervención radical y permitiendo un estudio histopatológico más minucioso. Cuando su biopsia resulta negativa, se evita el vaciamiento axilar, circunstancia que ocurre en el $65-70 \%$ de los tumores T1 y T2. Además, con la BSGC es posible realizar un diagnóstico histológico más preciso que permite identificar las micrometástasis y las células tumorales aisladas, con lo que se obtiene una estadificación más exacta que con la linfadenectomía axilar. Varios estudios han demostrado que la BSGC es un procedimiento seguro para predecir el compromiso axilar y los índices de recidiva son similares que con el vaciamiento axilar $(42,43)$. La BSGC se realiza tanto con cirugía conservadora como con mastectomía.

La localización del ganglio o ganglios centinela puede hacerse con isótopos radiactivos, generalmente nanocoloides de albúmina marcadas con 99-Tc, técnica que puede combinarse con la colorimétrica utilizando como colorantes el azul patente o el azul de isosulfán. Aunque el método combinado con isótopo y colorante incrementa la eficacia técnica (nivel de evidencia IIb) (44), se considera que usando solamente 99-Tc se puede obtener una tasa de falsos negativos igual o inferior al 5\% sin los riesgos del uso de colorantes, consistentes principalmente en reacciones anafilácticas.

\section{Estudio patológico del ganglio centinela: Método OSNA}

A lo largo de los años, se han hecho por parte de los patólogos grandes esfuerzos en el área del ganglio centinela, no sólo para conseguir la máxima sensibilidad y especificidad diagnóstica sino también para conseguir que tanto la cirugía sobre la mama como la cirugía sobre la axila pudieran realizarse en un solo tiempo quirúrgico, lo que implica la necesidad de que el diagnóstico intraoperatorio sea, a su vez, el diagnóstico definitivo. El estudio del ganglio centinela, base fundamental de la cirugía axilar conservadora para el cáncer de mama permite un diagnóstico mucho más minucioso y exhaustivo que el de la 
linfadenectomía axilar que, generalmente, incluye el estudio de una sola sección de aproximadamente $2 \mathrm{~mm}$ de grosor con Hematoxilina-Eosina. La aparición de una nueva técnica molecular, OSNA (One-Step-Nucleic-Acid-Amplification), ha marcado el inicio de una nueva etapa en la historia del ganglio centinela en cirugía mamaria. El procedimiento OSNA se basa en una reacción de amplificación en tiempo real mediada por "bucles" del ARNm (RT-LAMP) de la CK19 (ARNm-CK19). La técnica OSNA permite el diagnóstico del ganglio centinela en su totalidad, sin pérdida de tejido y en el tiempo intraoperatorio, reduciendo a cero el número de segundas intervenciones para la linfadenectomía (45). Las grandes aportaciones de este método incluyen su alta sensibilidad (82,7-98,2\%) y especificidad (94,8-97,7\%) diagnósticas y el permitir la estandarización al eliminar la variabilidad interobservador y unificar en un solo protocolo las distintas estrategias diagnósticas.

\section{Linfadenectomía axilar}

Idealmente, todas las pacientes con un cáncer invasivo en estadíos iniciales deberían ser sometidas a un estadiaje axilar $\mathrm{y}$, si es positivo, debería realizarse tratamiento quirúrgico de la axila. Su manejo adecuado es fundamental para prevenir la aparición de una recidiva axilar incontrolada. Algunas pacientes con cáncer invasivo pueden ser diagnosticadas de enfermedad axilar previamente al acto quirúrgico. La punción-aspiración con aguja fina guiada por ecografía puede, en ocasiones, diagnosticar la afectación ganglionar. La disección axilar total es efectiva para el control de la enfermedad local, y se han relatado tasas de recurrencia del 3 al 5\% a los 5 años. Resecciones menores, sin la posterior asociación de radioterapia, se asocian a mayores índices de recidiva axilar.

\section{Quimioterapia y terapias biológicas}

El tratamiento adyuvante sistémico tiene como objetivo la erradicación de la enfermedad micrometastásica, que potencialmente puede estar presente en todas las pacientes con cáncer de mama infiltrante a pesar de haber recibido un adecuado 
tratamiento local. El objetivo de la QT es reducir la recurrencia local y a distancia y aumentar la supervivencia.

Los fármacos más utilizados son adriamicina (A), 5 fluorouracilo $(F)$, metotrexate $(\mathrm{M})$, ciclofosfamida (C), taxotere (T) y vinorelbine (V), que se combinan en pautas de tratamiento como $\mathrm{CMF}, \mathrm{CAF}, \mathrm{TV}$. Otros fármacos de gran utilidad son mitoxantrone, taxol, gencitabina y capecitabina. Sus posibles efectos indeseables requieren un control de las dosis, modo y momento de administración.

Existen tres modalidades de quimioterapia para el tratamiento del cáncer de mama:

Quimioterapia neoadjuvante: antes de la cirugía. Está indicada en cánceres de mama localmente avanzados que no son resecables de entrada, y en el carcinoma inflamatorio. Una indicación opcional cada vez más utilizada es su utilización en tumores en estadíos iniciales con el fin de reducir el volumen tumoral y convertir una indicación de mastectomía en cirugía conservadora de mama. Se suele usar adriamicina y taxanos.

Quimioterapia adyuvante: después de la cirugía. Su indicación depende de los factores de pronóstico clásicos. Se consideran factores de riesgo según la conferencia de Sant Gallen de 2011 (46):

- edad $<35$ años.

- tamaño tumoral $>2 \mathrm{~cm}$.

- grado histológico 2-3.

- receptores hormonales negativos.

- sobreexpresión/amplificación de HER2.

- presencia de invasión vascular o linfática.

Cuando los ganglios axilares son negativos los pacientes se clasifican en bajo, medio y alto riesgo. Las pacientes de bajo riesgo (receptores hormonales + , tumores $<2 \mathrm{~cm}$, grado histológico I y mayores de 35 años no son susceptibles de QT adyuvante. Cuando existe riesgo medio o alto (receptores hormonales negativos, o positivos pero con alto grado histológico y en tumores $>2 \mathrm{~cm}$.) las pacientes se benefician de quimioterapia adyuvante. 
Cuando los ganglios axilares son positivos se pueden beneficiar de la quimioterapia, excepto en mujeres mayores de 70-75 años o con enfermedades que la contraindiquen.

Quimioterapia Paliativa.- Indicada en una enfermedad diseminada o en una recidiva, con receptores hormonales negativos, enfermedad visceral, intervalo corto desde la cirugía o sintomatología relacionada con la recidiva o la metástasis.

Actualmente, sin embargo, en base a los datos de múltiples estudios de biología molecular y perfiles génicos sabemos que esta clasificación basada en la afectación axilar engloba un mismo grupo a pacientes con características biológicas y pronósticas diversas. En el año 2000 se publicó en Nature el trabajo de Perou y cols. (47), en el que se describió que el cáncer de mama es en realidad una entidad heterogénea, con 4 grandes subtipos moleculares con un comportamiento clínico diferente (tabla 2): luminal A, luminal B, HER2 positivo y triple negativo. Sin embargo, el elevado coste y dificultad técnica de los arrays de secuenciación han propiciado la utilización de una clasificación más sencilla propuesta por Cheang y cols. (48) basada en los datos de expresión de receptores de estrógeno (RE) y progesterona (RP), HER2 y en el índice de proliferación Ki 67. El cáncer de mama HER2 + es un tipo específico de tumor, en que las células cancerosas presentan una sobreabundancia de pequeñas proteínas en su superficie, denominada factor de crecimiento epidérmico humano receptor de proteína 2 (HER2). Las proteínas HER2 se unen de forma exclusiva con otras proteínas llamadas factores de crecimiento que facilitan la duplicación y el crecimiento incontrolado de las células cancerosas.

\begin{tabular}{|c|c|c|c|c|c|}
\cline { 2 - 6 } \multicolumn{1}{c|}{} & LUMINAL A & \multicolumn{2}{|c|}{ LUMINAL B } & $\begin{array}{c}\text { HER2 (no } \\
\text { luminal) }\end{array}$ & $\begin{array}{c}\text { TRIPLE } \\
\text { NEGATIVO }\end{array}$ \\
\hline RE y/o RP & + & + & + & - & - \\
\hline HER2 & - & - & + & + & - \\
\hline Ki 67 & $\leq 15 \%$ & $>15 \%$ & Cualquier & $\mathrm{n} / \mathrm{a}$ & $\mathrm{n} / \mathrm{a}$ \\
\hline
\end{tabular}

Tabla 2: Características clinicopatológicas de los subtipos de cáncer de mama. 
Los tumores luminales A, son los de mejor pronóstico, y constituye el grupo menos quimiosensible. Los tumores luminales B son tumores más agresivos, con peor pronóstico y mayor quimiosensiblidad que los luminales A. Los tumores HER2 positivos son de mayor agresividad biológica y junto con los triple negativos, son los tumores de peor pronóstico, si bien la incorporación del trastuzumab en el tratamiento adyuvante de dichos tumores ha mejorado significativamente el pronóstico de los mismos. Los tumores triple negativos son agresivos, más quimiosensibles y de mal pronóstico.

El trastuzumab (Herceptin $\left.{ }^{\circledR}\right)$ es el primer fármaco de una nueva terapia en el cáncer de mama conocida como targeted therapies (49). Este tratamiento esta formado por un anticuerpo monoclonal humanizado que reconoce el dominio extracelular del receptor y posee actividad antitumoral. El trastuzumab ha demostrando diferencias estadísticamente significativas tanto en términos de supervivencia global y libre de enfermedad en pacientes HER2 + (50).

También forman parte esta nueva terapia biológica el lapatinib (una pequeña molécula tirosin quinasa que inhibe los receptores erbB2 y erbB1), el bevacizumad, un anticuerpo monoclonal anti VEGF y el pertuzumab, que es un anticuerpo monoclonal que bloquea el dominio extracelular del HER2 en un epítopo diferente al trastuzumab, que ha demostrado eficacia en combinación con este último.

\section{Radioterapia}

La radioterapia (RT) sigue siendo un pilar básico del tratamiento del cáncer de mama, con indicación en todas las fases de la enfermedad. En España la irradiación del cáncer de mama ha pasado del 45\% en el año 1990 al 59\% en el año 2000, siendo estas cifras similares a las publicadas internacionalmente $(7,51)$.

En un principio la irradiación se administraba tras la cirugía, pero la incorporación de estos esquemas de quimioterapia más agresiva han obligado a retrasar la irradiación hasta 
el final de la misma. Cuando no existe indicación de QT tras la cirugía, la RT debe iniciarse en los dos meses siguientes mientras que si hay indicación de QT la irradiación deberá administrarse en los seis meses siguientes, antes de un mes tras el último ciclo de quimioterapia.

Las recomendaciones actuales requieren la delimitación de volúmenes mediante imágenes de TC, planificación dosimétrica en tres dimensiones, tratamiento con acelerador lineal y verificación de las puertas de entrada de forma electrónica.

Los volúmenes que podemos tratar son los siguientes:

1. Mama: Se administra tras una cirugía conservadora, aunque también puede estar indicada en tumores localmente avanzados que tras QT neoadyuvante no cumplan criterios de resección quirúrgica. La dosis total a administrar variará entre 45-50 Gy.

2. Lecho tumoral: Su sobreimpresión está indicada en todas las pacientes menores de 70 años tras la irradiación de la mama.

3. Tumor: Cuándo no puede realizarse la cirugía, por negativa de la paciente, imposibilidad o contraindicación médica, se puede plantear una actuación subóptima con la sobreimpresión del tumor primario.

4. Región supraclavicular homolateral: $\mathrm{Su}$ irradiación está indicada en todas las pacientes que presenten afectación de 4 ó más ganglios axilares, linfadenectomía insuficiente (menos de 10 ganglios), afectación supraclavicular o tumores localmente avanzados. En el volumen de tratamiento se incluirán los ganglios supraclaviculares y los del nivel III axilar de Berg.

5. Niveles axilares I y II: La RT a este nivel está indicada en caso de enfermedad axilar voluminosa o persistente, o linfadenectomía insuficiente o inexistente.

6. Cadena mamaria interna: Su irradiación sigue siendo dudosa.

7. Pared torácica: Está indicada en recidivas locales de pacientes no irradiadas previamente, tras cirugía radical en casos de lesiones multifocales o localmente avanzadas (T3 ó T4) y/o cuando existe afectación de 4 ó más ganglios axilares. En pacientes con 1-3 ganglios afectos, debe individualizarse cada caso, en función de factores de riesgo. 
8. Prótesis: La administración de RT sobre prótesis no comporta una disminución de la eficacia de la irradiación.

9. Cuadrante o volumen parcial: Los buenos resultados obtenidos con el tratamiento quirúrgico conservador están conduciendo a intentos de limitar la cantidad de mama irradiada y con ello disminuir los efectos a largo plazo. A pesar de que todavía debemos esperar resultados definitivos el Grupo Europeo de Curieterapia la acepta en algunos casos (52).

Los efectos a largo plazo de la RT sobre la zona tratada incluyen aparición de telangiectasias, hiperpigmentación y fibrosis cutánea. Esta ampliamente documentada la elevada tasa de complicaciones en pacientes que han recibido o van a recibir RT sobre una reconstrucción mamaria basada en implante, como contractura capsular severa, dificultades o incapacidad para lograr una expansión adecuada, dolor, extrusión del implante, infecciones (53). Es por ello aconsejable emplear técnicas reconstructivas basadas en tejidos autólogos sobre zonas radiadas o cuando existe la sospecha de que va a ser necesario aplicar este tratamiento.

\section{Hormonoterapia}

Los beneficios de la terapéutica endocrina se basan en la dependencia del crecimiento tumoral al estímulo de los estrógenos endógenos y la capacidad de inhibir dicho crecimiento al bloquear los receptores hormonales en tumores con receptores biológicos positivos. El más utilizado es el tamoxifeno a dosis de $20 \mathrm{mg}$ al día, que administrado durante 5 años, continúa siendo hoy en día el pilar indiscutible del tratamiento hormonal adyuvante en las mujeres premenopáusicas con receptores hormonales positivos, significando una reducción del 30 y $24 \%$ en los riesgos de recurrencia y muerte (54). Sus efectos indeseables son escasos, pero puede incrementar ligeramente la incidencia de cáncer de endometrio y los fenómenos tromboembólicos. La ooforectomía es considerada también hormonoterapia. Otros fármacos muy utilizados en la hormonoterapia del cáncer de mama metastásico son el anastrozol, la medroxiprogesterona y el acetato de megestrol. 


\section{Protocolo combinado de tratamiento}

Utilizar la combinación terapéutica adecuada de todos los tratamientos descritos no depende sólo del estadio del cáncer o de la existencia de receptores hormonales, sino de los deseos de la paciente y de factores tales como la edad y estado general de salud de la mujer. A continuación se describen las pautas generales de tratamiento que, como se ha comentado, pueden variar en relación con los factores individuales de cada paciente (55).

a) En el cáncer lobulillar in situ, al ser una lesión pre maligna no se suele operar, aunque se considera un marcador de riesgo para el desarrollo de futuros tumores.

b) En el cáncer ductal in situ la recomendación es cirugía conservadora con RT complementaria o mastectomía con o sin reconstrucción. La indicación de QT y hormonoterapia se debe valorar individualizadamente.

c) En el cáncer infiltrante en estadio I y II se pueden utilizar varias alternativas de cirugía (cirugía conservadora o mastectomía con o sin reconstrucción), dependiendo de criterios establecidos y del deseo de la paciente de conservar la mama. Como parte de la cirugía se debe realizar la BSGC seguida o no según proceda de la linfadenectomía axilar.

Varias semanas después de la cirugía se inicia la RT. Si se precisa QT, la RT se suele posponer a la QT. La QT se recomienda si los ganglios axilares están afectados con células malignas o el cáncer es mayor de $1 \mathrm{~cm}$. Las pautas de tratamiento más utilizadas son CMF y CAF durante 6 ciclos. Cuando se ha utilizado cirugía conservadora, siempre se administra RT como parte fundamental del tratamiento. Se radia el tejido mamario, la pared torácica que está debajo y las zonas de ganglios axilares y supraclaviculares, si los ganglios de la axila tienen células malignas. Los ganglios de la cadena mamaria interna se radian en algunas situaciones.

El tratamiento hormonal con tamoxifeno se recomienda durante 5 años en las mujeres cuyas células malignas presentan receptores de estrógenos positivos. 
d) En el cáncer infiltrante estadio III de gran tamaño (T3), en el que está afectada la piel o la pared torácica (T4), en el cáncer inflamatorio y en el que existe una importante afectación ganglionar, la secuencia terapéutica es diferente: se administran 3 ciclos de quimioterapia según la pauta CAF o similar y en función de la mejoría experimentada, se procede a la cirugía, QT, RT y hormonoterapia. En estos casos la opción quirúrgica más frecuente es la mastectomía radical modificada.

e) En el cáncer diseminado (metastásico) se utiliza la QT y la hormonoterapia, dependiendo de la edad, localización de la enfermedad y estado de los receptores de estrógenos. En ocasiones se utiliza RT para controlar la enfermedad en lugares afectados como la columna, pelvis y cerebro. La evolución del cáncer diseminado es variable: las mujeres con metástasis viscerales múltiples, receptores de estrógenos negativos y un intervalo de tiempo pequeño entre la cirugía de la mama y la aparición de las metástasis suelen padecer un cáncer más agresivo y con peor respuesta a los tratamientos, mientras que las mujeres con metástasis en los huesos, receptores de estrógenos positivos y un intervalo de tiempo largo entre la cirugía y la aparición de las metástasis suelen padecer un cáncer de lento crecimiento y con buena respuesta a los tratamientos. 


\section{RECONSTRUCCIÓN MAMARIA}

La reconstrucción mamaria $(\mathrm{RM})$ forma parte fundamental del tratamiento del cáncer de mama. Aunque los primeros intentos de reconstrucción mamaria se remontan a finales del siglo XIX, no es hasta la década de los 70 del siglo XX cuando comienza la descripción y el desarrollo progresivo de las diversas técnicas empleadas en la actualidad. Por un lado se han logrado importantes avances en el desarrollo de materiales aloplásticos, que presentan una mejor biocompatibilidad con el cuerpo humano y unos altos niveles de seguridad, con índices de rotura y fuga cada vez menores. Por otro lado también se han descrito técnicas que permiten hacer reconstrucciones con tejido autólogo. El descubrimiento de nuevas zonas donantes, cada vez menos mórbiles para los pacientes y circulatoriamente más seguras, sobretodo con el desarrollo parejo de las técnicas microquirúrgicas, han permitido un salto cualitativo en la RM, pudiéndose obtener resultados en términos de simetría, calidad, naturalidad y perdurabilidad que superan en muchos casos las expectativas de la paciente (53).

La reconstrucción mamaria tiene como fin:

- Recrear una mama de aspecto natural, incluyendo la areola y el pezón.

- Eliminar la necesidad de llevar prótesis externas de relleno posibilitando llevar prendas de vestir que no serían posibles sin reconstrucción (bañadores, escotes, etc.).

- Rellenar el hueco y la deformidad que puede quedar en el tórax.

- Restaurar la imagen corporal y mejorar la calidad de vida de la paciente. Una reconstrucción mamaria es definitiva y permite hacer una vida absolutamente normal.

El abanico de opciones posibles no incluye sólo el tipo de reconstrucción con materiales protésico, tejido extraído de la propia paciente o una combinación de ambos, sino el momento, cobrando cada vez más protagonismo la reconstrucción inmediata en el mismo tiempo y a continuación de la resección oncológica para estadíos iniciales, frente a la diferida, que se practica tiempo después de finalizado el tratamiento oncológico. 
Por todo ello estamos asistiendo a una autentica revolución en el campo de la RM, viviendo un cambio de enfoque tanto a las técnicas como en la forma de hacer la RM, ofreciendo un futuro prometedor a todas aquellas pacientes que se enfrenten a un diagnóstico de cáncer de mama.

\subsection{Factores psicológicos relacionados con el cáncer de mama. Justificación de la reconstrucción mamaria}

El diagnóstico de cáncer representa una de las experiencias más estresantes y temidas en nuestra sociedad actual. Las pacientes tienen que hacer frente en poco tiempo al diagnóstico, pruebas, tratamiento. Atraviesan un proceso de enfermedad largo y doloroso a muchos niveles, con tratamientos agresivos quirúrgicos y médicos, y con mucho sufrimiento psicológico, social e incluso espiritual. El significado de la mama como símbolo inequívoco de feminidad y órgano de nutrición, estético y erótico, hacen de la pérdida traumática de ésta un acontecimiento de difícil superación. Este hecho unido a los efectos de tratamientos complementarios como la alopecia de la quimioterapia distorsionan la imagen que la mujer tiene de si misma, haciéndola sentir mutilada y deforme. Esta peor percepción de su imagen corporal se va a manifestar como de pérdida de la feminidad y la integridad corporal, la evitación de verse desnuda y recuperar su vida sexual, el sentimiento de ser menos atractiva e insatisfacción con el resultado quirúrgico (56) lo que va a ocasionar importantes repercusiones psicológicas a diferentes esferas, condicionando sus relaciones sociales, familiares, laborales y de pareja $(57,58)$. Asimismo, al menoscabo sufrido tras la mastectomía, se suma la sombría realidad del cáncer, hecho que condicionará el resto de su vida, con permanente miedo a la recidiva y la potencial y temida muerte.

Según la definición de la OMS de 1946, salud es el estado de completo bienestar físico, mental y social, y no solamente la ausencia de infecciones o enfermedades. Nuestros esfuerzos como profesionales de la salud no han de ir encaminados exclusivamente a la erradicación de la enfermedad, sino que la curación completa pasa porque nuestros 
pacientes puedan recibir apoyo y orientación psicológica a lo largo de todo el proceso y en último término recuperar su imagen corporal y con ella su autoestima.

Los objetivos principales de la intervención psicológica son mejorar la calidad de vida de la paciente y facilitar la adaptación a la enfermedad oncológica. Como objetivos secundarios (59) se busca disminuir las reacciones emocionales negativas (tabla 3) como la ansiedad, el miedo, la tristeza, la rabia, el estado de ánimo deprimido, disminuir las náuseas y vómitos anticipatorios, disminuir el dolor; mejorar la autoestima, mejorar la comunicación con las personas del entorno, principalmente la pareja, mejorar la percepción de control, facilitar estrategias de afrontamiento adecuadas y en definitiva, facilitar el proceso de adaptación de la persona a una situación de gran adversidad.

\begin{tabular}{|ll|}
\hline FASE ENFERMEDAD & ESTADO EMOCIONAL \\
\hline Prediagnóstico & Dudas. Ansiedad \\
\hline Diagnóstico & Shock. Miedo \\
\hline Tratamiento oncológico & Preocupación por efectos secundarios \\
\hline Intervalo libre & Miedo \\
\hline Recidiva & Desesperanza. Tristeza \\
\hline Fase avanzada & Distanciamiento emocional. Apatía \\
\hline
\end{tabular}

Tabla 3: Estados emocionales que predominan en las diferentes fases de la enfermedad.

En este punto juega un papel crucial la RM. Su efecto beneficioso no sólo se reduce a recuperar la autoimagen perdida, sino que también contribuye a cerrar y superar todas las heridas abiertas por la cirugía oncológica y los tratamientos complementarios, tanto desde un enfoque físico como mental y en último término recuperar la autoestima y devolver a la paciente a la situación social y personal que tenía antes del trance del diagnóstico de la enfermedad. 


\subsection{Evolución histórica de la reconstrucción mamaria}

Desde siempre la mama ha representado un símbolo de feminidad y el realce del pecho constituye un objetivo de todas las mujeres para reivindicar su sexo, además de ser un símbolo sexual y de belleza. Con la excepción de cortos períodos de tiempo entre los siglos $\mathrm{XV}$ y XX, dónde las mujeres trataban de disimular el tamaño de sus pechos, las mamas han sido desde la antigüedad y continúan siendo un ideal de belleza.

Una de las primeras alusiones históricas a la reconstrucción mamaria corresponde a la curación realizada por San Pedro a Santa Águeda (fig. 4). Esta mártir del siglo III d.C. sufrió la amputación de sus pechos por el procónsul Quinciano al no ser correspondido.

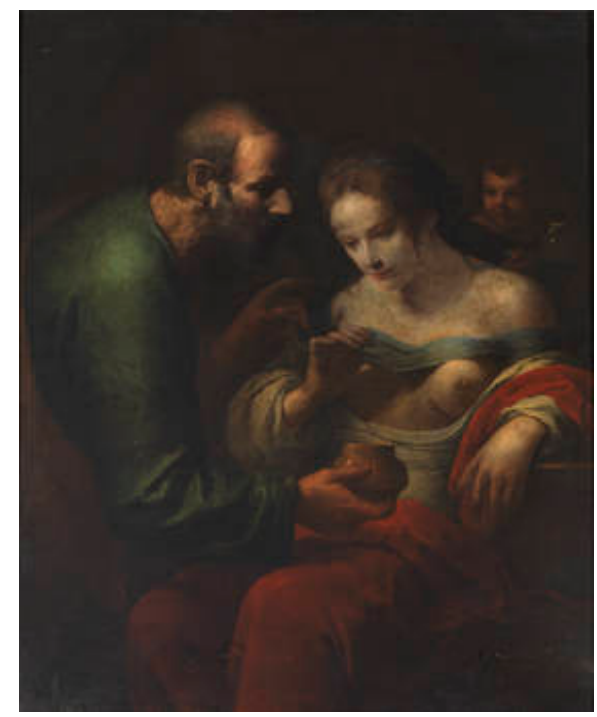

Figura 4: "Santa Águeda curada por San Pedro en la prisión”. Giovanni Martinelli. S. XVII. Museo del Prado, Madrid (España).

Los primeros intentos de aumento mamario se remontan al siglo de XIX empleándose diferentes materiales a modo de relleno como el caucho, metales, cristal,... lo que deparó multitud de problemas médicos en relación con la técnica quirúrgica y los materiales utilizados.

La primera reconstrucción mamaria exitosa de la que se tiene constancia se remonta a 1895. Czerny, un profesor de cirugía alemán de Heidelberg, trasplantó un lipoma de cadera 
a una mujer que había sido sometida a una resección parcial de la mama tras la exéresis de un fibroadenoma.

Sin embargo, no es hasta los años 70 del siglo pasado cuando comienzan a desarrollarse las técnicas sobre las que se asienta la reconstrucción mamaria actual. Así, en 1971, Snyderman y Guthrie (60) publican un caso de reconstrucción postmastectomía mediante la ubicación subcutánea de un implante de silicona bajo el remanente de piel de la pared torácica. Durante esta década, la reconstrucción diferida con implantes mamarios prevalece como la forma más común de reconstrucción. Aunque esta técnica proporciona múltiples ventajas, incluida su relativa simplicidad, la ausencia de cicatrices adicionales, la utilización de la piel local de excelente color y textura, e inexistencia de zonas donantes, múltiples inconvenientes comenzaron a emerger. La problemática más frecuente incluía la insuficiente calidad del colgajo local para dar cobertura al implante, la dificultad de integrar una prótesis de tamaño y volumen suficiente y similar a la de la mama contralateral, la incapacidad de conseguir una ptosis mamaria natural con el uso exclusivo del implante, el persistente déficit tisular en la prolongación axilar de la mama, y el inherente riesgo de exposición y contractura capsular (2).

El índice de contractura capsular decrece de forma significativa con la introducción de nuevas técnicas de emplazamiento del implante, especialmente con la ubicación del mismo en posición submuscular. Gruber y cols. (61) informan en 1981, de un descenso en la incidencia de contractura capsular de un $60 \%$ a un $26 \%$ al cambiar el emplazamiento del implante a un plano subpectoral-subserrato. Asplund (62) describió una reducción de hasta el $50 \%$ en la formación de contractura capsular para mamas reconstruidas mediante implantes de silicona, y de hasta un 16\%, en el caso de prótesis hinchables de suero salino, al situar el implante bajo cobertura muscular. Esta modificación fue confirmada por otros autores a largo plazo (63). Aunque retiradas del mercado por los potenciales problemas de toxicidad en sus productos de degradación, las prótesis de poliuretano, cuando se disponían en posición subpectoral, fueron asociadas a una menor incidencia $(6,3 \%)$ de contractura capsular precoz en la reconstrucción mamaria según un trabajo de Hester y cols (64). 
En 1982, Radovan (65) publica una serie de 68 pacientes tratadas mediante un expansor tisular temporal previo a la introducción de un implante mamario definitivo, en reconstrucciones diferidas postmastectomía. Radovan considera una reconstrucción mamaria infructuosa a menos que se consiga una aceptable simetría con la mama contralateral. Basándose en este precepto, defiende que la expansión tisular proporciona todas las ventajas de la reconstrucción protésica primaria y permite la obtención de mamas de mayor simetría y volumen. Su descripción más temprana implicaba la ubicación del expansor tisular en un emplazamiento subcutáneo, que era gradual y sistemáticamente insuflado en incrementos constantes de $50 \mathrm{ml}$ hasta alcanzar un volumen que oscilaba entre 100 y $250 \mathrm{cc}$, en un intervalo temporal entre 6 y 8 semanas y, transcurridas las cuales, era retirado el expansor para introducir el implante definitivo.

Como ya aconteciera en sus comienzos con la reconstrucción primaria mediante implantes, las técnicas de expansión tisular se vieron afectadas por diferentes problemas y complicaciones, muchos de ellos comunes a su predecesor, y que incluían la aparición de problemas en el colgajo de cobertura con exposición del expansor, divulgada en grandes series con una incidencia que oscilaba entre un $2 \%$ y un $4 \%$, infección, contractura capsular, dificultad en mantener una aceptable ptosis mamaria con un surco submamario bien definido, y el aditivo de la necesidad de cuantiosas intervenciones quirúrgicas $(65,66)$. La incidencia de estas complicaciones se redujo de forma espectacular con la implantación submuscular, y no subcutánea, de la prótesis expansora, especialmente en la reconstrucción mamaria inmediata. En 1990 Slavin y Colen (67) observaron que, incluso en reconstrucciones mamarias inmediatas, la cobertura completa del expansor bajo el músculo era de difícil obtención, e innecesaria si bajo el área crítica de la cicatriz de la incisión de mastectomía se garantizaba la protección del expansor bajo un músculo bien vascularizado, mientras la porción inferior expuesta del implante era usualmente bien protegida por la piel sana de la mitad inferior de la pared torácica. El retardo de la expansión de 1 a 3 semanas y la ampliación del régimen de expansión tisular, de 3 a 6 meses, con 2 a 3 semanas de intervalos, han reducido estas temidas complicaciones (68).

En el transcurso de la década de los ochenta se consigue un significativo descenso en la incidencia de infecciones protéticas, con valores que oscilan entre un $2.5 \%$ y un $7 \%$ en las 
grandes series $(65,66)$. Las válvulas expansoras integradas y la mejora de las condiciones estériles durante el proceso de expansión contribuyeron, sin duda a este progreso. El uso de expansores texturados de silicona en los que Maxwell y Falcone (68) fueron pioneros, seguidos de implantes permanentes rugosos de silicona en plano submuscular les permitió presentar una incidencia de contractura capsular severa inferior al $3 \%$, a la vez que la cápsula adherente que se formaba abolía el espacio periprotésico disminuyendo el riesgo de infección.

La persistente dificultad de conseguir y mantener una mama con un grado aceptable de ptosis y un surco submamario bien definido en los procesos de reconstrucción mamaria conduce, a la mayoría de los grupos reconstructores, a lanzarse en la búsqueda de técnicas reconstructivas suplementarias. Pennisi ideó en 1977 (69) y Ryan (70) definió y perfeccionó más tardíamente, una técnica en la que un colgajo inferior desepitelizado toracoepigástrico de avance era utilizado, en aras de recrear un surco inframamario poco definido, en reconstrucción protésica primaria. Baroudi y cols. (71) explotaron este recurso como método definitivo de reconstrucción. Posteriormente, dicha técnica fue adaptada en su uso combinado con las técnicas de expansión tisular (72).

Debido al alto índice de complicaciones e insatisfacción generada por los resultados obtenidos hasta el momento en la reconstrucción protésica primaria tras defectos de mastectomía radical y, como consecuencia de las precoces dificultades obtenidas tras la introducción de la expansión tisular, numerosos cirujanos comenzaron una búsqueda de métodos autólogos mediante los que la mama amputada pudiera ser reconstruida. El colgajo miocutáneo de dorsal ancho fue el primero descrito para su aplicación en reconstrucción mamaria por Schneider, Hill, y Brown en 1977 (73), que había sido descrito originalmente por Iginio Tansini en 1906 (74). La reconstrucción mamaria mediante el colgajo musculocutáneo de dorsal ancho aportó numerosas ventajas a los métodos tradicionales de reconstrucción, entre los que destacaba el aporte de abundante tejido bien vascularizado y una forma geométrica favorable en grandes defectos cutáneos tras mastectomía. Se suceden desde entonces las diferentes formas de extracción del colgajo, en los que la mayoría defienden el empleo de una isla elíptica de piel recolectada a través de incisiones oblicuas orientadas directamente sobre el músculo (75). La reconstrucción 
bajo esta alternativa terapéutica no eximía, en la mayoría de los casos, del uso de implantes para garantizar un adecuado volumen, por lo que se prodigan las modificaciones de la técnica básica, destacando el diseño en flor de lis y la versión extendida $(1,76)$. Estos primeros intentos se tradujeron en significativas cicatrices en tronco y espalda, y porcentajes de necrosis parciales de la isla cutánea de más del 10,8\% de las pacientes sometidas a esta técnica reconstructiva.

Estudios posteriores a largo plazo subrayaron algunas de las deficiencias de este método combinado con implantes, destacando el realizado por McCraw y Maxwell (77) en 1988, donde refieren que hasta el $75 \%$ de las pacientes reconstruidas tras mastectomía radical y el 39\% de las reconstruidas tras mastectomía radical modificada, presentaban diversos grados significativos de contractura capsular (grados III y IV de Baker) tras once años de seguimiento. No será hasta mediados de los noventa cuando nuevos y renovados estudios, con resultados excelentes, relancen la reconstrucción mamaria mediante colgajo miocutáneo de dorsal ancho, y estimulen a la mayoría de los cirujanos reconstructores, a incluirlo como una alternativa válida más en su arsenal reconstructor (2).

En la búsqueda de nuevas y más convincentes formas de reconstrucción con tejido autólogo, Robbins, en 1979 (78), fue el primero en utilizar el músculo recto del abdomen en reconstrucción mamaria. A principios de los 80 Dinner y Dowden (79) y Hartrampf y cols. (80) describen, respectivamente, el colgajo musculocutáneo vertical (VRAM) y transverso (TRAM) de recto abdominal. Aunque el VRAM resurgiría años más tarde, en una versión extendida o ampliada el colgajo TRAM se erige con prontitud como el método ideal de reconstrucción mamaria con tejido autólogo. En su inicios, el colgajo se transfería de forma pediculada, con numerosas publicaciones refiriendo resultados y complicaciones, entre las que destacaban de forma mayoritaria las necrosis parciales o totales del colgajo y los problemas de continencia de la pared abdominal. Se definen las diferentes áreas vasculares del colgajo $(81,82)$, dependientes hasta entonces de los vasos epigástricos superiores. Contrastan así las grandes y exitosas series, con otras de más discretos resultados, la mayoría precipitados por una mala selección o indicación de la paciente y problemas de cierre de la pared abdominal (83). 
Con la introducción de los medios ópticos de magnificación en la cirugía reconstructiva, el concepto de colgajo TRAM da un vuelco sorprendente e inesperado, ya que relevantes estudios anatómicos de principios de los 80 encuentran que el mayor aporte vascular al músculo proviene del tronco epigástrico inferior profundo (84). Nace la era de las transferencias microquirúrgicas y de los colgajos libres, y el colgajo TRAM libre se convierte en pionero en este modelo de reconstrucción mamaria. Las ventajas en cuanto a vascularización, posicionamiento y reducción de complicaciones abdominales son irrefutables frente al TRAM pediculado clásico.

Los paquetes vasculares axilares son los primeramente seleccionados como fuente receptora, primordialmente en reconstrucción mamaria inmediata, pero posteriores estudios y aplicaciones de la técnica en reconstrucciones diferidas apuntan a los vasos mamarios internos como los candidatos ideales (2).

De forma paralela, Bircoll (85) introduce en 1987 el uso del tejido adiposo como material de aumento para la mama, pero rápidamente se acumulan las malas experiencias y las complicaciones por esteatonecrosis, seguramente debidas a deficiencias en la técnica (86), por lo que un panel de expertos de la American Society for Plastic and Reconstructive Surgery emite un comunicado desaconsejando su práctica. Sin embargo, diferentes modificaciones introducidas por Coleman a finales de los años 90 (87), como la extracción de la grasa mediante lipoaspiración a baja presión, su purificación mediante diferentes técnicas como el centrifugado y el descripción de su técnica de implantación en pequeñas cantidades lograron aumentar los porcentajes de supervivencia de los injertos de tejido adiposo a la vez que se reducían sus complicaciones, consiguiendo introducir un nuevo recurso con multitud de posibilidades dentro de la cirugía reparadora mamaria y de la cirugía plástica tanto estética como reconstructiva (88).

La reconstrucción mediante tejido autólogo y la obsesión microquirúrgica conducen a la búsqueda de alternativas al TRAM libre cada vez menos mórbiles. En este sentido, diferentes estudios informan sobre las fuentes de aporte vascular al músculo recto y a la pared abdominal refiriendo la existencia de múltiples vasos perforantes musculocutáneos que atraviesan la fascia para irrigar la piel y el tejido celular subcutáneo subyacente. Este 
hecho unido a la introducción en 1987 por parte de Taylor y Palmer (89) del término "angiosoma", constituyeron un importante punto de partida para el desarrollo de los colgajos de perforantes. Serían los japoneses Koshima y Soeda (90) en 1989 los promeros en dar este importante salto, al utilizar colgajos cutáneos basados en una perforante paraumbilical de la arteria epigástrica inferior (a la postre, el primer colgajo de perforantes de arteria epigástrica inferior profunda, DIEP) para la reconstrucción de una ingle y el defecto resultante de la exéresis de un cáncer de suelo de boca. Este hecho marca el inicio de una nueva era en la cirugía reconstructiva, al ser colgajos que combinan la viabilidad de los colgajos musculocutáneos con la conservación funcional y anatómica de las unidades musculares y los resultados estéticos de los colgajos cutáneos. En 1994 Allen y Treece (91) y Blondeel y Boeckx (92) fueron los pioneros en utilizar el colgajo DIEP en reconstrucción mamaria. A pesar de la complejidad técnica que lleva pareja esta técnica, actualmente el colgajo DIEP ha revolucionando la cirugía reparadora de la mama, erigiéndose en el referente actual de la reconstrucción con tejido autólogo.

El desarrollo de la microcirugía y el descubrimiento de nuevos territorios tisulares ha posibilitado la descripción de múltiples alternativas de transferencias tisulares, destacando el colgajo SGAP (colgajo de perforante de la arteria glútea superior), IGAP (colgajo de perforante de la arteria glútea inferior), TMG (colgajo transverso miocutáneo de gracillis) y recientemente el PAP (colgajo de perforante de arteria femoral profunda) (93), pero sin que ninguno de ellos haya sido capaz de desbancar hasta el momento al colgajo DIEP.

El reciente desarrollo de la supramicrocirugía ha permitido también realizar las primeras anastomosis linfático-venosas, y poner en el punto de mira el tratamiento del linfedema secundario, como el que aparece tras los tratamientos del cáncer de mama que involucran a la axila (94). El futuro se presenta prometedor y sin que ninguna barrera parezca infranqueable. 


\subsection{Reconstrucción mamaria inmediata y diferida}

Según el tiempo en el que se realiza la reconstrucción mamaria, esta puede clasificarse en inmediata o diferida.

\section{Reconstrucción mamaria inmediata}

Es aquella que se realiza durante la misma intervención en la que se realiza la mastectomía. En esta técnica el cirujano que realiza la resección oncológica conserva prácticamente toda la envoltura cutánea de la mama a excepción de la areola y el pezón, lo cual contribuye a facilitar la reconstrucción en términos de simetría y resultado estético así como evita una futura intervención para hacer esta RM. Puede utilizarse tanto con técnicas de tejidos autólogos como implantes.

Sus principales ventajas son:

- Importante beneficio psicológico.

- Suelen implicar un mejor resultado estético, al preservar la envoltura mamaria.

- Menos costosa, al aprovechar el mismo acto quirúrgico en el que se extirpa el tumor para realizar la RM (95).

- Es segura oncológicamente en pacientes seleccionados.

- Existen datos contrapuestos en cuanto a la tasa de complicaciones de la reconstrucción inmediata (RMI) y diferida (RMD); un estudio multicéntrico prospectivo encontró que en dos años, las mujeres con reconstrucción inmediata tuvieron una mayor tasa de complicaciones, sobre todo entre aquellas RM con colgajo TRAM, aunque otros no han observado este resultado $(96,97)$.

La reconstrucción inmediata permite una recuperación psicológica más rápida para la paciente, pues no llega a verse mastectomizada, además de acortar el número de intervenciones quirúrgicas necesarias para completar el tratamiento. La RMI no interfiere ni retrasa la administración del tratamiento del cáncer de mama (quimioterapia o radioterapia). Los estudios de costes revisados concluyen que los costes de la RMI son 
significativamente menores que los de la RMD. La mayoría son estudios de costeminimización, por tanto no evalúan ni la efectividad de la intervención ni los costes de las complicaciones (tabla 4). Los estudios de evaluación económica reflejan que en el caso de la reconstrucción con implantes las diferencias en el coste entre RMI/RMD son menores (98). En nuestro medio, al $27,4 \%$ de las pacientes sometidas a una mastectomía se les realiza la RM en el mismo acto quirúrgico (39).

Sus desventajas son las siguientes:

- La reconstrucción inmediata prolonga significativamente el tiempo quirúrgico.

- La necrosis de los colgajos de piel postmastectomía puede afectar negativamente el resultado estético de la reconstrucción.

- En algunas circunstancias puede estar indicada la administración de RT postoperatoria, lo que puede afectar negativamente a la reconstrucción inmediata con expansor y prótesis (99). En cambio las reconstrucciones con tejido autólogo soportan mejor los efectos nocivos de la RT, hasta el punto de que la tendencia actual es realizar la reconstrucción inmediata con esta técnica aún aceptando que la paciente va a recibir RT en el postoperatorio (100).

- La valoración por la paciente del resultado de la reconstrucción es más pobre.

De todo esto se desprende que pueden ser contraindicaciones relativas a la reconstrucción inmediata:

- Enfermedad avanzada (estadios III o superior).

- Necesidad de RT postoperatoria, fundamentalmente en las reconstrucciones con implantes.

- Comorbilidades médicas, tales como el tabaquismo activo, obesidad o enfermedades cardiopulmonares. 


\begin{tabular}{|c|c|c|c|c|}
\hline Tipo de reconstrucción & RMI/RMD & Coste & Diferencia & $\mathrm{p}$ \\
\hline Expansor/implante & $\begin{array}{l}\text { RMI (77) } \\
\text { RMD (5) }\end{array}$ & $\begin{array}{l}\$ 17.514 \\
\$ 25.411\end{array}$ & $\$ 7.897$ & 0,034 \\
\hline Colgajo TRAM & $\begin{array}{l}\text { RMI (142) } \\
\text { RMD (52) }\end{array}$ & $\begin{array}{l}\$ 17.957 \\
\$ 29.173\end{array}$ & $\$ 11.216$ & $<0,001$ \\
\hline TRAM unilateral & $\begin{array}{l}\text { RMI (87) } \\
\text { RMD (52) }\end{array}$ & $\begin{array}{l}\$ 17.301 \\
\$ 29.173\end{array}$ & $\$ 11.872$ & $<0,001$ \\
\hline Unilateral + bilateral & $\begin{array}{l}\text { RMI } \\
\text { RMD }\end{array}$ & $\begin{array}{l}\$ 17.801 \\
\$ 28.843\end{array}$ & $\$ 11.042$ & $<0,001$ \\
\hline Unilateral & $\begin{array}{l}\text { RMI } \\
\text { RMD }\end{array}$ & $\begin{array}{l}\$ 16.946 \\
\$ 28.843\end{array}$ & $\$ 11.897$ & $<0,001$ \\
\hline $\mathrm{RT}$ previa & $\begin{array}{l}\text { RMI (13) } \\
\text { RMD (25) }\end{array}$ & $\begin{array}{l}\$ 19.876 \\
\$ 29.687\end{array}$ & $\$ 9.811$ & 0,001 \\
\hline Sin RT previa & $\begin{array}{l}\text { RMI (206) } \\
\text { RMD (32) }\end{array}$ & $\begin{array}{l}\$ 17.671 \\
\$ 28.184\end{array}$ & $\$ 10.513$ & $<0,001$ \\
\hline Sin RT, unilateral TRAM & $\begin{array}{l}\text { RMI (81) } \\
\text { RMD (27) }\end{array}$ & $\begin{array}{l}\$ 17.333 \\
\$ 28.678\end{array}$ & $\$ 11.345$ & $<0,001$ \\
\hline $\begin{array}{l}\text { Análisis varianza (controlando } \\
\text { RT, lateralidad, tipo } \\
\text { reconstrucción) }\end{array}$ & $\begin{array}{l}\text { RMI (219) } \\
\text { RMD (57) }\end{array}$ & $\begin{array}{c}\$ 18.738 \\
(\mathrm{SE} \$ 695) \\
\$ 29.908 \\
(\mathrm{SE} \$ 979)\end{array}$ & $\$ 11.170$ & 0,0001 \\
\hline
\end{tabular}

Tabla 4: Diferencias de coste entre reconstrucción mamaria inmediata y diferida según el tipo de técnica empleada. Tabla extraída de Khoo A, Kroll SS, Reece GP, Miller MJ, Evans GR, Robb GL, et al. A comparison of resource costs of immediate and delayed breast reconstruction. Plast Reconstr Surg. 1998;101(4):964-8.

\section{Reconstrucción diferida}

Es la que se lleva a cabo un tiempo después de practicarse la mastectomía y una vez finalizados los tratamientos coadyuvantes del cáncer de mama, RT y QT. Es aconsejable que haya transcurrido un tiempo desde la conclusión de estos tratamientos complementarios con el fin de que a nivel local los tejidos hayan recuperado la normalidad (6-12 meses).

Las ventajas de la reconstrucción diferida incluyen:

- Garantía de márgenes libres antes de la reconstrucción definitiva. 
- Minimiza los defectos de vascularización de los colgajos de piel postmastectomía.

- Permite completar todo el tratamiento adyuvante sin la interferencia de la RM.

- Mejor valoración del resultado por parte de la paciente.

Las desventajas de la reconstrucción diferida incluyen:

- Necesidad de cirugías posteriores y nuevos ingresos hospitalarios.

- Calidad estética menor en comparación con la reconstrucción inmediata.

- Trauma psicológico por la amputación en el tiempo entre la mastectomía y la reconstrucción.

- Mayor coste económico.

En el pertinaz afán de evitar el mayor número de secuelas tanto físicas como psicológicas derivadas de tan traumática intervención, la mayoría de los grandes centros y grupos mundiales senológicos de reconstrucción promulgan y promueven la reconstrucción inmediata como alternativa menos traumática. No obstante, en nuestro medio, nadie duda de las enormes dificultades de coordinar, a altos niveles y grandes volúmenes, grupos multidisciplinares que puedan asumir la responsabilidad conjunta de un problema social y sanitario de tal envergadura, lo que está generando una asimilación desigual dentro del sistema sanitario público español (2).

\subsection{Técnicas de reconstrucción mamaria}

Las mujeres que deciden someterse a una reconstrucción mamaria no sólo deben elegir el tiempo en el que se realiza (RMI/RMD) sino el tipo de reconstrucción. El progreso en las técnicas de RM en las últimas décadas ha permitido desarrollar un gran arsenal de posibilidades con sus variantes, aunque estas se pueden agrupar fundamentalmente en dos métodos:

a) Técnicas basadas en implantes. Utilizan materiales aloplásticos colocados bajo la piel y el músculo pectoral para recrear la forma de la mama. 
b) Técnicas basadas en tejido autólogo: se basa en la transferencia de tejidos del mismo paciente basados en patrones circulatorios conocidos, denominados colgajos, a la zona anterior del tórax, moldeándolos para que adopten forma de mama. Estos colgajos se pueden extraer de zonas próximas al tórax o bien de zonas distantes.

\section{Técnicas basadas en implantes}

La base fundamental de este método de reconstrucción es el empleo de materiales basados en polímeros sintéticos de silicona (CH3)2SiO. Sus propiedades beneficiosas incluyen estabilidad en un amplio rango de temperaturas, flexibilidad con memoria, repelencia al agua (aunque no llega a ser hidrófila) y baja toxicidad y reactividad química. Desde su desarrollo en 1961 por Cronin y Gerow, se han sucedido varias generaciones de implantes, encontrándonos actualmente en la $3^{\text {a }}$ generación, caracterizada por cubiertas más gruesas y geles más cohesivos con respecto a la generación precedente. En 1989 aparecieron los implantes de superficie texturizada y posteriormente se lanzó el gel cohesivo, más espeso, manteniendo, o al menos a si se preconiza, su forma incluso después de cortarlo, minimizando así la migración de silicona en caso de que el implante se rompa (fig. 5).

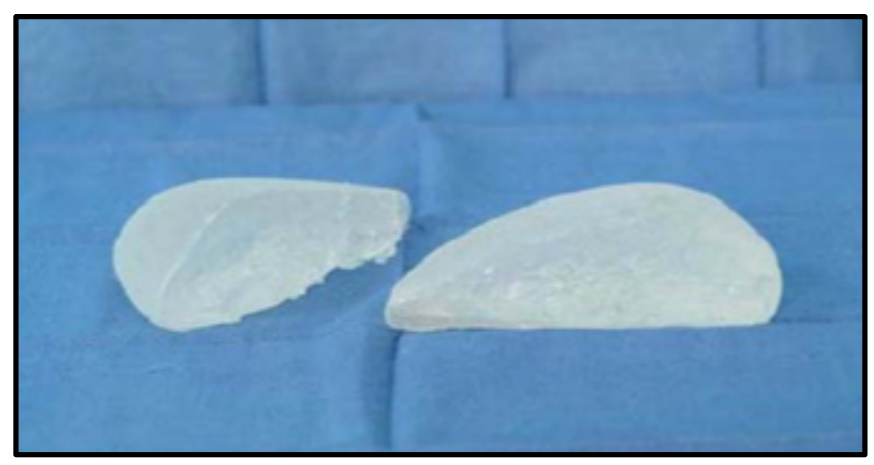

Figura 5: Implante mamario cortado a la mitad. El gel de alta cohesividad reduce la migración de silicona. Tomado de Grabb and Smith's plastic surgery. Seventh edition. Philadelphia: Lippincott Williams \& Wilkins Health; 2014. 1030 p. 
La reconstrucción con implantes originalmente implicaba la colocación de una prótesis de silicona debajo de los colgajos de piel que quedaban tras la mastectomía y debajo del músculo pectoral mayor. Este enfoque se llama reconstrucción inmediata con implante. El problema fundamental es que sin proporcionar una cobertura adicional de tejidos blandos para reemplazar la piel perdida en la mastectomía, la forma estética de las mamas es defectuosa y carece de la proyección adecuada. Con la llegada del expansor tisular, la reconstrucción primaria con implante prácticamente se ha abandonado, y suele reservarse para los casos en que la mama reconstruida tiene un volumen pequeño y es mínimamente ptósica.

El fundamento de la reconstrucción mamaria con expansores, es la obtención de piel suplementaria, del mismo color y textura que la piel de la mama. La técnica consiste en la colocación del expansor tisular (fig. 6) en un primer tiempo quirúrgico previo a la implantación de la prótesis, situándolo en un bolsillo submusculofascial, subpectoral en el caso de las RMD y subpectoral-serrato en las RMI. La disección debe ser lo suficientemente amplia como para ubicar el expansor sin pliegues, mas no excesiva, que posibilitaría un desplazamiento o rotación del mismo.

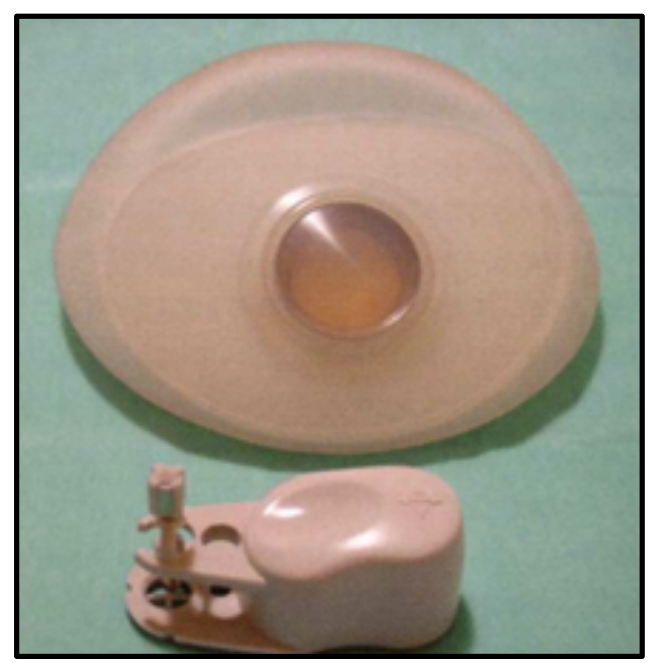

Figura 6: Expansor mamario con válvula incorporada Contour Profile 6.200 de MENTOR. Dispositivo magnético para localizar la válvula sobre la piel una vez implantado.

A continuación se va aumentando su tamaño progresivamente, mediante la introducción de suero salino en la válvula en visitas sucesivas en la consulta, con el fin de 
permitir a la piel y los tejidos blandos subyacentes crecer hasta conseguir el volumen necesario para cubrir la prótesis definitiva. El volumen de suero inyectado en cada visita es variable, según la tolerancia de la paciente y los tejidos, aunque suele oscilar entre 30 y 80 cc. Una vez conseguida una expansión suficiente, el expansor es retirado tras un tiempo que suele oscilar entre los tres y los seis meses y sustituido por la prótesis definitiva. Esta técnica se llama reconstrucción con implante en dos tiempos (fig. 7). En la tabla 5 se describen las principales ventajas e inconvenientes de la técnica.

\begin{tabular}{|ll|}
\hline \multicolumn{1}{|c|}{ VENTAJAS } & \multicolumn{1}{c|}{ INCONVENIENTES } \\
\hline Técnicamente más sencilla que las autólogas & $\begin{array}{l}\text { Requiere visitas frecuentes para aumentar el } \\
\text { volumen del expansor }\end{array}$ \\
\hline Emplea tejidos estéticamente similares & $\begin{array}{l}\text { Precisa de una segunda cirugía para colocar el } \\
\text { implante definitivo }\end{array}$ \\
\hline Ausencia de zonas donantes & $\begin{array}{l}\text { En muchas ocasiones precisa cirugías de } \\
\text { simetrización en la mama contralateral }\end{array}$ \\
\hline Recuperación postoperatoria más rápida & $\begin{array}{l}\text { Peor resultado estético y menor satisfacción } \\
\text { que con los reconstrucciones autólogas. El } \\
\text { resultado estético se deteriora con el tiempo. }\end{array}$ \\
\hline Buena opción en pacientes de edad avanzada & $\begin{array}{l}\text { Contraindicada si la paciente ha recibido o va } \\
\text { a recibir RT }\end{array}$ \\
\hline con comorbilidad médica importante & $\begin{array}{l}\text { Puede necesitar revisiones quirúrgica a largo } \\
\text { plazo por contractura capsular, rotura,... }\end{array}$ \\
\hline
\end{tabular}

Tabla 5: Ventajas e inconvenientes de la reconstrucción con implantes

Son requisitos para poderse beneficiar de esta técnica (101):

- Piel de buena calidad y cantidad suficiente para aportar buena cobertura tanto al expansor como a la prótesis definitiva.

- Paciente con mamas de pequeño tamaño a moderado, forma redondeada, con mínima ptosis de la mama sana, o pacientes con mastectomía bilateral. En el caso de que presenten mamas hipertróficas o ptósicas a menudo es recomendable corregir 
también la otra mama, lo que ayuda a conseguir una mejor simetría, ampliando el abanico de pacientes que pueden beneficiarse de esta técnica .

- Integridad del músculo pectoral mayor, para dotar al implante de una adecuada cobertura.

- Ausencia de radioterapia pre o post reconstrucción, que suponen un alto riesgo de extrusión del expansor.

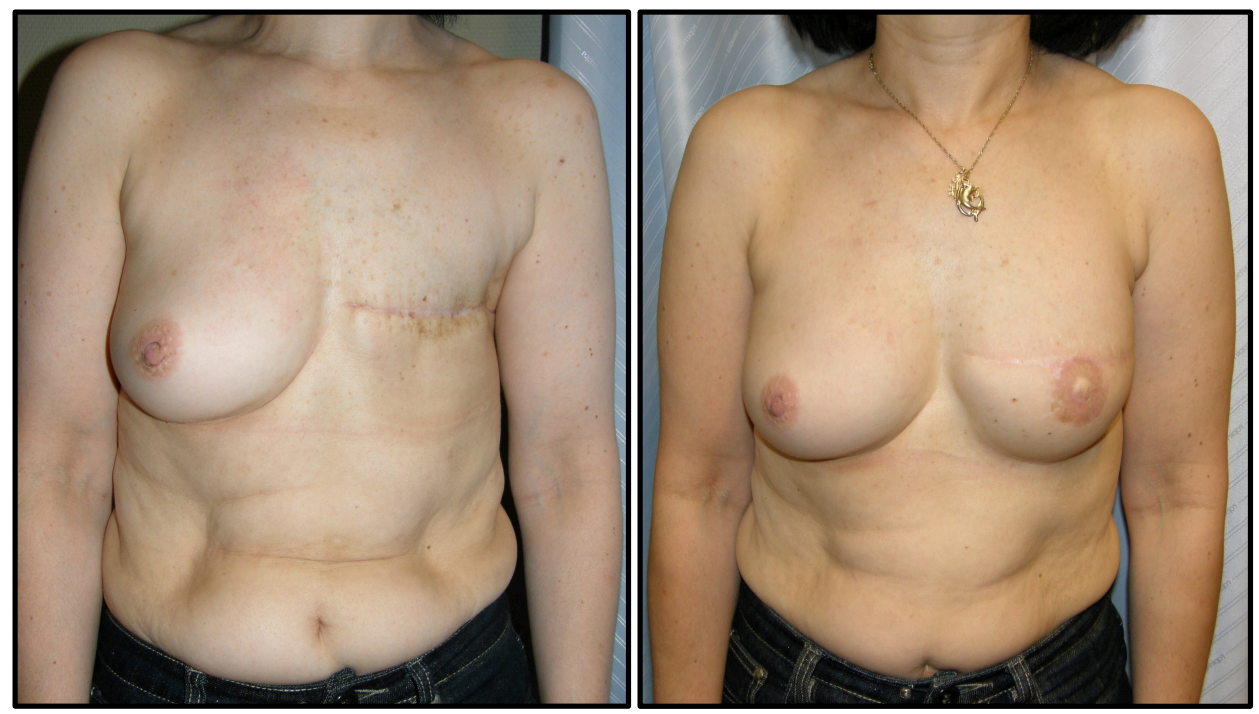

Figura 7: Reconstrucción mamaria izquierda en dos tiempos con expansor y prótesis. Reconstrucción de areola pezón.

Aunque las potenciales complicaciones no difieren, en general, a las de cualquier procedimiento quirúrgico (hematoma, seroma, infección), existen un conjunto de ellas que se caracterizan por su especificidad, entre las que destacan:

- Contractura capsular: Es la complicación más frecuente, y en casos severos provoca un cambio en el contorno, que se hace hemisférico, y en la consistencia, traducido en un endurecimiento de grado variable. En los casos graves (grados III-IV de Baker) suelen requerir una reintervención por dolor, molestias, o compromiso estético de la reconstrucción.

- Extrusión del implante: Infrecuente pero sin duda la complicación más temida.

- Rotura de la prótesis, normalmente por desgaste.

- Ondulaciones palpables.

- Desplazamientos o malposiciones, que derivan en asimetrías mamarias.

- Deformidades o fracturas costales. 


\section{Técnicas basadas en tejido autólogo}

Se han descrito multitud de zonas donantes en el cuerpo humano aptas para realizar una RM. Las más comúnmente utilizadas son la espalda, de la que se extrae el colgajo de dorsal ancho y el abdomen, de donde se extrae los colgajos TRAM y DIEP. Por definición, un colgajo es una porción de tejido que mantiene su aporte vascular intacto como método de nutrición, a diferencia de los injertos, que utilizan el lecho recepto para nutrirse por imbibición hasta se que produce la angiogénesis. Los colgajos se pueden clasificar en pediculados, cuando se individualiza el tejido manteniendo el pedículo vascular intacto y se usa como punto pivote para movilizar este tejido desde la zona donante a la receptora, o bien libres, cuando se disecciona este pedículo y se autonomiza con el tejido, para ser anastomosado a unos vasorreceptores próximos a la zona a reconstruir. Otra clasificación de los colgajos es la que viene determinada por el tipo de tejidos que lo conforman: así, hay colgajos compuestos de piel con su fascia (fasciocutáneo), piel con una isla de musculo subyacente (musculocutáneo), hueso (óseo),... existiendo un gran número de combinaciones posibles, dependiendo de las necesidades de la zona a reconstruir.

\section{Reconstrucción con colgajo musculocutáneo de dorsal ancho}

Actualmente es el colgajo más generalizado de la cirugía plástica, tanto por sus posibilidades de uso (muscular o musculocutáneo, pediculado o libre) como su potencial gran tamaño, su simplicidad técnica y su gran fiabilidad. Aplicado a la RM, el músculo dorsal ancho con una isla de piel supra adyacente ipsilateral a la mama extirpada es transpuesto hacia la pared anterior del tórax tunelizado a través de la axila como colgajo pediculado sobre la arteria y la vena toracodorsal que le aportan su vascularización (fig. 8). Es habitual denervar el colgajo mediante la resección de aproximadamente $1 \mathrm{~cm}$. del nervio toracodorsal con el fin de evitar contracciones indeseables del músculo en la reconstrucción al movilizar el brazo en algunas posiciones. Puede emplearse tanto en la reconstrucción mamaria inmediata como diferida. El diseño de la isla cutánea es variable, pudiendo ser horizontal, a lo largo de la línea del sujetador, lo que permitirá que la cicatriz quede oculta por el mismo, u oblicuo. Aunque puede utilizarse la modalidad de colgajo miocutáneo de dorsal ancho extendido según la descripción de Hokin en 1983 (102), 
incluyendo la totalidad del músculo con múltiples bolsas de tejido adiposo y una gran isla cutánea de 30x8 cm. orientada oblicuamente para realizar la RM con tejido de la espalda exclusivamente, es más frecuente que se asocie a una prótesis mamaria para dotar a la reconstrucción del volumen y la proyección suficiente. Por otra parte, algunos cirujanos prefieren combinarlo con un expansor, que luego será reemplazado por un implante, con el fin dotar a la reconstrucción de una ptosis lo mas natural posible y afinar el volumen de cara a conseguir un resultado lo más simétrico posible. En la tabla 6 se describen su principales ventajas e inconvenientes.

Las complicaciones más frecuentes son (53):

- Pérdida parcial o total del colgajo.

- Extrusión del implante.

- Malposición.

- Retracción capsular.

- Asimetría en la espalda.

- Pérdida de fuerza muscular.

- Seroma en la espalda

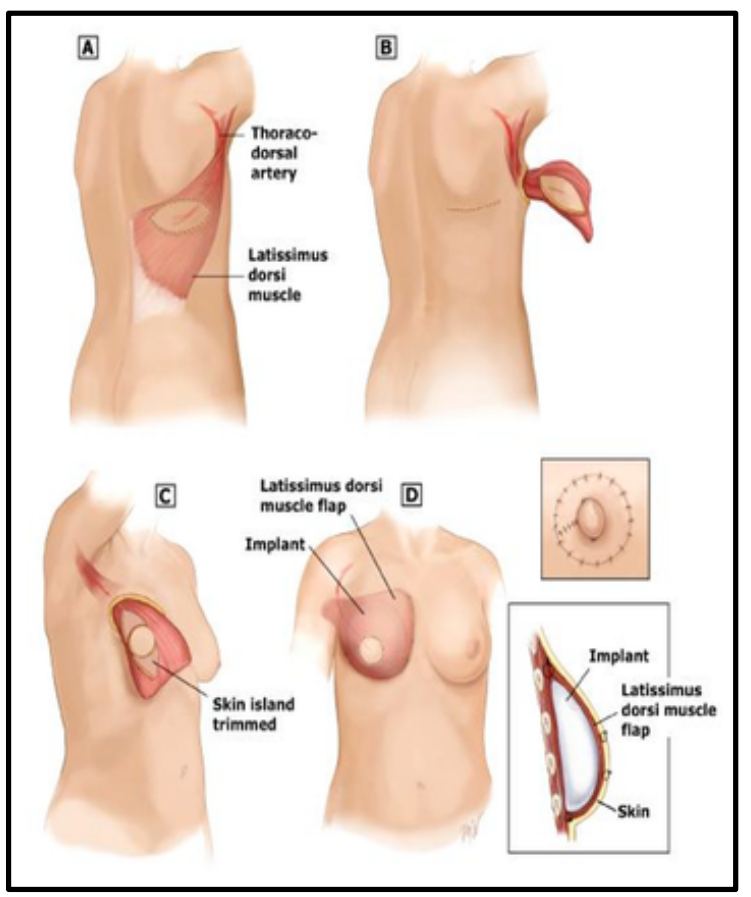

Figura 8: Reconstrucción con colgajo LD. A: disección del colgajo del área donante. B y C: tunelización del colgajo a través de la axila. D: resultado final y esquema anatómico de la colocación del colgajo sobre un implante. Tomado de URL: www.uptodate.com 


\begin{tabular}{|ll|}
\hline \multicolumn{1}{|c|}{ VENTAJAS } & \multicolumn{1}{c|}{ INCONVENIENTES } \\
\hline $\begin{array}{l}\text { Es un colgajo de fácil obtención y disección, } \\
\text { índices de necrosis total inferiores al 1\% }\end{array}$ & $\begin{array}{l}\text { Requiere el reposicionamiento de la paciente } \\
\text { durante la intervención }\end{array}$ \\
\hline $\begin{array}{l}\text { Las secuelas en la movilidad del hombro son } \\
\text { mínimas }\end{array}$ & $\begin{array}{l}\text { La cicatriz de la zona donante puede ser } \\
\text { dehiscente y de mala calidad }\end{array}$ \\
\hline $\begin{array}{l}\text { Técnica apta en pacientes que han recibido } \\
\text { radioterapia }\end{array}$ & $\begin{array}{l}\text { Con frecuencia es necesario implantes para } \\
\text { lograr una forma y volumen adecuados }\end{array}$ \\
\hline & $\begin{array}{l}\text { La atrofia del músculo puede condicionar } \\
\text { irregularidades en el contorno de la RM }\end{array}$ \\
\hline
\end{tabular}

Tabla 6: Ventajas e inconvenientes de la reconstrucción con colgajo de LD

\section{Colgajo dorsal ancho ahorrador de músculo}

Michel Saint-Cyr y cols. describió en 2009 una variante del colgajo clásico de LD (103). En un intento de reducir al máximo la morbilidad en la zona donante, publicó una técnica en la que la isla cutánea de la espalda se transportaba a la pared anterior del tórax por una tira de $3 \mathrm{~cm}$ de anchura de la porción más anterior del músculo dorsal ancho (fig. 9). Esta alternativa presentaba una serie de ventajas: Se conserva la gran mayoría del músculo dorsal ancho, respetando su función y sin perdida de fuerza con respecto al lado contralateral; menor dolor durante el postoperatorio al recolectarse una porción muscular más pequeña; menor riesgo de seroma ya que el despegamiento de los colgajos cutáneos es menor; fácil disección; permite elevar con seguridad una isla cutánea de dimensiones similares a la de la variante clásica. La desventaja fundamental es que se prescinde del volumen que aporta la totalidad del músculo dorsal ancho; sin embargo, hay que tener en cuenta que a largo plazo se produce una atrofia considerable de esta musculatura y que además, en la mayoría de las situaciones hay que complementar la reconstrucción con un implante mamario. En los últimos años se han descrito el uso de injertos de tejido adiposo como alternativa al uso de implantes mamarios con el fin de aportar volumen a la reconstrucción, evitando los inconvenientes del uso de materiales aloplásticos. Su uso habitualmente es diferido, meses después de la transposición del colgajo, aunque 
recientemente se ha publicado el uso de lipoinjertos en el mismo tiempo con el fin de reducir el número de intervenciones $(104,105)$.
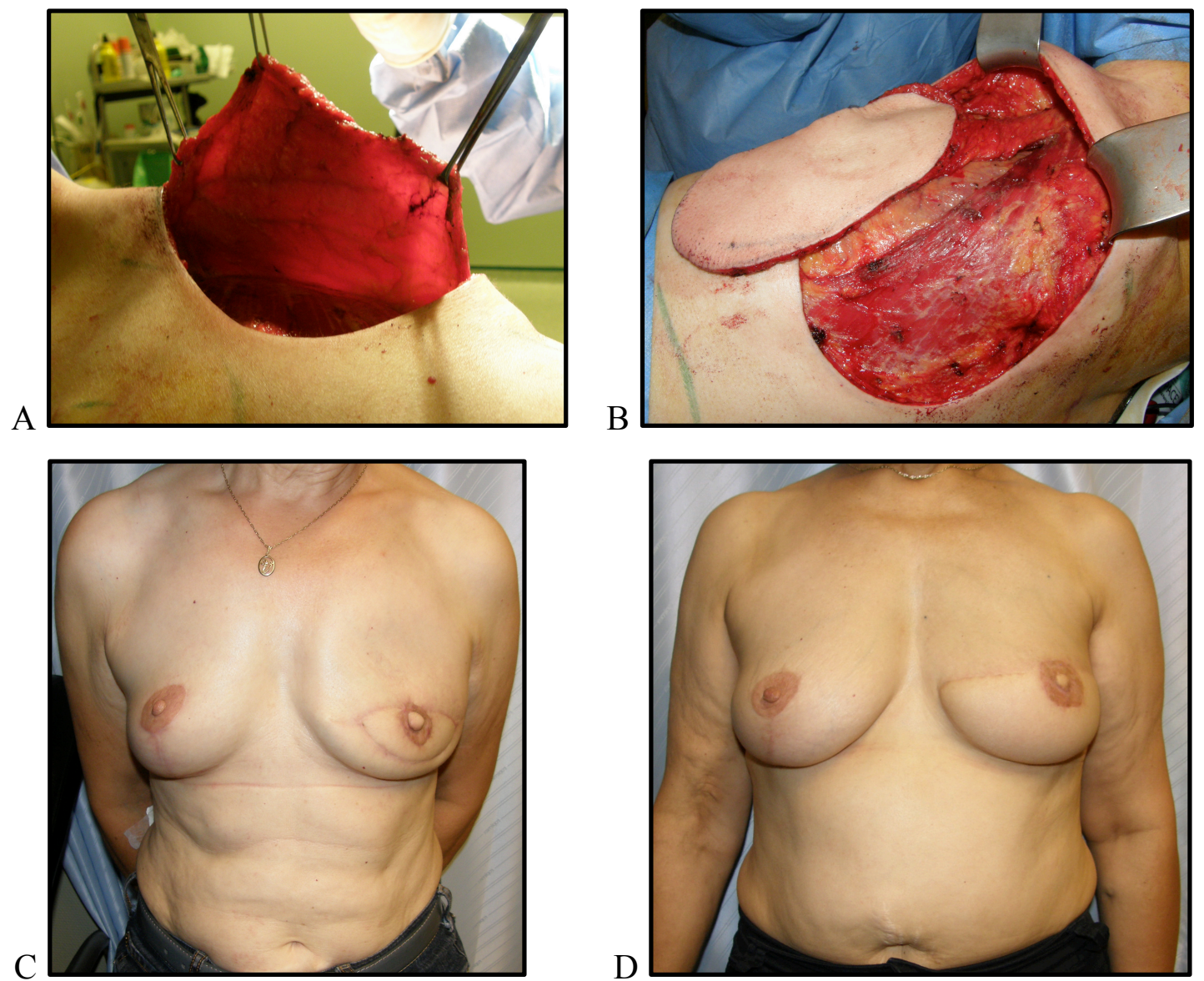

Figura 9: A: Músculo LD con las ramas longitudinales del pedículo toracodorsal usadas en su modalidad ahorradora de músculo. B: Colgajo ahorrador de LD izquierdo antes de tunelizarse por la axila. C: Resultado de RM izquierda con colgajo ahorrador de LD con pexia mamaria contralateral. D: Reconstrucción mamaria izquierda diferida con colgajo miocutáneo de dorsal ancho y reconstrucción de complejo areola-pezón. Simetrización con mamoplastia de reducción derecha.

\section{Colgajo musculocutáneo transverso de recto abdominal (transverse rectus abdominis musculocutaneous, TRAM)}

Este colgajo esta compuesto por la piel y grasa del abdomen inferior así como el músculo recto anterior del abdomen, generalmente del lado contralateral al de la mama mastectomizada (fig. 10A). En su forma clásica se utiliza de forma pediculada, basado en la arteria y venas epigástricas superiores (80). Aunque tuvo su época dorada en los años 80 
y 90, actualmente está en desuso por sus potenciales complicaciones y por haber sido superado por evoluciones de esta técnica.

La vascularización del colgajo TRAM divide la isla del colgajo en 4 partes, de una espina iliaca anterosuperior a la contralateral (fig. 10B). Es importante conocer que el área I será la mejor vascularizada, seguida del área II y la parte más medial del área III. La parte más externa del área III puede tener una vascularización deficiente y el área IV se considera mal perfundida y por tanto no utilizable $(81,82)$.
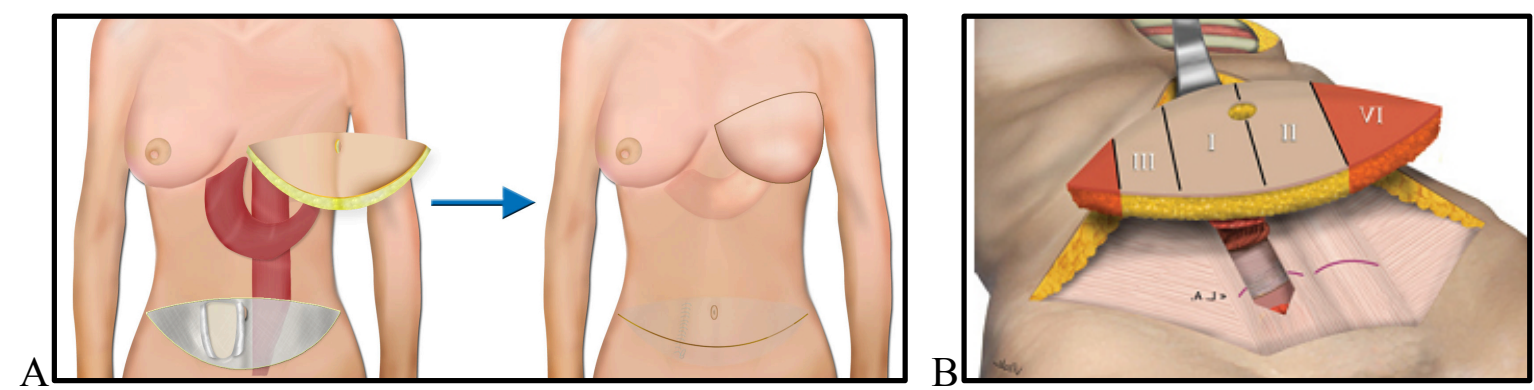

Figura 10: A: Elevación de colgajo TRAM pediculado y transposición para reconstrucción de la mama contralateral. Tomado de URL: www.microsurgery.net B: Zonas de vascularización del colgajo TRAM. Fuente: Keppke EM. Bipedicled TRAM flap with rectus abdominis muscle preservation below the arcuate line without reinforcing mesh. Rev Bras Cir Plástica. 2012;27(1):49-57.

La ventaja fundamental del colgajo TRAM es la gran cantidad de tejido cosechable permite corregir los defectos precedentes y reconstruir el relieve mamario, incluso en pacientes que han recibido RT, logrando interesantes simetrías con mamas contralaterales ptósicas o voluminosas, y reduciendo la necesidad de cirugías simetrizadoras sobre la mama sana. Sin embargo presenta dos grandes inconvenientes. Por una parte es la debilidad muscular que deja al recolectar un músculo recto abdominal, con el riesgo de aparición de fallos de la pared abdominal y hernias (2,6\%-8,8\%), lo que obliga a colocar una malla de refuerzo para minimizar el impacto de esta secuela $(106,107)$. Por otro lado están los problemas circulatorios del colgajo debido a que el pedículo epigástrico inferior no es dominante en la vascularización del abdomen inferior (84), presentando elevados índices de necrosis grasas y pérdidas parciales y totales del colgajo. Con el objeto de reducir el grado de pérdida tisular se describieron factores de riesgo que ayudaron a hacer 
una mejor selección de las pacientes, destacando el tabaquismo, el antecedente de cirugía abdominal, la lesión del pedículo mamario interno homolateral por RT o cirugía y la obesidad (83). Para pacientes con alto riesgo de necrosis, se desarrollaron diversos tipos de colgajo TRAM pediculado, con el fin de mejorar el aporte vascular: TRAM retardado, por división de los vasos epigástricos inferiores profundos, 1 a 2 semanas antes de la transferencia; TRAM bipediculado (empleando los dos músculos rectos abdominales); TRAM medioabdominal (localización alta de la isla cutánea); TRAM recargado (anastomosis entre los vasos epigástricos inferiores profundos de ambos lados, para mejorar la vascularización de la porción contralateral de la isla cutánea) y el TRAM supercargado (anastomosis microquirúrgica entre los vasos epigástricos inferiores profundos y vasos de la zona receptora). Sin embargo ninguna de estas modalidades se impuso de manera clara y fue el colgajo TRAM libre el que finalmente desplazo a su versión pediculada (2).

\section{Colgajo TRAM libre}

En el colgajo TRAM libre sólo se sacrifica la porción de músculo recto abdominal subyacente a la isla cutánea de piel y grasa, y tras disecarse el pedículo epigástrico inferior profundo se autonomiza completamente del resto del cuerpo para anastomosarse mediante técnicas microquirúrgicas a vasorreceptores de la pared torácica, habitualmente los vasos mamarios internos o ramas del eje subescapular. Aunque conlleva un mayor tiempo operatorio, dificultad técnica y necesidad de dominio de las técnicas microquirúrgicas, presenta una mejor perfusión del colgajo, con menores índices de necrosis y con mayor flexibilidad a lo hora de su posicionamiento y remodelación, traduciéndose en mejores resultados estéticos. Sin embargo, esta evolución no solucionó los problemas de debilidad de la pared abdominal como consecuencia de la porción muscular incluida en el colgajo. Esto dio lugar a refinamientos cada vez mayores de la técnica, con procedimientos conservadores de músculo (fundamentalmente de una banda lateral y sus nervios motores segmentarios) o muscle sparing, hasta alcanzar, con el nacimiento del colgajo DIEP (deep inferior epigastric perforator), el grado máximo de conservación muscular. 


\section{Colgajo de perforantes abdominal: DIEP y SIEA}

Los colgajos de perforantes se han constituido en el escalón reconstructivo de mayor refinamiento quirúrgico por sus beneficios al dejar mínima morbilidad en las áreas donantes y permitir el tallado de los tejidos más precisos a los defectos a reconstruir, permitiendo al mismo tiempo la transferencia de varios tipos de tejidos, constituyéndose así en una herramienta versátil para casos complejos, con defectos tridimensionales y necesidades tisulares específicas (108).

Un colgajo de perforantes es aquel cuyo aporte sanguíneo procede de vasos perforantes, es decir, vasos que pasan a través de tejidos profundos, principalmente músculo, antes de perforar la fascia para irrigar la piel (109). Los colgajos de perforantes pueden ser pediculados, cuando el vaso no es seccionado para ser anastomosado a vasos distantes (son frecuentes en la reconstrucción de miembros inferiores) o libres, cuando el vaso es seccionado para la transposición del colgajo a tejidos alejados, siendo preciso realizar la anastomosis entre los vasos donantes y los receptores.

\section{Colgajo DIEP}

Es un colgajo constituido por piel y grasa del abdomen inferior, con las dimensiones de la isla cutánea empleada en el colgajo TRAM libre, pero nutrido únicamente por uno, dos o tres vasos perforantes procedentes de los vasos epigástricos inferiores profundos y sin dañar el músculo recto abdominal. Sus ventajas e inconvenientes se describen en la tabla 7.

Cualquier paciente sin comorbilidades médicas importantes puede ser candidato para esta técnica, siendo contraindicaciones relativas la obesidad, el tabaquismo y la presencia de cirugías abdominales previas. La única contraindicación absoluta es que la paciente se haya sometido a una abdominoplastia previamente, debido a la lesión de las perforantes abdominales que nutren el colgajo (110). Aquellas pacientes muy delgadas no son buenas candidatas debido a que el panículo adiposo del colgajo extraído va a ser muy fino, con las consiguientes dificultades para recrear adecuadamente la mama a reconstruir. 


\begin{tabular}{|c|c|}
\hline $\begin{array}{l}\text { Aporta gran volumen de tejido, suficiente } \\
\text { para la RM en la mayoría de las pacientes }\end{array}$ & Intervención larga y compleja \\
\hline $\begin{array}{l}\text { Menor debilidad de la pared abdominal, } \\
\text { afectación muscular, dolor postoperatorio } \\
\text { estancia hospitalaria en relación al TRAM }\end{array}$ & $\begin{array}{l}\text { Es primordial realizar una buena selección de } \\
\text { perforantes para prevenir fenómenos de } \\
\text { insuficiencia venosa en el colgajo }\end{array}$ \\
\hline $\begin{array}{l}\text { Técnica apta en pacientes que han recibido } \\
\text { radioterapia }\end{array}$ & Curva de aprendizaje larga \\
\hline $\begin{array}{l}\text { Menor coste que otras alternativas } \\
\text { reconstructivas }\end{array}$ & $\begin{array}{l}\text { Necesita un equipo altamente experimentado } \\
\text { en la técnica microquirúrgica }\end{array}$ \\
\hline $\begin{array}{l}\text { Mejoría del contorno corporal muy valorada } \\
\text { por la paciente }\end{array}$ & \\
\hline $\begin{array}{l}\text { Cicatriz similar a la de una abdominoplastia } \\
\text { estética, ocultable con ropa o traje de baño }\end{array}$ & \\
\hline $\begin{array}{l}\text { La disección del colgajo en decúbito supino } \\
\text { admite el trabajo simultáneo de dos equipos }\end{array}$ & \\
\hline
\end{tabular}

Tabla 7: Ventajas e inconvenientes del colgajo DIEP.

\section{Técnica quirúrgica}

La técnica se describe de forma pormenorizada en el apartado de material y métodos, pero sintetizando, el procedimiento consiste en la elevación de una isla cutáneo-adiposa de la porción inferior del abdomen nutrida por vasos perforantes provenientes del pedículo epigástrico inferior profundo. Este tejido se autonomiza para a continuación realizar una microanastomosis del pedículo a los vasorreceptores, habitualmente la arteria y vena mamarias internas, previamente disecadas. Finalmente se realiza un cierre directo de la pared abdominal dejando una cicatriz transversa en la porción inferior del abdomen y se moldea el tejido transferido para que tenga la forma y el volumen más parecido posible a la mama sana contralateral (fig. 11). Si se detectan signos de congestión venosa, se refuerza el drenaje mediante una anastomosis de la vena epigástrica inferior superficial a la vena cefálica, o una rama del eje subescapular habitualmente. En el caso de que la mama 
contralateral necesite de algún procedimiento como una reducción o una mastopexia, este se suele ejecutar en el mismo acto quirúrgico.

Las complicaciones del colgajo DIEP son similares a las del TRAM e incluyen necrosis grasa, pérdida parcial o total del colgajo. La morbilidad del área donante es inferior en todos los estudios con la técnica DIEP.

A

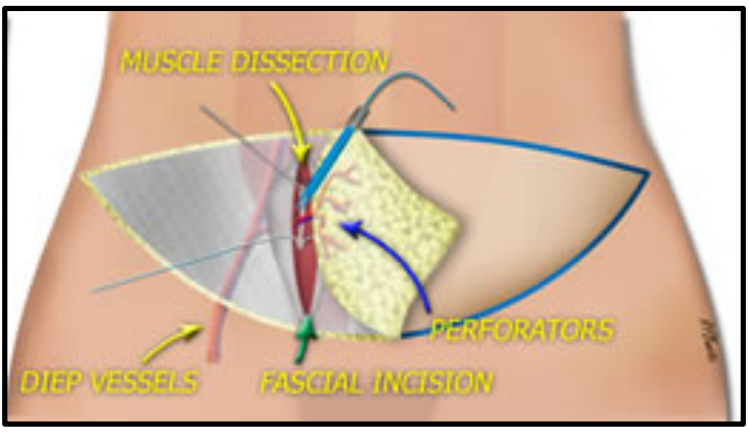

$\mathrm{B}$
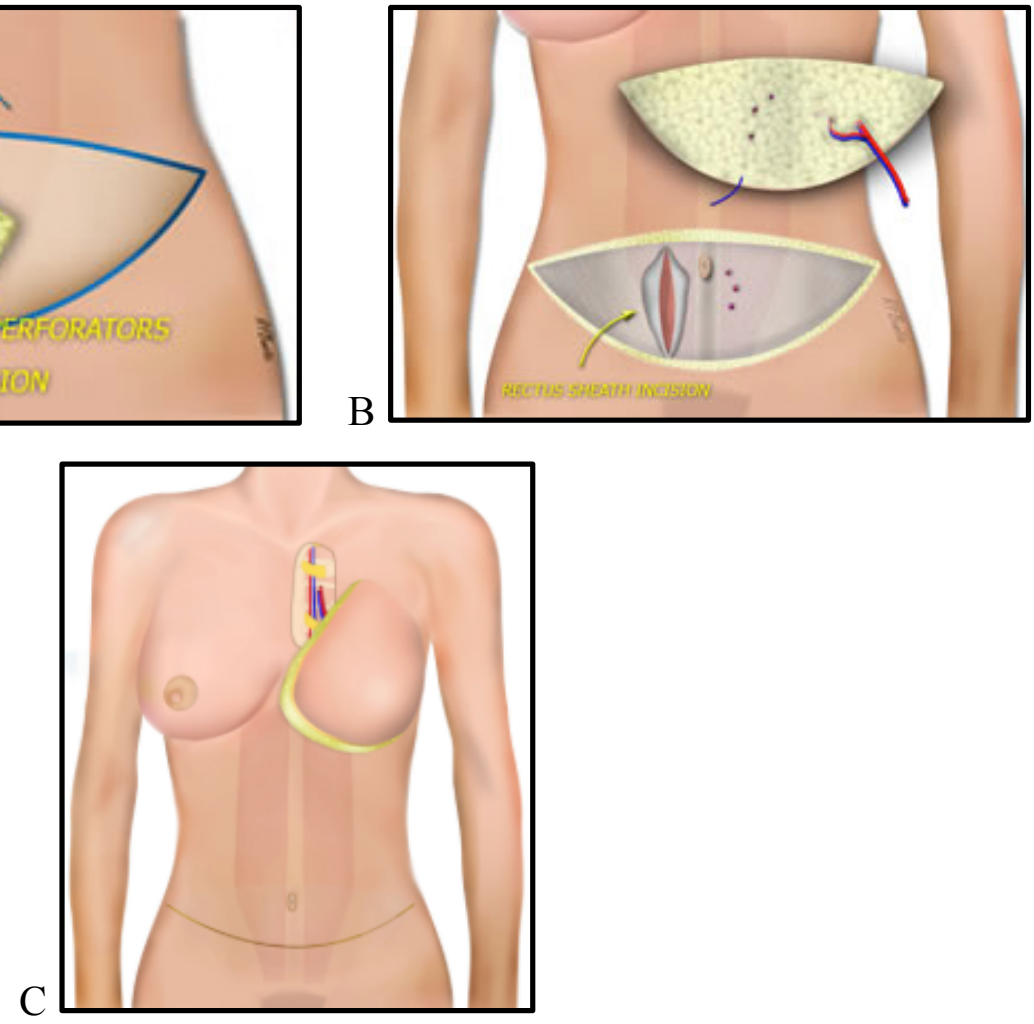

Figura 11: Secuencia de la RM con colgajo DIEP. A: Localización y disección de la perforante a través de la musculatura abdominal. B: Autonomización del colgajo con su pedículo y el sistema venoso superficial. C: Anastomosis a vasos mamarios internos, remodelado del colgajo y cierre del defecto abdominal. Fuente: www.microsurgery.net

\section{Colgajo SIEA}

El colgajo perforante de arteria epigástrica inferior superficial (superficial inferior epigastric artery, SIEA) fue descrito por Grotting en 1991 (111). Al utilizar el pedículo vascular que da nombre al colgajo y que discurre por encima de la fascia muscular, evita 
sacrificar el aporte vascular dominante del músculo recto abdominal y la posibilidad de lesionar su inervación motora, lo cual puede ocurrir al disecar el colgajo DIEP. Sin embargo, tiene como principal inconveniente la ausencia en un 35\% de los casos de la arteria epigástrica inferior superficial (112) y solo en un 30\% de la población el calibre de la arteria es mayor de $1.4 \mathrm{~mm}$, encontrando en el resto de las pacientes arterias filiformes e incluso inexistentes, lo cual conlleva que, en un porcentaje elevado de casos, este pedículo no tenga entidad suficiente como para nutrir todo el colgajo (113). En este tipo de colgajo conviene utilizar la zona contralateral a la mama a reconstruir para mejor posicionamiento ulterior del mismo, y únicamente se podrá utilizar un hemiabdomen, ya que no contiene vasos que crucen la línea media pudiendo dar origen a complicaciones circulatorias en el tejido transferido si no se respeta esta norma (114).

\section{Otras alternativas de reconstrucción autóloga con colgajos microvascularizados}

Se han descrito diferentes zonas donantes de colgajos para utilizar en aquellas pacientes que deseen beneficiarse de una reconstrucción con tejido autólogo pero en las que no puede utilizarse el colgajo DIEP ya sea porque la zona haya sido violada por una cirugía previa o bien presenten insuficiente tejido abdominal. Cada alternativa presenta sus ventajas e inconvenientes, pero hasta el momento ninguna ha sido capaz de desplazar al colgajo DIEP como referencia en reconstrucción autóloga microvascularizada.

\section{a) Colgajos SGAP e IGAP:}

Para la obtención del colgajo libre SGAP, se utiliza el tejido graso y piel de la parte superior de los glúteos, lo que resulta en una cicatriz del área donante fácilmente ocultable con la mayoría de los trajes de baño (fig. 12A). Si se lleva a cabo un colgajo IGAP, la cicatriz del área donante se encuentra en el pliegue glúteo inferior. Son menos usados en nuestro medio por las alteraciones en el contorno glúteo que ocasionan, sus pedículos cortos, su mayor complejidad técnica y la necesidad de cambiar de posición al paciente durante la intervención lo que imposibilita el trabajo

b) Colgajo TMG:

Se basa en la utilización de una isla cutánea de la cara superointerna del muslo que es transportada en unión con el músculo gracillis y su pedículo vascular, la rama ascendente 
de la arteria circunfleja femoral medial (115). Aunque de disección más sencilla que el colgajo DIEP, aporta poco volumen de tejido, el pedículo vascular es corto $(7-9 \mathrm{~cm})$ y con frecuencia tiene un diámetro inferior al de los vasorreceptores mamarios (fig. 12B).

c) Colgajo PAP:

Descrito en 2011 por Allen y cols. (93), es un colgajo de perforantes de la arteria femoral profunda (profunda artery perforator, PAP). Aunque de difícil disección, tiene como ventajas con respecto a los anteriores que aporta gran cantidad de tejido (entre 235695 gr.) procedente de la región superoposterior del muslo sin lesionar ningún musculo y permitiendo una cicatriz fácilmente ocultable en el surco glúteo. Además tiene un pedículo de mayor longitud $(7-13 \mathrm{~cm}$.) y de mayor diámetro (media de la arteria $2,2 \mathrm{~cm}$ ).
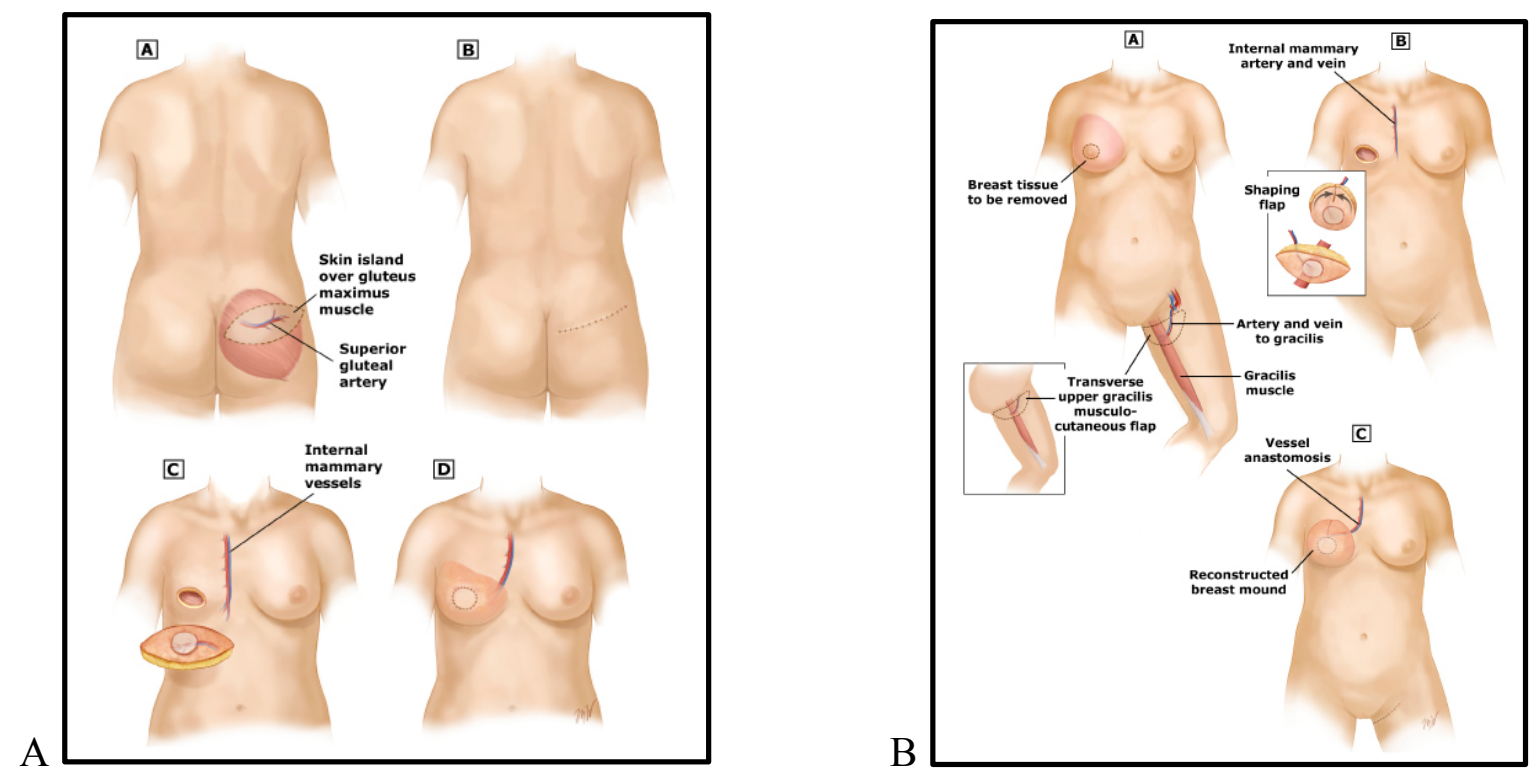

Figura 12: A: Esquema de la extracción del colgajo SGAP con la localización de su zona donante y su anastomosis en la cara anterior del tórax. B: Esquema de la elevación del colgajo TMG, la conización y su anastomosis a los vasos mamarios internos. Fuente de URL: www.uptodate.com

\section{Reconstrucción con grasa autóloga}

La reconstrucción mamaria mediante injerto de tejido adiposo, conocida como lipoinfiltración, lipofilling o lipoestructura, es una técnica de reciente introducción y que 
aún esta en desarrollo. Después de numerosas fases en las que se discutió la conveniencia del uso de grasa para la reconstrucción de mama, en el año 2007, la Asociación Americana de Cirugía Plástica publicó un artículo dónde se establecía la seguridad y efícacia del procedimiento (88).

La grasa está considerada como un relleno ideal, ya que es blanda, no alergénica, disponible en cantidad y fácil de obtener y trasplantar con mínima morbilidad. El principal inconveniente es su reabsorción y existen estudios que muestran una pérdida del volumen injertado de entre un $20 \%$ y $90 \%$ al cabo de un año.

Actualmente la grasa se extrae mediante una liposucción del abdomen, de la cara interna de los muslos, de los flancos o de la zona trocantérea. El denominador común de estas zonas es que permite obtener de una grasa no fibrosa. El método descrito por Coleman (87) parece ser el más efectivo, en cuanto que un número mayor de adipocitos sobreviven, debido a las bajas presiones de vacío empleadas para extraer la grasa (fig. 13).

Cualquier paciente puede ser candidato a esta técnica, teniendo en cuenta que el prendimiento del lipoinjerto va a estar condicionado por el lecho receptor así como por las condiciones circulatorias del paciente. De este modo, la inyección en zonas mal vascularizadas y en pacientes fumadores o con comorbilidades médicas que afecten a la microcirculación, como la diabetes mellitus o la dislipemia, va a traducirse en unos porcentajes de prendimiento menor con mayor reabsorción del lipoinjerto.

Sus aplicaciones en reconstrucción mamaria son las siguientes:

- Reconstrucción de defectos parciales como en tumorectomías y corrección de alteraciones del contorno de colgajos e implantes.

- Como método para aportar el volumen que falta en reconstrucciones con colgajos e implantes.

- Mejoría de la cobertura de prótesis mamarias de forma previa o posterior a la implantación.

- Reconstrucción total (con expansión externa). 
La complicación más habitual es la presencia de nódulos e induraciones palpables como consecuencia de una necrosis grasa. Otras complicaciones menos frecuentes son las infecciones, disestesias, hematoma y dolor.
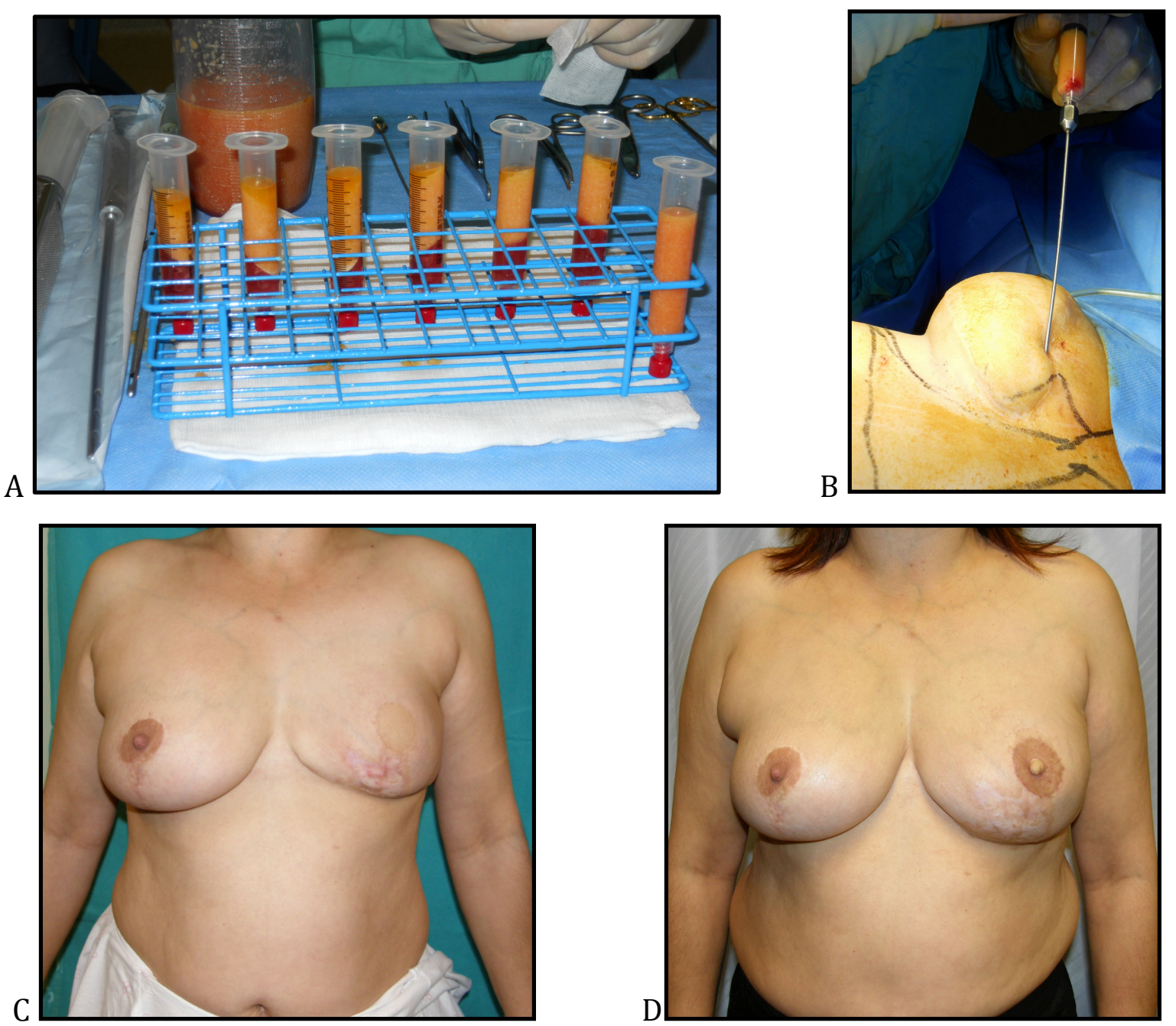

Figura 13: A: Tejido adiposo extraido mediante lipoaspiración a baja presión y ya centrifugado. Se observan las fase oleosa, adiposa y de suero. B: Colocación del injerto con cánula. C: Reconstrucción mamaria inmediata izquierda con colgajo de LD y mastopexia derecha. D: Resultado después de dos lipoinfiltraciones, injertándose un total de $350 \mathrm{cc}$ de tejido adiposo procesado según la técnica de Coleman y reconstrucción de complejo areola-pezón.

\section{Reconstrucción del complejo areola-pezón}

La reconstrucción del complejo areola-pezón (CAP) crea un efecto óptico que permite que el montículo reconstruido adquiera el aspecto de una mama. Desde que Adams realizó 
en 1944 el primer injerto compuesto de areola y pezón (116), han ido apareciendo una amplia variedad de técnicas que incluyen diferentes tipos de injertos y colgajos locales.

Aunque la reconstrucción del CAP se puede realizar en el mismo tiempo operatorio que el del resto de la mama, se aconseja retrasarlo hasta que desaparezca la inflamación, los tejidos se adapten a su nueva disposición y la mama reconstruida haya adquirido su conformación definitiva, con el fin de que la posición en la que se coloca el nuevo CAP sea la más correcta posible en relación con esta mama y con el CAP contralateral. En este caso el procedimiento se puede realizar con anestesia local.

Las dimensiones medias de una areola oscilan entre 35 y $45 \mathrm{~mm}$, mientras que la proyección habitual del pezón son $5 \mathrm{~mm}$ (117). Sin embargo habrá que tener en cuenta las dimensiones del CAP contralateral de cara a lograr una reconstrucción lo más simétrica posible, que es el parámetro más valorado por las pacientes. Los métodos para la recreación de la areola van desde un simple tatuaje hasta técnicas que involucran la toma de un injerto de piel total, habitualmente extraído de la zona de la ingle. La decisión acerca de cuál es la técnica más apropiada depende del estilo de vida y las preferencias de la paciente.

Con respecto a la reconstrucción del pezón, se han propuesto diferentes opciones como el uso de cartílago auricular para crear un relieve subcutáneo, tatuaje con sombras para simular proyección, porciones del pezón contralateral a modo de injerto, aunque sin duda las que gozan de mayor popularidad son los colgajos locales, que pueden ser elevados y plegados con diferentes patrones según la técnica seleccionada (fig. 14).

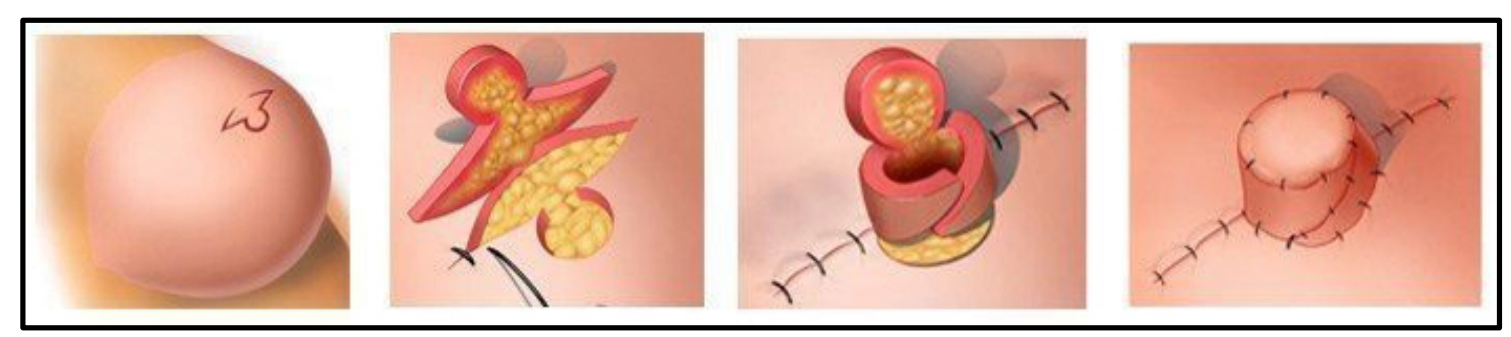

Figura 14: Secuencia de la reconstrucción de un pezón con el colgajo C-V. Fuente URL: www. mdanderson.org 
Entre las opciones con colgajos locales, sobresalen el colgajo "C-V" (118), colgajo "en patín” (119) y el colgajo “en estrella” (120) (fig. 15). Estos colgajos consiguen recrear el pezón de forma fidedigna y no suelen ser necesarias las revisiones a medio o largo plazo. Hay que reseñar que aunque consiguen una buena proyección en el postoperatorio inmediato, en muchos casos esta disminuye al cabo de varias semanas hasta proyecciones medias de 2,5 mm, que pueden resultar insuficientes cuando el pezón contralateral tiene mayor entidad. Además, al elevarse sobre piel blanca de la reconstrucción del montículo, no tienen la tonalidad oscura de un pezón natural.

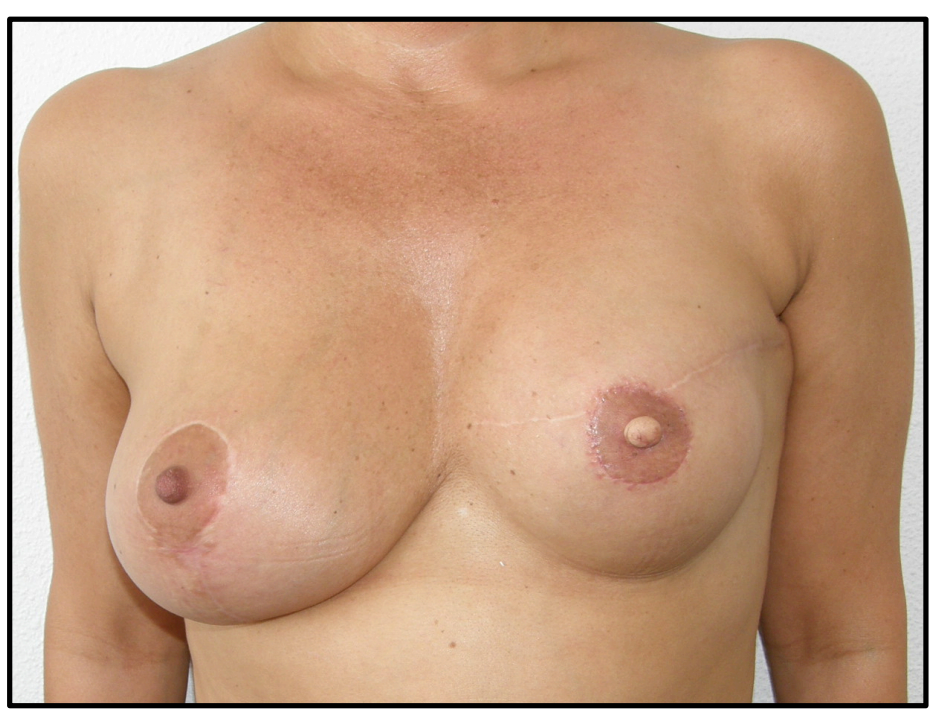

Figura 15: Reconstrucción mamaria izquierda con técnica de expansor y prótesis y mastopexia contralateral de simetrización. Reconstrucción de CAP izquierdo con injerto de piel total para la areola y colgajo C-V para el pezón.

\section{Simetría de la mama reconstruida y la contralateral}

La finalidad última de la RM es recuperar la imagen corporal de la mujer pero muy especialmente la percepción que de ella tiene la paciente. La reconstrucción de la mama amputada no asegura por sí misma la consecución de dicho fin y en muchos casos hay que lograr la simetría mediante técnicas complementarias (53). 
Para lograr un resultado óptimo debemos guiarnos por una serie de principios:

- El diseño de la resección oncológica debe incluir el de la reconstrucción y simetría buscando siempre la excelencia en el resultado.

- Se debe establecer de forma clara e informada con la paciente si prefiere una asimetría de forma o volumen variable según cada caso o acepta cicatrices adicionales para reducir estas asimetrías.

- Se valorará la obtención de la simetría de la mama contralateral en el mismo acto de la RM.

- Es importante considerar el riesgo de la mama contralateral para decidir desde el principio si es candidata a una mastectomía reductora de riesgo, ya que va a tener consecuencias transcendentales sobre el camino a tomar en la reconstrucción.

Técnicas sobre la mama contralateral

Las modificaciones sobre la mama contralateral van a ir encaminadas a dotar a esta de un aspecto más normalizado dentro de los cánones estéticos actuales y facilitar la RM, ya que algunas técnicas se muestran insuficientes para alcanzar volúmenes grandes o bien conseguir una ptosis importante. Esto puede implicar corregir ptosis del montículo mamario, malposiciones del CAP, excesos y defectos de volumen, etc.

Estas actuaciones se pueden clasificar en:

1. Aumento del volumen y/o proyección de la mama. En este caso se usan normalmente implantes mamarios o técnicas de lipoinfiltración.

2. Ascenso del CAP. Mediante dermopexias circumareolares.

3. Pexia mamaria con o sin reducción del volumen. Existen multitud de técnicas, gozando de popularidad las técnicas descritas por Lejour, McKissock, Robbin (pedículo inferior) o Ribeiro (autoprótesis).

Es importante informar a la paciente que estas técnicas no están exentas de riesgo y que suponen una modificación importante para la mama. 
Técnicas sobre la mama reconstruida

Aunque han sido descritas las principales técnicas de RM, en ocasiones puede ser necesario pequeñas modificaciones que doten a la reconstrucción de la máxima simetría posible en términos de forma y volumen. La mayoría de estas correcciones pueden practicarse bajo anestesia local o bien con anestesia general de forma ambulatoria.

Las principales herramientas de las que disponemos son:

1. Lipoaspiración: Permite reducir volumen adiposo de aquellas zonas que se muestran mas prominentes o bien de la reconstrucción en general. Se realiza introduciendo una cánula de liposucción por incisiones inferiores a $1 \mathrm{~cm}$ infiltrando previamente con una solución de Klein que facilite la extracción del tejido adiposo y minimice el sangrado.

2. Lipoinfiltración: Técnica descrita previamente, permite aportar volumen en zonas deprimidas, o en toda la reconstrucción en general.

3. Remodelado: Mediante plastias locales y resecciones localizadas de piel y grasa podemos lograr transformaciones que eliminen redundancias en zonas concretas, $\mathrm{y}$ aportar una forma más redondeada a la mama reconstruida.

Al igual que la reconstrucción del CAP, estas técnicas se realizan varios meses después de la reconstrucción con la técnica principal y una vez que la forma de la mama es estable, con el fin de evitar sobre correcciones que den lugar a asimetrías mayores. Como ventaja, estos procedimientos se pueden combinar con la reconstrucción del CAP, con el fin de acortar el número de tiempos quirúrgicos, ya que con frecuencia las pacientes se muestran cansadas después del proceso tan largo vivido desde el diagnóstico de la enfermedad y se muestran satisfechas ya de por si con el resultado conseguido. 


\section{CONSIDERACIONES ANATÓMICAS DE LA PARED ANTERIOR DEL ABDOMEN Y DEL COLGAJO DIEP}

El conocimiento adecuado de la vascularización y perfusión tisular de los territorios cutáneos son la base sobre la que diseñar colgajos que permitan reconstrucciones más adaptadas a las necesidades de los pacientes.

El colgajo DIEP se localizada en la mitad inferior de la pared anterior del abdomen, por lo que el conocimiento de su irrigación es fundamental para la disección de este colgajo con garantías de éxito. La vascularización de la pared abdominal se basa en un sistema profundo procedente de la arteria epigástrica profunda superior e inferior y de un sistema superficial, basado en la arteria epigástrica superficial, circunfleja iliaca superficial (ACIS) y ramas cutáneas de las arterias intercostales.

Vascularización profunda y superficial de la pared abdominal

La pared abdominal anterior se irriga a través de una intrincada red vascular que, de manera superficial y profunda, la recorre longitudinalmente interconectando las arterias subclavias con las arterias ilíacas externas y femorales. Existen múltiples trabajos en la literatura que demuestran la enorme variabilidad anatómica e intentan sistematizar la vascularización de esta región del cuerpo.

Las dos principales arterias encargadas de la vascularización de la pared abdominal son la arteria epigástrica inferior profunda (AEIP) y la arteria epigástrica superior profunda (AESP). La parte inferior del abdomen recibe también aporte de la arteria epigástrica inferior superficial (AEIS), que presenta una importante variabilidad interpersonal y puede ser filiforme o estar ausente (113) (fig. 16).

La arteria epigástrica superior profunda se origina como rama de la arteria mamaria interna a nivel del sexto cartílago costal y desciende hasta alcanzar el último cartílago costal, para posteriormente abandonar el tórax y penetrar en la musculatura del recto 
anterior del abdomen. A este nivel muestra un patrón de ramificación variable como tronco único, bifurcado o trifurcado, dando por último lugar a vasos de calibre cada vez menor, los cuales se anastomosan con las ramas terminales de la AEIP (121).

La arteria epigástrica inferior profunda nace de la arteria iliaca externa, inmediatamente por encima del ligamento inguinal. Se curva hacia craneal en el tejido subperitoneal, acompañada por la vena del mismo nombre, y asciende de manera oblicua por el margen medial del anillo inguinal para terminar alcanzando el recto abdominal homolateral y su fascia posterior, donde se terminará dividiendo en múltiples ramas por encima del ombligo para anastomosarse con las ramas de la AESP y las arterias intercostales $(121,122)$.

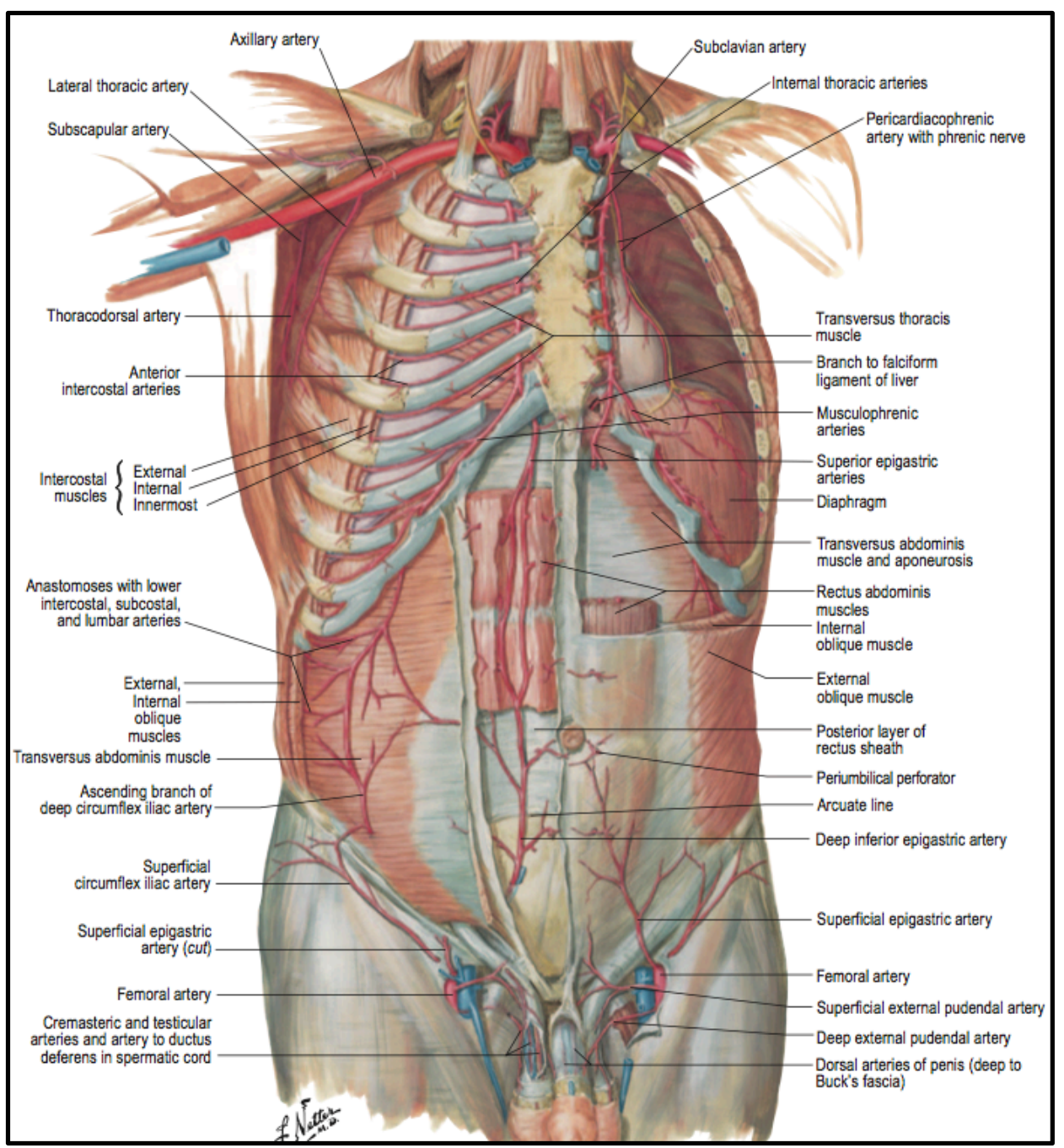

Figura 16: Vascularización y relaciones anatómicas de la pared abdominal. Se observan las anastomosis entre la AEIS, AEIP, AESP y ACIS. Fuente: Netter FH. Atlas of human anatomy. Sixth edition. Philadelphia, PA: Saunders/Elsevier; 2014. p. 251. 
Según Milloy (123), la AEIP asciende anteriormente en la cara posterior del músculo recto anterior del abdomen y entra a nivel del tercio medio (78\%), tercio inferior $(17 \%)$ o tercio superior (5\%) de dicho músculo.

Moon y Taylor (124) describieron tres variaciones anatómicas de la arteria epigástrica inferior profunda a nivel de la arcada del Douglas (fig. 17):

- Tipo 1 (29\%): una sola arteria epigástrica inferior profunda intramuscular.

- Tipo 2 (57\%): la arteria epigástrica inferior profunda se divide en dos ramas intramusculares generando una rama medial y una lateral.

- Tipo 3 (14\%): la arteria epigástrica inferior profunda se divide en tres ramas intramusculares.

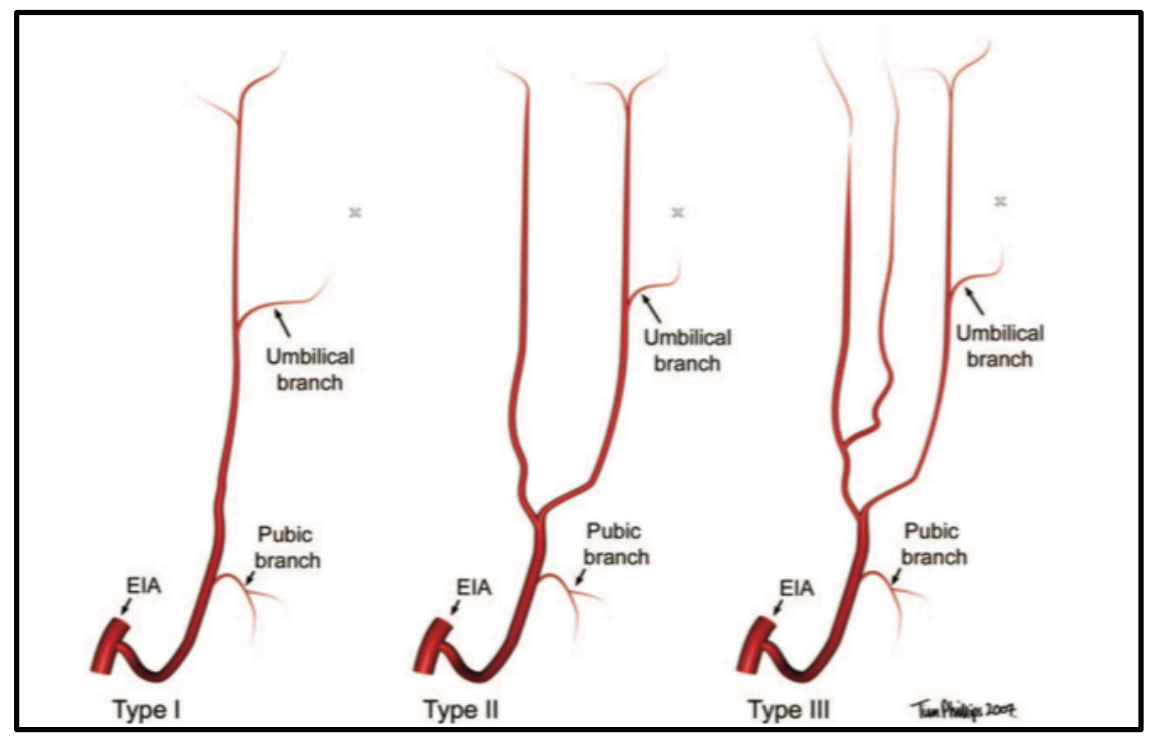

Figura 17: Patrones circulatorios de la arteria epigástrica inferior profunda. Fuente: Moon HK, Taylor GI. The vascular anatomy of rectus abdominis musculocutaneous flaps based on the deep superior epigastric system. Plast Reconstr Surg. 1988 Nov;82(5):815-32.

Recientemente, Rozen y cols. (125) han revisado esta clasificación, realizando un estudio in vivo, sobre 250 pacientes a los que se les ha realizado una reconstrucción DIEP. Sobre sus resultados, cabe destacar la definición de dos nuevos patrones, poco frecuentes: el tipo 0, es decir, ausencia de AEIP y el tipo 4, que corresponde a una AEIP con cuatro ramas . Por otro lado los autores destacan mayor incidencia "in vivo" de los patrones tipo 1 
y menor de los patrones tipo 3 de las descritas previamente y una concordancia significativa del 51\% entre ambos hemiabdómenes en el patrón tipo 1.

En el caso de que la AEIP se bifurque en varias ramas, parece que la más lateral se comporta como dominante en términos de calibre. En un estudio presentado por Itoh y Arai (126) sobre 34 músculos rectos abdominales de 17 cadáveres, en el $82.4 \%$ de los casos la AEIP se bifurcaba en dos ramas. En el $88.2 \%$ de los casos la rama lateral presentaba un calibre mayor y perforantes más numerosas y grandes, considerándose dominante. En el resto de los casos, no se han encontraron dominancias. Este estudio concuerda con las observaciones de Blondeel y cols. sobre 50 pacientes estudiadas con doppler color (127). En este trabajo el $72 \%$ la arteria se divide en dos ramas, de las cuales, la lateral resulta ser más frecuentemente la dominante (54\%) respecto a la medial $(18 \%)$. En el 28\%, la arteria no se dividía, presentándose como único vaso central. En este mismo estudio, se localizaron de dos a ocho perforantes de buen calibre $(>0,5 \mathrm{~mm})$ por cada hemiabdomen. Pacientes obesas presentaban perforantes de calibre y flujo mayores. La mayor densidad de estas perforantes se encontró en un área rectangular paramediana situada $2 \mathrm{~cm}$ cranealmente y $6 \mathrm{~cm}$ caudalmente respecto al ombligo, y entre 2 y $6 \mathrm{~cm}$ lateralmente al ombligo.

La arteria epigástrica inferior superficial constituye, tras la AEIP, el segundo aporte vascular para la piel y el tejido graso de la región inferior abdominal. Esta arteria es un vaso cutáneo directo que se origina en la arteria femoral común, 2-3 cm por debajo del ligamento inguinal en el $17 \%$ de los casos o en un tronco común con la arteria ilíaca circunfleja superficial en el $48 \%$ de los pacientes. La arteria se encuentra ausente o hipoplásica en el $35 \%$ de los sujetos y en tales casos se sustituye por una gran rama ascendente de la ACIS (113). Tras su origen adopta una dirección craneal hasta entrar en el abdomen donde muestra una localización profunda a la fascia de Scarpa. El vaso continúa en sentido superomedial hacia el ombligo, penetrando la fascia de Scarpa bastante por encima del ligamento inguinal, para seguir por el tejido subcutáneo superficial (121). Por último, la AEIS se anastomosa con la AESS, con la AEIP (fig. 18) y, de manera lateral, con ramas perforantes de vasos intercostales y con la arteria ilíaca circunfleja superficial. La AESS es una rama terminal de la AESP, teniendo frecuentemente su origen una vez que la AESP abandona el tórax. 


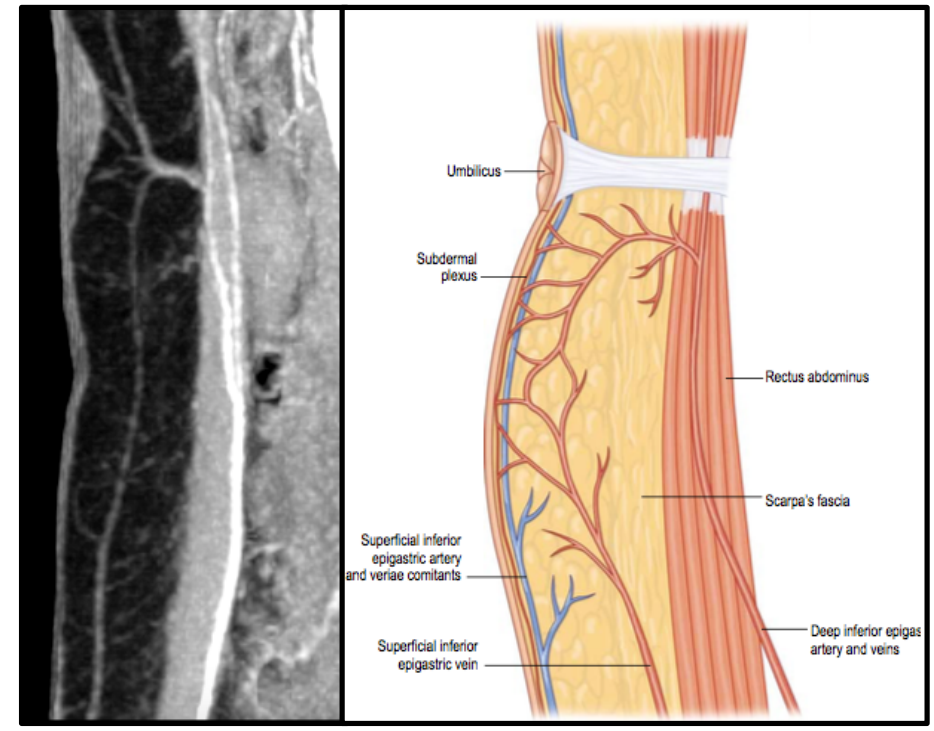

Figura 18: Corte paramediano sagital de la pared abdominal. En el lado izquierdo se presenta una imagen MIP de angio TC en el que se observa la anastomosis de la AEIS con la AEIP con su derecha diagrama explicativo en el lado derecho. Este ultimo diagrama ha sido tomado de Wei F-C, Mardini S, editors. Flaps and reconstructive surgery. Edinburgh: Saunders Elsevier; 2009. $638 \mathrm{p}$.

$\underline{\text { Sistema venoso de la pared abdominal }}$

La anatomía del sistema venoso de la zona abdominal inferior es similar a la anatomía arterial ya que las diferentes venas concomitantes acompañan a sus arterias hacia los vasos proximales. Ciertamente, las pequeñas venas que perforan la vaina anterior del recto abdominal drenan en las venas epigástricas inferiores profundas y éstas en la vena iliaca externa. De modo similar, la AEIS se acompaña de 2 venas concomitantes que drenan en la vena femoral común y ocasionalmente, en el bulbo safeno. Sin embargo, muchas veces estas venas son pequeñas o pueden incluso estar ausentes. Por otro lado, existe una vena que es constante y de un calibre grande en la mayoría de ocasiones, la vena epigástrica inferior superficial (VEIS), que se localiza medial a la arteria epigástrica inferior superficial y más superficial (fig. 19). La VEIS no se acompaña de arteria y es tributaria de la vena safena mayor, cerca de la fosa oval. De hecho, drena un extenso entramado poligonal de venas subcutáneas en la pared abdominal anterior. Existen conexiones anastomóticas entre este sistema superficial y las venas perforantes de la vena epigástrica inferior profunda (128). La vena epigástrica inferior superficial es considerada por algunos 
autores como el drenaje preferencial del panículo abdominal en condiciones normales y no quirúrgicas (129).

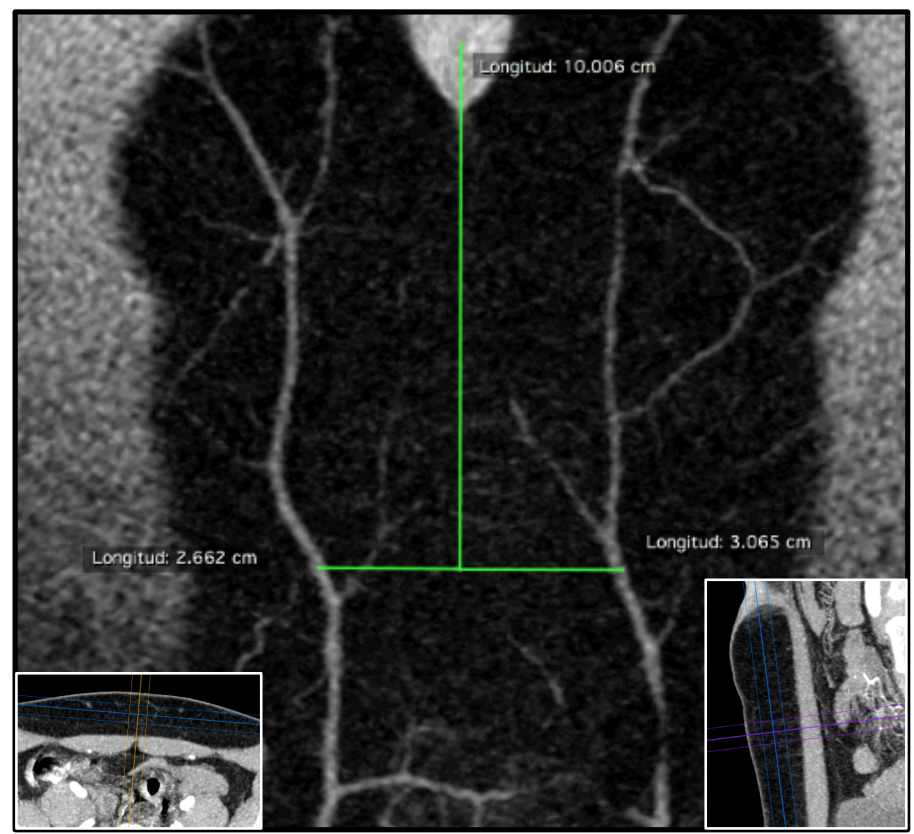

Figura 19: Imagen MPR y MIP de las VEIS en un corte coronal del panículo adiposo anterior del abdomen.

\section{Vasos perforantes}

Se definen los vasos perforantes de la pared abdominal anterior como aquellos vasos tanto arteriales como venosos que, con origen y drenaje en la circulación axial, atraviesan la musculatura de la pared abdominal. El conjunto de la arteria perforante y las venas que la acompañan al atravesar la pared muscular se denominan "pedículo vascular" (124).

De esta manera la perforante se origina de la arteria epigástrica inferior profunda, que se localiza en la cara posterior de la fascia y los músculos rectos anteriores. Penetra en el músculo donde tiene un segmento intramuscular de trayecto y longitud extremadamente variable. En los casos en los que la perforante atraviesa la línea alba, este segmento intramuscular está ausente. A continuación la perforante emerge del músculo describiendo un segmento subfascial, paralelo a la superficie muscular, que de nuevo puede tener longitud variable o estar ausente si la perforante emerge completamente perpendicular a la 
superficie muscular (fig. 20-21). Por último existe un trayecto subcutáneo, donde la arteria se conduce por el tejido graso subcutáneo, pudiendo realiza anastomosis con el sistema arterial epigástrico superficial.

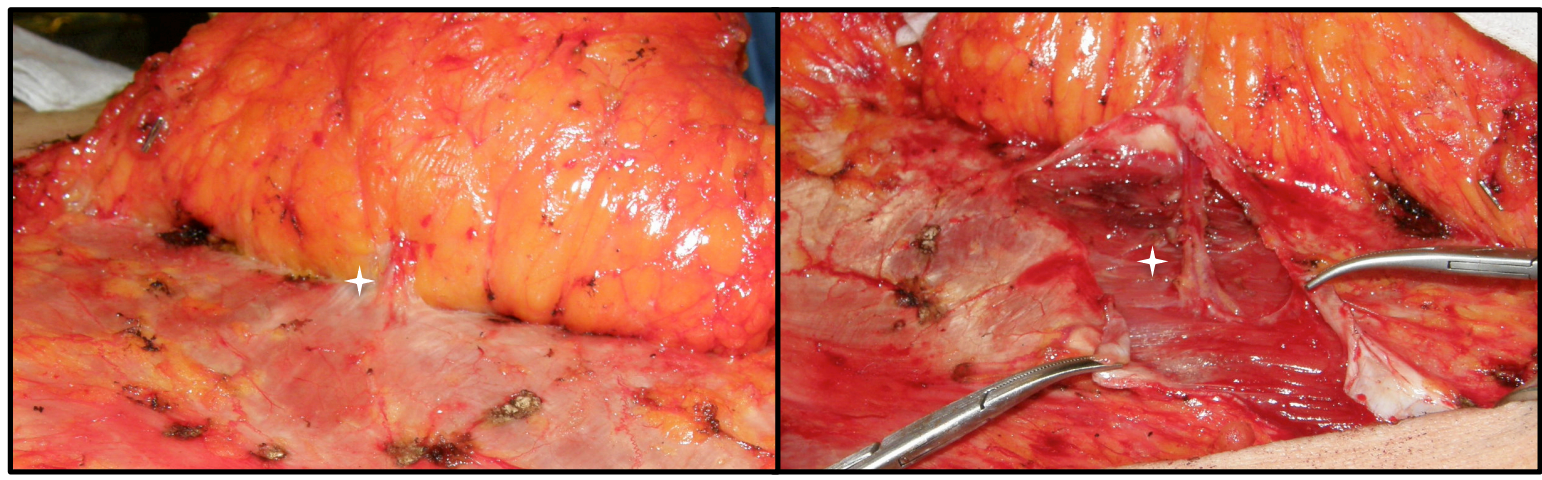

Figura 20: A la izquierda se observa un vaso perforante atravesando la fascia para introducirse en el panículo adiposo. A la derecha se presenta la misma perforante tras incidir la fascia del recto abdominal.

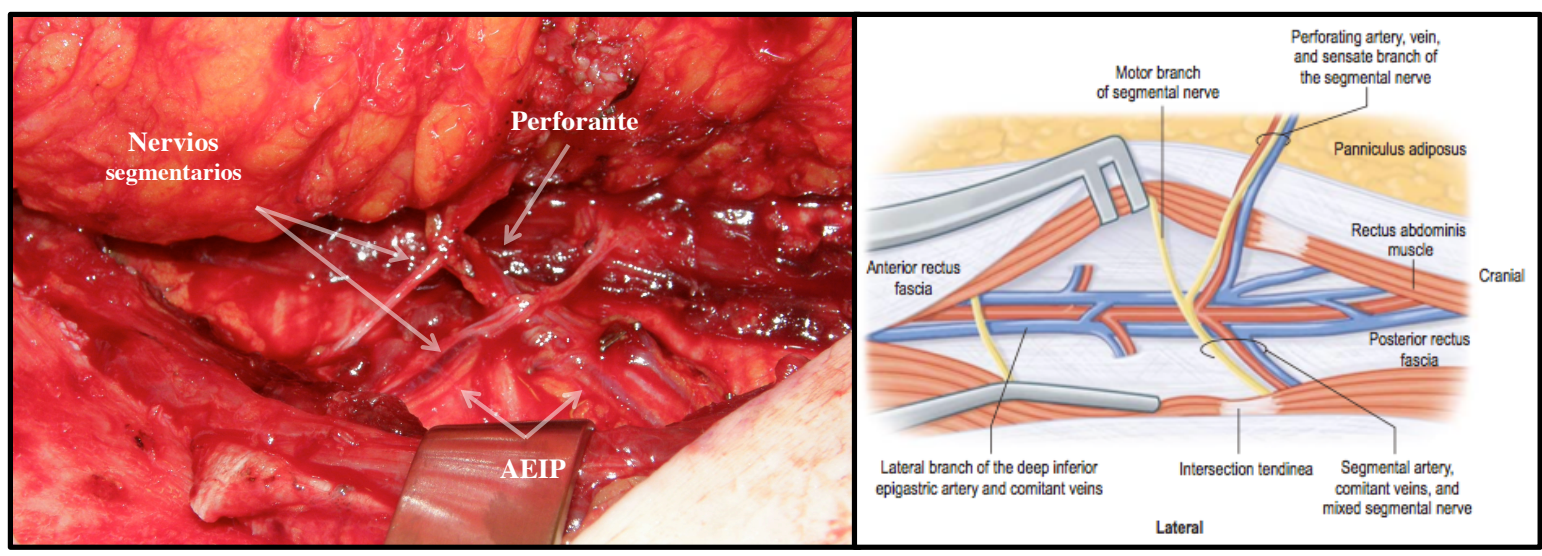

Figura 21: En la izquierda se observa la salida del vaso perforante de la AEIP tras su disección en el músculo recto abdominal, y su entrada de el tejido adiposo del colgajo. Se acompaña en el lado derecho de un diagrama explicativo tomado de Wei F-C, Mardini S, editors. Flaps and reconstructive surgery. Edinburgh: Saunders Elsevier; 2009. 638 p

Se han realizado diferentes estudios con el fin de localizar o al menos establecer unas normas que faciliten la ubicación de la salida de los vasos perforantes. Heitmann y cols. (130) efectuaron un estudio de disección en cadáver sobre 40 casos, resultando que hay por lo menos 1 perforante musculocutánea de calibre superior a $1 \mathrm{~mm}$ en cada hemiabdomen. 
En el $68 \%$ se han encontrado 2 perforantes musculocutáneas, en el $22 \%$ una perforante musculocutánea y en el 10\% 3 perforantes musculocutáneas. Todas las perforantes $(n=75)$ han sido localizadas en un radio de $8 \mathrm{~cm}$ alrededor del ombligo:

- En 34 casos (45\%) en un radio de $2 \mathrm{~cm}$ del ombligo.

- En 20 casos (27\%) en un radio comprendido entre 2 y $4 \mathrm{~cm}$.

- En 16 casos (21\%) en un radio comprendido entre 4 y $6 \mathrm{~cm}$.

- En 5 casos (7\%) en un radio comprendido entre 6 y $8 \mathrm{~cm}$.

Tregaskiss y cols. (131) han estudiado la anatomía vascular de la pared abdominal de 10 cadáveres inyectados con medios de contraste y escaneados con TC de 16 detectores. Los autores han descrito que las perforantes a nivel subcutáneo se distribuyen de manera extremadamente variable no siendo posible individualizar ninguna norma o predicción en el ángulo y en el tipo de patrón de ramificación de los vasos. También la dirección es extremadamente irregular existiendo una compleja y difusa red de conexiones presentes entre las perforantes a nivel del plexo subdérmico.

\section{Conceptos anatómicos y circulatorios del colgajo DIEP}

El tamaño medio de la paleta adipocutánea que se obtiene al elevar un colgajo tipo DIEP es de $34 \times 14 \mathrm{~cm}$ pero puede alcanzar hasta 50 x $20 \mathrm{~cm}$ según la constitución del paciente y los requerimientos de tejido. Lo más habitual es que la zona IV no se necesite y se descarte. Sin embargo, el mismo diseño elíptico de un colgajo DIEP se utiliza para facilitar el cierre de la zona dadora pero generalmente en la reconstrucción sólo se utiliza la mitad ipsilateral del colgajo (fig. 22). Hay que prestar especial atención a las cicatrices abdominales. Aunque la presencia de una cicatriz abdominal transversal baja (p.e. Pfannenstiel) pueda constituir una contraindicación para un colgajo tipo SIEA, no representa un inconveniente para los colgajos DIEP ya que la incisión del margen inferior puede estar situada al mismo nivel. Sin embargo, perforantes musculocutáneas de gran calibre procedentes de los músculos rectos abdominales pueden o no hallarse presentes, según el alcance de la disección del colgajo superior realizada en la intervención previa. 
Las cicatrices abdominales menores como las de apendicectomía también pueden ser ignoradas ya que éstas no afectan significativamente la vascularización del colgajo.

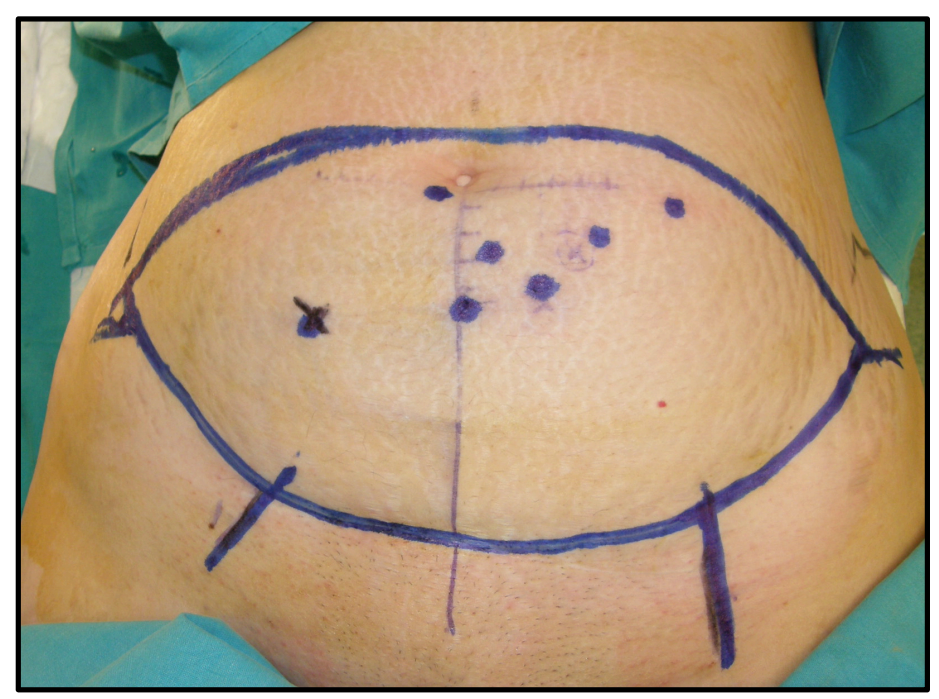

Figura 22: Marcaje cutáneo del colgajo DIEP con sus vasos perforantes y las VEIS

El colgajo DIEP está perfundido sólo por una o más perforantes de la AEIP. Estas perforantes se distribuyen de manera longitudinal en una línea media o una línea lateral tomándose como referencia el músculo recto anterior del abdomen. Parece que estas líneas tienen un origen embrionario durante la constitución de este músculo y son independientes del patrón de la AEIP (132). La perfusión del colgajo DIEP tiene su origen en las zonas de perfusión del colgajo TRAM (fig. 10B), descritas por primera vez por Scheflan y Dinner $(81,82)$. Estas zonas dividen la elipse abdominal del colgajo en 4 partes iguales con diferente perfusión. La zona I comprende el tejido entre la línea media y la línea semilunar del lado donde se diseca el colgajo, la zona II es la homónima contralateral, la zona III está entre la línea semilunar y la línea axilar anterior del lado ipsilateral al colgajo mientras que la zona IV es la homónima contralateral (fig. 23). La calidad de la vascularización empeora a medida que aumenta el número. Aunque después Dinner y cols. (133) corrigieron la descripción original intercambiando las zonas II y III al observar que la perfusión del colgajo en el lado ipsilateral era más fuerte que en el lado contralateral a la línea media, la descripción original ya había sido popularizada por Hartrampf y cols. (80). Con 
posterioridad, Holm y cols. (134) demostraron que las zonas II y III deben intercambiarse de acuerdo a la corrección hecha por Dinner y cols. Recientemente y con el desarrollo de la teoría de los perforasomas, Wong y cols. (135) han propuesto una nueva revisión de dichas zonas.

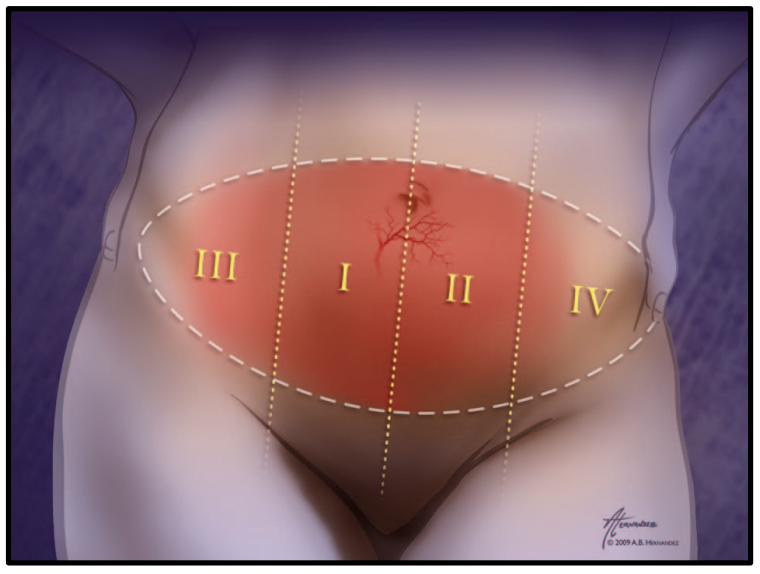

Figura 23: Territorios circulatorios de los colgajos TRAM y DIEP según Scheflan y Dinner. Fuente: Wong C, Saint-Cyr M, Mojallal A, Schaub T, Bailey SH, Myers S, y cols.. Perforasomes of the DIEP flap: vascular anatomy of the lateral versus medial row perforators and clinical implications. Plast Reconstr Surg. 2010;125(3):772-82.

Cuando se diseca el pedículo hacia el borde del recto abdominal inferior, se obtiene generalmente un pedículo de 10 a $14 \mathrm{~cm}$ de longitud, dependiendo de la posición de la perforante. Éste se puede incrementar unos $4 \mathrm{~cm}$ si se diseca el pedículo hasta su origen. En este punto, el diámetro de la arteria es de 3 a $3.5 \mathrm{~mm}$. (122). Un aporte sanguíneo secundario proviene de la arteria epigástrica superior, de las arterias intercostales más caudales, de las arterias iliacas circunfleja superficial y profunda y de la arteria pudenda externa. Como el colgajo DIEP se eleva basado en su pedículo dominante, los vasos secundarios deben ser ligados durante la disección del colgajo. Sin embargo, está descrito la disección de un pedículo menor y anastomosarlo también al pedículo dominante para poder extender el territorio del colgajo.

En la mayoría de los casos, el colgajo DIEP drena principalmente a través de las venas epigástricas inferiores profundas. Estas venas presentan cerca de su unión con la vena 
iliaca externa un diámetro medio de 3.5 a $4.5 \mathrm{~mm}$. Sin embargo, existe una relación inversa entre las venas del sistema profundo y las venas superficiales. De hecho, el sistema de la vena epigástrica inferior superficial suele ser el dominante en la mayoría de los casos (129). Cuando la vena epigástrica inferior superficial presenta un diámetro considerable debería ser preservada porque la vena perforante de la vena epigástrica inferior profunda puede ser insuficiente (136). Por el contrario, si las venas superficiales han sido interrumpidas por una incisión tipo Pfannenstiel, puede tener lugar el fenómeno de retardo con el resultado de un potenciamiento del sistema venoso profundo $(137,138)$.

\section{$\underline{\text { Vasorreceptores }}$}

Existen varias alternativas útiles de vasorreceptores en la pared anterolateral del tórax. Las opciones más populares corresponden a las ramas del eje subescapular y a los vasos mamarios internos. En el primer caso, estos receptores pueden consistir en los vasos circunflejos escapulares, los toracodorsales o bien en su rama colateral para el músculo serrato anterior (139). Estos vasos se muestran especialmente útiles en las reconstrucciones inmediatas de pacientes sometidas a mastectomía con linfadenectomía axilar, ya que si no se lesionan en el transcurso de la misma, quedan expuestos y sólo es necesario completar su disección (140). Por el contrario, en el caso de una reconstrucción diferida es dificil conocer con exactitud la permeabilidad de este eje, la RT puede hacer que la disección sea compleja o que no puedan utilizarse estos vasorreceptores por el daño intimal y la fibrosis que origina este tratamiento. Además, el uso de los vasos toracodorsales imposibilita la utilización del colgajo miocutáneo de dorsal ancho que suele ser la principal alternativa en el caso de que la reconstrucción con el colgajo DIEP fracase.

La alternativa más popular son los vasos mamarios internos (fig. 24). La arteria mamaria interna es una rama colateral descendente de la arteria subclavia y tras alcanzar el tronco venoso braquiocefálico se dirige hacia delante en busca de la primera costilla, descendiendo por detrás de las uniones condroesternales hasta alcanzar el $6^{\circ}$ cartílago costal donde se divide en sus dos ramas terminales, la arteria epigástrica superior y la arteria musculofrénica. En su discurrir bajo la parrilla costal y a la altura del $4^{\circ}$ cartílago o 
espacio intercostal, la vena mamaria interna con frecuencia se divide en dos ramas colocándose a cada lado de la arteria mamaria interna $(141,142)$. La disección de estos vasos se hace resecando un cartílago costal, habitualmente el $2^{\circ}$ o el $3^{\circ}$ y un espacio intercostal anexo, lo que permite una exposición lo suficientemente amplia para realizar la microanastomosis de manera termino-terminal con relativo confort. Sin embargo, y con la intención de reducir el riesgo de que aparezcan depresiones cutáneas en la zona de la anastomosis en pacientes delgadas se ha descrito el abordaje preservando todos los cartílagos costales y resecándose sólo el espacio intercostal $(143,144)$. Los estudios preoperatorios de imagen pueden aportar información útil de la localización de estos vasos, la salida de ramas o las dimensiones de los espacios intercostales que facilitarán su disección $(145,146)$.
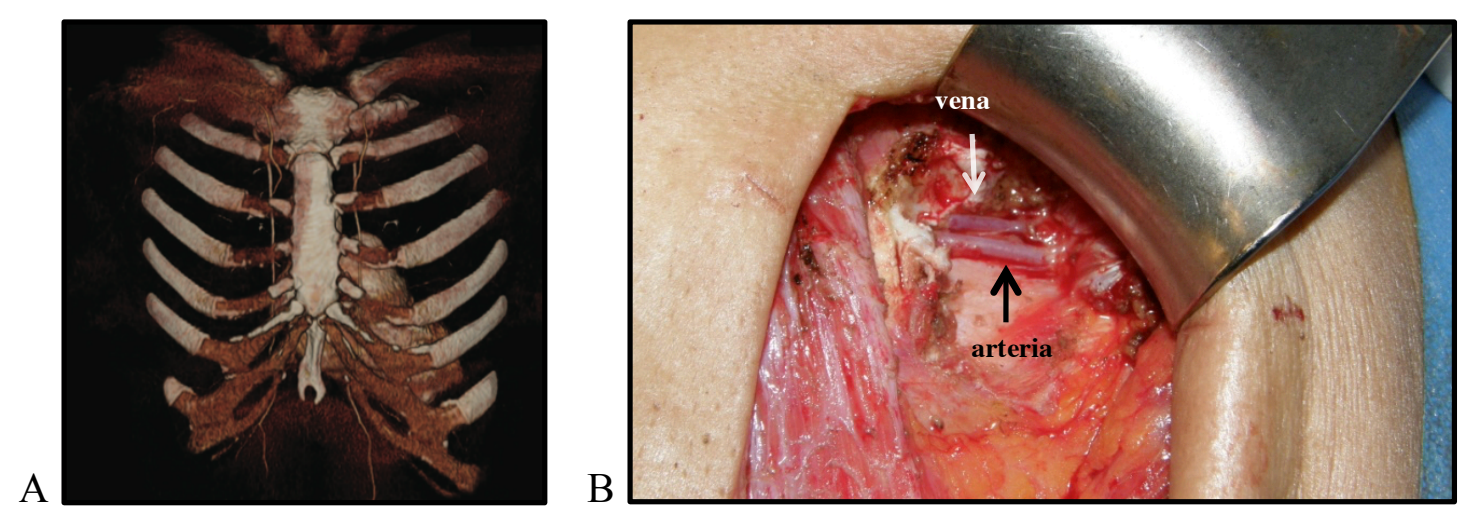

Figura 24: A: Reconstrucción 3D de angio TC en el que se observa el trayecto de los vasos mamarios internos. Fuente: Kim H, Lim S-Y, Pyon J-K, Bang S-I, Oh KS, Mun G-H. Preoperative computed tomographic angiography of both donor and recipient sites for microsurgical breast reconstruction. Plast Reconstr Surg. 2012 Jul;130(1):11e - 20e. B: Disección de vasos mamarios a través del $2^{\circ}$ espacio intercostal resecándose parcialmente el $3^{\circ}$ cartílago costal

Factores dinámicos circulatorios de los colgajos

El concepto de angiosoma es el resultado del trabajo de Taylor y Palmer (Melbourne, Australia) (89), que durante los últimos 30 anos han documentado la anatomía vascular del cuerpo humano y ha descrito los resultados en una larga serie de importantes documentos.

Los angiosomas son territorios vasculares tridimensionales irrigados por una arteria fuente y su vena o venas acompañantes. Cada uno puede subdividirse en un arteriosoma y 
en un venosoma que corresponden al territorio arterial y venoso que conforman el angiosoma. Los angiosomas pueden estar compuestos de piel, músculo, hueso y otros tejidos blandos, mostrando gran extensión del área cutánea y poco tejido profundo y viceversa (fig. 25).

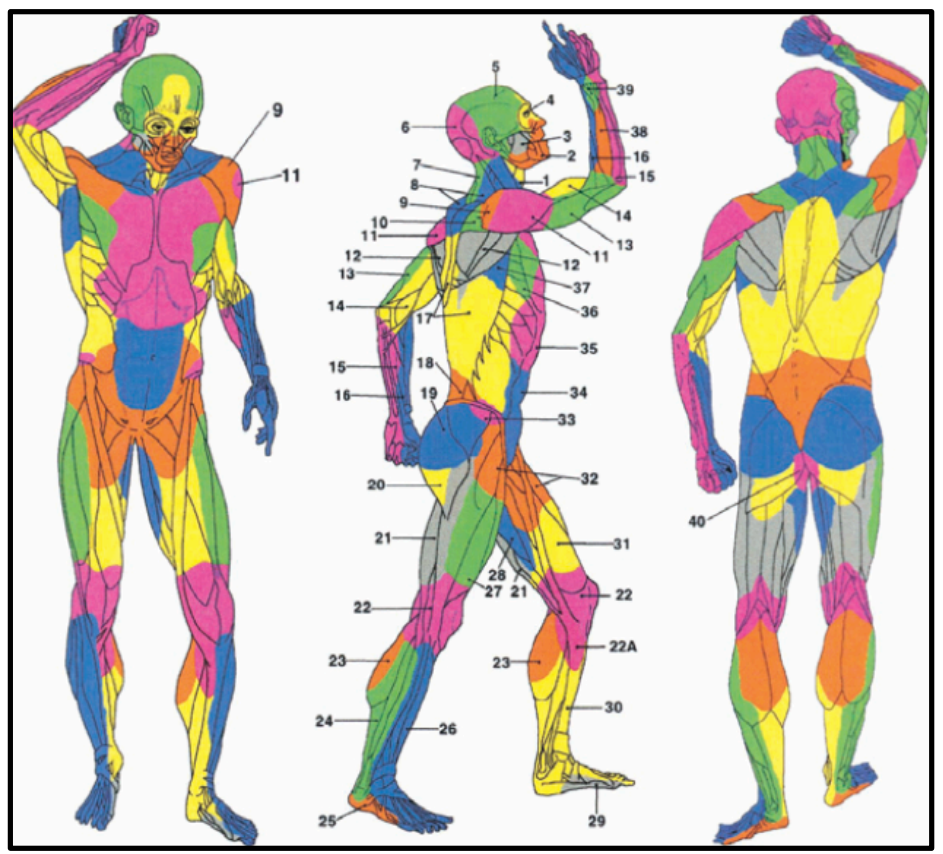

Figura 25: Mapa corporal de los angiosomas publicado por Taylor en 1987. Fuente: Taylor GI, Palmer JH. The vascular territories (angiosomes) of the body: experimental study and clinical applications. Br J Plast Surg. 1987;40(2):113-41.

Cada angiosoma está conectado con un angiosoma vecino por medio de anastomosis verdaderas en cuyo caso el calibre del vaso interconector no cambia, y a través de vasos de choque en el caso de interconexiones de pequeño calibre. El concepto de angiosoma presentas importantes implicaciones clínicas:

- Cada angiosoma define el limite de seguridad vascular de cada capa que puede transferirse de forma separada o de forma combinada a partir de los vasos fuentes subyacentes como un colgajo compuesto.

- Cada angiosoma puede capturar angiosomas vecinos con seguridad cuando estos se incluyen dentro del diseño del colgajo. 
- Ya que la zona de unión entre angiosomas se presenta de forma intramuscular, los músculos proporcionan un desvío anastomótico si llegara el caso de que su arteria fuente o su vena se obstruyan

- Debido a que los músculos atraviesan 2 ó más angiosomas y son irrigados a partir de cada territorio, es posible capturar una isla cutánea con músculo que se encuentre irrigado en el territorio adyacente.

En 1973, McGregor y Morgan (147) demostraron que, en caso de ocluir una arteria de dos territorios vecinos, se produce una disminución de la presión de perfusión en la zona ocluida y un cambio del equilibrio vascular, reajustándose el flujo para complementar la zona avascular. Esto permite demostrar por qué un colgajo puede ser disecado con una isla cutánea mayor de lo habitual y sobrevivir gracias a los vasos de choque, cuando en la zona contigua disminuye la presión.

El desarrollo de los colgajos de perforantes ha permitido comprobar que respetan estas mismas reglas, por lo que Michel Saint-Cyr y cols. elaboraron su teoría de los perforasomas en 2009 (148) en el que enumera los siguientes principios:

- El territorio de perfusión vascular de los vasos perforantes es muy complejo y variable.

- Cada perforasoma está vinculado con perforasomas adyacentes por medio de dos mecanismos principales que incluyen tanto vasos directos como indirectos de unión (fig. 26).

- El eje vascular principal sigue este eje de los vasos de unión.

- Una perforante que sale cerca de una articulación va a vascularizar una masa de tejido que se aleja de dicha articulación. Una perforante que nace en un punto medio entre dos articulaciones va a presentar una distribución de flujo multidireccional.

Progresivamente los colgajos de perforantes han ido incorporándose a los diferentes campos de la cirugía plástica. Hoy día son los colgajos de elección para múltiples técnicas. Basado en los trabajos de Taylor (89) sobre los angiosomas, es posible elevar en el cuerpo 
más de 35 diferentes colgajos de perforantes (109), aunque, para ser considerados como realmente útiles deben cumplir las siguientes premisas (149):

- Tener un aporte vascular consistente y predecible.

- Contar con una perforante de buen calibre (mayor a 0,5mm).

- Una longitud adecuada del pedículo.

- Cierre primario de la zona donante sin excesiva tensión.

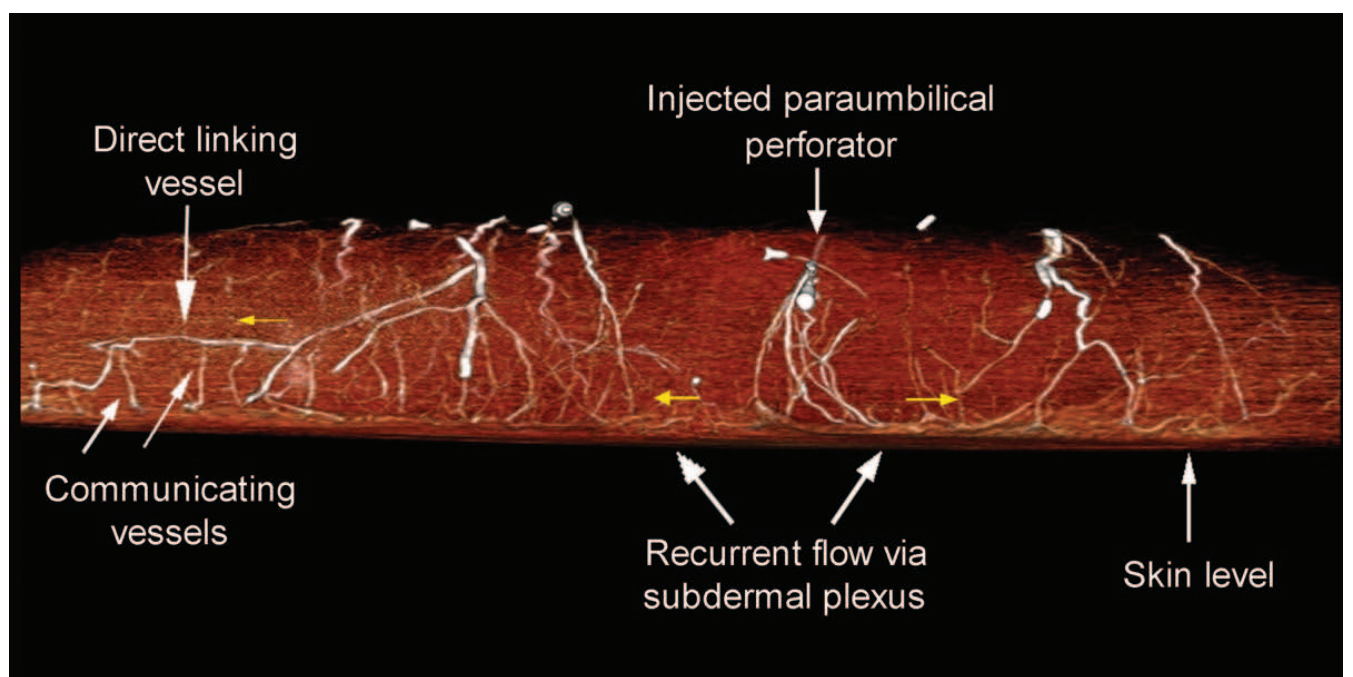

Figura 26: Vista transversal de un colgajo abdominal, donde se inyectó una perforante paraumbilical con contraste para determinar su perforasoma. Se demuestra la existencia de vasos directos e indirectos de unión, con flujo recurrente a través del plexo subdérmico. Ramas comunicantes conectan los vasos diretos e indirectos de unión. Las flechas amarillas indican la dirección del flujo. Fuente: Saint-Cyr M, Wong C, Schaverien M, Mojallal A, Rohrich RJ. The perforasome theory: vascular anatomy and clinical implications. Plast Reconstr Surg. 2009;124(5):1529-44.

Desafortunadamente, a pesar de los avances en el conocimiento anatómico de los territorios cutáneos, no es posible realizar un mapeo sistemático de la localización precisa de las perforantes dominantes, por lo que, como veremos a continuación, se han desarrollado múltiples procedimientos para conocer la ubicación preoperatoria de estos vasos de manera individualizada. 


\section{ESTUDIO VASCULAR DE LA PARED ABDOMINAL CON TÉCNICAS RADIOLÓGICAS}

Como hemos comprobado, a pesar de los avances en el conocimiento anatómico de los territorios cutáneos, no es posible realizar un mapeo sistemático de la localización precisa de las perforantes dominantes extrapolable o generalizable a todos los cuerpos humanos $(127,131,150)$. Esta situación muestra su máximo exponente en el colgajo DIEP, donde la enorme variabilidad anatómica de las perforantes a nivel inter e intraindividual, hace que el disponer de un sistema fiable de localización preoperatoria de los vasos en que vamos a basar la transferencia de nuestros colgajos sea de una enorme utilidad (151).

Una correcta valoración preoperatoria de los colgajos de perforantes debe incluye los siguientes aspectos (151):

- Definir, de la forma más precisa posible, la anatomía de nuestra perforante (localización, trayecto intramuscular, ramificación intratisular, etc.).

- Realizar el mapeo de las perforantes en la misma posición en que el paciente va a estar en la mesa operatoria.

- Valorar posibles alteraciones anatómicas provocadas por cirugías previas o secuelas cicatriciales, así como variaciones anatómicas de la normalidad.

- Valorar la existencia de otras alternativas vasculares, como venas superficiales u otras perforantes, para poder resolver complicaciones intra o postoperatorias.

La planificación quirúrgica de los colgajos DIEP fueron analizadas y discutidas en una reunión internacional y multidisciplinar en Navarra (España) en abril de 2008 (152). Entre otros resultados, se llegó a un acuerdo sobre los criterios que debe cumplir el pedículo vascular ideal:

1. AEIP de calibre grueso con pedículo largo.

2. Calibre de la perforante grueso (tanto de la arteria como de la vena).

3. Entrada central de la perforante en el colgajo. 
4. Trayecto intramuscular corto.

5. Conexión entre la vena de la perforante y la red venosa superficial.

6. Ramificación amplia de la perforante dentro del colgajo.

7. Trayecto subfascial largo.

8. Que su trayecto evite las intersecciones tendinosas.

El objetivo de estos criterios es facilitar la elección adecuada de la perforante con el fin de reducir al máximo el número de complicaciones y el tiempo operatorio, hecho fundamental para lograr la supervivencia completa del colgajo.

En la actualidad disponemos de diversas técnicas diagnósticas que pueden ser utilizadas en el mapeo y planificación de los colgajos de perforantes abdominales, cada una con sus ventajas e inconvenientes:

- Ecografía doppler color.

- Doppler bidireccional.

- Angio TC multicorte.

- Angio RNM.

\subsection{Ecografía doppler color}

El efecto doppler consiste en el cambio de frecuencia que experimenta un sonido cuando se desplaza el emisor con respecto a un receptor inmóvil. La aplicación de este fenómeno en el campo médico permite que el mismo transductor que se usa para obtener imágenes ecográficas en escala de grises y en tiempo real, puede también detectar un cambio de frecuencia y fase de cualquier objeto que se mueva en el campo que está siendo estudiado. Debido a que las estructuras anatómicas son habitualmente estáticas, esto sólo puede corresponder al flujo sanguíneo. Cuando añadimos un espectro de color al componente en movimiento y combinamos ambas técnicas, obtenemos un eco doppler color "dúplex". El color que observamos en el monitor, depende de la dirección del flujo sanguíneo en relación con el transductor y arbitrariamente suele ser asignado como azul o 
rojo. El color rojo indica flujo que se aproxima y el azul flujo que se aleja. El dúplex logra la visualización del vaso explorado, aportando detalles acerca de la morfología del mismo; por otra parte permite la colocación precisa del volumen de muestra a analizar del doppler, lo que posibilita el cálculo de la velocidad de flujo, dato que se correlaciona con la situación hemodinámica objeto del estudio (fig. 27). Además permite obtener una imagen de relleno del vaso que logra discernir la interfase de la pared y estudiar su complianza o elasticidad lo que en último término nos traduce la "salud" del vaso. Esta última información es muy útil en el estudio de perforantes y vasorreceptores en miembros inferiores, ya que la pérdida de la onda trifásica característica puede avisarnos sobre la presencia de enfermedad inflamatoria perivascular o cualquier otra enfermedad de pequeño vaso y en definitiva nos previene sobre su idoneidad como fuente de vascularización de un colgajo (119).
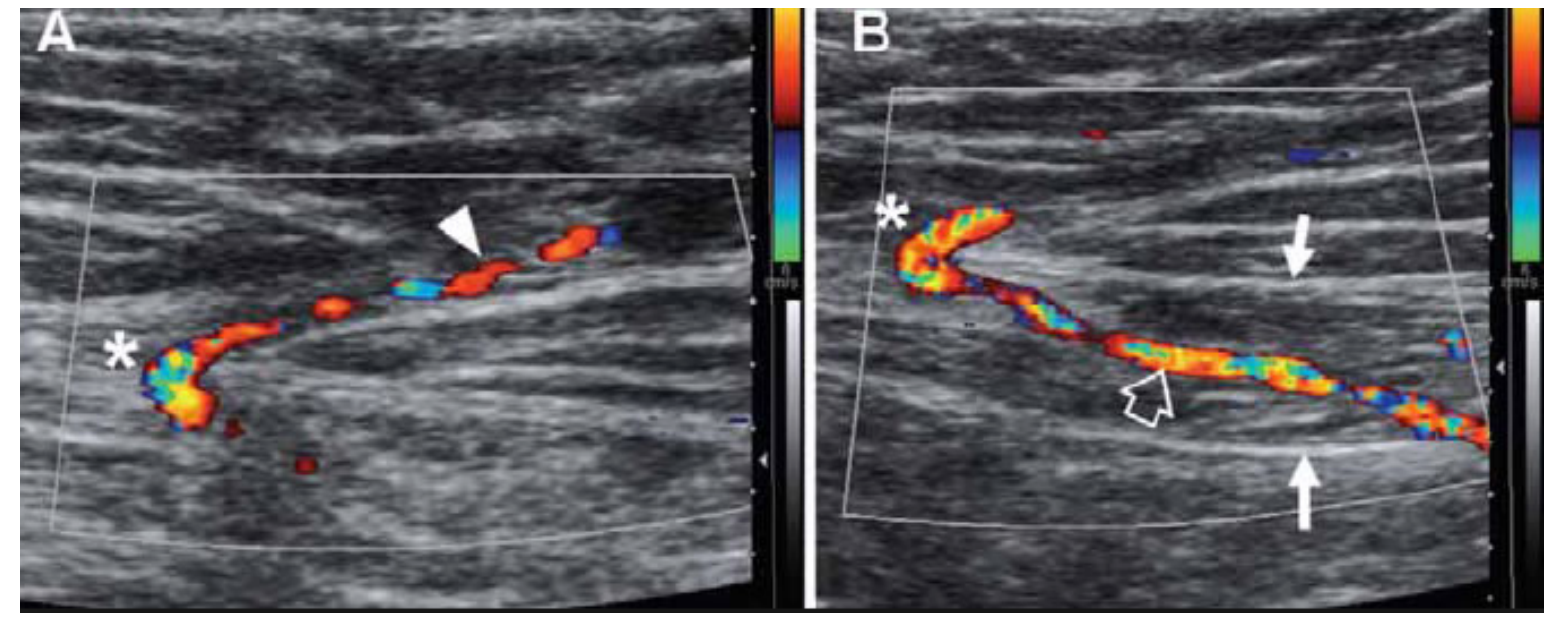

Figura 27: Imagen de eco Doppler-color en la que se aprecia el músculo recto anterior del abdomen (delimitado por flechas en B) así como el trayecto intramuscular de la perforante (flecha hueca en B). El punto donde atraviesa la fascia superficial del recto anterior (* en A y B) se sigue del trayecto subcutáneo del vaso (cabeza de flecha en A). Fuente: Castro García J, García-Tutor E, Alonso A, Pina L, De Luis E. Análisis de perforantes de la epigástrica inferior profunda con Angio TC 3D, Eco Doppler color y Doppler simple de ultrasonidos en colgajo DIEP: resultados preliminares. Cir Plástica Ibero-Latinoam. 2008;34(3):223-34.

Durante la última década, los avances tecnológicos en este tipo de Doppler han permitido escanear vasos de diámetro de hasta $0.2 \mathrm{~mm}$ desde la superficie cutánea hasta los planos más profundos. Por tanto podemos afirmar que la información que podemos obtener con este método es altamente fiable. 
Las ventajas principales de esta técnica son:

- Alta especificidad y sensibilidad en manos expertas $(127,150)$, con elevada calidad de los estudios y concordancia con la angiografía.

- Es una técnica barata y accesible, sobretodo comparada con las alternativas.

- Suministra información hemodinámica.

- Posibilidad de valorar localización, el diámetro y el curso de los vasos, la salida de ramas colaterales así como el calibre y trayecto de las perforantes y las posibles variaciones anatómicas de la zona quirúrgica. Permite localizar el punto exacto de la salida de la perforante a través de la fascia muscular.

- Segura y sin complicaciones para el paciente, ya que no implica exposición radiológica.

Las desventajas principales son:

- Técnica operador dependiente, se necesita una curva de aprendizaje y la valoración puede variar en función de factores individuales. La presión de la sonda sobre el tejido puede alterar la morfología de vasos pequeños a estudio.

- No reproducibilidad.

- Aunque el estudio se practica de una manera confortable, el tiempo de ejecución cercano a una hora puede no ser bien tolerado por la paciente.

- Imágenes no fáciles de interpretar por el cirujano plástico.

Como conclusión cabe resaltar que a pesar de su valor predictivo del $100 \%$, ha tenido una escasa implantación debido al tiempo necesario de exploración (inviable en la mayoría de los hospitales por la presión asistencial), su escasa reproductibilidad y la dificultad de interpretación de las imágenes por el cirujano, lo que ha determinado su abandono progresivo en favor de la TC multicorte. 


\subsection{Doppler bidireccional}

Se trata de una técnica no invasiva que utiliza el medidor de flujo bidireccional Doppler para valorar el plexo vascular superficial (fig. 28). Es una herramienta compacta, portátil y está disponible en la mayoría de los centros debido a su bajo coste (150). La frecuencia de la sonda ecográfica que se utiliza varía de 5 a $10 \mathrm{MHZ}$.

Presenta la ventaja de ser fácil de utilizar e interpretar aunque, como ya referían Taylor y Palmer en sus estudios anatómicos sobre los angiosomas (89), requiere de una curva de aprendizaje: "al igual que el estudiante de Medicina que debe familiarizarse con los complicados ruidos y murmullos cardiacos en la facultad".

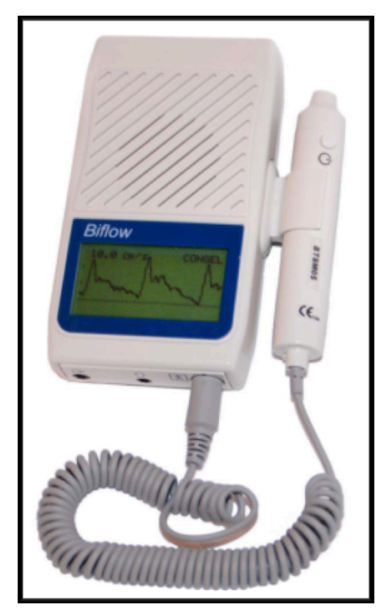

Figura 28: Doppler portátil bidireccional.

Como desventajas hay que reseñar que pequeñas variaciones en la presión de la sonda sobre la piel pueden alterar la percepción. Una presión excesiva puede hacer que los vasos de pequeño calibre se colapsen y sean por tanto imperceptibles, o que por el contrario, estemos detectando vasos que se encuentran en la profundidad y que no llegan a alcanzar la grasa subdérmica. De la misma forma, una presión insuficiente sobre la piel puede hacer que no lleguemos a detectar los vasos que buscamos. Requiere por tanto, de una curva de aprendizaje para aplicar la presión adecuada sobre la superficie cutánea del área a estudiar y para familiarizarse, identificar y relacionar los diferentes sonidos que nos encontramos con la calidad de las perforantes que buscamos (153). En ocasiones, la correcta salida de 
las perforantes puede no ser detectada, sobre todo cuando su origen está en grandes vasos, debido al ruido de fondo existente. En ocasiones, cuando los vasos axiales son superficiales, podemos llegar a confundirlos con perforantes dando lugar a falsos positivos (127). Otras veces, un panículo dermograso importante puede distorsionar los hallazgos. Tenemos que tener en cuenta también que la percepción es subjetiva, e incluso cuando la prueba la realiza la misma persona, puede llevarnos a errores. Es por tanto una herramienta que puede sernos de gran utilidad en el seguimiento postoperatorio en microcirugía, al detectar fácilmente la permeabilidad de la anastomosis. Su portabilidad, lo hace muy útil en ciertas ocasiones, como es su uso intraoperatorio; sin embargo, la gran sensibilidad que presenta, unida a su baja especificidad (153), limita su utilidad en la valoración en el colgajo DIEP a certificar el marcaje de las perforantes sobre la piel realizado con otros estudios.

\subsection{Angiografía por TC multicorte}

La tomografía computerizada es un método basado en la medida de la densidad de volúmenes que constituyen una sección corporal. La técnica se basa en la emisión de un haz colimado de radiaciones $\mathrm{X}$ que después de ser atenuadas por una sección anatómica, inciden sobre un detector (o grupo de detectores) y se envían a una estación de trabajo donde se procesa a través de unos algoritmos específicos, transformando la información en imágenes visualizables en un monitor.

La incorporación de diversos avances han dado lugar a tiempos de rotación de la carcasa más rápidos, tubos de rayos $\mathrm{X}$ más potentes, que unidos a la mejora de los algoritmos de interpolación han permitido obtener imágenes de mejor calidad con un tiempo de adquisición menor. Con la introducción de la tecnología de la tomografía computerizada por multidetectores (TCMD) estos beneficios se multiplicaron. Estos detectores de pequeñas dimensiones están dispuestos en estratos contiguos, para obtener más barrido por cada rotación del tubo de rayos X. Si además movemos la mesa sobre la que está el paciente, el tubo de rayos $\mathrm{X}$ y el detector describen una hélice que permite obtener una imagen de "volumen" del cuerpo, consiguiendo "presentar" zonas sobre las que no tenemos información (fig. 29) (154). 


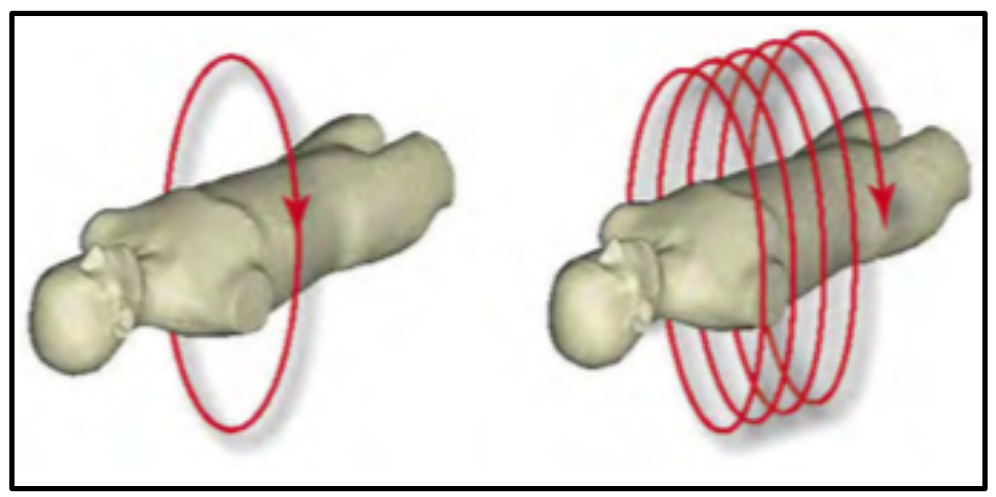

Figura 29: Geometría de una adquisición axial (izquierda). La trayectoria circular del tubo lo es también desde la perspectiva del paciente. En la geometría de adquisición helicoidal (derecha) la trayectoria circular del tubo se con- vierte en helicoidal desde la perspectiva del paciente. Fuente: Calzado A, Geleijns J. Tomografía computarizada. Evolución, principios técnicos y aplicaciones. Rev Física Médica. 2010;11(3):163-80.

A través del aumento en el número de detectores se ha logrado tiempos de exploración más cortos y un mayor volumen de cobertura, con mejora en la resolución temporoespacial. Por último, si administramos una inyección de contraste yodado por una vía venosa periférica, este medio va a circular por los vasos aumentando la densidad de la sangre que circula en su interior y por consiguiente sus valores de atenuación, facilitando su visualización en las imágenes y dando lugar a la angiografía por TC multicorte (angio TC) (155). En muchos centros, la angio TC ha sustituido a la angiografía convencional invasiva en la evaluación diagnóstica de la enfermedad vascular pudiendo considerarse la técnica de imagen de elección para un número de indicaciones vasculares (fig. 30).

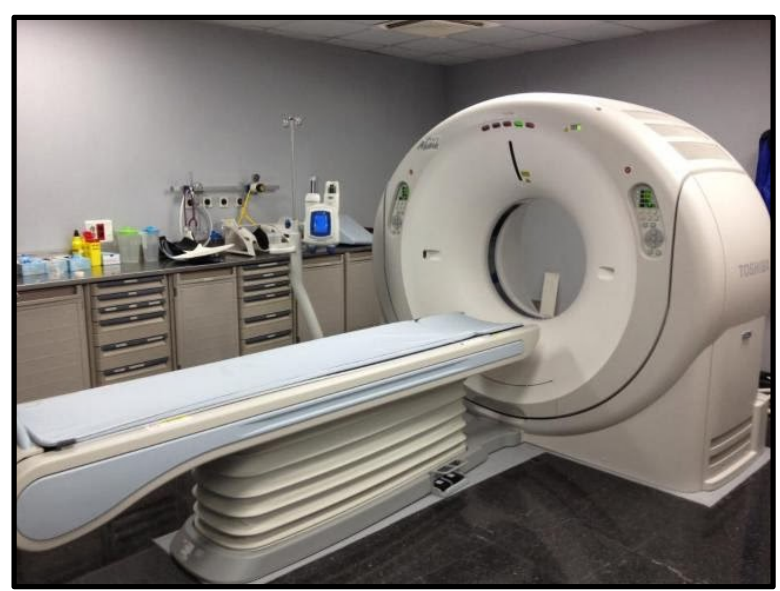

Figura 30: TC multicorte de 128 detectores. 
Las ventajas de la angio TC son múltiples (151):

- Permite obtener cortes muy finos de volúmenes extensos con una elevada resolución espacial en un corto espacio de tiempo.

- A través de la aplicación de un software específico y la optimización de los parámetros técnicos, se puede obtener una resolución espacial de hasta $0,2-0,3 \mathrm{~mm}$.

- La técnica, es altamente específica y sensible y no es objeto de interpretación subjetiva por parte del operador (no operador dependiente). Permite manejar imágenes anatómicas que son fácilmente interpretables tanto por parte del radiólogo como del cirujano plástico sin necesidad de una curva de aprendizaje extensa.

- Los datos se pueden registrar en un soporte digital que permite su uso y visualización en cualquier ordenador personal.

- El tiempo de escaneo depende del número de detectores de la TC y del grosor de los cortes seleccionados, aunque es muy breve. Esto permite analizar un gran volumen corporal en el curso de una sola apnea, con la consiguiente reducción de artefactos.

Estas ventajas se incrementan con los avances técnicos de los equipos y con el aumento en el número de detectores. La calidad de las imágenes obtenidas ha mejorado mucho desde la aparición en 1998 de los primeros TCMD que disponían de 4 detectores hasta los últimos modelos que llevan integrados hasta 320 detectores. Prácticamente en cualquier hospital hay disponible actualmente un TCMD de entre 16 a 64 detectores. Con un TC de 16 multidetectores, la imagen del territorio aortoilíaco abdominal se logra en 8-10 segundos con cortes de $1.25 \mathrm{~mm}$ de grosor. Es destacable la aplicación del angio TC en el estudio coronario, ya que la sincronización del ciclo cardiaco con la adquisición de las imágenes unida a la rapidez con que se realiza ha permitido lograr reconstrucciones tridimensionales de alta calidad.

Los principales inconvenientes son:

- La irradiación, aunque cada vez es menor gracias a la reducción en el tiempo de adquisición de imágenes. 
- La inyección de contraste yodado. Sus potenciales efectos adversos incluyen insuficiencia renal, rash cutáneos, extravasación venosa y anafilaxia, además de estar contraindicado su uso en pacientes alérgicos o que sufran insuficiencia renal.

\subsection{Angiografía por resonancia nuclear magnética (Angio RNM)}

Las bases técnicas de la resonancia nuclear magnética son complejas, pero a modo de resumen se compone de los siguientes pasos:

Magnetización: se coloca al paciente dentro de un potente imán. Con esto, los protones que hay en los núcleos de los átomos de hidrógeno del cuerpo se orientan en sentido longitudinal al campo magnético externo. Se usan imanes muy potentes (p.e. 1,5 teslas), unas 10.000 veces más potentes que el campo magnético del planeta Tierra. Los protones, además de estar orientados longitudinalmente, están girando (movimiento de precesión) con una frecuencia conocida gracias a la ecuación de Largor en donde participan la constante giromagnética de cada elemento (en nuestro caso, el hidrógeno) y la intensidad del campo magnético dado por el equipo.

Resonancia: los protones son energizados por una onda de radio que tiene la misma frecuencia con la que los protones giran. Ganan energía, con lo que se pierde la magnetización longitudinal y aparece la magnetización transversal.

Obtención de la imagen: se interrumpe la onda de radio y los protones vuelven a la magnetización longitudinal, con lo que pierden energía en forma de señal electromagnética (onda de radio) que es captada por una antena.

La angio RNM es una especialización de la RNM diseñada para obtener información centrada en la morfología y flujo vascular. Al igual que en la angio TC, implica necesariamente la inyección de contraste intravenoso con la diferencia de que en este caso el contraste es gadolinio, una sustancia capaz de alterar el valor de un campo magnético.

La angio RM ha sido utilizada ampliamente para la caracterización de grandes vasos, llegando en algunas situaciones a superar a la angio TC. En el caso concreto de la planificación de los colgajos DIEP, estudios recientes demuestran que aporta una buena 
valoración de la AEIP y la AEIS, así como de alguna perforante de gran calibre, pero la información sobre todas las perforantes y sus relaciones anatómicas es escasa (156). Sin embargo, si nos ajustamos estrictamente a la elección de las perforantes de mayor calibre y a las relaciones con el sistema venoso superficial, los últimos estudios publicados parecen apuntar resultados similares entre ambas técnicas (157).

Como principales ventajas hay que señalar que no se expone a la paciente a radiaciones ionizantes y se utiliza un contraste no nefrotóxico sin prácticamente reacciones alérgicas. Estas ventajas permiten tomar nuevas imágenes si es preciso.

Entre los inconvenientes destacan que se trata de una exploración larga, que aumenta el estrés de las pacientes y que en algunos casos puede producir claustrofobia, por lo que hay que definir bien la zona de interés para evitar estudios excesivamente largos. También es una exploración más cara, menos accesible y con menor resolución espacial que la angio TC (156). Además, la administración de gadolinio en pacientes con síndrome hepatorrenal o insuficiencia renal crónica severa se ha asociado a una rara pero grave enfermedad llamado fibrosis sistémica nefrogénica (158).

La angio RNM es una modalidad emergente que depende mucho de la tecnología. El desarrollo de antenas de superficie e imanes cada vez más potentes esta reduciendo sus inconvenientes, por lo que es una prueba que puede ocupar un lugar relevante entre las técnicas de mapeo de perforantes en un futuro próximo.

\subsection{Procesamiento digital de imágenes}

Durante los últimos años hemos asistido a una verdadera revolución digital, la cual ha informado la medicina hasta niveles nunca pensados hace 30 años cuando en 1979 MacLeod y Hounsfield recibieron el Nobel de Medicina por el desarrollo de la Tomografía Axial Computerizada (TAC). Hoy en día la mayoría de las técnicas de imagen médica incorporan ordenadores para su adquisición y postprocesamiento, desplazando a las técnicas de fluoroscopia y revelado clásicas. Con el desarrollo de la imagen médica digital 
se ha abierto una nueva era. La imagen adquirida es codificada en unos y ceros para, a continuación, convertirse en píxeles. La imagen puede ser procesada por un ordenador, convertida en otros formatos, o enviada a distancia por medio de una red de servicios. Sin embargo, estos procedimientos hasta hace pocos años se realizaban por medio de estaciones de trabajo cuyo acceso estaba sólo al alcance de profesionales especializados y se encontraban confinadas en los hospitales debido a su complejidad y coste (159).

\section{Fundamentos básicos de la imagen médica digital}

La información emitida por el tubo de rayos $\mathrm{X}$ es captada por un detector y la convierte en una escala de unidades Hounsfield (HU) que es el resultado de la transformación de la escala de coeficientes de atenuación lineal de rayos X. Esta escala confiere valores comprendidos entre -1000 a +1000 HU según el valor de atenuación de las diferentes densidades de un organismo: aire (-1000) - agua (0) - víscera - contraste - placa - hueso $(+1000)$. Con la ayuda de un sistema y un software informático se forma una imagen digital compuesta por puntos o píxeles (acrónimo del ingles "picture element") en el que cada uno tiene asignado una densidad HU. Para mostrar esta información en pantalla, el ordenador, mediante una función matemática llamada "transformación de Fourier" convierte estas HU de cada pixel en un valor de entre 0 y 255 correspondiente a uno de los 256 tonos de grises que se pueden registrar en una imagen digital. De este modo, una imagen tendrá más definición y sobre todo información conforme más píxeles tenga. La gran cantidad de cálculos necesarios para estas conversiones ha hecho que no dispusiéramos hasta hace poco de herramientas domésticas que permitieran procesar esta información con la aparente facilidad de hoy en día.

A finales de los setenta y con el desarrollo de la TAC, se creó un método para transmitir imágenes médicas que fue aprobado por el American College of Radiology llamado DICOM (Digital Imaging and Communication in Medicine). Actualmente, DICOM es el estándar reconocido mundialmente para el intercambio, manejo, almacenamiento, impresión y transmisión de imágenes médicas. Incluye la definición de un formato de fichero y un protocolo de comunicación de red. DICOM permite la 
integración de escáneres, servidores, estaciones de trabajo, impresoras y hardware de múltiples proveedores dentro de un sistema de almacenamiento y comunicación de imágenes, por lo que ha sido adoptado ampliamente en los centros hospitalarios.

\section{Definición de Vóxel}

Hasta hace poco, cuando los profesionales médicos veían una serie de cortes axiales en un negatoscopio procedentes de una TAC, su cerebro tenía que hacer una composición tridimensional de la imagen. Sin embargo, actualmente las imágenes de una TAC están relacionadas entre sí en las tres coordenadas del espacio, y esta información esta incluida en todos y cada uno de los cortes de la TAC, de tal modo que cada corte se puede visionar no sólo en una proyección axial, sino también en las proyecciones coronal o sagital. Es por este aspecto por el que el nombre clásico de "tomografía axial computarizada" (TAC) ha dado paso al de "tomografía computarizada" (TC). Esta relación tridimensional ha sido posible gracias al desarrollo del vóxel.

Un vóxel son varios píxeles agrupados sobre un eje de coordenadas que, en conjunto, forman una imagen tridimensional, de tal forma que un vóxel es el homólogo 3D de un píxel. Para crear una imagen en tres dimensiones, los vóxeles tienen que sufrir una transformación de opacidad. Esta información da diferentes valores de opacidad a cada vóxel. Con el paso de los años la mejora de los detectores de las TAC ha hecho que los vóxeles sean cada vez más pequeños, o de otro modo, para poder representar un vóxel necesitamos menos píxeles y, por tanto, a igual volumen de vóxeles los actuales contienen más píxeles que los de hace 20 años, consiguiendo más calidad de imagen y definición.

Nivel y amplitud de Ventana. Tabla de colores

El nivel (WL) y la amplitud de ventana (WW) son dos parámetros físicos de imagen, característicos de la TC, que podrían compararse con el brillo y el contraste de los aparatos de televisión. En la visualización de las imágenes de la TC es muy importante definir los 
valores de gris que corresponden a un determinado tejido, lo que se consigue de modo óptimo ajustando adecuadamente los valores del nivel y del ancho de la ventana. Los valores comprendidos entre $-1.000 \mathrm{UH}$ y 10.000 ó más HU suelen visualizarse en una escala de gris de 8 bits, que proporciona 256 niveles de gris. Para visualizar, por ejemplo, el tejido blando, el tejido pulmonar o el hueso, se seleccionan diferentes ajustes de WW y WL. La escala de grises, tal como se define por el nivel y el ancho de la ventana elegidos, debe adaptarse a la tarea de diagnóstico, y por lo tanto depende de la pregunta clínica a la que se deba responder (155).

\section{Tabla de colores (CLUT, Color Look Up table)}

Las tablas de colores permite asignar diferentes colores y niveles de opacidad a los píxeles del estudio en función de su nivel de intensidad. La utilización de una CLUT en las reconstrucciones tridimensionales facilita la comprensión e interpretación de las diferentes estructuras y relaciones anatómicas sin obligarnos a hacer una representación mental (fig. $31)$.
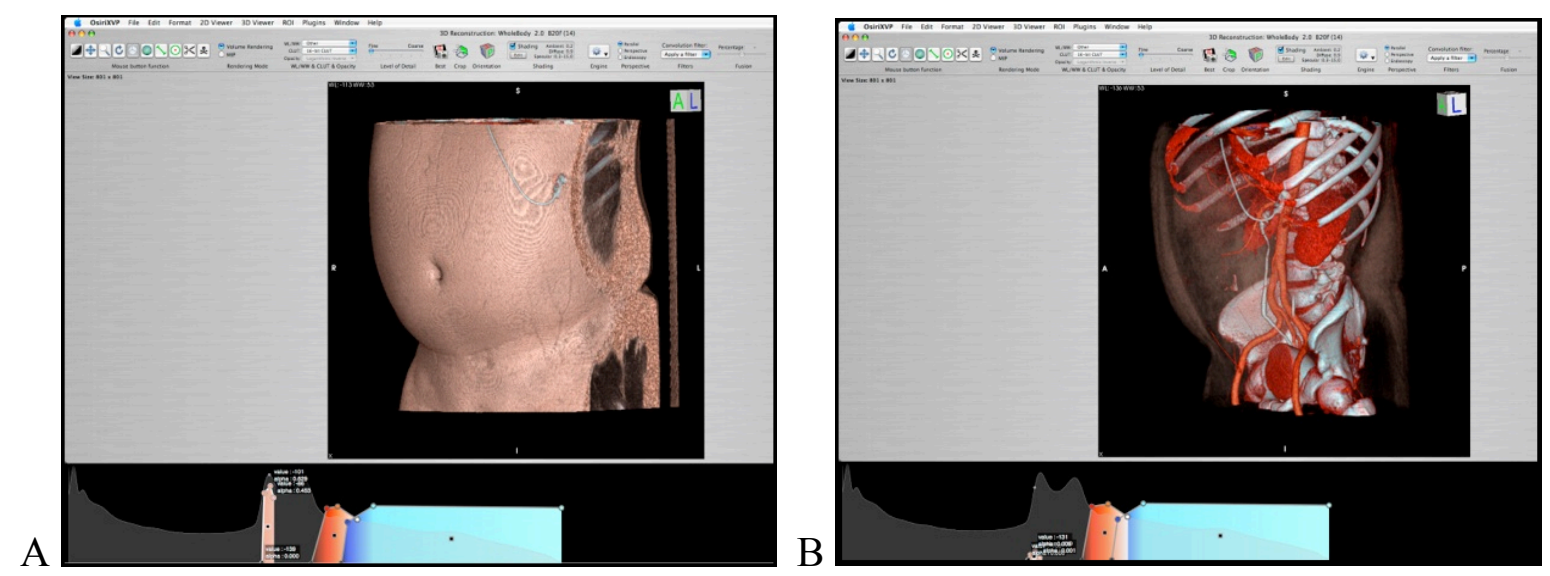

Figura 31: Ay B: Se presenta una reconstrucción abdominal en 3D. En el lado izquierdo se ha asignado color y opacidad a la piel, mientras que en el derecho se le dado cierto grado de transparencia y se ha asignado diferentes colores a las intensidades correspondientes a vasos, órganos internos y hueso, prescindiendo del resto de estructuras, lo que facilita el estudio de su morfología y las relaciones entre ellas. 


\section{Proyección de máxima intensidad}

La proyección de máxima intensidad (MIP) es un método matemático de visualización en 3D que extrae los vóxeles con mayores valores de atenuación localizados en un volumen y visualizados desde la perspectiva del observador. Estos vóxeles son seleccionados desde distintos ángulos mediante bloque de datos y son proyectados como una imagen 2D. En esta proyección el ordenador ensancha los cortes quedándose con aquellos píxeles de máxima intensidad, como los vasos, representando como un sumatorio de imágenes que se ven por transparencia (fig. 32). Hay que tener en cuenta que la superposición de varios cortes va a traducirse en una pérdida de profundidad, por lo que distintas estructuras anatómicas pueden representarse próximas entre sí, sin que esto sea cierto en la realidad. Este tratamiento de la imagen adquiere su mayor valor en el estudio y representación de árboles vasculares con sus ramas.
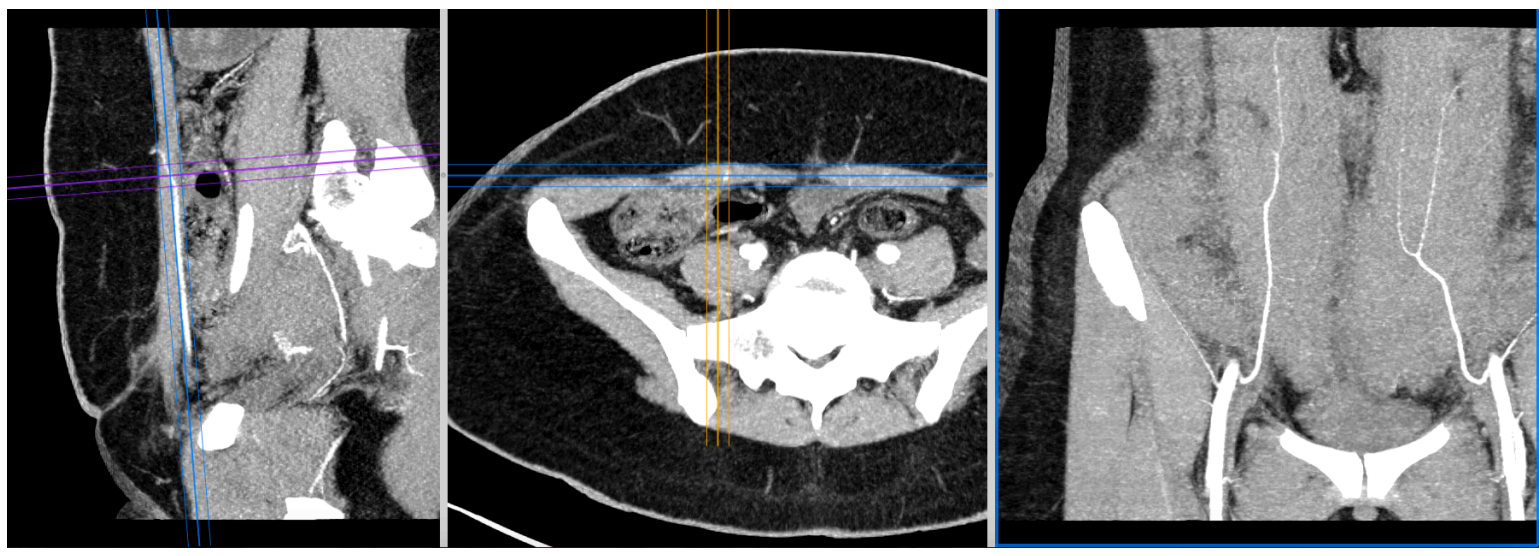

Figura 32: Estudio del patrón de la AEIP izquierdo (tipo I) y derecho (tipo II) mediante la selección de una MIP de $10,7 \mathrm{~mm}$.

\section{Planificación con OsiriX}

OsiriX es un software de código abierto dedicado al procesamiento de imágenes DICOM desarrollado en 2004 por un grupo de radiólogos e informáticos de la Universidad de Ginebra (Rosset, Spadola y Ratib) (160) que transforma un Apple Macintosh en una 
estación de trabajo para procesar y visualizar imágenes médicas. OsiriX es una herramienta que incorpora un visor de imágenes médicas digitales en formato DICOM, un módulo de reconstrucción 3D y un PACs (sistema de archivado y comunicación de imágenes, "picture archiving and communication system"). La aplicación se distribuye de manera gratuita en su versión 32-bit bajo licencia GNU. Existe una versión 64-bit que permite un uso extendido de la memoria RAM además de una versión OsiriX MD que dispone de la certificación de la FDA (Food and Drug Administration) como dispositivo médico de clase II para el diagnóstico de imágenes médicas. OsiriX fue diseñado específicamente para la navegación y visualización de imágenes multimodalidad y multidimensionales 2D (como una radiografía de tórax), 3D (como un TC), 4D (como las angio TC cardíacos dinámicos) y está construido según una arquitectura integralmente ampliable mediante extensiones denominados plugins, que permite aumentar las funcionalidades de OsiriX (161). Existen también una versión HD para Iphone y para Ipad que abre nuevos horizontes en la portabilidad de los estudios de la angio TC. OsiriX es utilizado en general como un excelente complemento al diagnóstico y tratamiento en diversos campos de la medicina por lo que ha ido ganando más adeptos en la comunidad médica general y en otros ámbitos de la imagen médica digital.

\section{Modo visor}

Este modo representa las imágenes DICOM mediante cortes simples como si de una imagen radiográfica se tratase, sin someterlas a ningún tipo de procesamiento (fig. 33). El modo visor de OsiriX es la base de trabajo sobre la cual indicaremos una reconstrucción u otra.

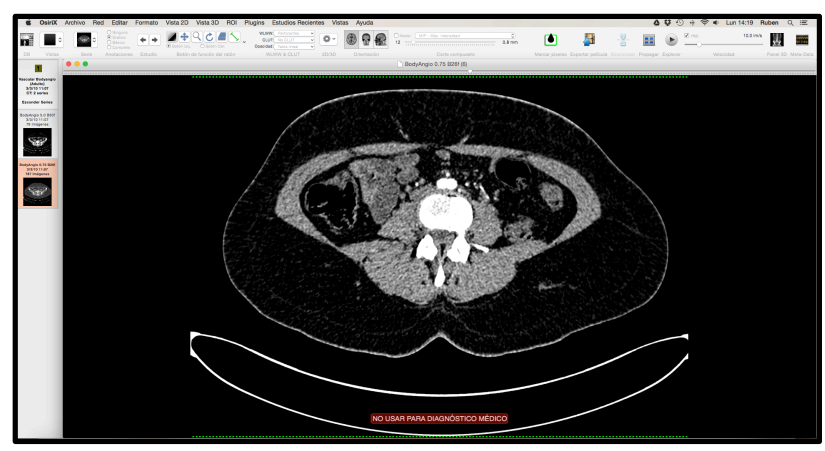

Figura 33: Modo visor de OsiriX, en la que se muestra un corte axial de un Angio TC abdominal. 
Reconstrucción ortogonal 2D

En este modo el programa crea una imagen bidimensional a partir de datos volumétricos obtenidos del corte axial, componiendo dos proyecciones añadidas a la axial, la coronal y la sagital, sobre un eje de coordenadas fijo (fig. 34). Es posible desplazarnos sobre los diferentes cortes de cada proyección siempre que mantengamos fijo el eje de coordenadas, es decir, no admite la rotación del estudio. Es útil para realizar una evaluación anatómica global e inicial (161).
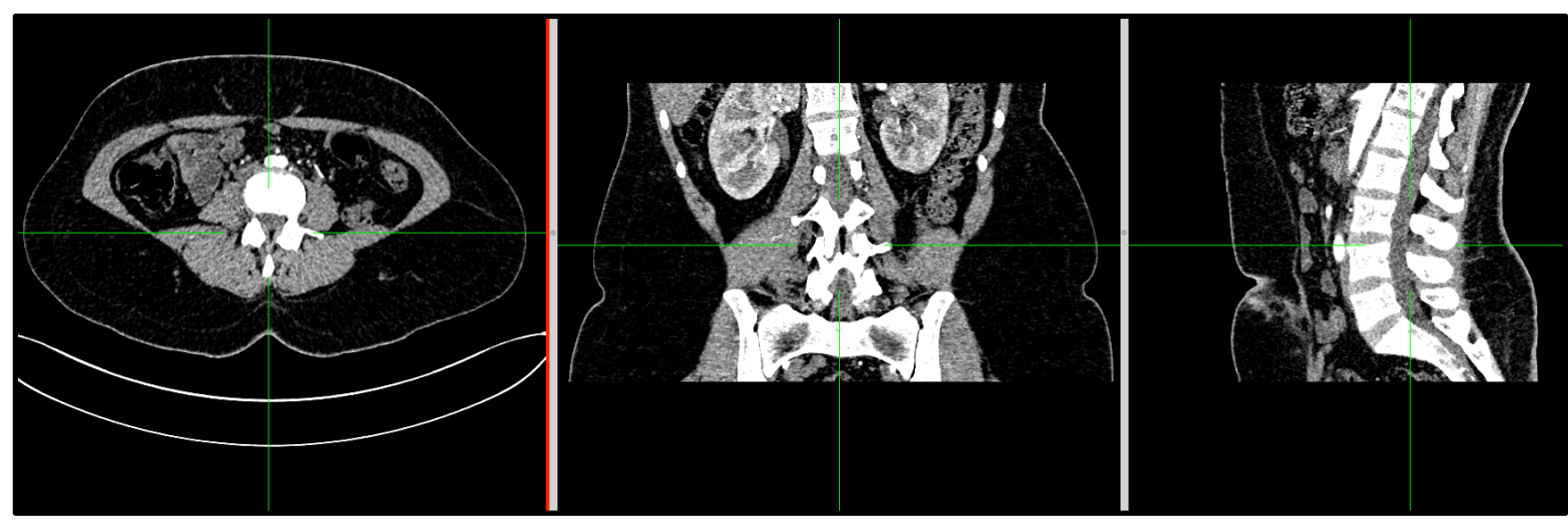

Figura 34: Reconstrucción ortogonal $2 \mathrm{D}$ en el que se muestran las proyecciones axial, coronal y sagital respectivamente de una angio TC abdominal.

$\underline{\text { Reconstrucción 3D multiplanar }}$

La reconstrucción 3D multiplanar (MPR) es similar a la reconstrucción 2D ortogonal con la diferencia de que permite la generación de un corte multiplanar (axial, sagital y coronal) en cualquier posición y orientación del volumen tridimensional, sin estar anclado a la disposición del eje de coordenadas (fig. 35). Esta característica posibilita la rotación de los cortes, la alineación con el eje del cuerpo y la correcta medida de distancias entre puntos. 


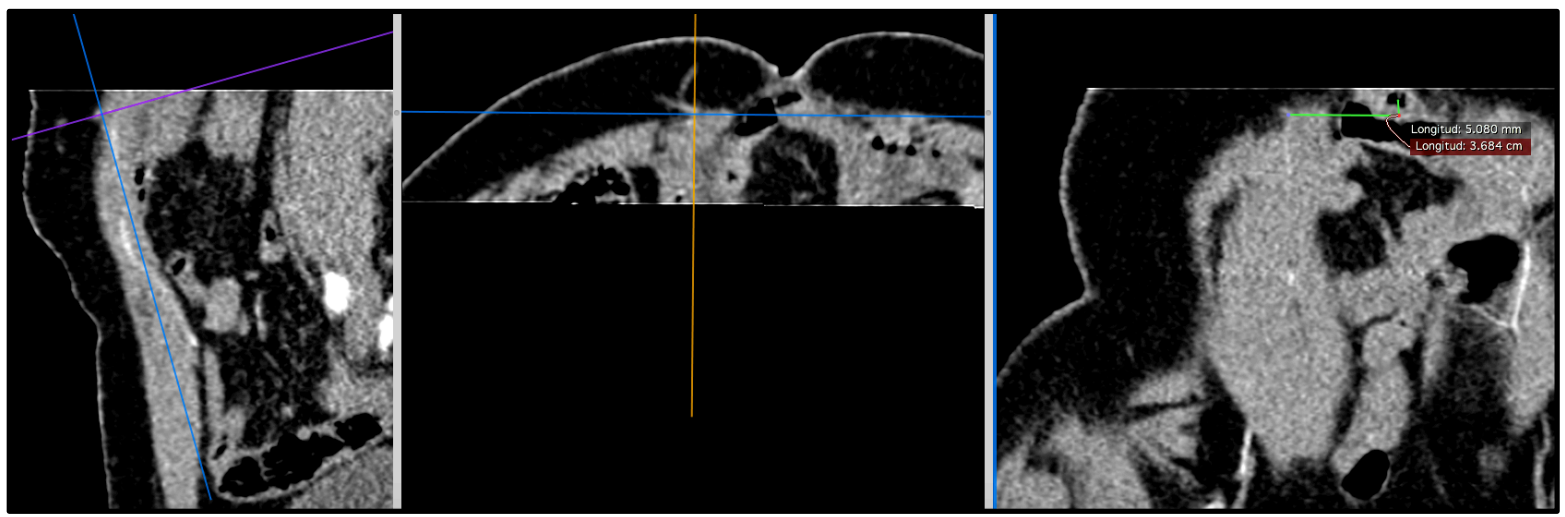

Figura 35: Localización con respecto al ombligo de la salida a nivel de fascia de un vaso perforante abdominal utilizando el modo 3D MPR de OsiriX.

En el modo 3D MPR curvo, es posible visualizar en una imagen toda la extensión de la anatomía de los vasos sanguíneos, su relación con estructuras adyacentes así como medir su longitud y diámetros vasculares al ser capaz de encontrar planos perpendiculares al eje del flujo en cada porción del vaso. Sin embargo, para conseguir una información veraz y útil con escaso margen de error es aconsejable utilizarlo sobre estructuras de más entidad que un vaso perforante.

\section{$\underline{\text { Reconstrucción volumétrica }}$}

La reconstrucción 3D volumétrica (VR) se basa en la agrupación de múltiples vóxeles de una misma densidad para crear polígonos a los que se les asigna una textura o color que los diferencia del resto de los polígonos. Por medio de una función matemática es posible segmentarlos, es decir hacerlos desaparecer o atenuar, de tal modo que es posible crear una imagen $3 \mathrm{D}$ en la que se distingan las diferentes estructuras anatómicas que nos interesa estudiar (fig. 36). Sumando varias imágenes en dos dimensiones se va a conseguir el efecto de profundidad y textura. Un VR es lo mas parecido que tenemos hoy a un mapa quirúrgico, proporcionándonos una imagen de realidad virtual sobre la zona que nos interesa estudiar. 


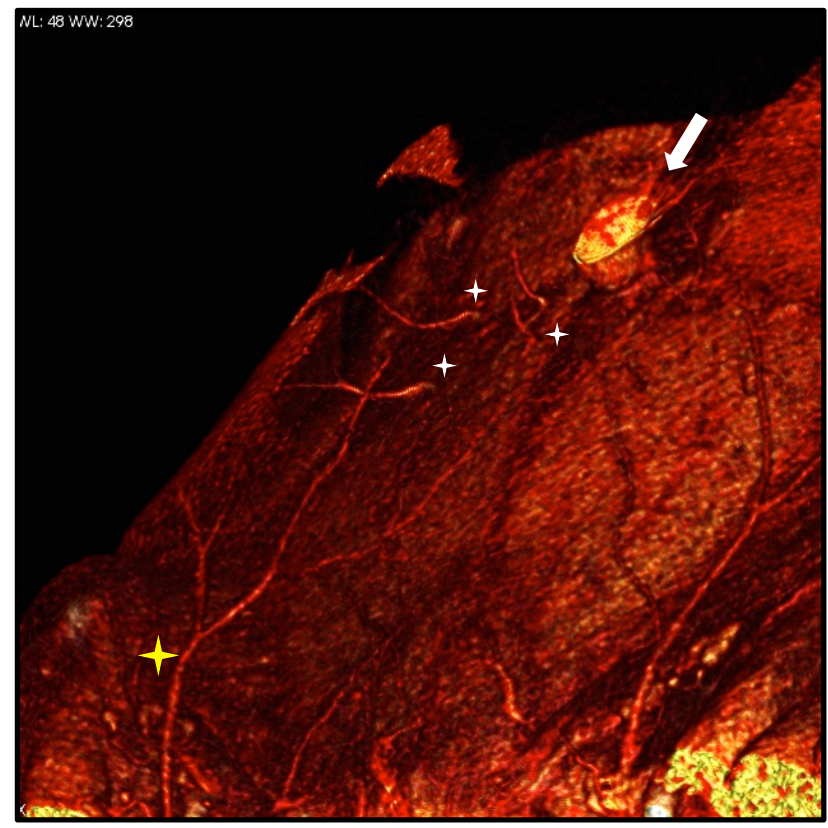

Figura 36: Reconstrucción volumétrica $3 \mathrm{D}$ en la que se observa la salida de los vasos perforantes (estrella blanca) a través de la fascia abdominal (se señala el ombligo con una flecha blanca) y su relación con la VEIS (estrella amarilla). 


\section{JUSTIFICACIÓN, HIPÓTESIS Y OBJETIVOS}





\section{JUSTIFICACIÓN}

Actualmente, el tratamiento del cáncer de mama tiene un carácter multidisciplinario y su manejo sólo se puede entender desde un concepto global. El manejo de esta enfermedad incluye en la mayoría de los casos la aplicación de técnicas quirúrgicas sobre la mama, que van desde resecciones parciales hasta, en muchos, casos su extirpación completa. Estas medidas van a dar como resultado secuelas visibles sobre un órgano con importantes connotaciones personales, sociales y sexuales. El daño ocasionado sobre la imagen corporal unido a los tratamientos prolongados de quimioterapia y radioterapia y el estigma diario de la ausencia de la mama como recuerdo continuo del cáncer van a producir disfunciones psicológicas en la paciente que se extiende más allá de su esfera personal, alterando sus relaciones familiares, sociales, laborales y sexuales. Es por ello que los procedimientos terapéuticos no van a ir únicamente encaminados a erradicar la enfermedad y/o mejorar la calidad de vida de la paciente, sino que nuestros esfuerzos también deben ir dirigidos a ayudar a estas personas a recuperar el equilibrio personal, social y psicológico tras un evento tan traumático como es el cáncer de mama. En este aspecto juega un papel fundamental la reconstrucción mamaria, ya que la recuperación de la imagen corporal y la autoestima son un paso previo e indispensable para superar la enfermedad y permitir a la persona su reincorporación plena y satisfactoria en todos los ámbitos de su vida.

El desarrollo de técnicas reparadoras sobre la mama en los últimos 40 años ha sido casi vertiginoso. Aunque el empleo de técnicas que involucran materiales implantables como sustitutivos de la mama esta ampliamente extendido y tienen sus indicaciones, nadie duda hoy en día de que la reconstrucciones con tejido autólogo superan claramente a las técnicas protésicas en términos de naturalidad, perdurabilidad y satisfacción por parte de las pacientes. En este aspecto el colgajo DIEP se ha erigido como la técnica autóloga de referencia en reconstrucción mamaria. La gran cantidad de volumen proporcionado, la baja morbilidad originada en su recolección, las posibilidades de moldeamiento y la similitud de su piel y tejido adiposo en términos de textura a la mama extirpada han dado lugar al lugar preponderante que ocupa este colgajo en la actualidad. Sin embargo, esta técnica no esta exenta de inconvenientes, entre las que destacan su alta complejidad unido a una lenta 
curva de aprendizaje, siendo necesario un equipo de profesionales con alto dominio de la técnica microquirúrgica. A esto se añade la marcada variabilidad anatómica interindividual de las arterias perforantes procedentes de la arteria epigástrica inferior profunda en cuanto a su disposición y morfología, siendo fundamental una adecuada selección del vaso perforante sobre el que basar el colgajo para reducir el riesgo de complicaciones circulatorias y maximizar el éxito de la intervención. La planificación preoperatoria con ayuda de técnicas radiológicas nos va a permitir conocer tanto la localización como el calibre de estos vasos perforantes, así como sus relaciones anatómicas con el sistema epigástrico superficial y con el resto de estructuras que conforman la pared abdominal. Esta información aportada por la planificación se va a traducir en una reducción en los tiempos de intervención, una mejora de los resultados de la cirugía y en último término, en un aumento de la seguridad del procedimiento y una reducción de los costes sanitarios. De entre las técnicas disponibles para realizar la planificación preoperatoria de los colgajos DIEP, la angiografía mediante TC multicorte se esta mostrando como la mejor técnica para describir el árbol circulatorio de la pared abdominal gracias a su alta sensibilidad y especificidad, bajo costes y escasa variabilidad inter-observador. Aunque la interpretación de este estudio habitualmente es realizado por un radiólogo, la multitud de peculiaridades técnicas de este procedimiento hacen recomendable que el cirujano plástico tenga una parte activa en la planificación preoperatoria de la intervención con el fin de tener un pleno conocimiento de la anatomía circulatoria de la pared abdominal a la que se va a enfrentar en la disección del colgajo DIEP. Esto va a permitir un mejor aprovechamiento de la información aportada por la angio TC así como una ayuda para el cirujano en la toma de decisiones frente a la aparición de complicaciones y situaciones inesperadas durante el transcurso de la intervención. En medicina cada vez es más habitual que diferentes especialistas adquieran conocimiento en el manejo de técnicas radiológicas. El desarrollo de la informática ha permitido disponer tanto de equipos como de herramientas a nivel doméstico que permiten hacer estos estudios en cualquier lugar sin estar sujetos a grandes estaciones de trabajo como era necesario hasta hace pocos años.

Este trabajo esta concebido para ayudar al cirujano plástico en el planeamiento preoperatorio de sus reconstrucciones mamarias con el colgajo DIEP y valorar las repercusiones de esta toma de decisiones en la aparición de complicaciones y en último término en la mejora de sus resultados. 


\section{HIPÓTESIS}

El cirujano plástico puede hacer de manera sencilla una adecuada planificación preoperatoria del colgajo DIEP utilizado en reconstrucción mamaria mediante la angio TC multicorte con ayuda de la herramienta OsiriX, con el fin de realizar una adecuada selección del vaso perforante que permita reducir la aparición de complicaciones circulatorias del colgajo y rentabilizar al máximo los beneficios de la técnica. 


\section{OBJETIVOS}

\subsection{OBJETIVO PRINCIPAL}

Utilizar la planificación preoperatoria del colgajo DIEP en reconstrucción mamaria mediante angio TC multicorte para conocer la repercusión de las diferentes variables que intervienen en la selección del vaso perforante del colgajo en la aparición de complicaciones circulatorias.

\subsection{OBJETIVOS SECUNDARIOS}

- Estudiar la repercusión de los factores de riesgo circulatorio en las complicaciones asociadas a la reconstrucción con colgajo DIEP.

- Describir un protocolo de planificación preoperatoria del colgajo DIEP al alcance de cualquier cirujano plástico empleando el software OsiriX.

- Estudio morfológico de la vascularización del colgajo DIEP.

- Determinar los procedimientos quirúrgicos asociados necesarios para completar la reconstrucción mamaria con colgajo DIEP. 
MATERIAL Y MÉTODOS 



\section{SELECCIÓN DE PACIENTES}

\subsection{Población objeto de estudio}

Este estudio ha sido llevado a cabo en las pacientes mastectomizadas reconstruidas mediante colgajo DIEP intervenidas en el Complejo Asistencial Universitario de León (CAULE) procedentes de las áreas sanitarias de León y El Bierzo en el periodo comprendido entre noviembre de 2009 y diciembre de 2014.

A todas las pacientes se les solicitó con posterioridad un consentimiento informado por escrito específico para la realización de este estudio retrospectivo. Este trabajo fue evaluado y aprobado por la comisión de ética del CAULE.

\subsection{Criterios de inclusión}

- Pacientes que presentan una mastectomía unilateral o bilateral por motivos oncológicos o reductores de riesgo sometidas a una reconstrucción mamaria inmediata o diferida con el colgajo DIEP.

- Las pacientes debían tener un estudio angio TC multicorte abdominal realizado de forma previa a la reconstrucción con el fin de hacer un mapeo de perforantes abdominales

\subsection{Criterios de exclusión}

- Pacientes reconstruidas con otros colgajos abdominales diferentes del DIEP o cualquier otra técnica.

- Pacientes reconstruidas con colgajo DIEP que no dispusieran de un estudio angio TC preoperatorio. 


\subsection{Criterios de indicación quirúrgica de colgajo DIEP}

Todas las pacientes incluidas en este estudio fueron valoradas en una primera consulta por un miembro del Servicio de Cirugía Plástica y Reparadora del CAULE con el fin de que cumplieran los siguientes requisitos:

- Presentar una mastectomía unilateral o bilateral o bien que fueran a ser sometidas a una mastectomía unilateral y que desearan una reconstrucción mamaria diferida o inmediata respectivamente.

- No sufrir ninguna comorbilidad médica importante que hiciera desaconsejable una intervención de larga duración.

- Ser no fumadoras o exfumadoras o bien comprometerse a dejar el hábito tabáquico tras su inclusión en lista de espera quirúrgica.

- No haber sido sometida a una liposucción abdominal. No fue criterio de exclusión haber recibido intervenciones quirúrgicas que involucrasen cicatrices en la pared abdominal, salvo en el caso de la laparotomía media, en cuyo caso la inclusión quedó condicionada a la visualización de vasos perforantes adecuados conectados al sistema epigástrico inferior profundo en la angio TC preoperatoria.

- Presentar un exceso dermograso abdominal moderado, excluyéndose aquellos abdómenes mórbidos. Se incluyeron también aquellas pacientes con redundancia escasa cuando la mama contralateral a simetrizar fuera de pequeño tamaño.

- No haber sido sometidas a intervenciones quirúrgicas que pudieran comprometer el estado de los vasorreceptores mamarios internos. El haber recibido RT en el lecho mamario no fue un criterio de exclusión.

- Comprender las ventajas e inconvenientes de una reconstrucción microquirúrgica con el colgajo DIEP y firmar por escrito el consentimiento informado de este procedimiento (ver anexo 3 ).

Todas aquellas pacientes que cumplieron estos requisitos en esta primera visita se les ofreció una reconstrucción con colgajo DIEP entre las diferentes alternativas a las que eran candidatas. Aquellas pacientes que tras resolver sus dudas en una segunda visita aceptaron este método de reconstrucción fueron incluidas en la lista de espera quirúrgica, siendo 
derivadas a la consulta de valoración preanestésica y al servicio de radiología para la realización de un mapeo de perforantes abdominales mediante angio TC multicorte.

\subsection{Registro preoperatorio de datos en la historia clínica}

Durante la primera visita se recogieron los siguientes datos en la historia clínica:

- Presencia de alergias medicamentosas.

- Antecedentes personales de enfermedades e intervenciones quirúrgicas y tratamientos médicos actuales.

- Existencia de hábito tabáquico.

- Peso, talla e IMC.

- Información relacionada con el proceso oncológico: tipo de mastectomía, realización de BSGC y/o linfadenectomía axilar con el número de ganglios afectos, extirpe del cáncer y dimensiones, tratamientos adyuvantes como RT, QT u HT.

- Condiciones locales de la pared torácica de la mama a reconstruir: estado de la piel de la mastectomía, dimensiones y orientación de la cicatriz, así como su extensión a la axila o presencia de cicatrices independientes en esta zona. También se registraron los intentos de reconstrucción previos con otras técnicas quirúrgicas.

- Presencia de linfedema en la extremidad superior homolateral a la mastectomía.

- Dimensiones de la mama contralateral sana: distancia desde la horquilla esternal al pezón y una estimación aproximada de su volumen para predecir la necesidad de procedimientos adicionales de mastopexia o reducción mamaria con el fin de lograr una adecuada simetría. También se interrogó sobre cirugías previas en dicha mama con fines oncológicos, estéticos o reconstructivos.

- Evaluación de la pared abdominal: valoración de la redundancia abdominal, presencia de cicatrices y fallos en la competencia de la pared como hernias o diástasis de músculos rectos abdominales. 


\section{ESTUDIO ANGIO TC PREOPERATORIO}

Todas las pacientes incluidas en la lista de espera para una reconstrucción mamaria con colgajo DIEP fueron sometidas a un estudio preoperatorio con angio TC multicorte para el mapeo de perforantes abdominales. Este fue llevado a cabo por el Servicio de Radiología del CAULE en todas las pacientes salvo en 3, que fue realizado por el servicio de Radiología del Hospital de El Bierzo. A todas las pacientes se les realizó un despistaje de alergia a contraste yodado e insuficiencia renal (determinado por una creatinina sérica superior a $1,2 \mathrm{mg} / \mathrm{dl}$ ) y se obtuvo el consentimiento informado específico para la realización del estudio.

Para realizar el estudio inicialmente se explicó a cada paciente en que consistía el procedimiento y se canalizó una vena periférica del lado contralateral a la mastectomía por el personal de enfermería para la posterior inyección del contraste yodado. A continuación se colocó a la paciente en la camilla del tomógrafo. Esta exploración se realiza en decúbito supino y con los brazos por encima de los hombros para evitar artefactos derivados de la incidencia del haz de rayos $\mathrm{X}$ sobre los mismos que afecten a la calidad de imagen de los cortes abdominales, siendo aconsejable la retirada de la ropa interior para evitar improntas sobre la piel de la pared abdominal que puedan alterar las mediciones de las perforantes abdominales a estudio. Estos detalles han de tenerse en cuenta a la hora de hacer el marcaje de las perforantes en la mesa de quirófano. La inyección de contraste consistió en un bolo de $100 \mathrm{ml}$ de contraste intravenoso iodado no iónico, de baja osmolaridad y alta concentración, mediante un sistema inyector a velocidad de $4 \mathrm{ml} / \mathrm{s}$, seguido inmediatamente por un bolo de $30 \mathrm{ml}$ de suero salino a una velocidad de $4 \mathrm{ml} / \mathrm{s}$, para empujar el contraste al torrente sanguíneo y favorecer su eliminación renal. Los parámetros de adquisición fueron seleccionados de acuerdo a la literatura relacionada y a la experiencia previa del Servicio de Radiología (161-163), respetando el principio ALARA (as low as reasonably achievable) (164). Esta bomba inyectora esta sincronizada con el tomógrafo, de tal modo que una vez que la bomba comienza a inyectar el contraste, el tomógrafo, mediante disparos sucesivos, detecta el nivel de densidad en un lugar seleccionado previamente a nivel de la luz aórtica distal justo previo a su bifurcación en las 
arterias ilíacas comunes. Se determinó que cuando este nivel alcanzase las $100 \mathrm{HU}$, el tomógrafo automáticamente comenzase el estudio en dirección caudo-craneal. La duración de la adquisición de las imágenes tuvo duración inferior a $10 \mathrm{~s}$. Esta demora del disparo es muy importante, ya que permite practicar el estudio en una fase arterial tardía o venosa inicial, lo que nos permite estudiar el calibre completo, tanto su componente arterial como venoso, de los pedículos y vasos perforantes así como sus relaciones con el sistema venoso superficial, lo cual es muy importante de cara a realizar una adecuada selección de perforante según los criterios descritos en la literatura $(152,165)$.

El rango de la exploración debe cubrir al menos desde $5 \mathrm{~cm}$ por encima del ombligo hasta los trocánteres femorales, para valorar las arterias epigástricas profundas desde su origen. En total, el tiempo necesario para realizar el estudio fue inferior a $10 \mathrm{~min}$ lo cual reduce el estrés de las pacientes y permite practicar gran número de estudios en una jornada de trabajo.

En la tabla 8 se describen los parámetros de adquisición, el material de contraste utilizado y los tomógrafos empleados en la adquisición del estudio.

\begin{tabular}{|c|c|c|c|}
\hline Tomógrafo & $\begin{array}{c}\text { Siemens Somaton } \\
\text { Definition AS }\end{array}$ & $\begin{array}{c}\text { Siemens Somaton } \\
\text { Sensation } 16\end{array}$ & $\begin{array}{l}\text { General Electric } \\
\text { LigthSpeed RT } 16\end{array}$ \\
\hline Colimación & 64 x $0,6 \mathrm{~mm}$. & $16 \times 0,75 \mathrm{~mm}$. & $16 \times 1,25 \mathrm{~mm}$ \\
\hline Voltaje del tubo & $120 \mathrm{kV}$ & $120 \mathrm{kV}$ & $120 \mathrm{kV}$ \\
\hline Corriente del tubo & $120-400 \mathrm{~mA}$ & $120-300 \mathrm{~mA}$ & $160-180 \mathrm{~mA}$ \\
\hline Velocidad de rotación & $0,37 \mathrm{~s}$ & $0,5 \mathrm{~s}$ & 0,7 \\
\hline Material de contraste & \multicolumn{3}{|c|}{ Ultravist 300 (Shering AG) } \\
\hline Sistema inyector & Medrad Stellant D & \multicolumn{2}{|c|}{ Medrad Vistron CT } \\
\hline $\begin{array}{l}\text { Grosor de la } \\
\text { reconstrucción }\end{array}$ & $0,75 \mathrm{~mm}$ & $1 \mathrm{~mm}$ & $1,25 \mathrm{~mm}$ \\
\hline $\begin{array}{l}\text { Intervalo de } \\
\text { reconstrucción }\end{array}$ & $0,5 \mathrm{~mm}$ & $0,7 \mathrm{~mm}$ & $1-1,25 \mathrm{~mm}$ \\
\hline
\end{tabular}

Tabla 8: Parámetros de adquisición y material de contraste 
Los estudios practicados con los TC Siemens Somaton Sensation 16 y Definition AS fueron llevados a cabo en el CAULE, mientras que en el Hospital de El Bierzo se llevaron a cabo los estudios realizados con el TC General Electric LigthSpeed RT 16. Las imagenes axiales obtenidas se procesaron con el software SYNGO CT 2010B y SYNGO CT 2011A. En el estudio de las angio TC intervinieron fundamentalmente cuatro radiólogos de dos hospitales diferentes no relacionados entre si, sin un protocolo común establecido. Al iniciar la técnica de RM con colgajo DIEP se proporcionó bibliografía a uno de los radiólogos del CAULE y se solicitó que en el informe radiológico se reflejasen los siguientes datos:

1. Localización de los vasos perforantes de mayor calibre a nivel de su salida a fascia y su disposición en relación con la porción más caudal del ombligo en un eje de coordenadas desde $1 \mathrm{~cm}$ por encima de este a $7 \mathrm{~cm}$ por debajo.

2. Referenciar la localización de las VEIS con respecto a la línea media a nivel de las espinas ilíacas anterosuperiores.

3. Imágenes MIP de las perforantes referenciadas que incluyeran su ramificación en el tejido adiposo, su trayecto muscular y su entrada en la AEIP.

4. Imágenes MIP que mostrasen el patrón de la AEIP.

Aunque los detalles técnicos de esta exploración y los datos que debían recogerse referentes al mapeo fue compartida en una sesión clínica del Servicio de Radiología del CAULE, la información registrada en los informes fue muy variable entre los diferentes radiólogos, lo que obligó a revisar de forma preoperatoria cada angio TC por los miembros del Servicio de Cirugía Plástica y Reparadora y a comentar algunos casos con el radiólogo correspondiente. Todos los informes incluyeron el punto número 1, aunque no siempre respetando los límites anatómicos referidos, señalando en ocasiones perforantes varios centímetros por encima del ombligo. La presencia de información referida a los puntos 2, 3 y 4 fue variable: la mayoría de los informes reflejaron la localización de las VEIS, pero no así los cortes MIP referente a la perforante y a la AEIP.

La elección última de la perforante sobre la que basar el colgajo DIEP fue realizada por los miembros del Servicio de Cirugía Plástica y Reparadora tras revisar las angio TC y el 
informe radiológico. El estudio de las pruebas de imagen se limitó a visionar únicamente los cortes axiales y las reconstrucciones suministradas por los radiólogos cuando estuvieron disponibles, lo que limitó la información que se extrajo de los mismos con respecto a nuestra practica actual, que incluye el manejo de la herramienta OsiriX, lo que nos permite hacer un procesamiento de las imágenes similar a la que puede realizar un radiólogo en una estación de trabajo avanzada.

A medida que el grupo adquirió experiencia y apareció nueva bibliografía, los criterios fueron evolucionando; de manera general, en todos los casos se intentó seleccionar la perforante de mayor calibre, siempre y cuando su entrada en el colgajo estuviese a más de $15 \mathrm{~mm}$ del borde del diseño de la isla. De una forma "elemental" mediante el avance de cortes sucesivos también se intentó seleccionar perforantes con trayecto intramuscular corto, y a medida que se sucedieron los casos, también se buscaron perforantes con conexión al sistema superficial y con un árbol vascular que se ramificase dentro de la isla del colgajo. Sin embargo, el no disponer de reconstrucciones MIP y MPR en la mayoría de los casos dificultó y hasta imposibilitó esta tarea.

Sólo se consideraron perforantes desde $1 \mathrm{~cm}$ por encima del punto medio del ombligo a $7 \mathrm{~cm}$ por debajo. Estos límites se marcaron con el fin de evitar el diseño de islas muy craneales que reclutasen un grosor de tejido adiposo menor correspondiente a la zona epigástrica y dejasen una cicatriz abdominal excesivamente alta por un lado o bien que al elegir perforantes demasiado bajas estas restasen demasiada longitud de pedículo que dificultase su anastomosis. Esta localización se corresponde de acuerdo a la bibliografía con la zona donde mayor perforantes se localizan (130). 


\section{PROCEDIMIENTO OPERATORIO}

Cada intervención quirúrgica fue realizada por cuatro especialistas del servicio de Cirugía Plástica y Reparadora del CAULE. En total, ocho cirujanos plásticos participaron a lo largo del periodo de este estudio con diferentes grados de responsabilidad, aunque en todas ellas estuvieron presente dos especialistas que fueron considerados séniores por tener un mayor grado de experiencia con la técnica del colgajo DIEP.

\subsection{Protocolo preoperatorio}

Tras recibir el informe anestésico favorable, revisar la angio TC y comprobar que todos los estudios preoperatorios estaban conforme a lo establecido, se programó a cada paciente realizándose el ingreso la tarde anterior a la intervención. Durante el ingreso hospitalario todas las pacientes fueron sometidas al protocolo de enfermería previamente consensuado por el Servicio de Cirugía Plástica del CAULE (ver anexo 1).

El protocolo de actuación antes de acudir a quirófano incluye los siguientes puntos:

- Preparación quirúrgica según el protocolo hospitalario.

- Rasurado de pubis y axilas.

- Aseptizar la cara anterior de tórax y abdomen con povidona yodada y cubrir con paño estéril.

- Colocación de medias elásticas.

- Administrar 2g intravenoso de Amoxicilina-Ácido clavulánico en el momento de ir al quirófano. En aquellas pacientes alérgicas se empleó 1g de Vancomicina.

- Administrar 300 mg de Ranitidina vía oral la noche previa a la intervención.

- Administrar 1mg de Lorazepam vía oral la noche previa (23 h) y la mañana de la cirugía (7 h). 


\subsection{Marcaje preoperatorio}

Una vez que la paciente llega al antequirófano se procede al fotografiado y marcaje de la paciente en bipedestación. En esta posición se dibuja con rotulador una línea media desde el yugulum esternal hasta el pubis, y los surcos submamarios. El surco de la neomama se suele dibujar 2-3 cm por encima del de la mama sana, ya que al abordar este zona es frecuente que los tejidos sometidos a RT se relajen y al traccionar de la piel del abdomen durante el cierre su disposición cambie. Si la paciente no ha recibido RT y no hay tensión en la piel de la mastectomía, el surco se puede dibujar a una altura similar o ligeramente superior al de la mama contralateral (fig. 37). En este momento también se realizan los marcajes precisos en el caso que la mama sana necesite algún procedimiento de reducción o mastopexia.

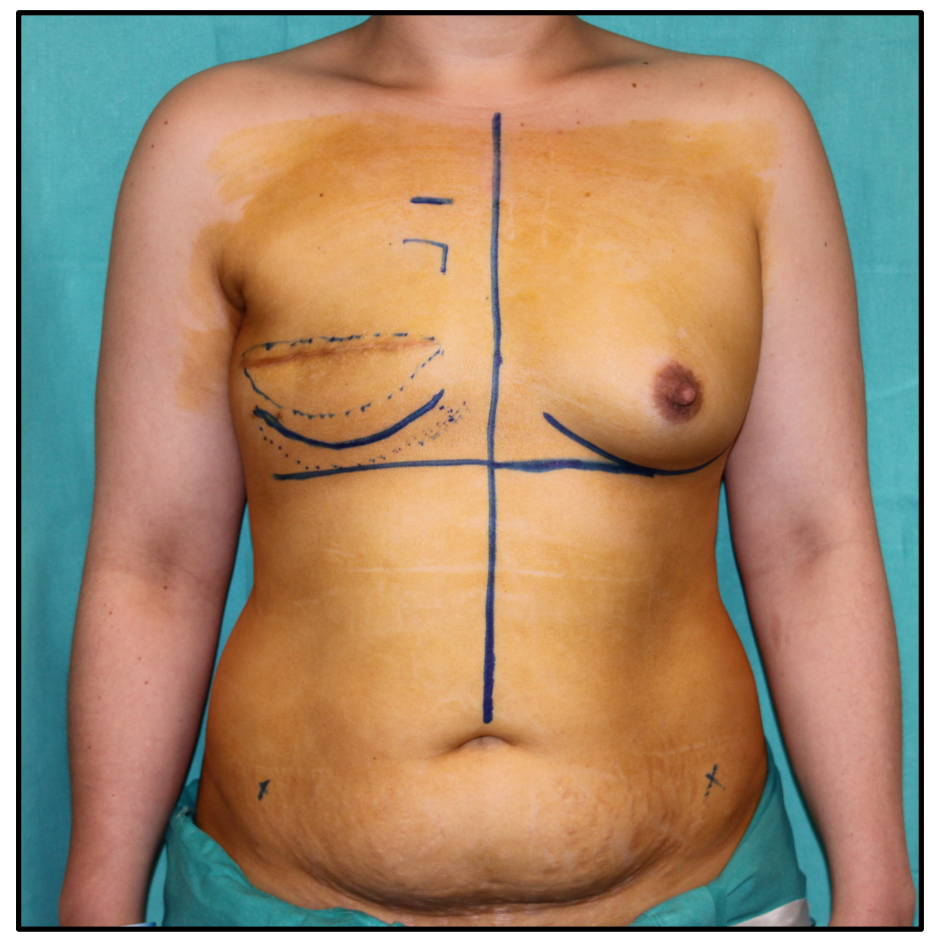

Figura 37: Marcaje y fotografiado en bipedestación. La zona quirúrgica se ha aseptizado previamente con povidona yodada.

A continuación la paciente pasa a la camilla de quirófano. La posición es en decúbito supino con los brazos a lo largo del cuerpo. El campo quirúrgico comprende el tronco y el 
abdomen desde la región clavicular hasta el pubis y raíz de muslos. Los electrodos se posicionan en la espalda y la placa del bisturí en el muslo. Desde el primer momento se procede a calentar a la paciente con una manta térmica (la vasoconstricción periférica ocasionada por el frío pude dificultar la detección de los vasos perforantes con el doppler portátil).

Durante la preparación anestésica se dibuja un eje de coordenadas y se procede a señalar los vasos perforantes seleccionados y las VEIS estudiadas en la angio TC (fig. 38), confirmando su flujo y localización mediante un doppler portátil. A continuación se diseña el colgajo a partir de una elipse horizontal con el borde craneal en el borde superior del ombligo de unas dimensiones aproximadas 30-45 x 12-15 cm (166). También se marca el segundo o tercer espacio y cartílago costal de la mama a reconstruir, donde se prepararán los vasorreceptores mamarios internos (fig. 37).

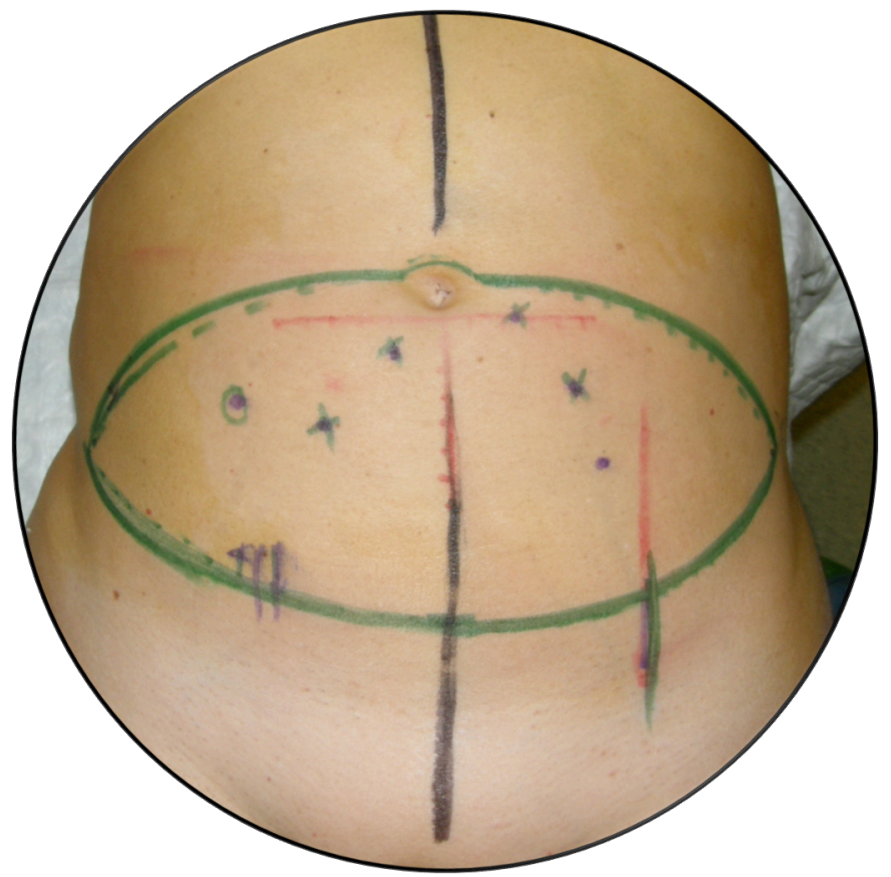

Figura 38: Diseño de la isla cutánea del colgajo señalando los principales vasos perforantes y las VEIS (en el borde caudal del colgajo). 


\subsection{Técnica quirúrgica}

En este procedimiento trabajaron dos equipos de dos cirujanos simultáneamente. El primer equipo se ocupa de realizar la mastectomía en el caso de que se trate de una reconstrucción inmediata y de preparar el lecho y los vasorreceptores. También es el encargado de realizar la microanastomosis una vez se ha autonomizado el colgajo y de remodelarlo al concluir ésta, para lograr la mayor simetría posible con la mama contralateral. En el caso de que la mama contralateral necesite de algún procedimiento como una reducción o una mastopexia, este se suele ejecutar por parte del primer equipo al concluir la disección de los vasorreceptores. Por otro lado, el segundo equipo realiza la elevación del colgajo, y se ocupa de efectuar el cierre abdominal mientras el primer equipo remodela el colgajo en la última fase de la intervención.

\section{Preparación del lecho y de los vasorreceptores}

Esta primera fase consta de los siguientes pasos:

1. Resección de la cicatriz de mastectomía que se envía a estudio anatomo-patológico. En el caso de que se trate de una mastectomía con reconstrucción inmediata, se practica una mastectomía ahorradora de piel.

2. Disección del polo superior de la zona de mastectomía por encima del músculo pectoral y en el polo lateral entre las líneas axilares anterior y media. En estas zonas el colgajo se dispondrá desepitelizado bajo la piel del tórax con el fin de conseguir una transición homogénea desde la pared costal al polo inferior de la mama que es la zona más proyectada.

3. Separación de las fibras del músculo pectoral a nivel del $2^{\circ}$ espacio intercostal y $3^{\circ}$ cartílago costal en su proximidad con el esternón, con el fin de acceder a los vasos mamarios internos (fig. 39A). Se intenta abordar el espacio únicamente sin hacer resecciones completas del cartílago costal para prevenir depresiones visibles en el postoperatorio, aunque esto no siempre es posible y en ocasiones fue necesario eliminar una porción de $3 \mathrm{~cm}$ aproximadamente de cartílago costal (165) para facilitar la microanastomosis. 
4. Disección de entre $2-3 \mathrm{~cm}$ de los vasos mamarios internos y evaluación de su estado. Aunque estos vasos suelen soportar razonablemente bien la RT, si se comprueba fibrosis importante con estenosis severa fundamentalmente de la vena mamaria interna, se opta por buscar otros vasorreceptores, generalmente ramas del eje subescapular como el pedículo del músculo serrato anterior o los vasos toracodorsales (fig. 39B).

5. Finalmente se embeben en lidocaína para prevenir la vasoconstricción y se deja protegidos con una gasa con suero hasta el momento de realizar la microanastomosis.
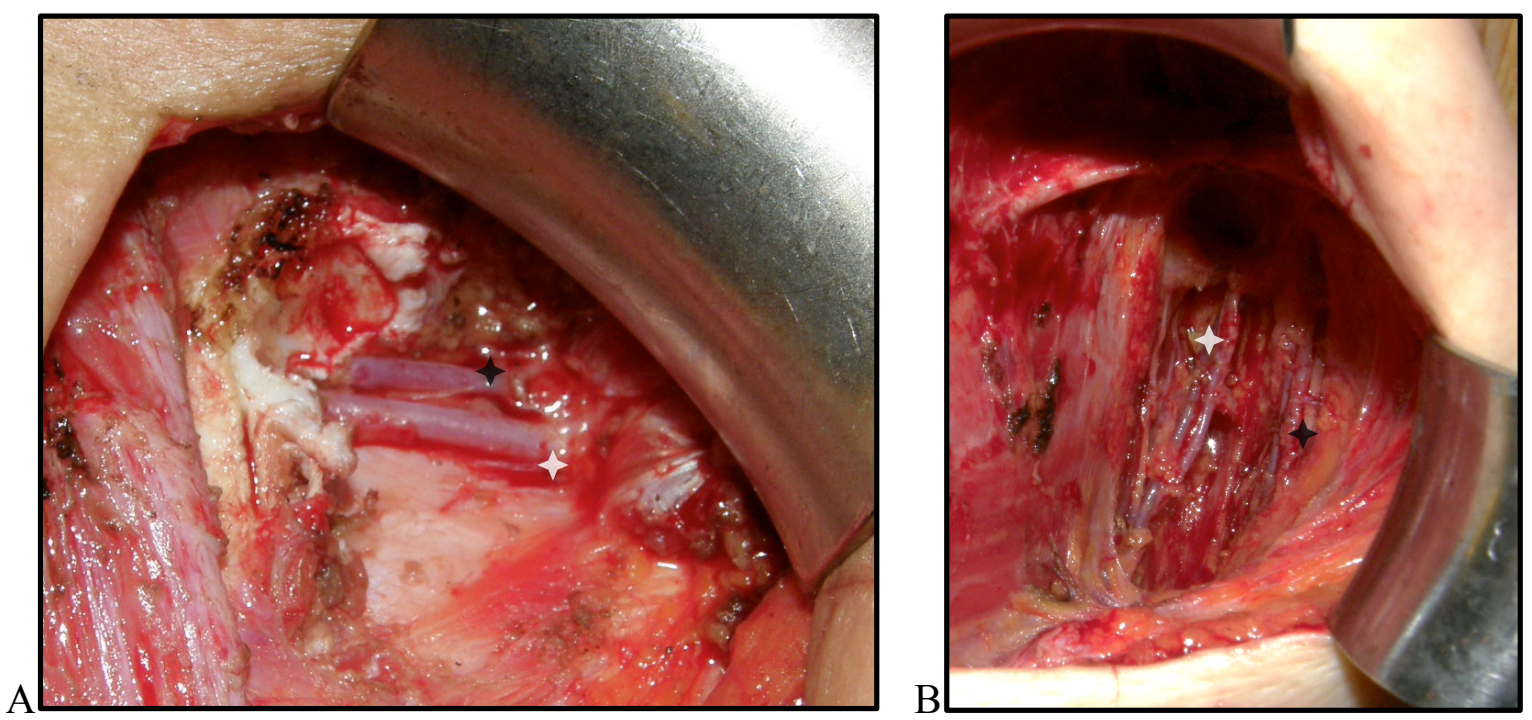

Figura 39: A: Disección de arteria (estrella blanca) y vena (estrella negra) mamarios internos con resección parcial del $3^{\circ}$ cartílago costal. B: Disección de vasos del serrato (estrella blanca) y vasos toracodorsales (estrella negra).

\section{Disección del colgajo DIEP}

El segundo equipo realiza la elevación del colgajo comenzando desde un lateral de la elipse diseñada avanzando por un plano suprafascial hasta localizar la perforante seleccionada, momento en el que incide la fascia del recto abdominal y sigue su trayecto a 
través del músculo cauterizando las pequeñas ramas que van apareciendo y procurando preservar los nervios segmentarios que van cruzando el músculo recto anterior del abdomen hasta su entrada en los vasos epigástricos inferiores profundos (fig. 40 A y B).

La disección continua y a medida que se avanza, el pedículo se posiciona bajo el vientre muscular para posteriormente abandonarlo en su región inferolateral. La disección finaliza cuando estos vasos alcanzan la longitud y el diámetro adecuados que permita realizar la sutura microquirúrgica, generalmente cerca de su origen en los vasos femorales (fig. 40C).

Es habitual dejar disecados una o ambas venas epigástricas inferiores superficiales en la zona inferior del colgajo, que se utilizará como drenaje venoso secundario en caso de congestión circulatoria.

Concluidos estos pasos se eleva la mitad contralateral del colgajo manteniendo una o dos perforantes de este lado reservadas y clampadas para testar la circulación del colgajo a través de la perforante seleccionada. El test consiste en observar sangrado activo por los bordes del colgajo y relleno capilar lento en su porción cutánea cuando está únicamente unido a la paciente por su pedículo (con las perforantes contralaterales clampadas temporalmente).

Una vez hecha esta comprobación se cauterizan las perforantes del lado opuesto reservadas y se autonomiza el colgajo mediante la sección fría primero de la arteria para que se evacúe la sangre, y a continuación las venas concomitantes (fig. 40D). 

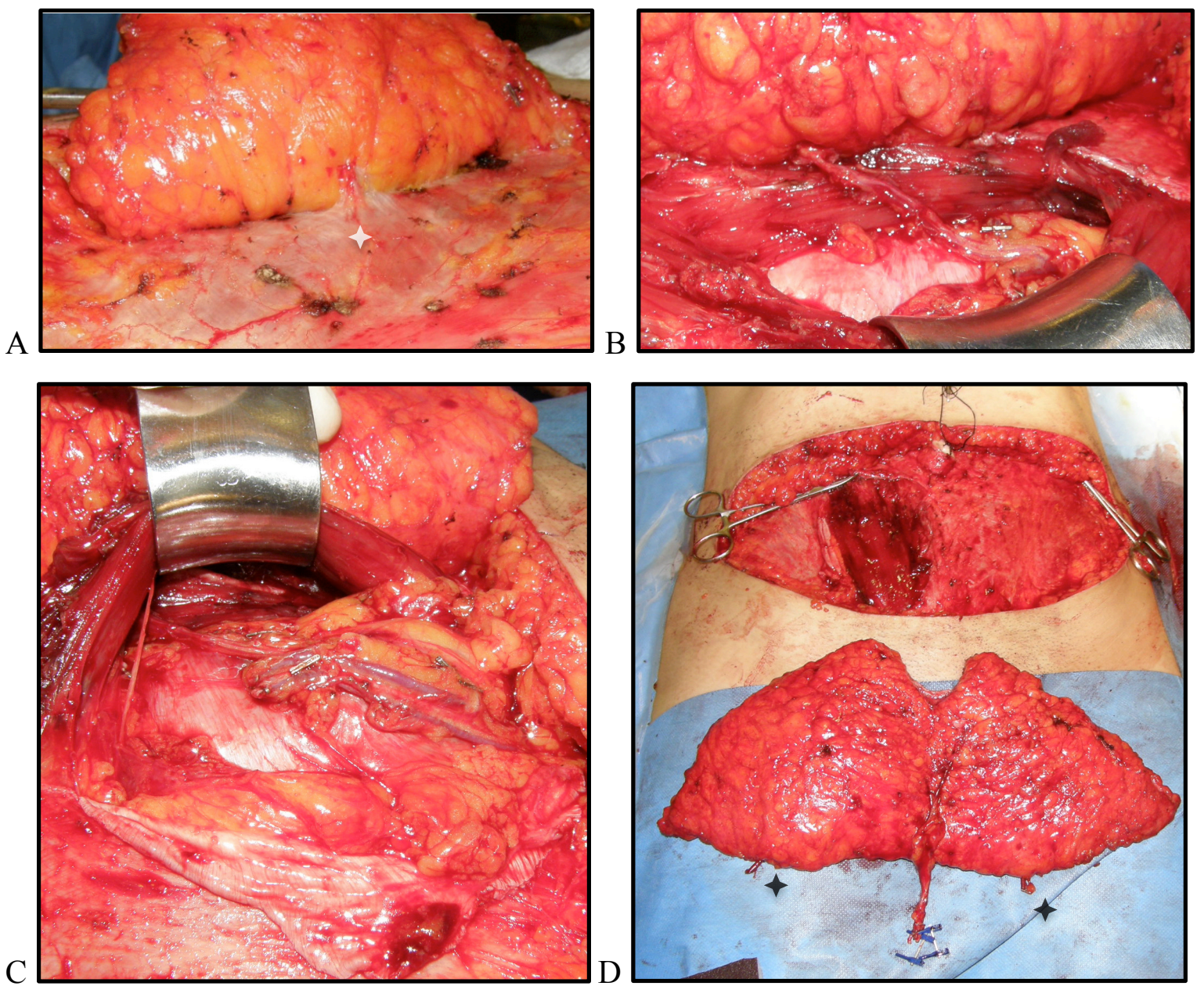

Figura 40. A: Elevación suprafascial del colgajo hasta alcanzar la salida de la perforante seleccionada (estrella blanca). B: Disección de la perforante a través del músculo recto anterior del abdomen. C: Entrada de la perforante en el pedículo epigástrico inferior profundo. D: Colgajo autonomizado con el pedículo clampado. Venas epigástricas superficiales clipadas y reservadas como rescate (estrella negra).

\section{$\underline{\text { Microanastomosis }}$}

Inmediatamente tras autonomizarse el colgajo se procede a realizar la anastomosis bajo magnificación con microscopio. La preparación de los vasos incluye adventiciectomía, dilatación y lavado con una solución de heparina diluida al $5 \times 10^{-4}$. Se realiza primero la anastomosis de la vena comitante de mayor calibre del pedículo del colgajo a la vena mamaria interna, y tras comprobarse la permeabilidad se procede a realizar la arteria (fig. 41). Todas las microsuturas practicadas fueron termino-terminales y sin ayuda de couplers o cualquier otro dispositivo automático. 
A continuación se procede al testado de la perfusión del colgajo de igual modo que se hizo antes de autonomizarlo. En el caso de que aparezcan signos de congestión venosa, se refuerza el drenaje mediante una anastomosis de la vena epigástrica inferior superficial a la vena cefálica, del serrato o la toracodorsal.

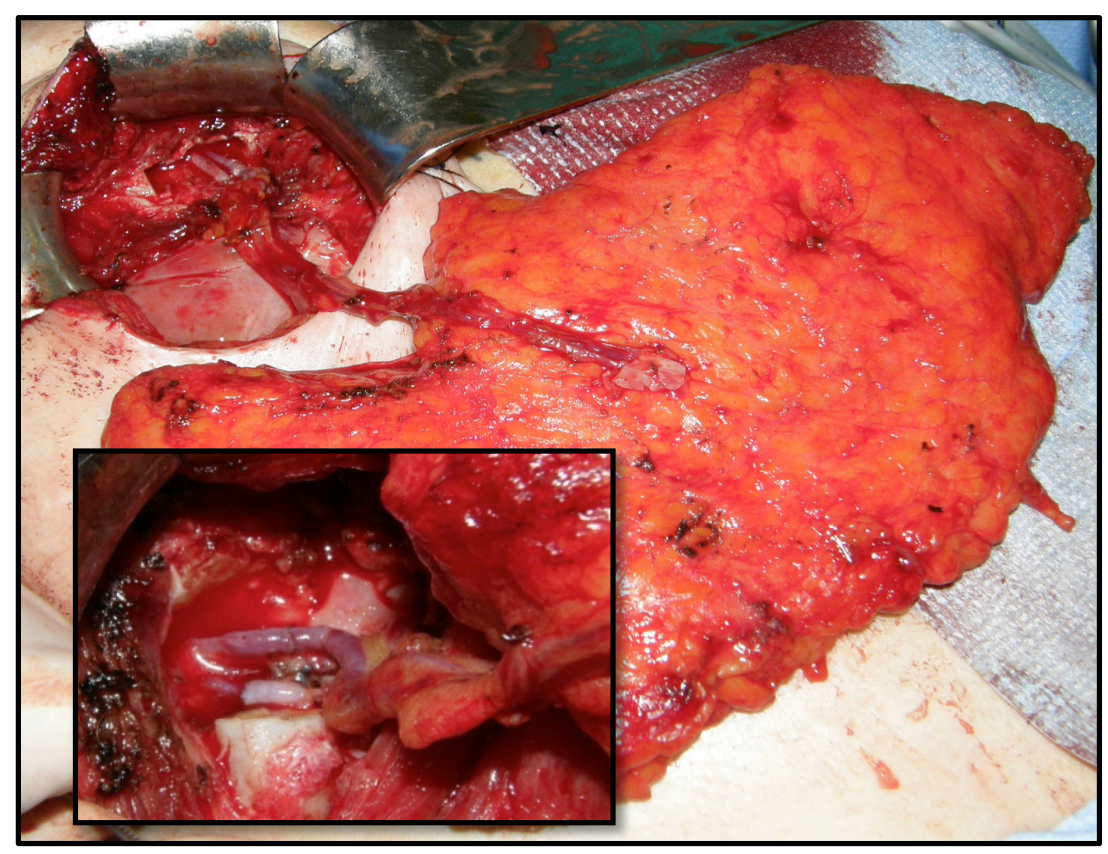

Figura 41: Colgajo DIEP anastomosado a vasos mamarios internos, con detalle de la microsutura.

\section{$\underline{\text { Remodelado del colgajo y cierre abdominal }}$}

El último paso de la intervención consiste en eliminar la zona IV del colgajo y una pequeña porción de la zona III para minimizar el riesgo problemas circulatorios en las zonas más alejadas de la entrada de la perforante en el colgajo. A continuación se sitúa el colgajo en la axila, siguiendo por el polo inferior, cuadrante interno y finalmente dejando parte del mismo en posición subcutánea en el polo superior. Durante este proceso se da gradualmente la proyección adecuada y se resecan las porciones del colgajo necesarias para conformar una mama similar a la contralateral $(167,168)$.

Al mismo tiempo se realiza el cierre de la fascia abdominal, se completa el despegamiento del colgajo abdominal superior para realizar el cierre del defecto de forma 
similar a la técnica de la abdominoplastia transversa baja clásica con umbilicoplastia. Antes de completarlo se pulveriza un adhesivo de fibrina (inicialmente $5 \mathrm{ml}$. de Tissucol ${ }^{\circledR}$ y desde el colgajo DIEP número 25 en adelante $4 \mathrm{ml}$ de Artiss ${ }^{\circledR}$, Baxter Internacional Inc., Estados Unidos) con el objetivo de reducir espacios muertos, favorecer la cicatrización y reducir el riesgo de seroma (169).

\subsection{Protocolo postoperatorio}

Al terminar la intervención la paciente es trasladada al área de reanimación postquirúrgica donde permanece $12 \mathrm{~h}$ en observación (ver protocolo operatorio para anestesia, anexo 2) respetando las siguientes indicaciones:

- Dieta absoluta.

- Colocación de la paciente en decúbito supino con las rodillas semiflexionadas.

- Control de la presión arterial, evitando hipotensiones mantenidas.

- Control del vacío y los volúmenes de los drenajes aspirativos.

- Testado del colgajo cada $2 \mathrm{~h}$, observando que se encuentre caliente, normocoloreado y con relleno capilar lento.

- Evitar cualquier maniobra que pueda comprimir el colgajo (vendajes o apósitos,..).

Si no surgen incidencias durante la estancia en la reanimación quirúrgica y la perfusión de colgajo y la situación clínica de la paciente es buena, esta es traslada a la planta de hospitalización a la mañana siguiente, donde se sigue el protocolo de enfermería (anexo 1) hasta el momento del alta, que suele ser entre 4 y 7 días después de la intervención salvo complicaciones.

\subsection{Simetrización de la mama reconstruida y la mama contralateral}

La RM con colgajo DIEP aporta un tejido del máximo parecido en términos de textura y naturalidad a la mama amputada. Sin embargo, la disposición de la mama contralateral en ocasiones indicó actuaciones sobre la misma para alcanzar una reconstrucción simétrica 
y de calidad. Inicialmente estos procedimientos se realizaron de forma diferida en una nueva intervención no antes de 4 meses desde la RM. Sin embargo desde la paciente número 22 se paso a hacer la simetrización en el mismo tiempo que la reconstrucción con el colgajo DIEP con el fin de ahorrar intervenciones a las pacientes (fig. 42 A y B). Las técnicas empleadas fueron las siguientes:

1. Reducción mamaria mediante técnicas de pedículo inferior, superior, superomedial, McKissock, Thorek, y Ribeiro.

2. Pexia mamaria mediante técnicas de pedículo inferior, superior, Ribeiro y circumareolares.

3. Reconstrucción mamaria con colgajo de dorsal ancho o con colgajo DIEP.

También fue preciso hacer actuaciones de manera diferida sobre la mama reconstruida con el colgajo DIEP en aquellos casos que presentaban irregularidades o asimetrías destacables para lograr el máximo parecido en términos de forma y de volumen con la mama contralateral. Estos procedimientos se demoraron al menos 4 meses desde la primera intervención para evitar actuar sobre un tejido con un resultado no definitivo debido al edema y los procesos de cicatrización. Estas correcciones se realizaron de forma ambulatoria en la gran mayoría de los casos (fig. 42C). Estos procedimientos fueron los siguientes:

1. Lipoaspiración para reducir zonas con exceso de volumen.

2. Lipoinfiltración según la técnica de Coleman en diferentes zonas de la mama reconstruida con lipoaspirado procedente del colgajo, el abdomen, flancos o el área trocantérea.

3. Remodelado mediante resecciones localizadas de piel y grasa y plastias locales para corregir cicatrices o dar una forma más redondeada a la mama.

\subsection{Reconstrucción del complejo areola-pezón}

A todas las pacientes se les ofreció crear un nuevo complejo areola-pezón tras finalizar la reconstrucción del montículo mamario. Esta técnica se realizó bien de manera exclusiva 
bajo anestesia local o bien con anestesia general asociada a algún procedimiento de simetrización de poca entidad que no comprometiese la posición del CAP tras la cicatrización de los tejidos intervenidos. En ambos casos la cirugía se realizó de manera ambulatoria.

La técnica empleada para la reposición del pezón fue un colgajo local tipo Star o tipo Little. En el caso de la areola se practicó un autoinjerto cutáneo de piel total extraído de la ingle. Algunas pacientes optaron por realizarse un tatuaje que simulase una areola, el cual fue realizado fuera de nuestro centro y de manera independiente (fig. 42D).
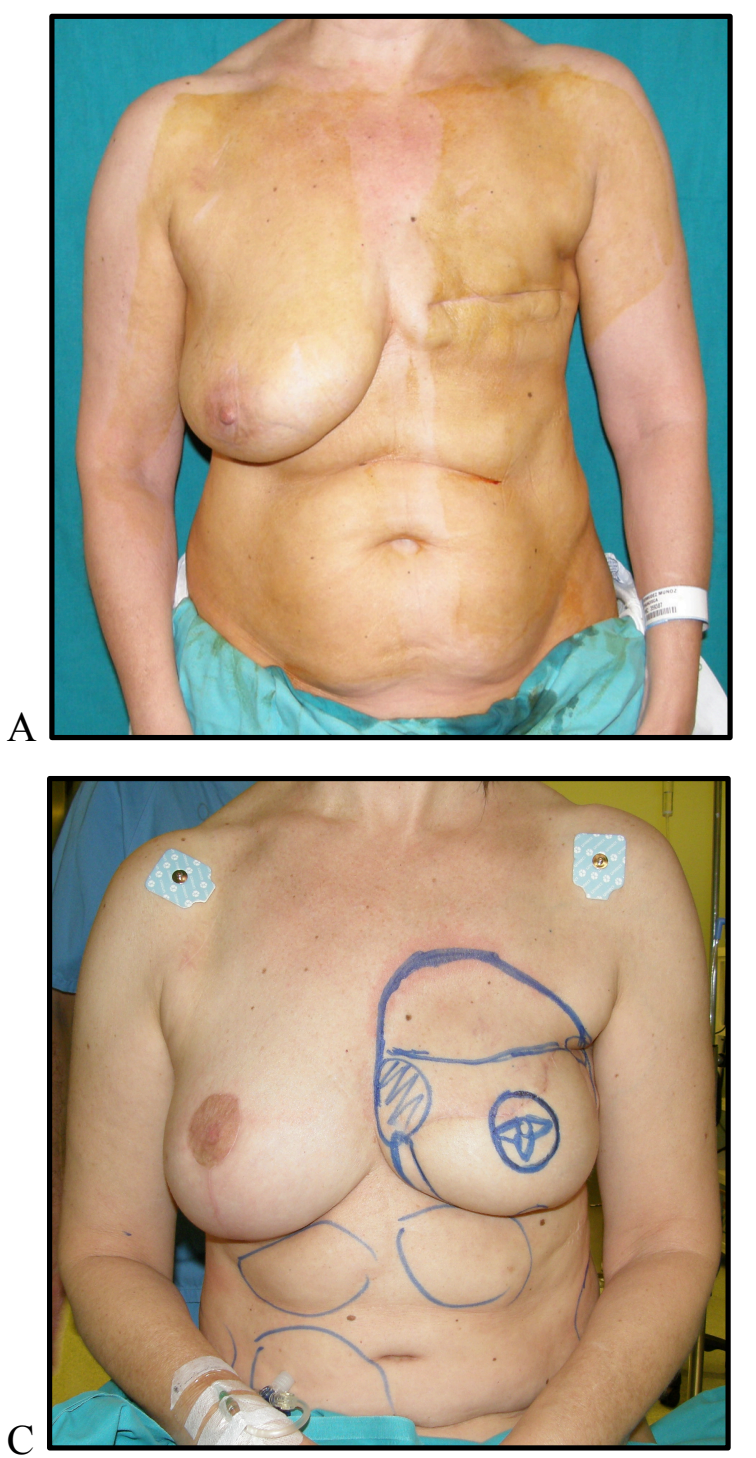
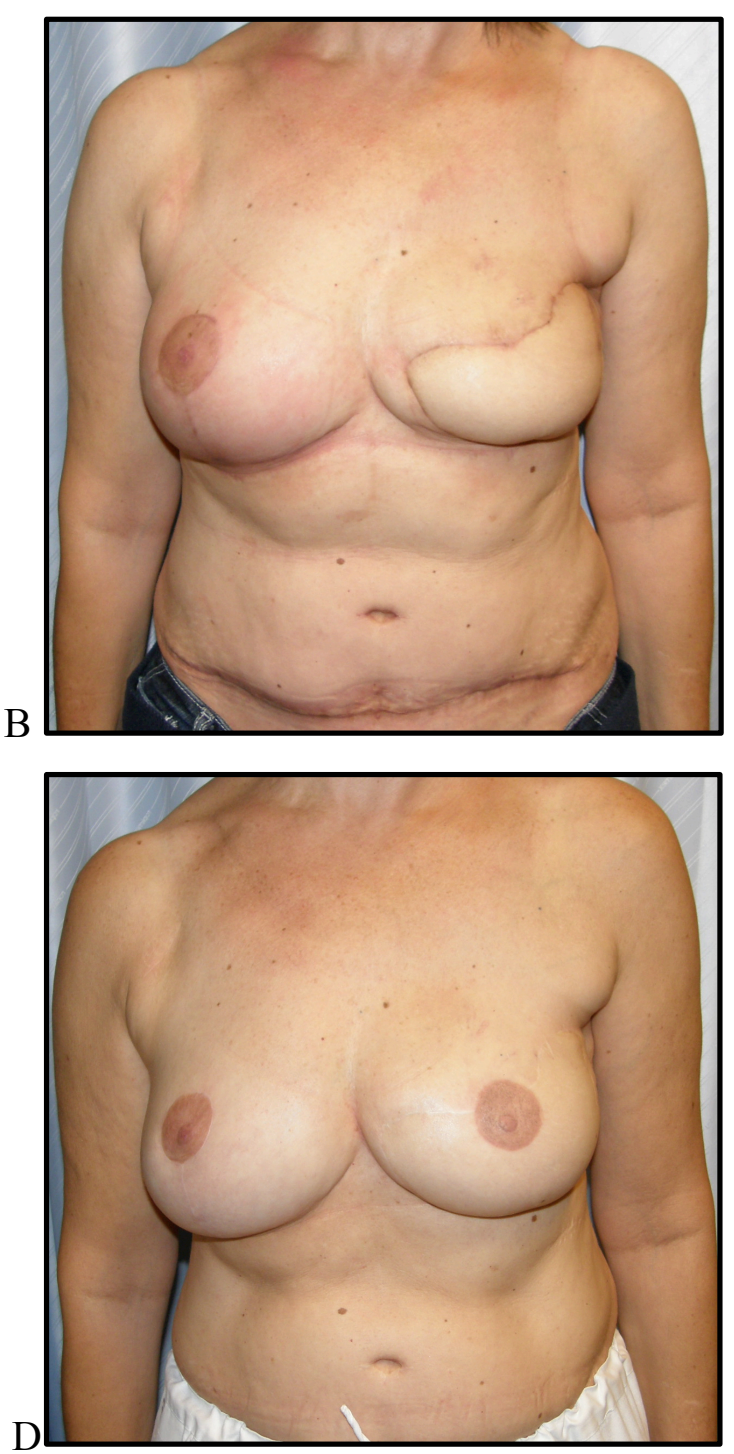

Figura 42: Secuencia de RM con colgajo DIEP. A: RM izquierda diferida tras MRM y RT. B: Resultado a los 3 meses de la reconstrucción con colgajo DIEP y reducción mamaria derecha con técnica de pedículo inferior. C: Marcaje de simetrización sobre el colgajo DIEP: Lipoinfiltración de 223 cc de tejido adiposo, remodelado de exceso de tejido en cuadrante ínferointerno y reconstrucción de pezón a los 6 meses de la primera intervención. D: Resultado final a los 26 meses con tatuaje de areola bilateral. 


\section{RECOGIDA DE DATOS}

Para realizar este estudio retrospectivo observacional se recogieron datos de las pacientes procedentes de la historia clínica, de las revisiones sucesivas en consulta durante el seguimiento de las mismas, así como se revisaron todas las angio TC realizadas de manera previa a la intervención, empleando el software OsiriX en el postprocesamiento de las imágenes.

\subsection{Datos relacionados con la paciente}

\section{Edad}

Se registró la edad que tenía la paciente el día que se realizó la reconstrucción mamaria con el colgajo DIEP.

\section{Enfermedades concomitantes}

Se recogieron todas las enfermedades, patologías y tratamientos que presentaba la paciente. Sin embargo, en función de los objetivos de este estudio sólo se consideraron aquellas que de algún modo puedan causar un alteración en el sistema circulatorio de la paciente y por consiguiente del colgajo, desestimándose el resto. Se tomaron como variables las siguientes patologías:

- Diabetes Mellitus tipo I y tipo II.

- Hipertensión arterial.

- Dislipemia.

\section{Antecedente de cirugía abdominal}

Debido a que cualquier cicatriz abdominal supone una interrupción de la red vascular a ese nivel y por consiguiente puede aumentar el riesgo de complicaciones y comprometer la 
vitalidad del colgajo, esta variable se clasificó según el tipo de cicatriz de cada intervención:

- Apendicectomía.

- Histerectomía abdominal o cesárea que presenta cicatriz de Pfannenstiel.

- Laparoscopia.

- Laparotomía media.

No se incluyeron la cicatrices en región epigástrica correspondiente a cirugías como la colecistectomía abierta al quedar esta fuera de la isla del colgajo y del trayecto del pedículo epigástrico inferior profundo.

\section{Tabaquismo}

A pesar de que el tabaquismo fue considerado un criterio de exclusión, no todas las pacientes que se comprometieron a abandonar el hábito lo hicieron. Algunas pacientes mintieron durante la realización de la historia clínica, confesando su consumo después de la intervención. Se establecieron tres grupos:

- No fumadoras.

- Fumadoras: pacientes con consumo activo en el momento de la intervención.

- Ex fumadoras: pacientes que habían abandonado el habito al menos 6 meses antes de la intervención.

\section{Medidas antropométricas}

Todas las pacientes fueron pesadas y talladas en la consulta, extrapolándose el índice de masa corporal que se utilizó como variable. En la bibliografía esta descrito que la obesidad puede relacionarse con un aumento del número de complicaciones en RM con colgajo DIEP (170). 


\subsection{Datos relacionados con el cáncer de mama}

\section{Histología}

Según el estudio anatomo-patológico se clasificó en:

- Carcinoma ductal in situ.

- Carcinoma ductal infiltrante.

- Combinación de carcinoma ductal in situ e infiltrante en la pieza de mastectomía.

- Carcinoma lobulillar infiltrante.

También se registró cuando la indicación de la mastectomía fue con fines reductores de riesgo.

\section{Biopsia selectiva de ganglio centinela}

Se registraron aquellas pacientes a las que se les realizó una BSGC y su resultado se clasificó como negativo, positivo para macrometástasis o positivo para micrometástasis.

\section{Linfadenectomía axilar}

Se contabilizaron las pacientes sometidas a este procedimiento, el número de ganglios extirpados y cuantos de estos ganglios presentaban enfermedad. Hay que tener en cuenta que este tipo de cirugía, sobretodo cuando se asocia a RT, puede dar lugar a retracciones axilares más difíciles de reconstruir y que precisen de un mayor número de intervenciones. La combinación de ambos factores también se asocia a un mayor riesgo de linfedema, lo situación que se puede agravar si es necesario emplear la vena cefálica para reforzar el drenaje del colgajo.

\section{Tratamientos adyuvantes}

Estos tratamientos consistieron en la administración de radioterapia, quimioterapia y hormonoterapia. 


\section{Tiempo transcurrido desde la mastectomía hasta la reconstrucción}

Se contabilizó este periodo en meses. Las reconstrucciones inmediatas no se consideraron en el estudio de este parámetro.

\section{Recidiva del cáncer}

Se registraron las pacientes que presentaron recidiva después de la reconstrucción con DIEP, la aparición de metástasis y las defunciones por este motivo.

\subsection{Datos relacionados con el colgajo y con la intervención quirúrgica}

\section{Lado de la reconstrucción mamaria y lado del colgajo}

Se dividieron en derecha e izquierda para cada variable.

\section{Número de perforantes en las que se basa el colgajo}

Aunque habitualmente el colgajo DIEP se eleva con una perforante procedente del pedículo epigástrico inferior profundo, con la intención de reforzar la vascularización se puede recolectar el colgajo con dos o tres perforantes que estén próximas.

\section{Vasorreceptores seleccionados}

Se recogieron los vasorreceptores utilizados para la anastomosis del colgajo. En este estudio se utilizaron los vasos mamarios internos, los toracodorsales o los vasos del serrato.

\section{Tiempo operatorio}

Se registraron los minutos requeridos por los cirujanos para completar la intervención, excluyéndose los tiempos consumidos en la preparación y por los médicos anestesiólogos. 


\subsection{Datos relacionados con la vascularización del colgajo}

Para la recogida de los datos relacionados con las características circulatorias del colgajo fue necesario utilizar un sistema informático equipado con un software que posibilitase el procesamiento y reconstrucción de los archivos DICOM que conforman cada angio TC. Estos archivos fueron descargados de la red del CAULE o bien aportados en soporte físico (CD) en el caso de los estudios practicados en el Hospital de El Bierzo.

La reconstrucción y análisis fue llevado a cabo en un equipo informático doméstico iMac de 21,5 pulgadas con procesador 2,9 GHz Intel Core i5, memoria RAM de16 GB y sistema operativo Mac OS X Yosemite v. 10.10 .4 (Apple Computer, Cupertino, CA, EE.UU.). La aplicación empleada en el procesamiento de los ficheros DICOM fue OsiriX MD PACS Workstation v. 2.8.5.

Para la elección de las variables a estudiar se consideraron los "criterios de Navarra", consistente en un consenso de expertos sobre las condiciones que debe cumplir el pedículo vascular ideal del colgajo DIEP publicados en 2010 (152):

1. AEIP de calibre grueso con pedículo largo.

2. Calibre de la perforante grueso (tanto de la arteria como de la vena).

3. Entrada central de la perforante en el colgajo.

4. Trayecto intramuscular corto.

5. Conexión entre la vena de la perforante y la red venosa superficial.

6. Ramificación amplia de la perforante dentro del colgajo.

7. Trayecto subfascial largo.

8. Que su trayecto evite las intersecciones tendinosas.

\section{Patrón de la arteria epigástrica inferior profunda}

Para estudiar este dato se emplearon reconstrucciones 3D MPR de una proyección coronal del abdomen, asignando un grosor de corte entre 10 y $25 \mathrm{~mm}$ (proyección MIP) según fuese preciso para visualizar la AEIP en todo su trayecto. 
Según la ramificación de la AEIP y atendiendo a la clasificación de Moon y Taylor (124), se designaron los patrones tipo I, II y III. Se tomaron los datos tanto del lado del colgajo como del lado contralateral (fig. 43).

\section{Estudio del vaso perforante seleccionado}

Este análisis se realizó empleando las proyecciones axial, coronal y sagital de las reconstrucciones 3D MPR. Para que las medidas tomadas fuesen lo más exactas posible se orientaron las reconstrucciones alineando los ejes de coordenadas con diferentes referencias anatómicas de tal modo que en la proyección coronal el eje Y quedó ubicado en una línea que uniese el punto medio del ombligo con la sínfisis pubiana, mientras que en la proyección axial el eje $\mathrm{X}$ se ubicó en una línea que pasase por las espinas ilíacas anterosuperiores. En esta situación se estudiaron las siguientes variables del vaso perforante en el que se basó el colgajo DIEP el día de la intervención reconstructiva:

- Calibre de la perforante: Mediante imágenes MIP de 10 a $25 \mathrm{~mm}$ de grosor se realizó una comparación visual del calibre total del vaso perforante con el resto de vasos perforantes que entraron en el colgajo a nivel de la fascia abdominal.

- Localización de la salida de la perforante a nivel de fascia abdominal: En la proyección coronal se midieron las distancias en mm en los ejes espaciales $\mathrm{X}$ e $\mathrm{Y}$ con respecto al punto medio del ombligo. Se utilizaron cortes del menor grosor disponible para lograr una medida lo más exacta posible (fig. 44).

- Rama de la AEIP: De acuerdo al origen de la perforante con respecto a la división de la AEIP, ésta se clasificó en medial o lateral. En los casos en los que por la variabilidad anatómica interindividual no se pudieran definir dos zonas de irrigación, se tomó como referencia el centro de la masa muscular de los rectos abdominales, definiendo una zona medial y otra lateral a cada lado de la línea media de cada uno de los rectos anteriores del abdomen (fig. 44 y 45). 
- Conexión de la perforante con el sistema venoso superficial: Mediante imágenes MIP en la proyección sagital se pudo evidenciar fácilmente la existencia de esta conexión (fig. 46).

- Ramificación amplia de la perforante en el tejido celular subcutáneo del colgajo: Con proyecciones MIP de los cortes axiales se pudo comprobar si la perforante se dividía en múltiples ramas para perfundir el colgajo o por el contrario seguía su trayecto sin ramificarse (fig. 45 y 46).

- Trayecto intramuscular: En función de la distancia entre la AEIP y la salida de la perforante a nivel de la fascia abdominal, este trayecto se definió como corto cuando fue directo y prácticamente perpendicular, intermedio cuando fue oblicuo y de una longitud entre 2 y $6 \mathrm{~cm}$ (fig. 45) y largo cuando la perforante recorrió gran parte de la masa muscular del recto anterior antes de entrar en la AEIP.

- Peculiaridad anatómica de la perforante: En el análisis de las imágenes se registraron aquellas perforantes con un trayecto subfascial largo o que atravesasen intersecciones tendinosas de la musculatura abdominal (fig. 46B). También se tuvo en cuenta aquellas cuyo curso fuese rodeando el musculo recto anterior por su borde medial sin penetrar en él y las que fuesen filiformes y su trayecto intramuscular no se resaltase en las proyecciones MIP del angio TC.

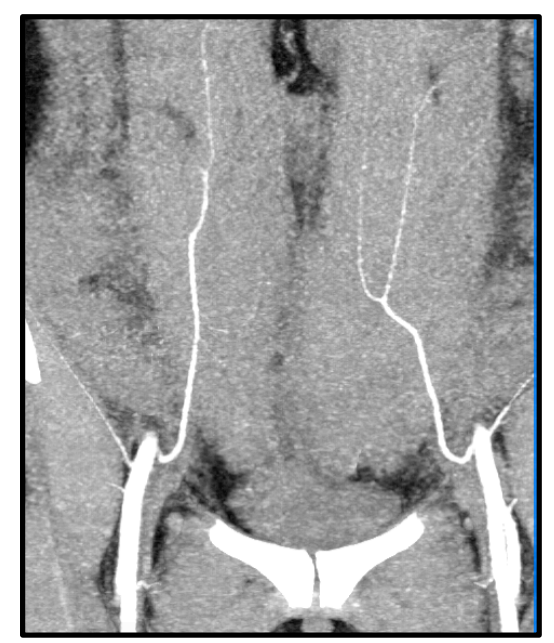

Figura 43: Reconstrucción 3D MPR. Proyección MIP 10,7 $\mathrm{mm}$. Patrón de la AEIP tipo I (derecha) y tipo II (izquierda). 


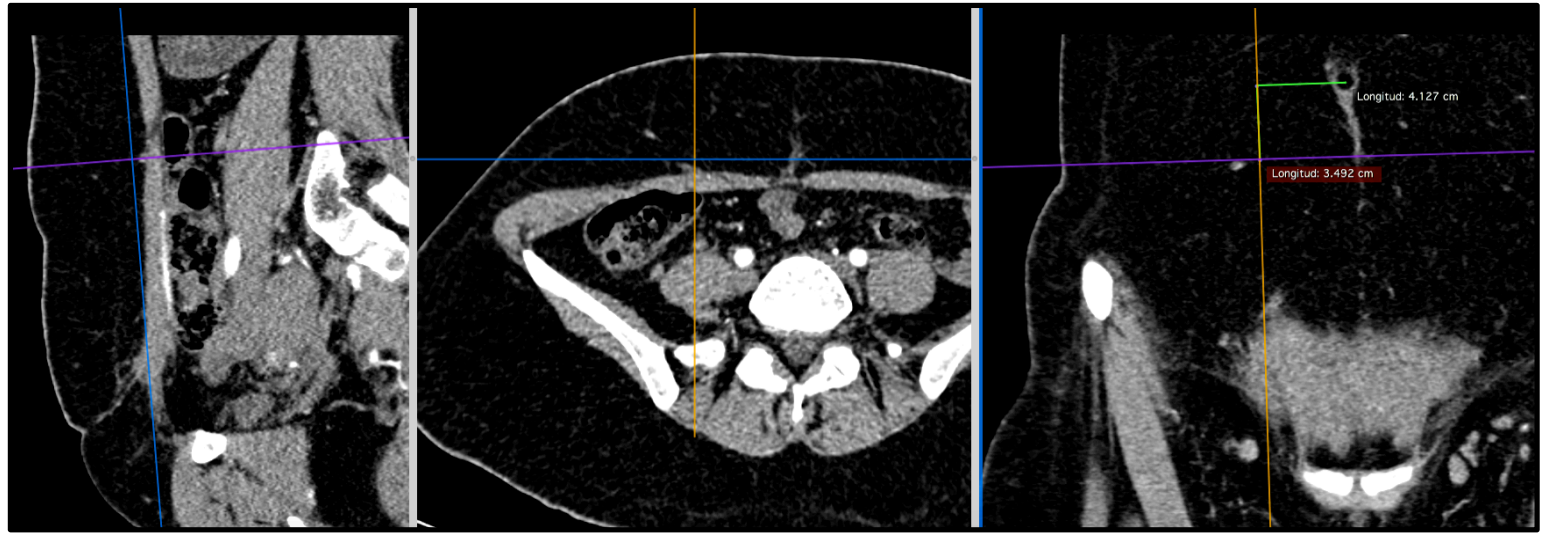

Figura 44: Referenciado de la salida de la perforante a nivel de fascia en los ejes X e Y con respecto al punto central del ombligo. Perforante lateral. Reconstrucción 3D MPR.

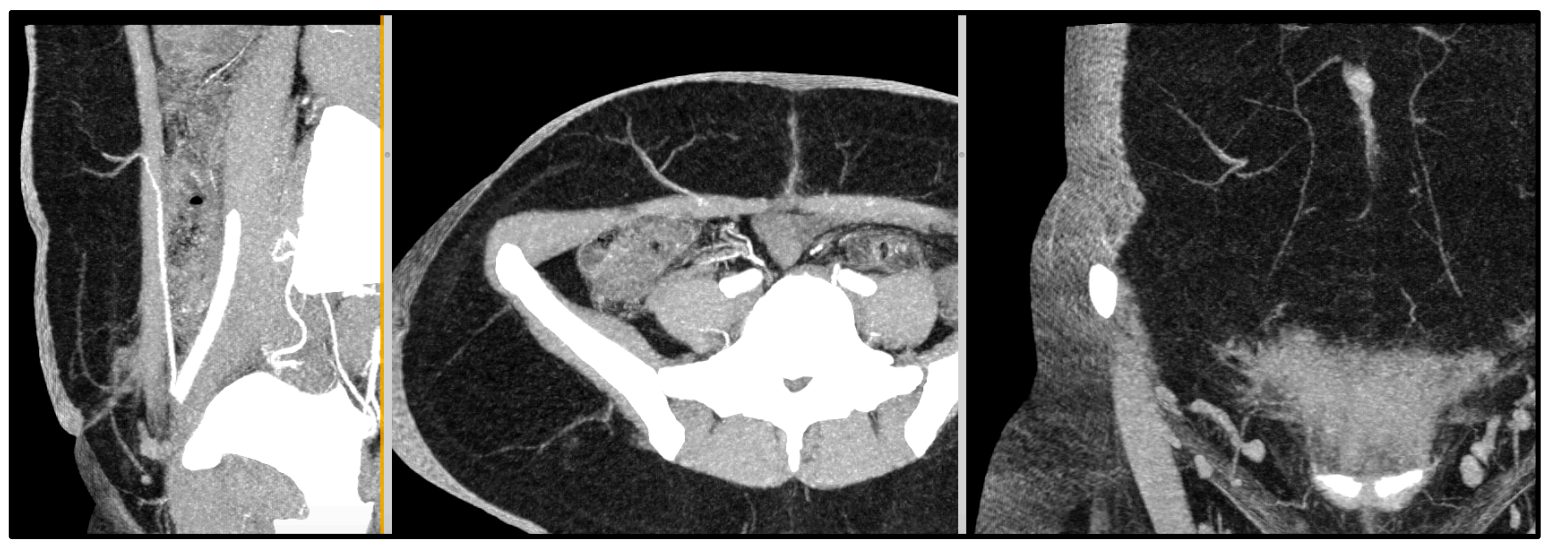

Figura 45: Misma perforante estudiada que en la figura anterior con proyección MIP de $25,11 \mathrm{~mm}$. En la proyección sagital se observa un trayecto intramuscular corto de la perforante, mientras que en la proyección axial se pone de manifiesto la localización lateral y una amplia ramificación de la perforante dentro del colgajo.

\section{Mejor perforante}

Se catalogó como mejor perforante desde el punto de vista circulatorio, aquel vaso de mayor calibre que presentase conexiones con el sistema venoso superficial y ramificaciones amplias dentro del colgajo.

Se comprobó si la perforante sobre la que se disecó el colgajo se correspondía con la mejor perforante observada al estudiar la angio TC utilizando el procesamiento de las imágenes con el software OsiriX o por el contrario había otro vaso perforante que se ajustase mejor a estos criterios. 


\section{Localización de las venas epigástricas inferiores superficiales}

Se tomó la distancia en el eje X de las VEIS con respecto a la línea media a $10 \mathrm{~cm}$ caudal al punto medio del ombligo, lugar por donde suele establecerse el borde inferior de la isla del colgajo (fig. 46A).

A
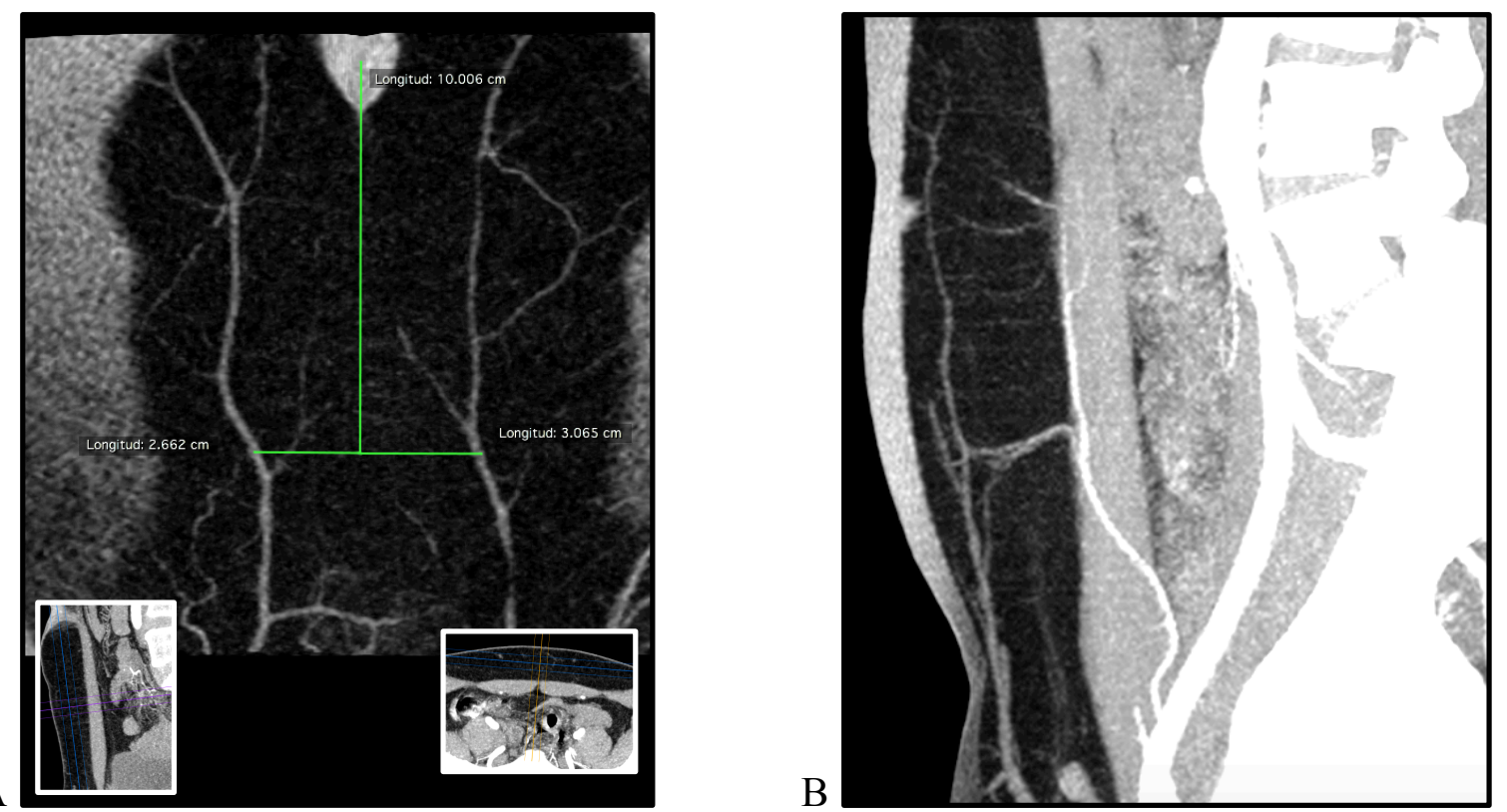

Figura 46: A: Referenciado de las venas epigástricas inferiores superficiales mediante una reconstrucción 3D MPR y un grosor de corte de 12,42 mm. B: Anastomosis de una perforante al sistema venoso superficial en una proyeccion sagital. Se puede observar el trayecto subfascial de la perforante más superior.

\section{Otros hallazgos anatómicos de la pared abdominal}

Durante el análisis de imágenes se pusieron en evidencia otros hallazgos que fueron de interés durante la elevación del colgajo:

- Presencia de hernias umbilicales.

- Diástasis de los músculos rectos anteriores del abdomen.

- Cicatrices en la pared abdominal de apendicectomía, laparotomía media o Pfannenstiel y su relación con la trama vascular subcutánea y los ejes circulatorios principales del colgajo.

- Localización de las intersecciones tendinosas de la musculatura abdominal.

- Conexiones entre los sistemas venosos superficiales de ambos lados. 


\subsection{Datos relacionados con las complicaciones}

Se contabilizaron el numero total de pacientes que presentaron algún tipo de complicación.

\section{Necrosis completa del colgajo}

Se incluyeron en esta categoría aquellos casos en los que se produjo la pérdida del colgajo independientemente de la causa considerándose como un fracaso de la reconstrucción.

\section{Necrosis parcial del colgajo}

Se registraron aquellos casos en los que la necrosis del colgajo fue parcial, involucrando parte de la piel y del tejido adiposo, pero que tras realizar los desbridamientos oportunos parte del colgajo fue viable.

\section{Necrosis grasa del colgajo}

Se incluyeron todos aquellos colgajos que presentaron una zona de necrosis grasa franca en la exploración física (superior a $2 \mathrm{~cm}$.) acompañada o no de repercusiones como dolor y/o molestias para la paciente, retracciones cutáneas o pérdida de calidad en el resultado estético de la reconstrucción.

Este tipo de complicación traduce generalmente un problema de perfusión del colgajo, como puede ser una insuficiencia venosa subclínica. No se incluyeron aquellos casos de pequeñas necrosis grasas objetivadas sólo ecográficamente al poder tener una etiología diferente (p.e. restos de tejido adiposo mal perfundido a consecuencia de la manipulación durante el remodelado del colgajo para darle forma de mama). 


\section{Dehiscencia cutánea del colgajo y dehiscencia cutánea abdominal}

Se incluyeron todas aquellas dehiscencias de herida en la mama reconstruida o en el cierre abdominal.

\section{Otras complicaciones}

Se otorgaron categorías diferentes a la aparición de las siguientes complicaciones:

- Seroma: Aparición de líquido seroso en el abdomen después de la retirada de los drenajes que precisó su punción y extracción con jeringa. No hubo seromas en el colgajo.

- Infección en la mama reconstruida. No hubo infecciones en la zona donante abdominal.

- Neumotórax: por apertura del espacio pleural durante la disección de los vasos axilares que tuvo repercusiones clínicas.

- Cicatrices queloides: No se incluyeron aquellos casos con mayor o menor grado de hipertrofia en las cicatrices sin cumplir los criterios de queloide.

- Abultamiento abdominal: Debilidad con integridad de la fascia abdominal.

- Hernia: Fallo de la pared abdominal sin integridad de la fascia.

- Hematoma en el colgajo sin relación con un problema de retorno venoso.

- Tromboembolismo pulmonar.

\section{Reintervenciones}

Se consignaron aquellas pacientes que precisaron ser reintervenidas para resolver la complicación.

\section{Tiempo de ingreso}

Número de estancias desde el día de la intervención hasta el día de alta. 


\section{Problemas circulatorios del colgajo}

En esta categoría se agruparon todas aquellas complicaciones que tradujeron un problema de perfusión del colgajo. Esta variable esta compuesta por casos que presentaron una necrosis parcial o grasa del colgajo. Con el fin de evitar sesgos de selección, se excluyeron las necrosis totales y aquellos otros casos en los que la complicación pudiese atribuirse a causas extrínsecas a la arquitectura circulatoria del colgajo (p.e. lesión iatrogénica del pedículo durante la disección) Durante la revisión individualizada de cada intervención se observó que algunos colgajos presentaron problemas circulatorios, manifestándose como una congestión venosa severa que se resolvió mediante la realización de una segunda vena de drenaje del colgajo, anastomosando una vena epigástrica inferior superficial a la vena cefálica homolateral a la reconstrucción. Esta maniobra redujo e incluso previno en muchos casos la aparición de las complicaciones antes descritas y por este motivo también se incluyeron estos casos dentro de esta categoría. El objetivo último de agrupar aquellos casos con problemas de perfusión del colgajo fue hacer una comparación con diferentes variables relacionadas con las características del vaso perforante y la trama circulatoria del colgajo, para ayudar a esclarecer que cualidades de éste se asocian a mayor riesgo de complicaciones de origen vascular en la reconstrucción.

\subsection{Intervenciones de simetrización y reconstrucción del CAP}

\section{Número de intervenciones quirúrgicas adicionales a la reconstrucción}

Incluyeron tanto la mama contralateral, como correcciones en la mama reconstruida y la creación de un nuevo complejo areola-pezón.

\section{Simetrización de la mama contralateral}

Se reflejaron las siguientes variables:

- Realización de cirugía de simetrización contralateral. 
- Tipo de cirugía: reducción mamaria, mastopexia o reconstrucción mamaria.

- En el caso de la reducción mamaria se registraron las siguientes técnicas:

1. Pedículo inferior.

2. Pedículo superomedial.

3. Pedículo superior.

4. Mckissock.

5. Thorek.

6. Ribeiro (pedículo superomedial con autoprótesis).

- En el caso de la mastopexia se emplearon los siguientes procedimientos:

1. Pedículo inferior.

2. Ribeiro (pedículo superomedial con autoprótesis).

3. Pedículo superior.

4. Pexia periareolar.

- Las técnicas empleadas en las reconstrucciones mamarias fueron:

1. Prótesis.

2. Colgajo de dorsal ancho.

3. Colgajo DIEP.

4. Colgajo perforante de femoral profunda (PAP).

\section{Actuaciones sobre la mama reconstruida}

Se registraron las siguientes intervenciones: lipoaspiración del colgajo, lipoinfiltración del colgajo con el volumen transferido, remodelado del colgajo y reconstrucción del complejo areola-pezón. 


\section{ANÁLISIS ESTADÍSTICO}

Las técnicas estadísticas aplicadas dependen del tipo de variable analizada y de los objetivos perseguidos. En cualquier estudio estadístico, el primer paso se centra en el cálculo de los denominados estadísticos unidimensionales que permiten analizar de manera individual cada variable. Posteriormente, se pueden aplicar otras técnicas estadísticas con el fin de identificar la existencia o no de relaciones entre las variables dos a dos, variables que se irán cruzando según los objetivos de la investigación.

De manera muy breve, describimos las técnicas estadísticas aplicadas en este trabajo, distinguiendo entre variables cuantitativas y variables cualitativas.

\section{Variables cuantitativas:}

El análisis de estas variables comienza con el cálculo de la media aritmética y de la desviación típica. También en algunos casos es interesante analizar el rango o recorrido de las mismas, así como sus valores mínimo y máximo. En algunos casos se ha incluido algún gráfico, como el diagrama de barras o el histograma.

En un segundo paso, se ha analizado el comportamiento de las variables cuantitativas frente a los diferentes niveles (grupos o categorías) de otras variables (factor), siendo el objetivo establecer si hay o no diferencias estadísticamente significativas entre la media aritmética de la variable por cada nivel del factor.

La técnica apropiada para este fin es el Análisis de la varianza (ANOVA), basado en el valor del estadístico $F$ de Snedecor. Dado que se trata de una técnica paramétrica, se requiere el cumplimiento de ciertos requisitos estadísticos: normalidad de los datos e igualdad de varianzas entre los niveles (grupos) evaluados. Sin embargo, en caso de grupos muy desiguales en los que se sospeche el incumplimiento de estos requisitos, es preferible sustituir el estadístico $F$ y emplear otro, como la prueba robusta de Welch. 
Sea la $F$ de Snedecor o la prueba de Welch., si el valor $p$ ( $p$-value) asociado al estadístico obtenido es inferior a 0,05 , significa que hay evidencia estadística de que las medias aritméticas son diferentes entre los niveles. Es decir, la diferencia de medias aritméticas observadas no se debe al azar. Si la diferencia de medias ha resultado ser estadísticamente significativa, el siguiente paso es evaluar de manera más concreta la influencia de la variable cuantitativa sobre un nivel concreto del factor. Para ello, se aplica la técnica estadística denominada Regresión Logística. Esta técnica permite obtener un coeficiente para la variable cuantitativa que se denomina odds ratio. Cuando este valor es superior a 1, la variable analizada es un riesgo: por cada incremento unitario de la variable cuantitativa el riesgo de alcanzar el nivel del factor aumenta en un porcentaje (odds-1) $\times 100$.

Variables cualitativas:

El primer paso del análisis fue el cálculo de estadísticos unidimensionales, lo que permitió analizar de manera descriptiva cada variable. En este caso, es de gran interés el análisis detallado del recuento y de los porcentajes que forman la tabla de datos. Se incluyeron diagramas de barras para completar la descripción.

Cuando se estudiaron dos variables cualitativas $(X$ e $Y$ ), el objetivo fue analizar la existencia o no de relación entre ellas. Los datos se ordenaron en una tabla de contingencia, donde las filas fueron las modalidades de $X$ ( $k$ filas) y las columnas las modalidades de $Y$ ( $q$ columnas). La tabla resultante tuvo una dimensión $k \times q$ y cada celda expresó el número de individuos que pertenecían simultáneamente a la modalidad $i$ de la variable $X$ y a la modalidad $j$ de la variable $Y$.

Se utilizaron diagramas de barras para representar la información de la tabla e identificar asociaciones entre las categorías de ambas variables. El cálculo del estadístico Chi-cuadrado de Pearson permitió evaluar esas relaciones: cuando el valor $p$ ( $p$-value) obtenido fue inferior a 0,05 las asociaciones se consideraron estadísticamente significativas y no se debieron únicamente al azar. Sin embargo, si la tabla de contingencia fue de una 
dimensión $2 \times 2$ y alguna celda presentó pocos efectivos, se ajustó el valor $p$ obtenido, aplicando el test exacto de Fisher y evaluando el nuevo $p$ con el mismo criterio.

Todos los análisis fueron realizados empleando el programa IBM Statistical Package for Social Sciences (SPSS®, ver. 21.0; SPSS Inc. Chicago, IL, USA). 
RESULTADOS 



\section{DESCRIPCIÓN DE LA MUESTRA}

En el periodo comprendido entre noviembre de 2009 y diciembre de 2014 fueron intervenidas por el Servicio de Cirugía Plástica del CAULE un total de 62 pacientes a las que se le realizó una reconstrucción mamaria utilizando colgajos libres de perforantes abdominales.

Para la realización de este trabajo se utilizó esta población, incluyéndose finalmente 60 pacientes en la muestra, sobre las que se realizó en total 61 reconstrucciones mamarias con colgajo DIEP. En una paciente se practicó una reconstrucción bilateral diferida, empleándose un colgajo DIEP de cada lado del abdomen para reconstruir cada una de las mamas en el mismo tiempo quirúrgico.

Dos pacientes excluidas del estudio. La primera exclusión fue debida a que durante la intervención se hizo un cambio de indicación de colgajo DIEP a colgajo SIEA al presentar unos vasos epigástricos inferiores superficiales de calibre y longitud adecuadas para realizar la microanastomosis, lo que imposibilitó el estudio de los factores circulatorios relacionados con el colgajo DIEP. La segunda paciente fue excluida por no disponer del estudio angio TC preoperatorio al ausentarse el día que se le citó para realizar el mapeo de perforantes. La intervención se practicó únicamente con el apoyo del doppler portátil, siendo imposible valorar las características circulatorias del colgajo para este estudio.

Todos las reconstrucciones se realizaron de manera diferida, salvo en 5 casos en las que la reconstrucción se practicó de forma inmediata tras la mastectomía. La indicación quirúrgica de estas pacientes fue en 4 casos por diagnóstico de cáncer de mama mientras que la otra restante fue para reconstruir una mastectomía reductora de riesgo. Del total de 56 reconstrucciones mamarias diferidas, 14 habían tenido un intento reconstructivo anterior fallido, con expansor, prótesis o colgajo de dorsal ancho. 


\section{ANÁLISIS DE LAS COMPLICACIONES}

\subsection{Descripción de las complicaciones}

En nuestro estudio se constató algún tipo de complicación en 34 reconstrucciones mamarias $(55,7 \%)$ considerándose una cifra relativamente alta. Sin embargo, tras un análisis minucioso, se consideró la reconstrucción como exitosa cuando no hubo una necrosis total o parcial del colgajo, situación que ocurrió en 56 casos $(91,8 \%)$. El resto de las complicaciones fueron en la mayoría menores y no comprometieron el resultado ni dejaron secuelas, implicando un aumento del tiempo de ingreso o bien precisando una intervención quirúrgica menor para solucionar la complicación .

Clasificándose por zonas, 18 reconstrucciones mamarias (29,5\%) presentaron complicaciones sobre el colgajo (tabla 9), apareciendo 2 complicaciones en 2 de estos casos $(3,3 \%)$ y 1 en el resto $(26,2 \%)$.

En 3 pacientes (4,9\%) se produjo una necrosis total del colgajo En 2 casos el origen fue la trombosis arterial del pedículo por vasoespasmos repetidos tras la anastomosis, con pérdida completa del colgajo por un fenómeno de no-reflow, mientras que en el otro caso la causa fue una tracción importante del pedículo con lesión intimal en el momento de la autonomización y tras un test de perfusión positivo de tal modo que no hubo reperfusión del colgajo tras la anastomosis.

En 2 casos $(3,3 \%)$ se produjo una necrosis parcial del colgajo a consecuencia de una congestión venosa severa que dio lugar a una pérdida del colgajo del $70 \%$ y $30 \%$ respectivamente (fig. 47).

En 8 reconstrucciones $(13,1 \%)$ apareció alguna zona de necrosis grasa en el interior del colgajo, relacionada con una peor perfusión local en esa zona del colgajo.

En 3 casos apareció un hematoma (4,9\%) y 2 casos una infección localizada. En 4 casos $(6,6 \%)$ se observó pequeñas dehiscencias del colgajo, teniendo origen esta 
complicación a consecuencia de una de las tres anteriores, como vía de drenaje de la necrosis grasa, el hematoma o la infección.

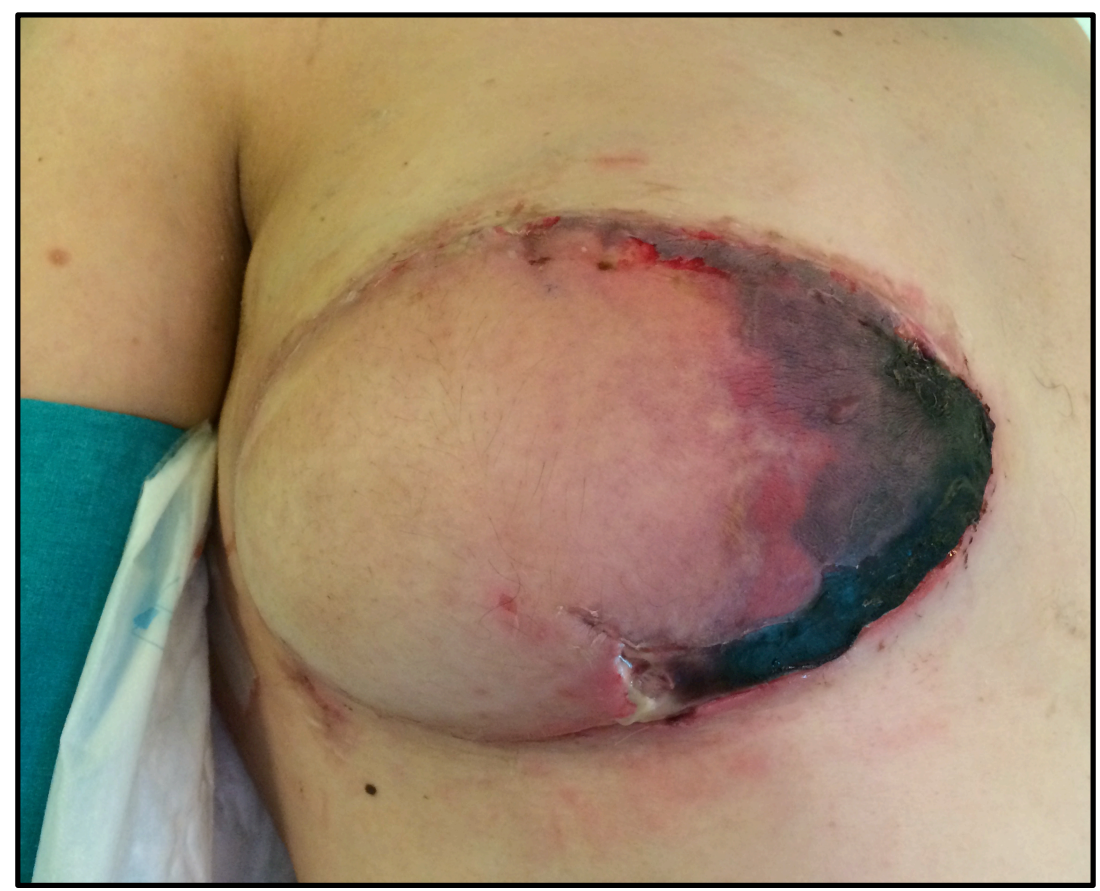

Figura 47: Necrosis parcial del colgajo por congestión venosa

En la zona donante abdominal surgieron complicaciones en 21 casos $(34,4 \%)$, todas ellas con 1 única complicación salvo en 3 casos los que hubo 2 complicaciones (tabla 9). En 9 casos $(14,7 \%)$ se produjo una dehiscencia en el cierre, en 7 casos $(11,5 \%)$ apareció un seroma tras la retirada de los drenajes, en 6 pacientes $(9,8 \%)$ se produjo un abultamiento de la pared abdominal y en 1 caso $(1,6 \%)$ se constato una hernia en el abdomen a consecuencia de la intervención.

En 6 casos $(9,8 \%)$ apareció cicatrices hipertróficas o queloides que precisaron tratamiento médico o revisión quirúrgica. El origen de estas complicación fue por un lado intrínseco a cada paciente, pero en ocasiones pudo haber otros factores implicados como la cura por segunda intención de una zona de dehiscencia cutánea o infección. Debido a que esta complicación no se suele considerar en la literatura, se ha registrado de manera separada a efectos comparativos. 
Hubo 2 complicaciones sistémicas. Una paciente sufrió un tromboembolismo pulmonar $(1,6 \%)$ y otra paciente presentó un neumotórax $(1,6 \%)$, resolviéndose ambos casos con tratamiento médico.

La baja frecuencia de aparición de algunas de estas complicaciones imposibilito buscar asociación con algunas de las variables estudiadas. Al analizar la aparición de necrosis grasa en función de diferentes parámetros siempre se excluyeron los casos de necrosis total o parcial del colgajo al no ser posible su estudio por definición.

\begin{tabular}{|c|c|c|}
\hline COMPLICACIÓN & $\begin{array}{c}\text { Frecuencia } \\
\quad(n=61)\end{array}$ & Porcentaje (\%) \\
\hline RECONSTRUCCIONES CON COMPLICACIONES & 34 & 55,7 \\
\hline COMPLICACIONES EN LA MAMA RECONSTRUIDA & 18 & 29,5 \\
\hline Necrosis total del colgajo & 3 & 4,9 \\
\hline Necrosis parcial del colgajo & 2 & 3,3 \\
\hline Necrosis grasa & 8 & 13,1 \\
\hline Dehiscencia pequeña de colgajo & 4 & 6,6 \\
\hline Hematoma & 3 & 4,9 \\
\hline Infección & 2 & 3,3 \\
\hline COMPLICACIONES EN EL ABDOMEN & 21 & 34,4 \\
\hline Dehiscencia del cierre cutáneo & 9 & 14,7 \\
\hline Seroma & 7 & 11,5 \\
\hline Abultamiento abdominal & 6 & 9,8 \\
\hline Hernia abdominal & 1 & 1,6 \\
\hline OTRAS & 7 & 11,5 \\
\hline Cicatrices patológicas & 6 & 9,8 \\
\hline Neumotórax & 1 & 1,6 \\
\hline Tromboembolismo pulmonar & 1 & 1,6 \\
\hline
\end{tabular}

Tabla 9: Frecuencia y porcentaje de las complicaciones 


\subsection{Problemas circulatorios del colgajo}

Se definió una variable denominada problemas circulatorios del colgajo que incluyó todos aquellos colgajos que presentaron una necrosis parcial del colgajo, una necrosis grasa o bien precisaron la realización de una segunda anastomosis venosa mediante una vena superficial del colgajo con la intención de prevenir cualquiera de las dos complicaciones anteriores. Los casos de necrosis total fueron excluidos al tener su origen en errores técnicos del procedimiento, como han postulado algunos autores(171). El objetivo de esta variable fue incluir aquellos colgajos que manifestaron algún tipo de problema circulatorio independiente de que se lograse su resolución o no mediante la realización de un segundo drenaje venoso, con la intención de buscar una relación de causalidad con diferentes características de la arquitectura circulatoria del colgajo.

Con el fin de evitar sesgos, fueron excluidas todas aquellas reconstrucciones en las que la causa de la complicación se pudiese explicar por causas extrínsecas a la trama vascular del colgajo y a las variables de los vasos perforantes y del pedículo vascular definidos.

En nuestro estudio se excluyeron un total de 7 reconstrucciones:

- El primer caso presentó una vena mamaria extremadamente fina en comparación con su arteria homónima con el antecedente de administración de RT. Aunque el colgajo presento un test de perfusión adecuado antes de su autonomización, tras la anastomosis se manifestó un problema de congestión venosa que no pudo resolverse con la anastomosis de una segunda vena epigástrica superficial al haberse lesionado durante su disección, terminando en una necrosis del 70\% del colgajo.

- El segundo caso fue debido a la formación de trombosis arteriales repetidas a nivel de la anastomosis, probablemente al lesionar la arteria mamaria interna durante su disección, con resultado de fracaso de la reconstrucción.

- En el tercer caso se produjeron trombosis repetidas a nivel de la anastomosis venosa, quedándose sin vasorreceptor tras varias suturas. Como método de salvamento se 
hizo una anastomosis al cabo opuesto de la vena mamaria interna, de modo que el retorno venoso se produjo a contraflujo. Aunque el colgajo sobrevivió totalmente, la aparición de una necrosis grasa hizo que excluyéramos este caso al no poder ponderar la influencia de la anastomosis venosa a flujo retrógrado en la complicación (fig. 48A).

- El cuarto caso fue excluido debido a la lesión de la vena epigástrica inferior profunda durante la disección del colgajo. La situación se resolvió haciendo un único drenaje venoso a partir de una vena epigástrica superficial del colgajo. La reconstrucción fue viable, apareciendo como única complicación la formación de un hematoma que se drenó mediante punción guiada por ecografía (fig. 48B).

- El quinto caso se desestimó por tracción del vaso perforante con lesión intimal durante la autonomización del colgajo con un test de perfusión previo favorable. No se consiguió la reperfusión del colgajo con necrosis del mismo tras realizarse una anastomosis permeable, por un fenómeno de no-reflow.

- El sexto caso se excluyó excluyó excluyó por presentar 2 venas mamarias internas extremadamente finas, con aparición de congestión tras la anastomosis de una de ellas. Se realizó la anastomosis de una vena circunfleja ilíaca superficial (muy lateral en el colgajo) a una vena toracodorsal, sin que esta resolviese el problema de retorno venoso. Se realizó una tercera anastomosis de la otra vena comitante epigástrica inferior profunda a la vena cefálica contralateral, lo que permitió salvar el colgajo sin la aparición de complicaciones en el postoperatorio (fig. 48C).

- El último caso excluido fue por trombosis repetidas a nivel de la anastomosis en una paciente en la que los vasorreceptores mamarios internos estaban extremadamente fibrosados y lábiles por la radioterapia. Tras varias espasmos con trombosis a nivel de la anastomosis que afectó a la AEIP, se consiguió revascularizar el colgajo utilizando la AEIS anastomosado a la arteria mamaria interna y la VEIP a la vena cefálica. Sin embargo un nuevo espasmo horas después, la formación de un hematoma y todo ello unido a que no se consideraron óptimos los vasos acromiotorácicos como nuevos receptores nos hizo desistir y retirar el colgajo. 

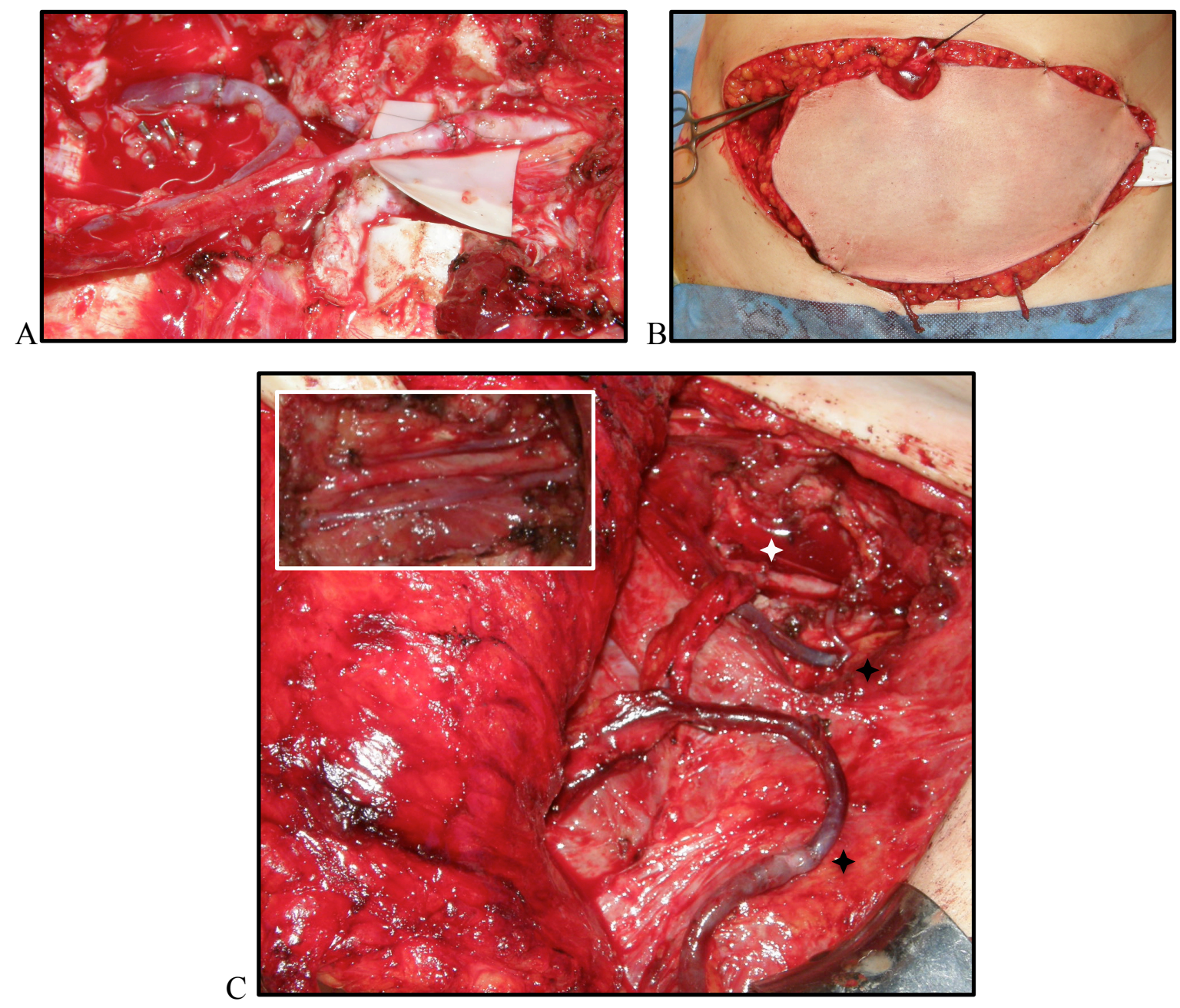

Figura 48: A: Caso 3. Anastomosis anterógrada del pedículo a la AMI y retrógrada a la VMI. B: Caso 4. Congestión severa del colgajo antes de su autonomización por lesión de la vena del pedículo. C: Caso $6^{\circ}$. Se observa un calibre muy fino de las VMI (arriba a la izquierda) en relación con la AMI. En la imagen se observan 2 anastomosis venosas (estrella negra) y 1 arterial (estrella blanca).

En total hubo 42 colgajos $(77,8 \%)$ que no presentaron problemas circulatorios frente a 12 casos $(22,2 \%)$ que si los presentaron (tabla 10). De estos doce casos, 6 presentaron una necrosis grasa en el colgajo de diferente consideración, en 4 casos se resolvió mediante la anastomosis de una segunda vena superficial, en 1 caso se produjo una necrosis parcial del colgajo y en otro caso apareció una necrosis grasa a pesar de la realización de una segunda anastomosis venosa. 


\begin{tabular}{lcc}
\hline PROBLEMA CIRCULATORIO & $\begin{array}{r}\text { Frecuencia } \\
(\mathbf{n = 5 4 )}\end{array}$ & $\begin{array}{c}\text { Porcentaje } \\
\mathbf{( \% )}\end{array}$ \\
\hline NO PROBLEMAS CIRCULATORIOS & $\mathbf{4 2}$ & $\mathbf{7 7 , 8}$ \\
SI PROBLEMAS CIRCULATORIOS & $\mathbf{1 2}$ & $\mathbf{2 2 , 2}$ \\
Necrosis parcial del colgajo & 1 & 1,8 \\
Necrosis grasa & 6 & 11,1 \\
Anastomosis de 2a vena superficial & 4 & 7,4 \\
Necrosis grasa $+2^{\text {a }}$ vena superficial & 1 & 1,8 \\
\hline
\end{tabular}

Tabla 10: Frecuencia y porcentaje de problemas circulatorios del colgajo.

\subsection{Reintervenciones}

En nuestro estudio, un total de 16 pacientes $(26,2 \%)$ precisaron de una intervención quirúrgica posterior para corregir algún tipo de complicación (tabla 11). En 4 ocasiones $(6,6 \%)$ la intervención pudo diferirse y asociarse a algún procedimiento de simetrización tiempo después, mientras que en las 12 pacientes restantes $(19,6 \%)$ se realizó durante el postoperatorio. Los procedimientos consistieron en el desbridamiento y cierre de zonas de dehiscencia cutánea, necrosis grasa, necrosis completa del colgajo o zonas infectadas, corrección de una eventración abdominal y la realización de una $2^{\mathrm{a}}$ vena por congestión del colgajo al cabo de pocas horas tras la finalización de la cirugía . En un caso se produjo una necrosis umbilical tras la reparación de una hernia umbilical en la cirugía de reconstrucción del DIEP, que fue visualizada de forma casual durante el estudio angio TC. 


\begin{tabular}{lcc}
\hline \multicolumn{1}{c}{ REINTERVENCIONES } & $\begin{array}{c}\text { Frecuencia } \\
(\mathbf{n = 6 1 )}\end{array}$ & $\begin{array}{c}\text { Porcentaje } \\
\mathbf{( \% )}\end{array}$ \\
\hline NO PRECISARON REINTERVENCIONES & $\mathbf{4 5}$ & $\mathbf{7 3 , 8}$ \\
\hline SI PRECISARON REINTERVENCIONES & $\mathbf{1 6}$ & $\mathbf{2 6 , 2}$ \\
En el postoperatorio inmediato (antes del alta) & 12 & 19,6 \\
En el postoperatorio tardío (después del alta) & 4 & 6,6 \\
& & \\
\hline MOTIVO DE LA REINTERVENCIÓN & $\mathbf{1 6}$ & $\mathbf{1 0 0}$ \\
Exéresis de necrosis grasa & 3 & 18,6 \\
Desbridamiento de colgajo por infección & 1 & 6,3 \\
Corrección de eventración abdominal & 1 & 6,3 \\
Cierre de dehiscencia abdominal & 4 & 25 \\
Cierre de dehiscencia del colgajo & 2 & 12,5 \\
Realización de una 2a vena en el post inmediato & 1 & 6,3 \\
Retirada del colgajo por necrosis & 4 & 25 \\
\hline
\end{tabular}

Tabla 11: Pacientes reintervenidos por complicaciones y motivo de la cirugía.

\subsection{Estancia hospitalaria}

El tiempo medio de estancia hospitalaria fue de 5,72 $\pm 2,543$ días (rango: 4-21 días) (tabla 12). En la tabla 13 se describen las frecuencias y porcentajes de las reconstrucciones distribuidas según el número de estancias.

\begin{tabular}{lr}
\hline \multicolumn{2}{c}{ ESTANCIA HOSPITALARIA } \\
\hline Media & 5,7213 \\
Desviación típica & 2,54382 \\
Rango & 17,00 \\
Mínimo & 4,00 \\
Máximo & 21,00 \\
\hline
\end{tabular}

Tabla 12: Estancia hospitalaria. 


\begin{tabular}{ccc}
\hline DíAS DE INGRESO & $\begin{array}{c}\text { Frecuencia } \\
\mathbf{N = 6 1}\end{array}$ & $\begin{array}{c}\text { Porcentaje } \\
(\%)\end{array}$ \\
\hline 4 & 12 & 19,7 \\
5 & 32 & 52,5 \\
6 & 6 & 9,8 \\
7 & 5 & 8,2 \\
8 & 1 & 1,6 \\
9 & 2 & 3,3 \\
11 & 1 & 1,6 \\
12 & 1 & 1,6 \\
21 & 1 & 1,6 \\
\hline
\end{tabular}

Tabla 13: Número de estancias tras la reconstrucción.

En nuestro estudio, la aparición de una necrosis total o parcial del colgajo aumentó el número de estancias de 5,30 $\pm 1,306$ días a 10,40 \pm 6,618 días. Debido a la baja frecuencia de esta variable, el resultado se ajustó con el test de Welch. Esta diferencia no llegó a ser significativa ( $\mathrm{p}$-value $=0,16$ ) aunque con un aumento de la muestra probablemente se alcanzase una significación estadística (tabla 14).

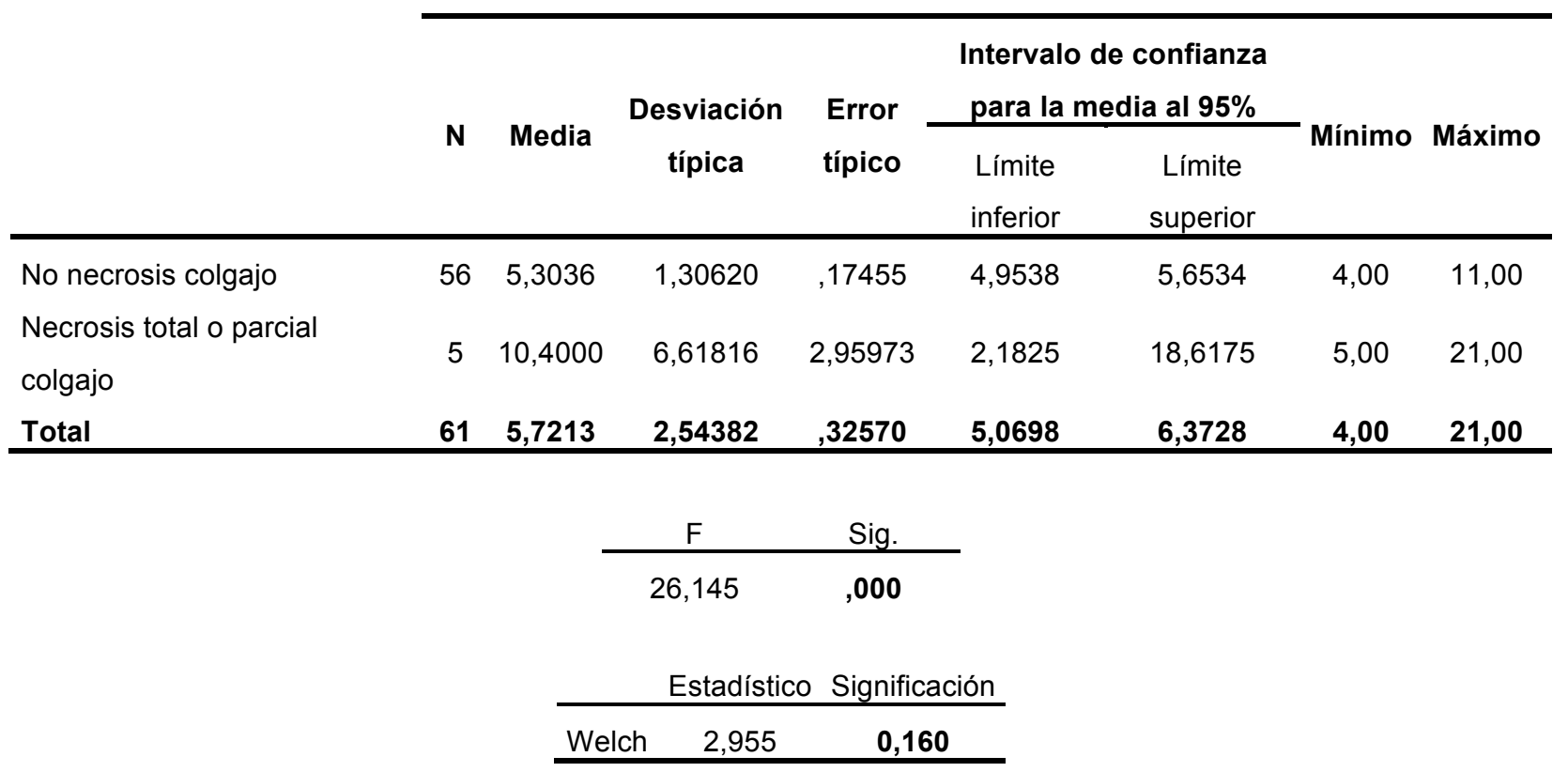

Tabla 14: Estancias en relación con la necrosis del colgajo 
En nuestro estudio tampoco se encontró significación estadística en el aumento en el número de estancias las pacientes que presentaron una necrosis grasa en el colgajo $(7,12 \pm$ $5,617$ días; $p$-value $=0,397)$ o una dehiscencia en el cierre abdominal $(6,77 \pm 5,356$ días; $\mathrm{p}$-value $=0,179)$. Las pacientes que presentaron una de estas dos complicaciones tuvieron una estancia media mayor, pero al tratarse de un grupo pequeño con una varianza grande serían necesarios más casos para poder demostrar una asociación estadística en el caso de que la hubiese (tablas 15 y 16).

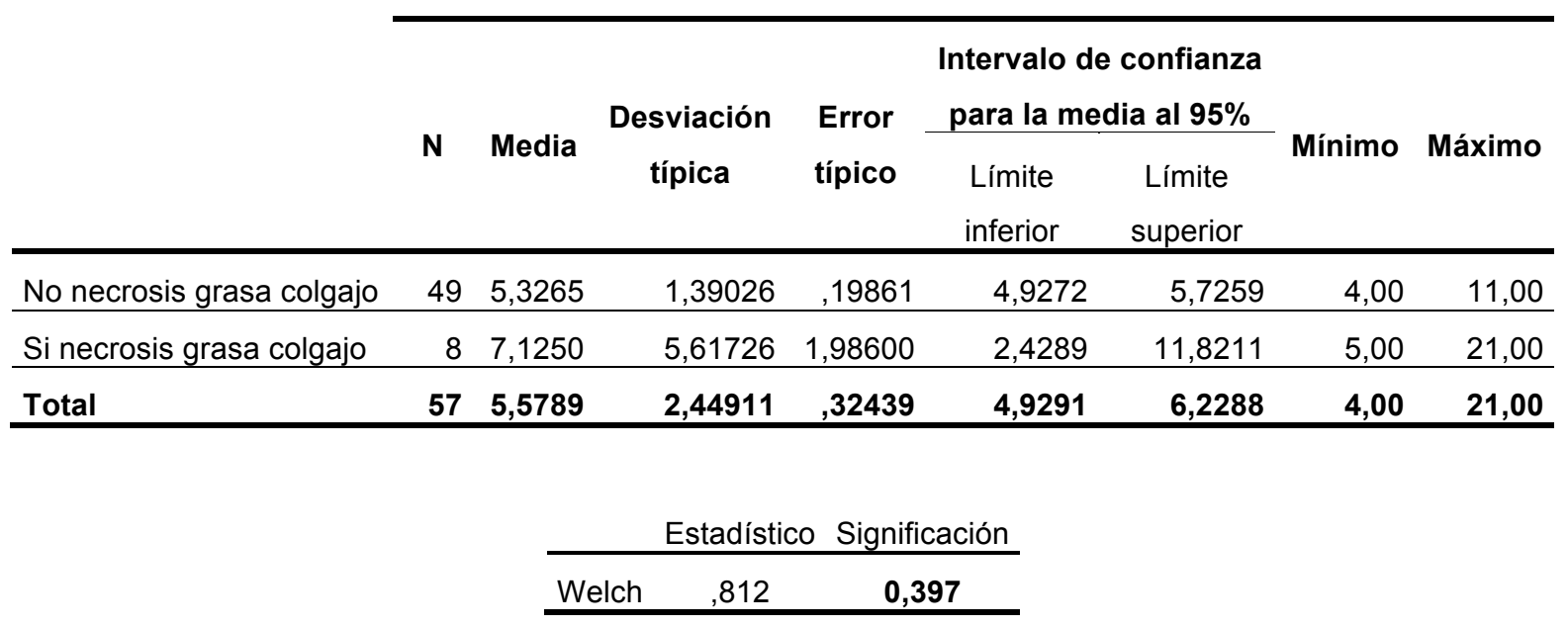

Tabla 15: Estancias en relación con la necrosis grasa del colgajo.

\begin{tabular}{|c|c|c|c|c|c|c|c|c|}
\hline & \\
\hline & \multirow{2}{*}{$\mathbf{N}$} & \multirow{2}{*}{ Media } & \multirow{2}{*}{$\begin{array}{l}\text { Desviación } \\
\text { típica }\end{array}$} & \multirow{2}{*}{$\begin{array}{l}\text { Error } \\
\text { típico }\end{array}$} & \multicolumn{2}{|c|}{$\begin{array}{l}\text { Intervalo de confianza } \\
\text { para la media al } 95 \%\end{array}$} & \multirow{2}{*}{ Mínimo } & \multirow{2}{*}{ Máximo } \\
\hline & & & & & $\begin{array}{l}\text { Límite } \\
\text { inferior }\end{array}$ & $\begin{array}{l}\text { Límite } \\
\text { superior }\end{array}$ & & \\
\hline $\begin{array}{l}\text { No Dehiscencia cutánea } \\
\text { abdomen }\end{array}$ & 52 & 5,5385 & 1,69731 & 23537 & 5,0659 & 6,0110 & 4,00 & 12,00 \\
\hline $\begin{array}{l}\text { Si Dehiscencia cutánea } \\
\text { abdomen }\end{array}$ & 9 & 6,7778 & 5,35672 & 1,78557 & 2,6602 & 10,8953 & 4,00 & 21,00 \\
\hline Total & 61 & 5,7213 & 2,54382 & 32570 & 5,0698 & 6,3728 & 4,00 & 21,00 \\
\hline & & & $\mathrm{F}$ & Sig. & & & & \\
\hline & & & 1,847 & 0,179 & & & & \\
\hline
\end{tabular}

Tabla 16: Estancias en relación con la dehiscencia cutánea abdominal. 
En el gráfico 1 se relacionan los días de estancia de cada paciente y el número de complicaciones presentadas en cada caso.

\section{Complicaciones y dias de estancia por paciente}

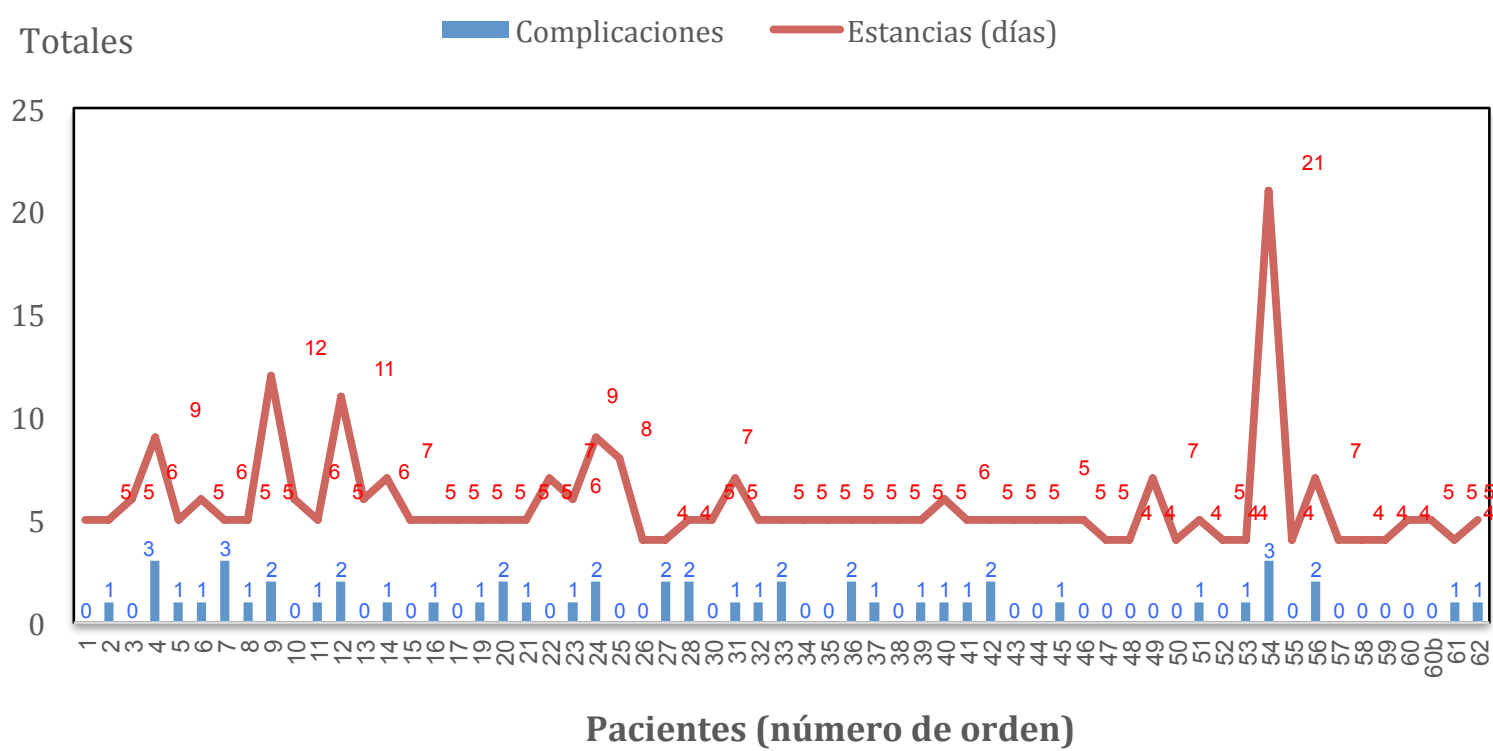

Gráfico 1: Número de complicaciones y días de estancia de las pacientes. 


\section{VARIABLES EPIDEMIOLÓGICAS Y FACTORES DE RIESGO CIRCULATORIO}

\subsection{Edad}

La edad media de las pacientes reconstruidas fue de 47,10 \pm 7,761. El rango de edad de las pacientes incluidas en el estudio osciló entre los 29 años y los 59 años (tabla 17 y gráfico 2).

\begin{tabular}{lcc}
\hline \multicolumn{1}{c}{ Total pacientes } & $\mathbf{6 0}$ \\
\hline Media & 47,10 \\
Mediana & 48,50 \\
Desviación Típica & 7,761 \\
Mínimo & 29 \\
Máximo & & 59 \\
& 25 & 43,25 \\
Percentiles & 50 & 48,50 \\
& 75 & 53,00 \\
\hline
\end{tabular}

Tabla 17: Edad de las pacientes

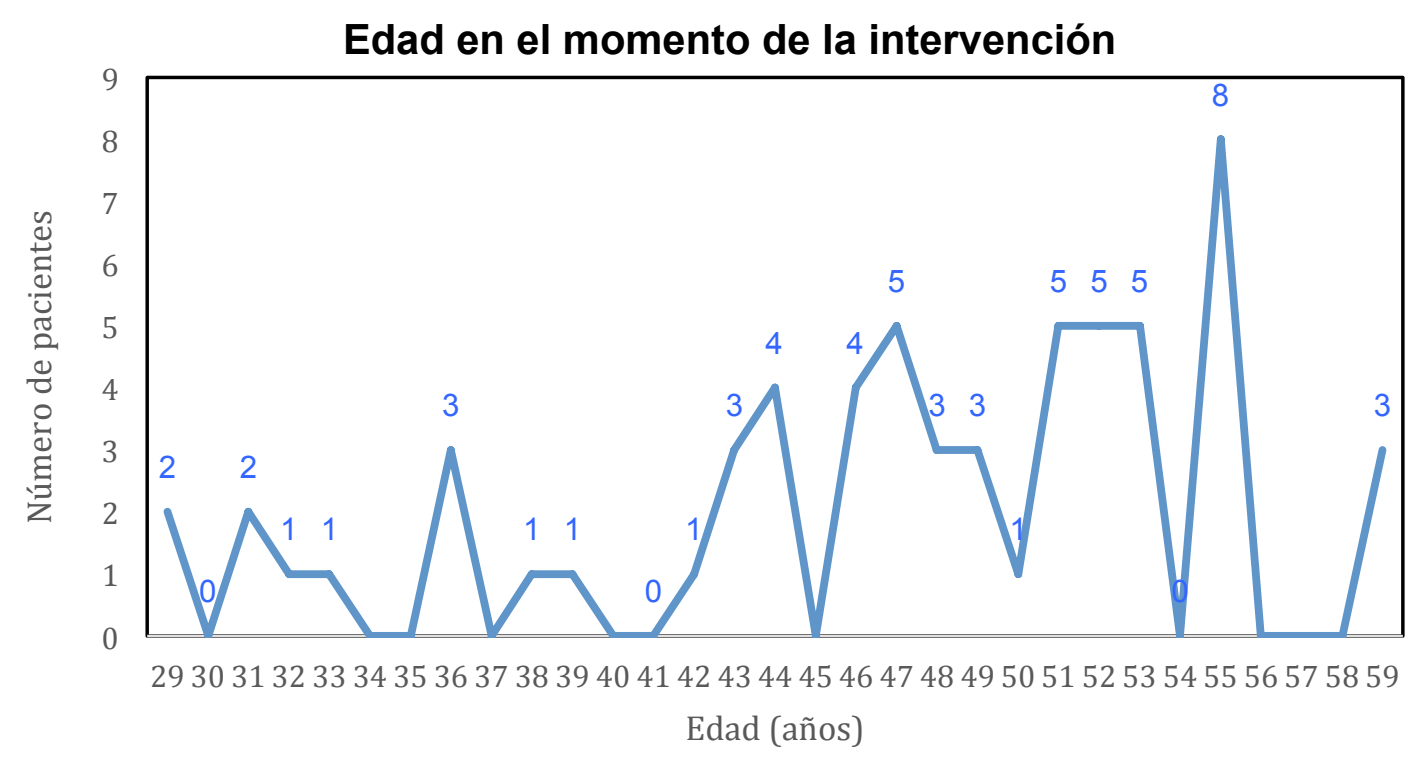

Gráfico 2: Edad de las pacientes en el momento de la reconstrucción mamaria. 
No se encontró una relación estadísticamente significativa entre la edad de las pacientes y la aparición de complicaciones $(\mathrm{p}$-value $=0.617$ ). No se estudiaron relaciones de causalidad con otras variables de acuerdo con la literatura existente ya que existen otros factores de más peso que la edad en la aparición de complicaciones (tabla 18).

\begin{tabular}{|c|c|c|c|c|c|c|c|c|}
\hline & \multirow{2}{*}{$\mathbf{N}$} & \multirow{2}{*}{ Media } & \multirow{2}{*}{$\begin{array}{c}\text { Desviación } \\
\text { típica }\end{array}$} & \multirow{2}{*}{$\begin{array}{l}\text { Error } \\
\text { típico }\end{array}$} & \multicolumn{2}{|c|}{$\begin{array}{l}\text { Intervalo de confianza } \\
\text { para la media al } 95 \%\end{array}$} & \multirow{2}{*}{ Mínimo } & \multirow{2}{*}{ Máximo } \\
\hline & & & & & $\begin{array}{l}\text { Límite } \\
\text { inferior }\end{array}$ & $\begin{array}{l}\text { Límite } \\
\text { superior }\end{array}$ & & \\
\hline No Complicaciones & 27 & 46,5556 & 6,87992 & 1,32404 & 43,8339 & 49,2772 & 31,00 & 55,00 \\
\hline Si complicaciones & 34 & 47,5588 & 8,36367 & 1,43436 & 44,6406 & 50,4770 & 29,00 & 59,00 \\
\hline \multirow[t]{3}{*}{ Total } & 61 & 47,1148 & 7,69653 & ,98544 & 45,1436 & 49,0859 & 29,00 & 59,00 \\
\hline & & & $\mathrm{F}$ & Sig. & & & & \\
\hline & & & ,253 & ,617 & & & & \\
\hline
\end{tabular}

Tabla 18: Distribución de la edad en función de las complicaciones.

\section{2. Índice de masa corporal}

Con respecto al índice de masa corporal, la media fue $25,49 \pm 3,21$. El rango del IMC osciló entre el 20,9 y el 35,5 (tabla 19).

\begin{tabular}{lcc}
\hline \multicolumn{1}{c}{ Total pacientes } & $\mathbf{6 0}$ \\
\hline Media & 25,495 \\
Mediana & 25,250 \\
Desviación Típica & 3,2125 \\
Mínimo & 20,9 \\
Máximo & & 35,5 \\
& 25 & 22,750 \\
Percentiles & 50 & 25,250 \\
& 75 & 27,650 \\
\hline
\end{tabular}

Tabla 19: Índice de masa corporal. 
En nuestro estudio no se observó una relación estadísticamente significativa entre el IMC y la aparición de una dehiscencia del cierre abdominal ( $\mathrm{p}$-value $=0,590$ ), un seroma $(p$-value $=0,289)$ o un abultamiento abdominal $(p$-value $=0,394)($ tablas 20-22)

\begin{tabular}{|c|c|c|c|c|c|c|c|c|}
\hline & \multirow{2}{*}{$\mathbf{N}$} & \multirow{2}{*}{ Media } & \multirow{2}{*}{$\begin{array}{l}\text { Desviación } \\
\text { típica }\end{array}$} & \multirow{2}{*}{$\begin{array}{l}\text { Error } \\
\text { típico }\end{array}$} & \multicolumn{2}{|c|}{$\begin{array}{l}\text { Intervalo de confianza } \\
\text { para la media al } 95 \%\end{array}$} & \multirow{2}{*}{ Mínimo } & \multirow{2}{*}{ Máximo } \\
\hline & & & & & $\begin{array}{l}\text { Límite } \\
\text { inferior }\end{array}$ & $\begin{array}{l}\text { Limite } \\
\text { superior }\end{array}$ & & \\
\hline No dehiscencia abdomen & 51 & 25,400 & 3,1802 & ,4453 & 24,506 & 26,294 & 20,9 & 35,5 \\
\hline Si dehiscencia abdomen & 9 & 26,033 & 3,5380 & 1,1793 & 23,314 & 28,753 & 21,3 & 33,3 \\
\hline Total & 60 & 25,495 & 3,2125 & ,4147 & 24,665 & 26,325 & 20,9 & 35,5 \\
\hline & & & $\mathrm{F}$ & Sig. & & & & \\
\hline & & & ,294 &, 590 & & & & \\
\hline
\end{tabular}

Tabla 20: Distribución del IMC en función de la dehiscencia abdominal.

\begin{tabular}{|c|c|c|c|c|c|c|c|c|}
\hline & \multirow{2}{*}{$\mathbf{N}$} & \multirow{2}{*}{ Media } & \multirow{2}{*}{$\begin{array}{c}\text { Desviación } \\
\text { típica }\end{array}$} & \multirow{2}{*}{$\begin{array}{l}\text { Error } \\
\text { típico }\end{array}$} & \multicolumn{2}{|c|}{$\begin{array}{c}\text { Intervalo de confianza } \\
\text { para la media al } 95 \%\end{array}$} & \multirow{2}{*}{ Mínimo } & \multirow{2}{*}{ Máximo } \\
\hline & & & & & $\begin{array}{l}\text { Límite } \\
\text { inferior }\end{array}$ & $\begin{array}{c}\text { Límite } \\
\text { superior }\end{array}$ & & \\
\hline No seroma & 53 & 25,334 & 3,1771 & ,4364 & 24,458 & 26,210 & 20,9 & 35,5 \\
\hline Si seroma & 7 & 26,714 & 3,4696 & 1,3114 & 23,505 & 29,923 & 21,5 & 30,1 \\
\hline \multirow[t]{3}{*}{ Total } & 60 & 25,495 & 3,2125 &, 4147 & 24,665 & 26,325 & 20,9 & 35,5 \\
\hline & & & $\mathrm{F}$ & Sig. & & & & \\
\hline & & & 1,144 & ,289 & & & & \\
\hline
\end{tabular}

Tabla 21: Distribución del IMC en función de la aparición de seroma. 


\begin{tabular}{|c|c|c|c|c|c|c|c|c|}
\hline & \multirow[b]{2}{*}{$\mathbf{N}$} & \multirow{2}{*}{ Media } & \multirow{2}{*}{$\begin{array}{c}\text { Desviación } \\
\text { típica }\end{array}$} & \multirow{2}{*}{$\begin{array}{l}\text { Error } \\
\text { típico }\end{array}$} & \multicolumn{2}{|c|}{$\begin{array}{l}\text { Intervalo de confianza } \\
\text { para la media al } 95 \%\end{array}$} & \multirow{2}{*}{ Mínimo } & \multirow{2}{*}{ Máximo } \\
\hline & & & & & $\begin{array}{l}\text { Límite } \\
\text { inferior }\end{array}$ & $\begin{array}{l}\text { Límite } \\
\text { superior }\end{array}$ & & \\
\hline No abultamiento & 54 & 25,376 & 3,1828 & ,4331 & 24,507 & 26,245 & 20,9 & 35,5 \\
\hline Si abultamiento & 6 & 26,567 & 3,5870 & 1,4644 & 22,802 & 30,331 & 22,4 & 30,5 \\
\hline \multirow[t]{3}{*}{ Total } & 60 & 25,495 & 3,2125 & ,4147 & 24,665 & 26,325 & 20,9 & 35,5 \\
\hline & & & $\mathrm{F}$ & Sig. & & & & \\
\hline & & & 0,739 & 0,394 & & & & \\
\hline
\end{tabular}

Tabla 22: Distribución del IMC en función de la aparición de abultamiento abdominal.

\subsection{Factores de riesgo vascular}

De las pacientes intervenidas, 3 eran diabéticas $(5,0 \%), 7$ hipertensas $(11,7 \%)$ y 5 presentaban dislipemia $(8,3 \%)$. La baja frecuencia de estas variables imposibilitó estudiar su relación con las diferentes complicaciones descritas. En nuestra serie, 9 pacientes eran fumadoras activas en el momento de la intervención y 15 pacientes tenían cicatrices abdominales a consecuencia de una intervención previa. Se estudió la causalidad del tabaco y la cirugía abdominal frente a la aparición de diferentes complicaciones relacionadas (tabla 23 y gráfico 3).

En total 26 pacientes presentaron un único factor de riesgo, mientras que una paciente presentó dos (tabaquismo y cicatriz de apendicectomía), otra paciente tenía tres (hipertensión, dislipemia y tabaquismo activo) y dos tenían 4 factores de riesgo (diabetes, hipertensión, dislipemia y mientras que una era fumadora, la otra tenía cicatrices de laparoscopia). 


\begin{tabular}{lcc}
\hline FACTORES DE RIESGO CIRCULATORIO & $\begin{array}{c}\text { Frecuencia } \\
(\mathbf{n = 6 0})\end{array}$ & $\begin{array}{c}\text { Porcentaje } \\
(\mathbf{\%})\end{array}$ \\
\hline DIABETES MELLITUS & $\mathbf{3}$ & $\mathbf{5 , 0}$ \\
\hline HIPERTENSIÓN ARTERIAL & $\mathbf{7}$ & $\mathbf{1 1 , 7}$ \\
\hline DISLIPEMIA & $\mathbf{5}$ & \\
& $\mathbf{8 , 3}$ \\
ANTECEDENTE DE TABAQUISMO & $\mathbf{1 7}$ & $\mathbf{2 8 , 3}$ \\
Tabaquismo activo & 9 & 15 \\
Exfumadora & 8 & 13,3 \\
& & \\
CIRUGÍA ABDOMINAL & $\mathbf{1 5}$ & $\mathbf{2 5}$ \\
$\quad$ Apendicectomía & 4 & 6,7 \\
Phannenstiel (cesarea o histerectomía) & 6 & 10,0 \\
Laparoscopia & 3 & 5,0 \\
$\quad$ Laparotomía media & 2 & 3,3 \\
\hline
\end{tabular}

Tabla 23: Frecuencia y porcentaje de los factores de riesgo circulatorios.

\section{Complicaciones y factores de riesgo vascular}

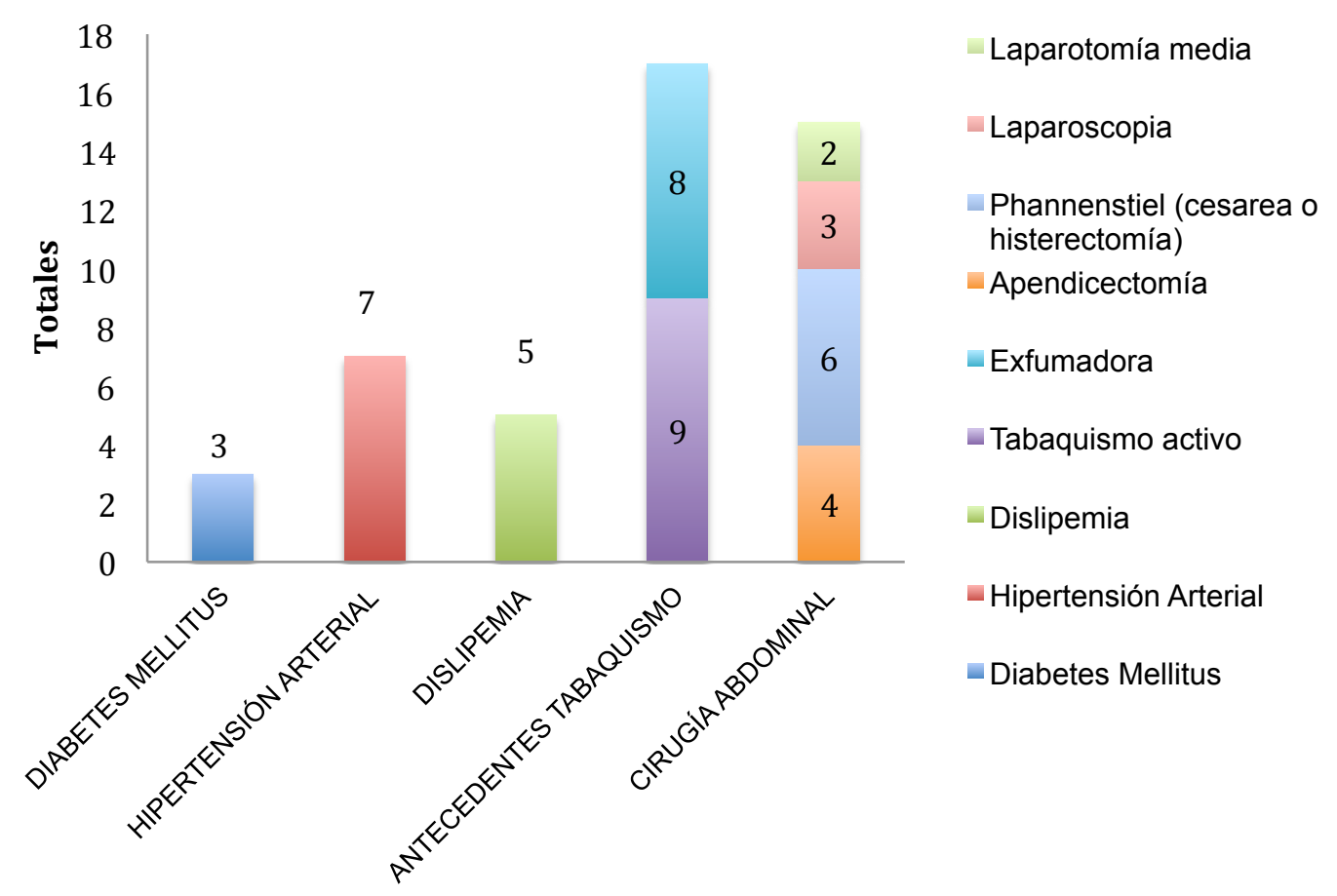

Gráfico 3: Complicaciones distribuidas según factores de riesgo vascular 


\section{Tabaquismo}

En el momento de la cirugía 9 pacientes eran fumadoras activas (15\%), a pesar de su compromiso de abandonar el hábito tabáquico en el momento de su inclusión en lista de espera, aunque todas relataron un descenso en su consumo. Hubo 8 pacientes que habían abandonado el hábito al menos un año antes de la realización de la intervención quirúrgica.

En nuestro estudio el tabaquismo activo en el momento de la cirugía mostró una asociación aunque no estadísticamente significativa con la aparición de dehiscencia del cierre abdominal ( $p$-value $=0,125)$ o de necrosis grasa $(p$-value $=0,108)$, El 33\% de las pacientes con tabaquismo activo presentaron estas complicaciones frente al 13,3\% y al 11,9\% respectivamente de las no fumadoras observándose una tendencia a la aparición de estas dos complicaciones, siendo aconsejable estudiar esta relación sobre una muestra más grande para alcanzar conclusiones más sólidas (tablas 24 y 25).

Aquellas pacientes fumadoras activas presentaron una asociación significativa con la aparición de problemas circulatorios en el colgajo ( $p$-value $=0,048)$ (tabla 26 y gráfico 4).

\begin{tabular}{|c|c|c|c|c|}
\hline & \multicolumn{3}{|c|}{ Necrosis grasa colgajo } & \multirow[b]{2}{*}{ Total } \\
\hline & $\begin{array}{c}\text { No necrosis grasa } \\
\text { colgajo }\end{array}$ & \multicolumn{2}{|c|}{$\begin{array}{c}\text { Sí necrosis grasa } \\
\text { colgajo }\end{array}$} & \\
\hline No fumadora & 42 & \multicolumn{2}{|c|}{5} & 47 \\
\hline Sí fumadora & 6 & \multicolumn{2}{|c|}{3} & 9 \\
\hline Total & 48 & \multicolumn{2}{|c|}{8} & 56 \\
\hline & Valor & gl & \multicolumn{2}{|c|}{$\begin{array}{l}\text { Sig. exacta } \\
\text { (bilateral) }\end{array}$} \\
\hline Chi-cuadrado de Pearson & 3,177 & 1 & & \\
\hline \multicolumn{2}{|c|}{ Estadístico exacto de Fisher } & \multicolumn{3}{|c|}{0,108} \\
\hline
\end{tabular}

Tabla 24: Aparición de necrosis grasa en función del consumo de tabaco. 


\begin{tabular}{lccc}
\cline { 2 - 3 } & \multicolumn{2}{c}{ Dehiscencia cutánea abdomen } & \multirow{2}{*}{ Total } \\
\cline { 2 - 3 } & No dehiscencia & Si dehiscencia & \\
\hline No fumadora & 45 & 6 & $\mathbf{5 1}$ \\
Sí fumadora & 6 & 3 & $\mathbf{9}$ \\
Total & $\mathbf{5 1}$ & $\mathbf{9}$ & $\mathbf{6 0}$ \\
\hline
\end{tabular}

\begin{tabular}{llll} 
& Valor & gl & $\begin{array}{c}\text { Sig. exacta } \\
\text { (bilateral) }\end{array}$ \\
\hline $\begin{array}{c}\text { Chi-cuadrado de Pearson } \\
\text { Estadístico exacto de Fisher }\end{array}$ & 2,791 & 1 & \\
\hline
\end{tabular}

Tabla 25: Distribución del antecedente de tabaquismo en función de la aparición de dehiscencia en el cierre abdominal

\begin{tabular}{lccc} 
& \multicolumn{2}{c}{ Problemas circulatorios del colgajo } & \multirow{2}{*}{ Total } \\
\cline { 2 - 3 } & No problemas & Sí problemas & \\
\hline No fumadora & 37 & 10 & 47 \\
Sí fumadora & 4 & 5 & $\mathbf{9}$ \\
Total & $\mathbf{4 1}$ & $\mathbf{1 5}$ & $\mathbf{5 6}$ \\
\hline
\end{tabular}

\begin{tabular}{cccc} 
& Valor & gl & $\begin{array}{c}\text { Sig. exacta } \\
\text { (bilateral) }\end{array}$ \\
\hline $\begin{array}{c}\text { Chi-cuadrado de Pearson } \\
\text { Estadístico exacto de Fisher }\end{array}$ & 4,526 & 1 & \\
\hline
\end{tabular}

Tabla 26: Distribución de los problemas circulatorios del colgajo en relación con el tabaquismo. 


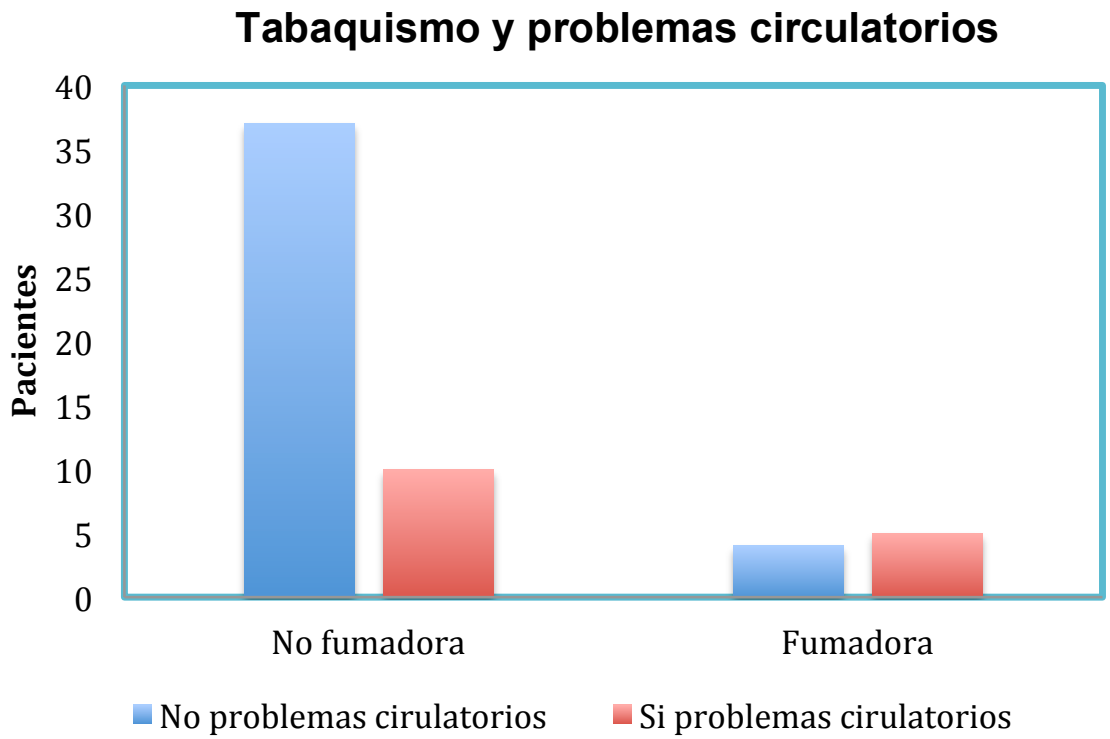

Gráfico 4: Relación entre tabaquismo y problemas circulatorios del colgajo.

\section{Cirugía abdominal}

El 25\% de las pacientes presentaban antecedentes de cirugía abdominal, de las cuales el 10\% $(n=6)$ tenían una cicatriz de Pfannenstiel por histerectomía o cesárea, el 6,7\% $(n=4)$ habían sufrido una apendicectomía, el 5\% $(\mathrm{n}=3)$ tenían pequeñas cicatrices de laparoscopia y el 3,3\% (n=2) habían tenido una laparotomía media (tabla 23).

Un antecedente de cirugía abdominal no supuso en nuestro estudio un factor de riesgo en la aparición de dehiscencia del cierre abdominal ( $p$-value $=0,858)$, en la formación de seroma ( $\mathrm{p}$-value $=0,178)$, en la aparición de debilidad con abultamiento de la pared abdominal $(\mathrm{p}$-value $=0,635)($ tablas 27-29).

\begin{tabular}{lccc}
\cline { 2 - 3 } & \multicolumn{2}{c}{ Dehiscencia cutánea abdomen } & \multirow{2}{*}{ Total } \\
\cline { 2 - 3 } & No dehiscencia & Si dehiscencia & \\
\hline No cirugía previa & 39 & 7 & $\mathbf{4 6}$ \\
Si cirugía previa & 13 & 2 & $\mathbf{1 5}$ \\
Total & $\mathbf{5 2}$ & $\mathbf{9}$ & $\mathbf{6 1}$ \\
\hline
\end{tabular}




\begin{tabular}{lccc} 
& Valor & gl & $\begin{array}{c}\text { Sig. asintótica } \\
\text { (bilateral) }\end{array}$ \\
\hline Chi-cuadrado de Pearson & 0,032 & 1 & $\mathbf{0 , 8 5 8}$ \\
\hline
\end{tabular}

Tabla 27: Distribución del antecedente de cirugías en función de la aparición de dehiscencia en el cierre abdominal

\begin{tabular}{lccc}
\cline { 2 - 3 } & \multicolumn{2}{c}{ Seroma } & \multirow{2}{*}{ Total } \\
\cline { 2 - 3 } & No Seroma & Si Seroma & \\
\hline No cirugía previa & 39 & 7 & 46 \\
Si cirugía previa & 15 & 0 & $\mathbf{1 5}$ \\
Total & $\mathbf{5 4}$ & $\mathbf{7}$ & $\mathbf{6 1}$ \\
\hline
\end{tabular}

\begin{tabular}{lccc} 
& Valor & gl & $\begin{array}{c}\text { Sig. exacta } \\
\text { (bilateral) }\end{array}$ \\
\hline $\begin{array}{l}\text { Chi-cuadrado de Pearson } \\
\text { Estadístico exacto de Fisher }\end{array}$ & 2,579 & 1 & \\
$\mathrm{~N}$ de casos válidos & 61 & & $\mathbf{0 , 1 7 8}$ \\
\hline
\end{tabular}

Tabla 28: Distribución del antecedente de cirugía en función de la formación de seroma

\begin{tabular}{lccc}
\cline { 2 - 3 } & \multicolumn{2}{c}{ Abultamiento (Bulging) } & \multirow{2}{*}{ Total } \\
\cline { 2 - 3 } & No abultamiento & Si abultamiento & \\
\hline No cirugía previa & 41 & 5 & 46 \\
Si cirugía previa & 14 & 1 & $\mathbf{1 5}$ \\
Total & $\mathbf{5 5}$ & $\mathbf{6}$ & $\mathbf{6 1}$ \\
\hline
\end{tabular}

\begin{tabular}{lccc} 
& Valor & gl & $\begin{array}{c}\text { Sig. asintótica } \\
\text { (bilateral) }\end{array}$ \\
\hline Chi-cuadrado de Pearson & 0,225 & 1 & $\mathbf{0 , 6 3 5}$ \\
\hline
\end{tabular}

Tabla 29: Distribución del antecedente de cirugía en función de la aparición de abultamiento abdominal. 
No se estudió la relación entre la aparición de hernias y el antecedente de cirugía previa al presentarse un único proceso en nuestra casuística. En este caso la paciente tenía el antecedente de una cirugía de apendicectomía y tuvo que ser intervenida con posterioridad a la reconstrucción para reparar la eventración. En este caso el colgajo se extrajo del lado contralateral al de la cicatriz de apendicectomía. Hubo otra paciente que presentaba una hernia umbilical en el momento de la reconstrucción, aprovechándose esta intervención para su reparación.

De las 12 reconstrucciones que presentaron problemas circulatorios en el colgajo, en 11 casos no presentaron cicatrices de cirugías abdominales mientras que una paciente con cicatriz de Pfannenstiel presentó esta complicación ( $\mathrm{p}$-value $=0,648)($ tablas 30 y 31).

\begin{tabular}{lccc} 
& \multicolumn{2}{c}{ Problemas circulatorios del colgajo } & \multirow{2}{*}{ Total } \\
\cline { 2 - 3 } & No problemas & Si problemas & \\
\hline No & 29 & 11 & 39 \\
Apendicectomía & 4 & 0 & 4 \\
Pfannenstiel & 4 & 1 & 5 \\
Laparoscopia & 3 & 0 & 3 \\
Laparotomía media & 2 & 0 & 2 \\
Total & $\mathbf{4 2}$ & $\mathbf{1 2}$ & $\mathbf{5 4}$ \\
\hline
\end{tabular}

Tabla 30: Distribución de los problemas circulatorios del colgajo en función del tipo de cirugía.

\begin{tabular}{lccc} 
& \multicolumn{2}{c}{ Problemas circulatorios del colgajo } & \multirow{2}{*}{ Total } \\
\cline { 2 - 3 } & No problemas & Si problemas & \\
\hline No Pfannenstiel & 38 & 11 & 49 \\
Si Pfannenstiel & 4 & 1 & 5 \\
Total & $\mathbf{4 2}$ & $\mathbf{1 2}$ & $\mathbf{5 4}$ \\
\hline
\end{tabular}

\begin{tabular}{cccc} 
& Valor & gl & $\begin{array}{c}\text { Sig. exacta } \\
\text { (bilateral) }\end{array}$ \\
\hline $\begin{array}{c}\text { Chi-cuadrado de Pearson } \\
\text { Estadístico exacto de Fisher }\end{array}$ &, 170 & 1 & \\
\hline
\end{tabular}

Tabla 31: Distribución de los problemas circulatorios en función de una cicatriz de Pfannenstiel. 


\section{VARIABLES RELACIONADAS CON EL CÁNCER DE MAMA}

\subsection{Histología}

Con respecto al estudio anatomo-patólogo de la pieza de mastectomía, 6 casos $(9,8 \%)$ presentaban un carcinoma ductal in situ, en 29 piezas (47,5\%) el diagnóstico fue de carcinoma ductal infiltrante, mientras que en 21 casos $(34,4 \%)$ combinaron ambos tipos de variedad histológica en la pieza. En 4 estudios $(6,5)$ el resultado fue de carcinoma lobulillar infiltrante. Por ultimo, en la paciente a la que se realizó la mastectomía reductora de riesgo el resultado fue negativo para malignidad (1,6\%) (gráfico 5).

\section{Histología}

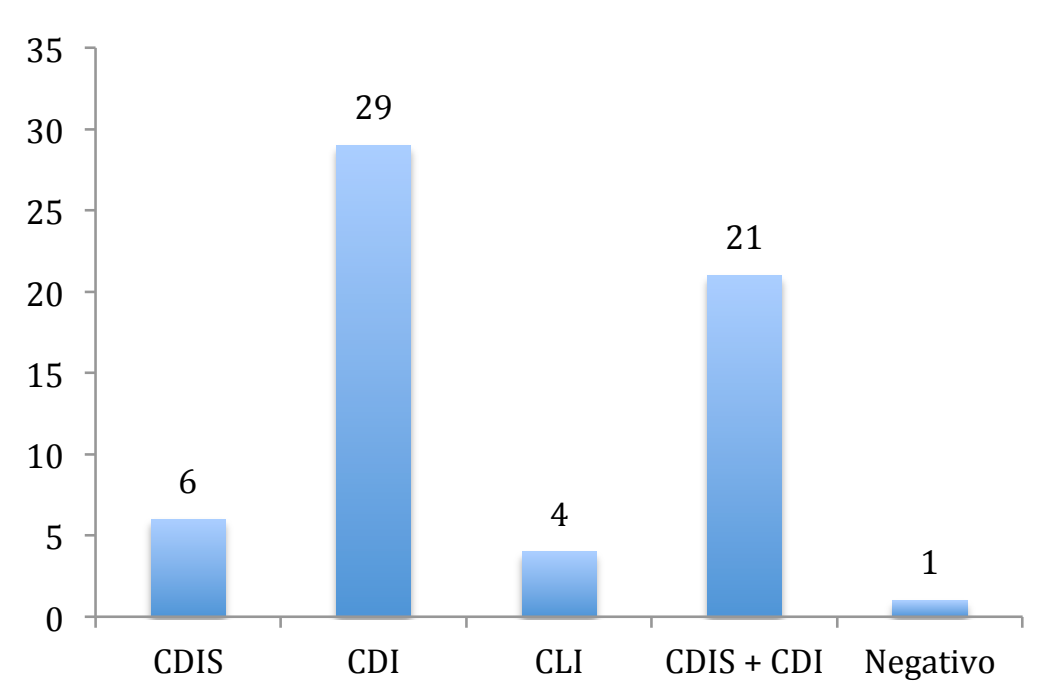

Gráfico 5: Distribución según el tipo histológico en el estudio de la mastectomía.

\subsection{Biopsia selectiva de ganglio centinela}

Se practicó una BSGC en 22 de las 61 mastectomías realizadas (36,1\%), ofreciendo un resultado positivo para macrometástasis en 7 casos, positivo para micrometástasis en 4 casos y negativo en 11 casos (tabla 32). 


\begin{tabular}{lcc}
\hline BIOPSIA DE GANGLIO CENTINELA & $\begin{array}{c}\text { Frecuencia } \\
(\mathbf{n = 6 1 )}\end{array}$ & $\begin{array}{c}\text { Porcentaje } \\
\mathbf{( \% )}\end{array}$ \\
\hline No BSGC & $\mathbf{3 9}$ & $\mathbf{6 3 , 9}$ \\
\hline BSGC & 22 & $\mathbf{3 6 , 1}$ \\
Negativo & 7 & 11,5 \\
Positivo para macrometástasis & 11 & 18,0 \\
Positivo para micrometástasis & 4 & 6,6 \\
\hline
\end{tabular}

Tabla 32: Frecuencia y porcentaje de BSGC

\subsection{Linfadenectomía axilar}

De las 61 mastectomías realizadas, en 45 casos $(73,8 \%)$ se practicó una linfadenectomía axilar mientras que en los 16 restantes $(26,2 \%)$ no fue indicada (tabla 33$)$. Cuando se realizó la linfadenectomía axilar, en 23 casos no hubo ningún ganglio afecto, 6 disecciones presentaron un ganglio afecto, en 5 casos se hallaron 2 ganglios enfermos y 11 casos presentaban 3 o más ganglios positivos.

\begin{tabular}{c|ccc}
\hline \multicolumn{2}{c}{ LINFADENECTOMíA } & $\begin{array}{c}\text { Frecuencia } \\
(\mathbf{n = 6 1 )}\end{array}$ & $\begin{array}{c}\text { Porcentaje } \\
\mathbf{( \% )}\end{array}$ \\
\hline \multicolumn{2}{l}{ No linfadenectomía } & $\mathbf{1 6}$ & $\mathbf{2 6 , 2}$ \\
\multicolumn{2}{l}{ Sí linfadenectomía } & & \\
Ganglios & 0 & $\mathbf{4 5}$ & $\mathbf{7 3 , 8}$ \\
afectos & 1 & 6 & 37,7 \\
& 2 & 5 & 9,9 \\
& 3 o más & 11 & 8,2 \\
\hline
\end{tabular}

Tabla 33: Linfadenectomías axilares realizadas y número de ganglios afectos. 


\subsection{Radioterapia}

En 34 casos $(55,7 \%)$ se indicó tratamiento con radioterapia tras la mastectomía lo que supuso encontrarse un lecho previamente radiado. En un caso $(1,6 \%)$ la radioterapia se aplicó después de la reconstrucción tras haberse practicado ésta de manera inmediata (tabla $34)$.

\begin{tabular}{lcc}
\hline \multicolumn{1}{c}{ RADIOTERAPIA } & $\begin{array}{c}\text { Frecuencia } \\
(\mathbf{n = 6 1 )}\end{array}$ & Porcentaje (\%) \\
\hline No RT & 26 & 42,6 \\
Sí RT & 34 & 55,8 \\
RT después de la RM & 1 & 1,6 \\
\hline
\end{tabular}

Tabla 34: Frecuencia y porcentaje de pacientes que han recibido radioterapia.

No se observó una relación significativa entre la aplicación de radioterapia y la aparición de necrosis grasa en la reconstrucción $(p$-value $=0,741)$, ni en la necesidad de realizar un drenaje venoso adicional ( $\mathrm{p}$-value $=0,448$ ), lo que habla a favor de que un lecho local radiado no interfiere en la reconstrucción (tablas 35 y 36).

\begin{tabular}{lccc}
\cline { 2 - 3 } & \multicolumn{2}{c}{ Necrosis grasa colgajo } & \\
\cline { 2 - 3 } & $\begin{array}{c}\text { No necrosis grasa } \\
\text { colgajo }\end{array}$ & $\begin{array}{c}\text { Si necrosis grasa } \\
\text { colgajo }\end{array}$ & Total \\
\hline No RT previa & 21 & 3 & $\mathbf{2 4}$ \\
Sí RT previa & 27 & 5 & $\mathbf{3 2}$ \\
Total & $\mathbf{4 8}$ & $\mathbf{8}$ & $\mathbf{5 6}$ \\
\hline
\end{tabular}

\begin{tabular}{lccc} 
& Valor & gl & $\begin{array}{c}\text { Sig. asintótica } \\
\text { (bilateral) }\end{array}$ \\
\hline Chi-cuadrado de Pearson & 3,177 & 1 & $\mathbf{0 , 7 4 1}$ \\
\hline
\end{tabular}

Tabla 35: Distribución de la RT en función de la aparición de necrosis grasa en el colgajo. 


\begin{tabular}{lccc}
\cline { 2 - 3 } & \multicolumn{2}{c}{$\mathbf{2}^{\mathbf{a}}$ vena } & \multirow{2}{*}{ Total } \\
\cline { 2 - 3 } & No segunda vena & Si segunda vena & \\
\hline No RT previa & 21 & 6 & $\mathbf{2 7}$ \\
Sí RT previa & 29 & 5 & 34 \\
Total & $\mathbf{5 0}$ & $\mathbf{1 1}$ & $\mathbf{6 1}$ \\
\hline
\end{tabular}

\begin{tabular}{lccc} 
& Valor & gl & $\begin{array}{c}\text { Sig. asintótica } \\
\text { (bilateral) }\end{array}$ \\
\hline Chi-cuadrado de Pearson & 0,575 & 1 & $\mathbf{0 , 4 4 8}$ \\
\hline
\end{tabular}

Tabla 36: Distribución de la RT en función de la realización de una $2^{\mathrm{a}}$ anastomosis venosa.

En nuestro estudio no hubo una relación estadísticamente significativa entre el tratamiento con RT preoperatoria y la aparición de problemas circulatorios en el colgajo (p-value $=0,410)$. En este caso se incluyeron 4 casos que presentaban una vena mamaria interna filiforme, claramente inferior a su arteria homónima (tabla 37).

\begin{tabular}{lccc} 
& \multicolumn{2}{c}{ Problemas circulatorios del colgajo } & \multirow{2}{*}{ Total } \\
\cline { 2 - 3 } & No problemas & Si problemas & \\
\hline No RT & 19 & 6 & $\mathbf{2 5}$ \\
Sí RT & 23 & 10 & $\mathbf{3 3}$ \\
Total & $\mathbf{4 2}$ & $\mathbf{1 6}$ & $\mathbf{5 8}$ \\
\hline
\end{tabular}

\begin{tabular}{cccc} 
& Valor & gl & $\begin{array}{c}\text { Sig. exacta } \\
\text { (bilateral) }\end{array}$ \\
\hline $\begin{array}{c}\text { Chi-cuadrado de Pearson } \\
\text { Estadístico exacto de Fisher }\end{array}$ &, $283^{\mathrm{a}}$ & 1 & \\
\hline
\end{tabular}

Tabla 37: Distribución de la línea de origen de la perforante en función de la aparición de necrosis grasa en el colgajo. 


\subsection{Quimioterapia}

En 50 de las 61 mastectomías practicadas (82,0\%) las pacientes recibieron quimioterapia en algún momento del tratamiento del cáncer. De estas, el tratamiento fue posterior al tratamiento quirúrgico en 43 casos, neoadyuvante en 6 casos, mientras que en 1 caso el tratamiento fue administrado anterior y posterior a la cirugía oncológica (tabla $38)$.

\begin{tabular}{lcc}
\hline \multicolumn{1}{c}{ QUIMIOTERAPIA } & $\begin{array}{r}\text { Frecuencia } \\
(\mathbf{n = 6 1 )}\end{array}$ & $\begin{array}{c}\text { Porcentaje } \\
(\mathbf{\%})\end{array}$ \\
\hline No quimioterapia & $\mathbf{1 1}$ & $\mathbf{1 8 , 0}$ \\
\hline Sí quimioterapia & & \\
$\quad$ Posterior a la cirugía oncológica & $\mathbf{5 0}$ & $\mathbf{8 2 , 0}$ \\
Neoadyuvante & 43 & 70,5 \\
Combinación de ambas & 6 & 9,9 \\
\hline
\end{tabular}

Tabla 38: Frecuencia y porcentaje de pacientes que han recibido quimioterapia.

En nuestro estudio no se observó una relación significativa entre la administración de quimioterapia y la aparición complicaciones $(\mathrm{p}$-value $=0.56)$, necrosis grasa del colgajo $(p$-value $=0,458)$ o de dehiscencias en el cierre abdominal ( $p$-value $=0.559)($ tablas 3941). Este hecho probablemente es debido a que el periodo comprendido entre el final del tratamiento quimioterápico y la cirugía reconstructiva diferida no fue nunca inferior a una año, dando oportunidad a la recuperación de las capacidades regenerativas de los tejidos. Las reconstrucciones inmediatas se realizaron en casos seleccionados de tal modo que ninguna tuvo indicación de neoadyuvancia previa. 


\begin{tabular}{lccc} 
& \multicolumn{2}{c}{ Complicaciones totales } & \multirow{2}{*}{ Total } \\
\cline { 2 - 4 } & No complicaciones & Si complicaciones & \\
\hline No quimioterapia & 4 & 7 & 11 \\
Si quimioterapia & 23 & 27 & 50 \\
Total & 27 & 34 & 61 \\
\hline & & & \\
& Valor & gl & Sig. asintótica \\
& & & (bilateral) \\
\hline Chi-cuadrado de Pearson & 0,339 & 1 & $\mathbf{0 , 5 6}$ \\
\hline
\end{tabular}

Tabla 39: Distribución de la administración de QT en función de la aparición de complicaciones.

\begin{tabular}{lccc}
\cline { 2 - 3 } & \multicolumn{2}{c}{ Necrosis grasa colgajo } & \multirow{2}{*}{ Total } \\
\cline { 2 - 3 } & No necrosis & Si necrosis & \\
\hline No quimioterapia & 7 & 2 & $\mathbf{9}$ \\
Si quimioterapia & 42 & 6 & $\mathbf{4 8}$ \\
Total & $\mathbf{4 9}$ & $\mathbf{8}$ & $\mathbf{5 7}$ \\
\hline
\end{tabular}

\begin{tabular}{lccc} 
& Valor & gl & $\begin{array}{c}\text { Sig. asintótica } \\
\text { (bilateral) }\end{array}$ \\
\hline Chi-cuadrado de Pearson & 0,552 & 1 & $\mathbf{0 , 4 5 8}$ \\
\hline
\end{tabular}

Tabla 40: Distribución de la administración de QT en función de la aparición de necrosis grasa en el colgajo.

\begin{tabular}{lccc}
\cline { 2 - 3 } & \multicolumn{2}{c}{ Dehiscencia cutánea abdomen } & \multirow{2}{*}{ Total } \\
\cline { 2 - 3 } & No dehiscencia & Si dehiscencia & \\
\hline No quimioterapia & 10 & 1 & 11 \\
Si quimioterapia & 42 & 8 & 50 \\
Total & 52 & 9 & 61 \\
\hline
\end{tabular}

\begin{tabular}{lccc} 
& Valor & gl & $\begin{array}{c}\text { Sig. asintótica } \\
\text { (bilateral) }\end{array}$ \\
\hline Chi-cuadrado de Pearson & 0,342 & 1 & $\mathbf{0 , 5 5 9}$ \\
\hline
\end{tabular}

Tabla 41: Distribución de la administración de QT en función de la dehiscencia del cierre abdominal. 


\subsection{Hormonoterapia}

Se prescribió tratamiento hormonal complementario en 47 casos (77,0\%). Las medicaciones administradas variaron de una paciente a otra, y en ocasiones fue preciso el cambio de prescripción como consecuencia de la aparición de efectos adversos. Los fármacos indicados fueron, tamoxifeno, anastrozol (arimidex ${ }^{\circledR}$ ), trastuzumab (herceptin $\left.{ }^{\circledR}\right)$, goreselina (zoladex $\left.{ }^{\circledR}\right)$ y letrozol (femara $\left.{ }^{\circledR}\right)$. No fue posible obtener esta información en el caso de una paciente (tabla 42).

\begin{tabular}{lcc}
\hline HORMONOTERAPIA & $\begin{array}{c}\text { Frecuencia } \\
(\mathbf{n = 6 1 )}\end{array}$ & $\begin{array}{c}\text { Porcentaje } \\
\mathbf{( \% )}\end{array}$ \\
\hline No HT & 13 & 21,3 \\
Sí HT & 47 & 77,1 \\
Sin datos & 1 & 1,6 \\
\hline
\end{tabular}

Tabla 42: Frecuencia y porcentaje del tratamiento hormonal.

En nuestro estudio no se observó una relación significativa entre los inhibidores hormonales y la aparición de complicaciones $(p$-value $=0.578)($ tabla 43$)$.

\begin{tabular}{lccc} 
& \multicolumn{2}{c}{ Complicaciones totales } & \multirow{2}{*}{ Total } \\
\cline { 2 - 3 } & No complicaciones & Si complicaciones & \\
\hline No terapia hormonal & 5 & 8 & $\mathbf{1 3}$ \\
Sí terapia hormonal & 22 & 25 & $\mathbf{4 7}$ \\
Total & 27 & 33 & $\mathbf{6 0}$ \\
\hline & & & \\
& Valor & gl & Sig. asintótica \\
& & & (bilateral) \\
\hline Chi-cuadrado de Pearson & 1,095 & 1 & $\mathbf{0 , 5 7 8}$ \\
\hline
\end{tabular}

Tabla 43: Distribución de la terapia hormonal en función de las complicaciones. 
Tampoco se encontró una asociación con la formación de necrosis grasa en el colgajo (p-value $=0,318)$, no existiendo una relación de causalidad entre la capacidad trombogénica de estos fármacos y la formación de microtrombos que condicionasen la aparición de esta complicación (tabla 44).

\begin{tabular}{lccc}
\cline { 2 - 3 } & \multicolumn{2}{c}{ Necrosis grasa colgajo } & \multirow{2}{*}{ Total } \\
\cline { 2 - 3 } & No necrosis & Si necrosis & \\
\hline No terapia hormonal & 10 & 3 & $\mathbf{1 3}$ \\
Sí terapia hormonal & 38 & 5 & $\mathbf{4 3}$ \\
Total & $\mathbf{4 8}$ & $\mathbf{8}$ & $\mathbf{5 6}$ \\
\hline
\end{tabular}

\begin{tabular}{lccc} 
& Valor & gl & $\begin{array}{c}\text { Sig. asintótica } \\
\text { (bilateral) }\end{array}$ \\
\hline Chi-cuadrado de Pearson & 0,997 & 1 & $\mathbf{0 , 3 1 8}$ \\
\hline
\end{tabular}

Tabla 44: Distribución de la terapia hormonal en función de la necrosis grasa del colgajo.

Encontramos una relación estadísticamente significativa y con carácter protector entre la hormonoterapia y la aparición de dehiscencia del cierre abdominal $(\mathrm{p}$-value $=0.007)$ (tabla 45). Después de revisar la ficha técnica de estos fármacos no se ha encontrado una efecto que justifique estos resultados. No hemos observado una relación entre la terapia hormonal y necesidad de realizar una segunda vena para mejorar el drenaje del colgajo (pvalue $=0.100)($ tabla 46$)$.

\begin{tabular}{lccc}
\cline { 2 - 3 } & \multicolumn{2}{c}{ Dehiscencia cutánea abdomen } & \multirow{2}{*}{ Total } \\
\cline { 2 - 3 } & No dehiscencia & Si dehiscencia & \\
\hline No terapia hormonal & 8 & 5 & 13 \\
Si terapia hormonal & 43 & 4 & 47 \\
Total & 51 & 9 & 60 \\
\hline
\end{tabular}

\begin{tabular}{cccc} 
& Valor & gl & $\begin{array}{c}\text { Sig. asintótica } \\
\text { (bilateral) }\end{array}$ \\
\hline Chi-cuadrado de Pearson & 7,165 & 1 & $\mathbf{0 , 0 0 7}$ \\
\hline
\end{tabular}

Tabla 45: Distribución de la terapia hormonal en función de la dehiscencia del cierre abdominal. 


\begin{tabular}{|c|c|c|c|c|}
\hline & \multicolumn{3}{|c|}{$2^{\mathrm{a}}$ vena } & \multirow{2}{*}{ Total } \\
\hline & No segunda vena & \multicolumn{2}{|c|}{ Si segunda vena } & \\
\hline No terapia hormonal & 13 & & & 13 \\
\hline Sí terapia hormonal & 36 & & & 47 \\
\hline \multirow[t]{2}{*}{ Total } & 49 & & & 60 \\
\hline & Valor & gl & \multicolumn{2}{|c|}{$\begin{array}{c}\text { Sig. exacta } \\
\text { (bilateral) }\end{array}$} \\
\hline Chi-cuadrado de Pearso & 3,726 & 1 & \multirow{2}{*}{\multicolumn{2}{|c|}{0,100}} \\
\hline \multicolumn{2}{|c|}{ Estadístico exacto de Fisher } & & & \\
\hline $\mathrm{N}$ de casos válidos & 60 & & & \\
\hline
\end{tabular}

Tabla 46: Distribución de la terapia hormonal en función de la realización de un $2^{\mathrm{a}}$ anastomosis venosa.

\subsection{Antecedente de cirugía conservadora de mama}

De las 61 mastectomías realizadas, 11 habían tenido un intento de cirugía conservadora anterior que hubo que reconvertir a una mastectomía por la aparición de bordes afectos en la resección o bien por la presentar una recidiva en la mama tiempo después.

\subsection{Tiempo transcurrido entre la mastectomía y la reconstrucción}

El tiempo transcurrido entre la mastectomía y la reconstrucción mamaria diferida fue de 46,39 $\pm 47,26$ meses. Como puede observarse, este tiempo fue muy variable y estuvo influenciado por los diferentes criterios entre cirujanos oncológicos sobre el tiempo que debe transcurrir desde la resección hasta la reconstrucción, la aplicación de tratamientos adyuvantes que alargan los tiempos desde la realización de la mastectomía, factores subjetivos de la paciente sobre si intervenirse y cuando a una reconstrucción mamaria así como la demora de la lista quirúrgica, que es mayor para este tipo de intervenciones. En algunos casos la paciente ya tenía una RM previa con un resultado insatisfactorio o con 
complicaciones que indicaron su conversión a una reconstrucción con colgajo DIEP (tabla 47 y gráfico 6).

\begin{tabular}{lc}
\hline \multicolumn{1}{c}{ Total pacientes } & $\mathbf{5 6}$ \\
\hline Media (meses) & 46,39 \\
Mediana & 26,50 \\
Desviación Típica & 47,26 \\
Rango & 193,00 \\
Mínimo & 10,00 \\
Máximo & 203,00 \\
\hline
\end{tabular}

Tabla 47: Tiempo transcurrido en meses entre la mastectomía y la reconstrucción mamaria diferida.

\section{Tiempo entre la mastectomia y la reconstrucción mamaria}

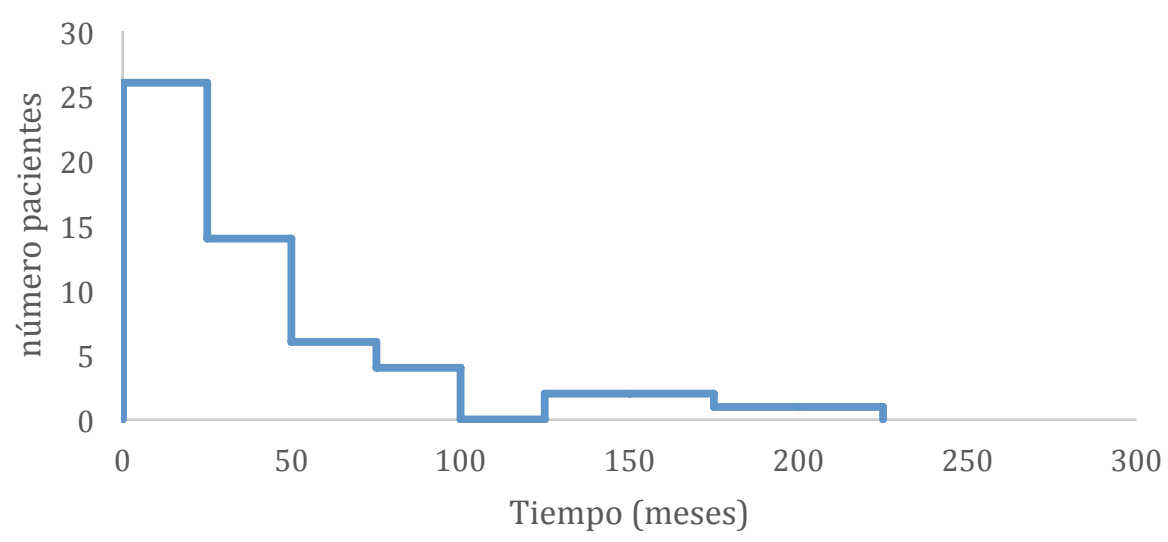

Gráfico 6: Tiempo transcurrido en meses entre la mastectomía y la reconstrucción mamaria diferida.

\subsection{Recidiva del cáncer}

Todas las reconstrucciones mamarias se realizaron con la paciente libre de enfermedad. Durante el seguimiento, 5 pacientes presentaron una enfermedad metastásica a distancia, de las cuales 3 han fallecido en el momento de la finalización de este estudio, una se 
encuentra en una fase muy avanzada de la enfermedad y otra esta siendo tratada por el servicio de oncología médica del Hospital de El Bierzo.

Una paciente que estaba en lista de espera para realizar una cirugía complementaria sobre el colgajo fue diagnosticada de un cáncer mamario primario en la mama contralateral. Se realizó una mastectomía ahorradora de piel y al no estar disponible el colgajo DIEP, se realizo una transferencia libre de un colgajo perforante de arteria femoral profunda de manera exitosa. Actualmente la paciente esta a la espera de realizarse la cirugía complementaria sobre el colgajo DIEP y la reconstrucción bilateral del complejo areola-pezón. 


\section{VARIABLES EN RELACIÓN CON LA INTERVENCIÓN QUIRÚRGICA}

\subsection{Lateralidad de la reconstrucción mamaria y de la disección del colgajo}

El colgajo DIEP fue extraído en 29 (47,5\%) intervenciones del lado derecho mientras que en $32(52,5 \%)$ cirugías se eligió el lado izquierdo, no existiendo prácticamente diferencias en la elección del lado. La mama reconstruida fue en 21 intervenciones la derecha $(34,4 \%)$ y en 40 la izquierda $(65,6 \%)$ (tabla 48$)$.

\begin{tabular}{lcccc} 
& \multicolumn{2}{c}{ Lado de la reconstrucción } & \multicolumn{2}{c}{ Lado del colgajo } \\
\cline { 2 - 5 } & Derecha & Izquierda & Derecha & Izquierda \\
\hline Frecuencia $(\mathrm{n}=61)$ & 21 & 40 & 29 & 32 \\
Porcentaje $(\%)$ & 34,4 & 65,6 & 47,5 & 52,5 \\
\hline
\end{tabular}

Tabla 48: Frecuencia y porcentaje de la lateralidad de la reconstrucción y del colgajo.

No se ha considerado estudiar la lateralidad del colgajo con respecto a las complicaciones debido a la similitud en la presentación de los patrones de la AEIP y al número de perforantes observadas entre ambos lados en nuestro estudio.

\subsection{Frecuencia de los vasorreceptores seleccionados}

Los vasos mamarios internos fueron los vasorreceptores de elección al inicio de todas las intervenciones, utilizándose finalmente en 58 reconstrucciones (95,1\%). En las situaciones en las que al concluir la exposición de estos se observó un calibre excesivamente pequeño, fundamentalmente de la vena, o bien presentaban una importante fibrosis o daño inducido por la radioterapia, se optó por emplear en su lugar vasos del eje subescapular. De esta forma, en 1 caso $(1,6 \%)$ se empleó la arteria y vena toracodorsales y en otro caso $(1,6 \%)$ los vasos del pedículo del serrato. En otra paciente $(1,6 \%)$ se utilizó como vasorreceptor 
una arteria y vena perforantes de los vasos mamarios internos al presentar un calibre destacable (tabla 49).

\begin{tabular}{lcc}
\hline \multicolumn{1}{c}{ VASORRECEPTOR } & $\begin{array}{c}\text { Frecuencia } \\
(\mathbf{n = 6 1 )}\end{array}$ & $\begin{array}{c}\text { Porcentaje } \\
\mathbf{( \% )}\end{array}$ \\
\hline Mamarios internos & 58 & 95,1 \\
Toracodorsal & 1 & 1,6 \\
Serrato & 1 & 1,6 \\
Perforantes mamarias & 1 & 1,6 \\
\hline
\end{tabular}

Tabla 49: Frecuencia y porcentaje de los vasorreceptores seleccionados.

Hay que reseñar que 4 de las 58 reconstrucciones en las que se utilizaron los vasos mamarios internos como vasorreceptores, se observó una vena mamaria interna de un calibre muy fino con respecto a la arteria mamaria interna. En 2 casos fue imperativo realizar una segunda anastomosis venosa lo que permitió salvar el colgajo, en otro caso no fue posible lo que desembocó en una necrosis parcial del colgajo y en el último caso se realizó una anastomosis a flujo inverso de la VMI, que mostraba un calibre superior, lo que permitió salvar el colgajo pero con aparición de una zona de necrosis grasa en el postoperatorio. Todos estos casos, unidos a dos reconstrucciones en las que se desestimó la VMI en favor del eje subescapular como vasorreceptor por el mismo motivo, tenían el antecedente de haber recibido tratamiento radioterápico previo.

\subsection{Tiempo operatorio}

El tiempo medio operatorio empleado en la realización de una reconstrucción unilateral con el colgajo DIEP fue de 413,39 \pm 72,667 minutos, con un rango de tiempo entre 290 y 600 minutos. En el estudio de este parámetro se excluyó el único caso de reconstrucción con colgajo DIEP bilateral de la muestra, el cual tuvo una duración de 720 minutos. Aunque no existen diferencias significativas $(p$-value $=0,441)$. El tiempo medio de los casos que presentaron alguna complicación fue ligeramente superior $(419,71 \pm 75,898$ 
min) en relación con los que no presentaron complicaciones $(404,80 \pm 68,609 \mathrm{~min})$, sin que esta diferencia sea significativa (tabla 50 y gráfico 7).

\begin{tabular}{|c|c|c|c|c|c|c|c|c|}
\hline & \multirow{2}{*}{$\mathbf{N}$} & \multirow{2}{*}{ Media } & \multirow{2}{*}{$\begin{array}{c}\text { Desviación } \\
\text { típica }\end{array}$} & \multirow{2}{*}{$\begin{array}{l}\text { Error } \\
\text { típico }\end{array}$} & \multicolumn{2}{|c|}{$\begin{array}{l}\text { Intervalo de confianza } \\
\text { para la media al } 95 \%\end{array}$} & \multirow{2}{*}{ Mínimo } & \multirow{2}{*}{ Máximo } \\
\hline & & & & & $\begin{array}{l}\text { Límite } \\
\text { inferior }\end{array}$ & $\begin{array}{l}\text { Límite } \\
\text { superior }\end{array}$ & & \\
\hline No complicaciones & 25 & 404,80 & 68,609 & 13,722 & 376,48 & 433,12 & 290 & 580 \\
\hline Sí complicaciones & 34 & 419,71 & 75,898 & 13,016 & 393,22 & 446,19 & 315 & 600 \\
\hline Total & 59 & 413,39 & 72,667 & 9,460 & 394,45 & 432,33 & 290 & 600 \\
\hline & & & $\mathrm{F}$ & Sig. & & & & \\
\hline & & & ,602 & 0,441 & & & & \\
\hline
\end{tabular}

Tabla 50: Comparación entre el tiempo de cirugía y la aparición de complicaciones.

En el gráfico 7 se observa una reducción del tiempo operatorio a partir de la RM número 14 con respecto a las reconstrucciones precedentes, con aumentos esporádicos en los que se necesitó mas tiempo para completar la intervención.

\section{Tiempo operatorio (min)}

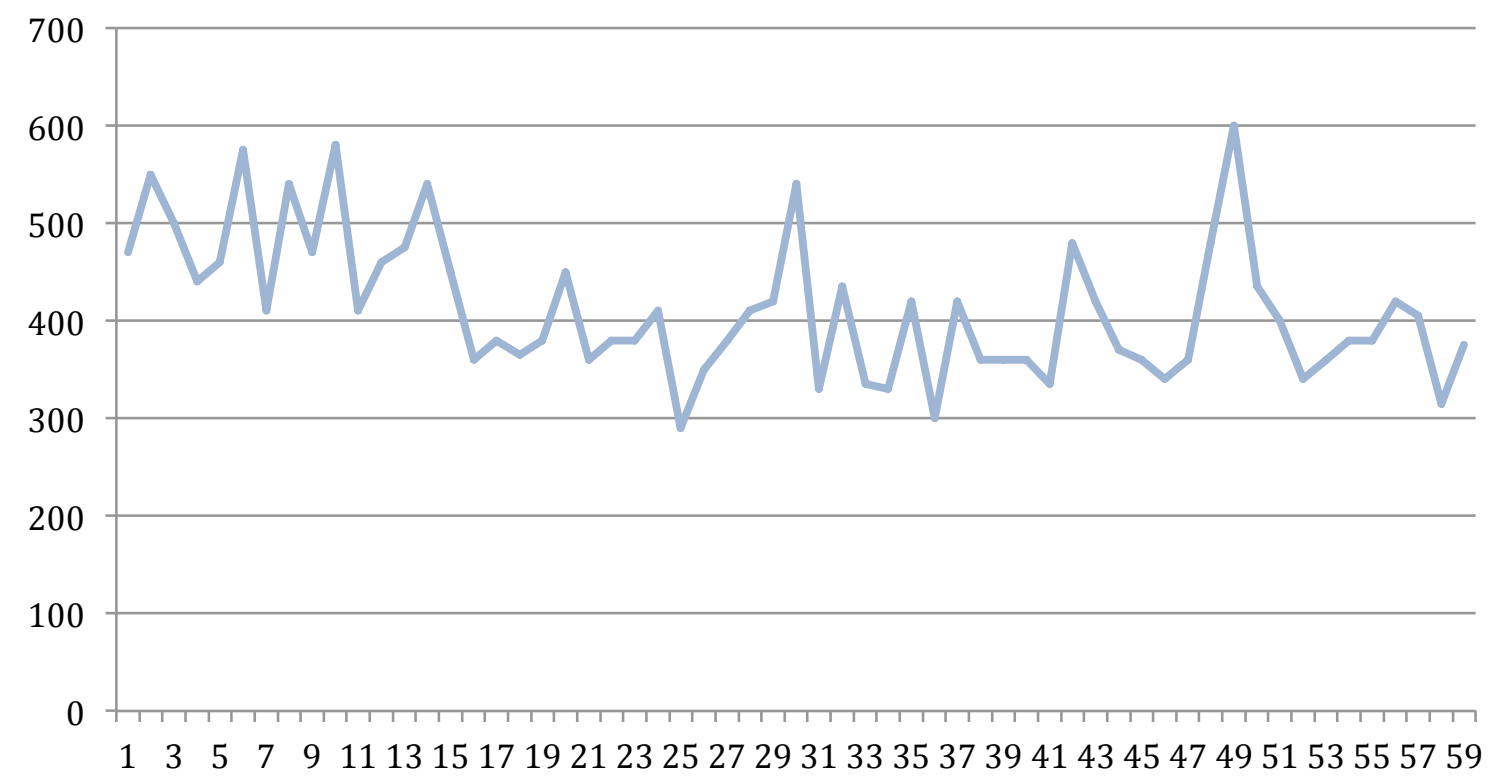

Gráfico 7: Duración en minutos de la intervención quirúrgica de la RM unilateral con colgajo DIEP. 
Al estudiar exclusivamente aquellos colgajos que han sufrido necrosis grasa, observamos que aunque no existe una diferencia con significación estadística ( $\mathrm{p}$-value $=0$. 398), el tiempo de intervención empleado en las reconstrucciones que no sufrieron necrosis grasa fue superior $(411,670 \pm 70,003 \mathrm{~min})$ a aquellas que si presentaron esta complicación $(388,75 \pm 72,592 \mathrm{~min})($ tabla 51$)$.

\begin{tabular}{|c|c|c|c|c|c|c|c|c|}
\hline & \multirow{2}{*}{$\mathbf{N}$} & \multirow{2}{*}{ Media } & \multirow{2}{*}{$\begin{array}{l}\text { Desviación } \\
\text { típica }\end{array}$} & \multirow{2}{*}{$\begin{array}{l}\text { Error } \\
\text { típico }\end{array}$} & \multicolumn{2}{|c|}{$\begin{array}{l}\text { Intervalo de confianza } \\
\text { para la media al } 95 \%\end{array}$} & \multirow{2}{*}{ Mínimo } & \multirow{2}{*}{ Máximo } \\
\hline & & & & & $\begin{array}{l}\text { Límite } \\
\text { inferior }\end{array}$ & $\begin{array}{l}\text { Límite } \\
\text { superior }\end{array}$ & & \\
\hline No necrosis grasa colgajo & 47 & 411,70 & 70,033 & 10,215 & 391,14 & 432,26 & 290 & 580 \\
\hline Sí necrosis grasa colgajo & 8 & 388,75 & 72,592 & 25,665 & 328,06 & 449,44 & 330 & 540 \\
\hline Total & 55 & 408,36 & 70,198 & 9,466 & 389,39 & 427,34 & 290 & 580 \\
\hline & & & $\mathrm{F}$ & Sig. & & & & \\
\hline & & &, 727 & 0,398 & & & & \\
\hline
\end{tabular}

Tabla 51: Comparación entre el tiempo de cirugía y la aparición de necrosis grasa en el colgajo.

Estos hallazgos sugieren dos hechos. Por un lado, sería adecuado valorar este parámetro con una muestra mayor de pacientes con necrosis grasa para confirmar o descartar esta asociación. Por otra parte, el mayor consumo de tiempo en aquellos colgajos que no presentan necrosis grasa apunta a que en estos se realiza algún procedimiento que puede prevenir esta complicación. Dado que la realización de la técnica es muy similar en todos los casos y la única diferencia sustancial es la realización de una segunda vena de drenaje, hemos estudiado este parámetro.

En nuestro estudio se observa que la realización de una segunda vena de drenaje supone un incremento significativo $(\mathrm{p}$-value $=0,027)$ en la duración de la intervención $(402,10 \pm 65,372 \mathrm{~min}$ frente a 485,00 \pm 73,294 $\mathrm{min})($ tabla 52). 


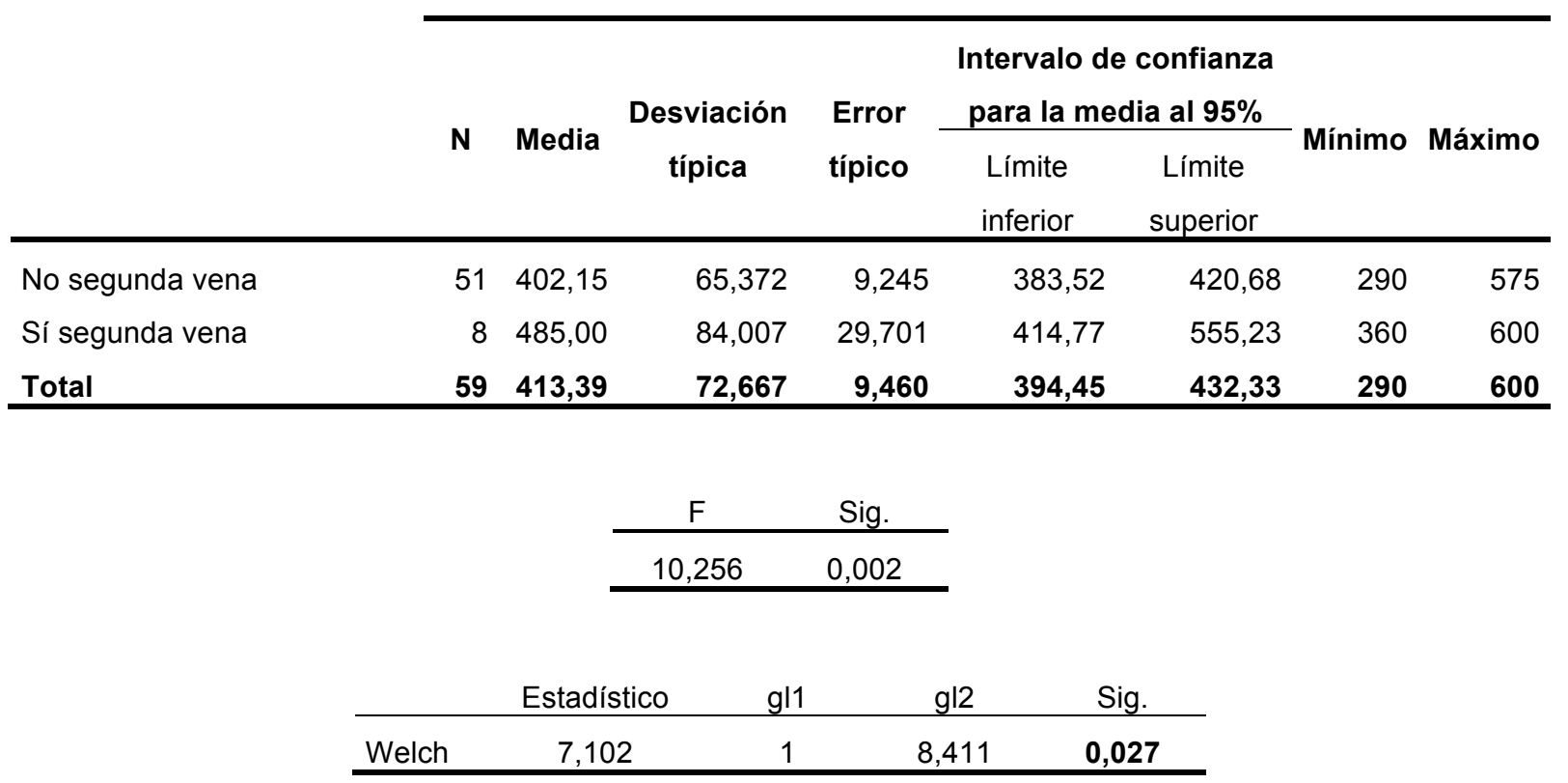

Tabla 52: Distribución del tiempo de cirugía en función de la realización de una $2^{\mathrm{a}}$ anastomosis venosa. 


\section{VARIABLES RELACIONADAS CON EL ANGIO TC $Y$ LA VASCULARIZACIÓN DE LA PARED ABDOMINAL}

\subsection{Tomógrafo}

En 35 reconstrucciones $(57,4 \%)$ el TC empleado en la planificación fue el Siemens Sensation 16, en 23 casos (37,7\%) se utilizó el Siemens SOMATON Definition AS, mientras que 3 angio TC (4,9\%) se realizaron con el modelo General Electric LigthSpeed RT (tabla 53).

\begin{tabular}{ccc}
\hline TOMÓGRAFO & Frecuencia $(\mathbf{n = 6 1 )}$ & Porcentaje (\%) \\
\hline Siemens SOMATON Sensation 16 & 35 & 57,4 \\
Siemens SOMATON Definition AS & 23 & 37,7 \\
General Electric LigthSpeed RT 16 & 3 & 4,9 \\
\hline
\end{tabular}

Tabla 53: Frecuencia y porcentaje de los tomógrafos utilizados en los mapeos.

\subsection{Patrón de la arteria epigástrica inferior profunda}

El patrón de la arteria epigástrica inferior profunda fue casi idéntico en el lado derecho con respecto al izquierdo, siendo la presentación más frecuente la tipo I (60,7\% en el lado derecho frente al $63,9 \%$ en el lado izquierda), seguida con la tipo 2 (36,1\% en el lado derecho frente al 32,8\% en el lado izquierdo) (tabla 54).

\begin{tabular}{lcccccc} 
& \multicolumn{3}{c}{ PATRÓN LADO DERECHO } & \multicolumn{3}{c}{ PATRÓN LADO IZQUIERDO } \\
\cline { 2 - 7 } & Tipo 1 & Tipo 2 & Tipo 3 & Tipo 1 & Tipo 2 & Tipo 3 \\
\hline Frecuencia $(\mathrm{n}=61)$ & 37 & 22 & 2 & 39 & 20 & 2 \\
Porcentaje (\%) & 60,7 & 36,1 & 3,3 & 63,9 & 32,8 & 3,3 \\
\hline
\end{tabular}

Tabla 54: Frecuencia y porcentaje del patrón de presentación de la arteria epigástrica inferior profunda. 


\subsection{Vasos perforantes}

En las pacientes de nuestro estudio se realizó un recuento de las perforantes abdominales de un calibre suficiente para ser patentes en la angio TC en el espacio comprendido entre el punto medio del ombligo y $6 \mathrm{~cm}$ por debajo de este. El número medio de perforantes abdominales correspondiente al lado derecho fue de 2,72 $\pm 1,240$ (rango 1-6) frente al lado izquierdo que fue de 2,84 $\pm 1,067$ (rango 1-5) (tabla 55). En todos los estudios se visualizó al menos 1 perforante, siendo habitual localizar 2 ó 3 perforantes ( $32,8 \%$ y $31,1 \%$ en el lado derecho frente a $26,2 \%$ y $34,4 \%$ respectivamente) (tabla 56). Con respecto a estos valores hay que considerar que en una disección anatómica el número de perforantes puede ser mayor, sin embargo la angio TC sólo nos mostrará las de mayor densidad y por tanto calibre, que son sobre las que nos interesa basar un colgajo DIEP.

\begin{tabular}{lrr}
\cline { 2 - 3 } & Perforantes Derechas & Perforantes Izquierdas \\
\hline Media & 2,72 & 2,84 \\
Desviación típica & 1,240 & 1,067 \\
Rango & 5 & 4 \\
Mínimo & 1 & 1 \\
Máximo & 6 & 5 \\
\hline
\end{tabular}

Tabla 55: Datos descriptivos de los vasos perforantes visualizados en el mapeo con angio TC.

\begin{tabular}{ccccc}
\hline \multirow{2}{*}{$\begin{array}{c}\text { NÚMERO DE } \\
\text { PERFORANTES }\end{array}$} & \multicolumn{2}{c}{ Lado derecho } & \multicolumn{2}{c}{ Lado izquierdo } \\
\cline { 2 - 5 } & Frecuencia & Porcentaje & Frecuencia & Porcentaje \\
\hline $\mathbf{1}$ & 9 & 14,8 & 7 & 11,5 \\
$\mathbf{2}$ & 20 & 32,8 & 16 & 26,2 \\
$\mathbf{3}$ & 19 & 31,1 & 21 & 34,4 \\
$\mathbf{4}$ & 7 & 11,5 & 14 & 23,0 \\
$\mathbf{5}$ & 4 & 6,6 & 3 & 4,9 \\
$\mathbf{6}$ & 2 & 3,3 & 0 & 0 \\
Total & $\mathbf{6 1}$ & $\mathbf{1 0 0 , 0}$ & $\mathbf{4 7 , 5}$ & $\mathbf{5 2 , 5}$ \\
\hline
\end{tabular}

Tabla 56: Frecuencia y porcentaje del número de vasos perforantes visualizados en el mapeo con angio TC. 


\subsection{Localización de las venas epigástricas inferiores superficiales}

En nuestro estudio la distancia de la vena epigástrica inferior superficial a $10 \mathrm{~cm}$ por debajo del punto medio del ombligo con respecto a la línea media fue de 48,12 $\pm 14,534$ $\mathrm{mm}$ en el lado derecho y de 48,09 $\pm 14,144 \mathrm{~mm}$ en el lado izquierdo, presentando una localización casi igual en ambos lados (tabla 57). Todas las pacientes presentaban VEIS en ambos lados a excepción de 1 caso $(1,6 \%)$ en el lado derecho y 2 casos $(3,3 \%)$ en el lado izquierdo. Ninguna de estas pacientes habían presentado cirugías abdominales previas que explicasen esta ausencia.

\begin{tabular}{cccccc}
\hline $\begin{array}{c}\text { SISTEMA } \\
\text { VENOSO } \\
\text { SUPERFICIAL }\end{array}$ & Frecuencia & Media & $\begin{array}{c}\text { Desviación } \\
\text { típica }\end{array}$ & Mínimo & Máximo \\
\hline Derecha & 59 & 48,12 & 14,534 & 7 & 78 \\
Izquierda & 58 & 48,09 & 14,144 & 11 & 73 \\
\hline
\end{tabular}

Tabla 57: Distancia de las venas epigástricas superficiales con respecto a la línea media.

No se observó una relación estadísticamente significativa entre la localización de las VEIS y la necesidad de realizar una anastomosis venosa del sistema superficial tanto en el lado derecho $(\mathrm{p}$-value $=0.558)($ tabla 58$)$ como en el lado izquierdo $(\mathrm{p}$-value $=0.825)$ (tabla 59).

\begin{tabular}{|c|c|c|c|c|c|c|c|c|}
\hline \multirow{2}{*}{$\begin{array}{c}\text { VEIS } \\
\text { DERECHA }\end{array}$} & \multirow{2}{*}{$\mathbf{N}$} & \multirow{2}{*}{ Media } & \multirow{2}{*}{$\begin{array}{l}\text { Desviación } \\
\text { típica }\end{array}$} & \multirow{2}{*}{$\begin{array}{l}\text { Error } \\
\text { típico }\end{array}$} & \multicolumn{2}{|c|}{$\begin{array}{l}\text { Intervalo de confianza } \\
\text { para la media al } 95 \%\end{array}$} & \multirow{2}{*}{ Mínimo } & \multirow{2}{*}{ Máximo } \\
\hline & & & & & $\begin{array}{l}\text { Límite } \\
\text { inferior }\end{array}$ & $\begin{array}{l}\text { Límite } \\
\text { superior }\end{array}$ & & \\
\hline No anastomosis venosa & 49 & 47,61 & 14,579 & 2,083 & 43,42 & 51,80 & 7 & 78 \\
\hline Sí anastomosis venosa & 10 & 50,60 & 14,819 & 4,686 & 40,00 & 61,20 & 25 & 67 \\
\hline \multirow[t]{3}{*}{ Total } & 59 & 48,12 & 14,534 & 1,892 & 44,33 & 51,91 & 7 & 78 \\
\hline & & & $\mathrm{F}$ & Sig. & & & & \\
\hline & & & ,347 & 0,558 & & & & \\
\hline
\end{tabular}

Tabla 58: Distribución de la localización de la VEIS derecha en función de la realización de una anastomosis venosa superficial. 


\begin{tabular}{|c|c|c|c|c|c|c|c|c|}
\hline \multirow{2}{*}{$\begin{array}{c}\text { VEIS } \\
\text { IZQUIERDA }\end{array}$} & \multirow{2}{*}{$\mathbf{N}$} & \multirow{2}{*}{ Media } & \multirow{2}{*}{$\begin{array}{l}\text { Desviación } \\
\text { típica }\end{array}$} & \multirow{2}{*}{$\begin{array}{l}\text { Error } \\
\text { típico }\end{array}$} & \multicolumn{2}{|c|}{$\begin{array}{l}\text { Intervalo de confianza } \\
\text { para la media al } 95 \%\end{array}$} & \multirow{2}{*}{ Mínimo } & \multirow{2}{*}{ Máximo } \\
\hline & & & & & $\begin{array}{l}\text { Limite } \\
\text { inferior }\end{array}$ & $\begin{array}{l}\text { Límite } \\
\text { superior }\end{array}$ & & \\
\hline No anastomosis venosa & 48 & 47,90 & 13,991 & 2,019 & 43,83 & 51,96 & 11 & 69 \\
\hline Sí anastomosis venosa & 10 & 49,00 & 15,606 & 4,935 & 37,84 & 60,16 & 31 & 73 \\
\hline Total & 58 & 48,09 & 14,144 & 1,857 & 44,37 & 51,81 & 11 & 73 \\
\hline & & & $\mathrm{F}$ & Sig. & & & & \\
\hline & & &, 050 & 0,825 & & & & \\
\hline
\end{tabular}

Tabla 59: Distribución de la localización de la VEIS izquierda en función de la realización de una anastomosis venosa superficial.

Durante el estudio del sistema venoso superficial se observaron las siguientes variantes anatómicas:

- En 2 pacientes $(3,3 \%)$ se observó una conexión entre ambos sistemas venosos superficiales.

- En 1 paciente (1,6\%) la VEIS derecha se encontró en una disposición medial (7 mm de la línea media). En otra paciente (1,6\%) sucedió una situación similar con la VEIS izquierda (11 mm de la línea media).

- En 2 pacientes $(3,3 \%)$ se observó una VEIS bifurcada, mientras que en otras 2 pacientes $(3,3 \%)$ se observó que la VEIS izquierda drenaba al lado derecho.

\subsection{Hallazgos complementarios del angio TC}

La finalidad del mapeo abdominal con angio TC fue estudiar las cualidades circulatorias de la pared abdominal de cara a la disección del colgajo DIEP, lo cual se logró en todos los casos. Sin embargo, esta prueba es capaz de aportar otros datos que pueden resultar ser tremendamente útiles en la planificación quirúrgica. 
El angio TC permite aportar información sobre:

- Permite crear un renderizado 3D que puede ayudar al cirujano a tener una representación de la ubicación de la perforante seleccionada con respecto a otros vasos perforantes, de tal modo que se pueda avanzar rápidamente en la disección hasta localizar referencias próximas al vaso seleccionado (fig. 49). También puede ayudar en la toma de decisiones en el caso de lesión iatrogénica de este vaso.

- Continencia de la pared abdominal. En el estudio se puede visualizar hernias umbilicales, zonas de labilidad de la pared o bien diástasis de rectos (fig. 50 A y B), que si no son tomadas en consideración durante el acto quirúrgico que puede dar lugar a una debilidad abdominal e incluso eventraciones tras la disección del colgajo DIEP.

- Estudio de las cicatrices abdominales originadas en cirugía previas y su relación con los pedículos vasculares utilizados en la extracción del colgajo (fig. 50C).

- Variaciones anatómicas de diferente relevancia (fig. 50D).
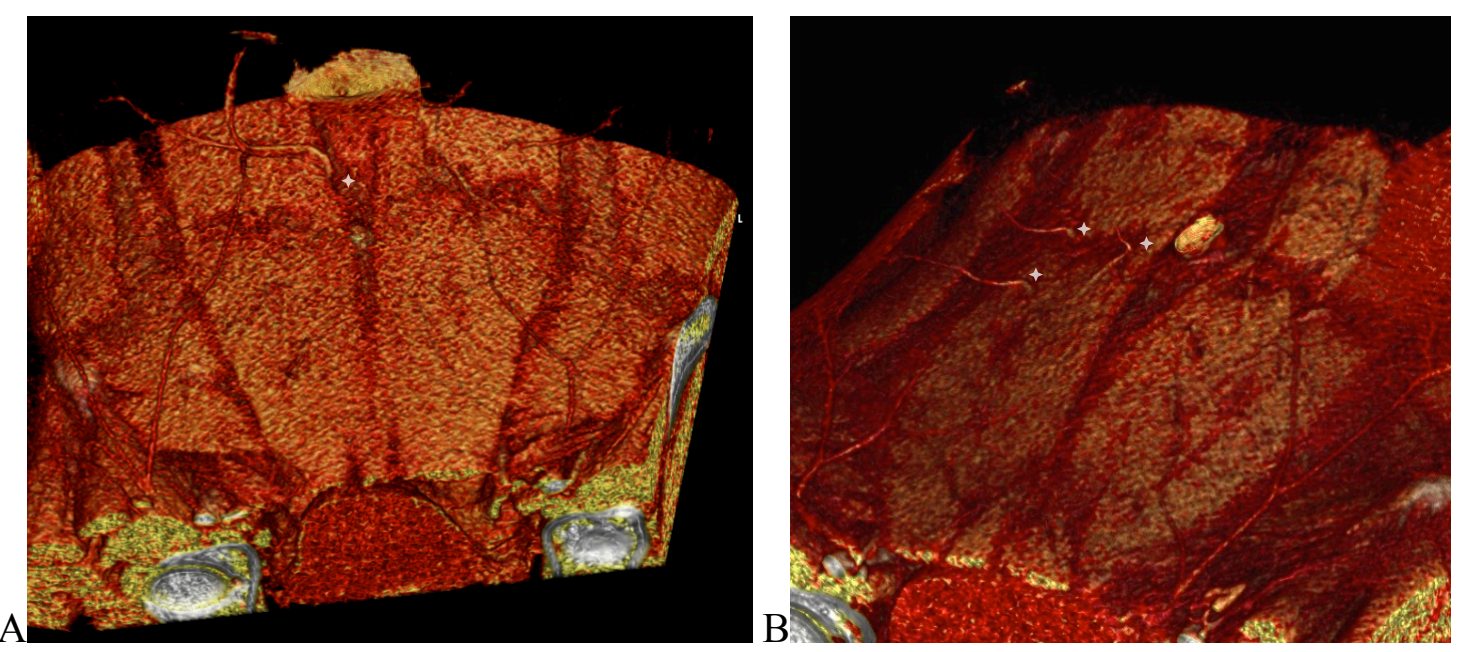

Figura 49. Proyección 3D VR A: Salida de perforante retromuscular derecha y su relación con el ombligo y el sistema venoso superficial. B: Salida a nivel de fascia de 3 perforantes derechas (estrellas blancas). 

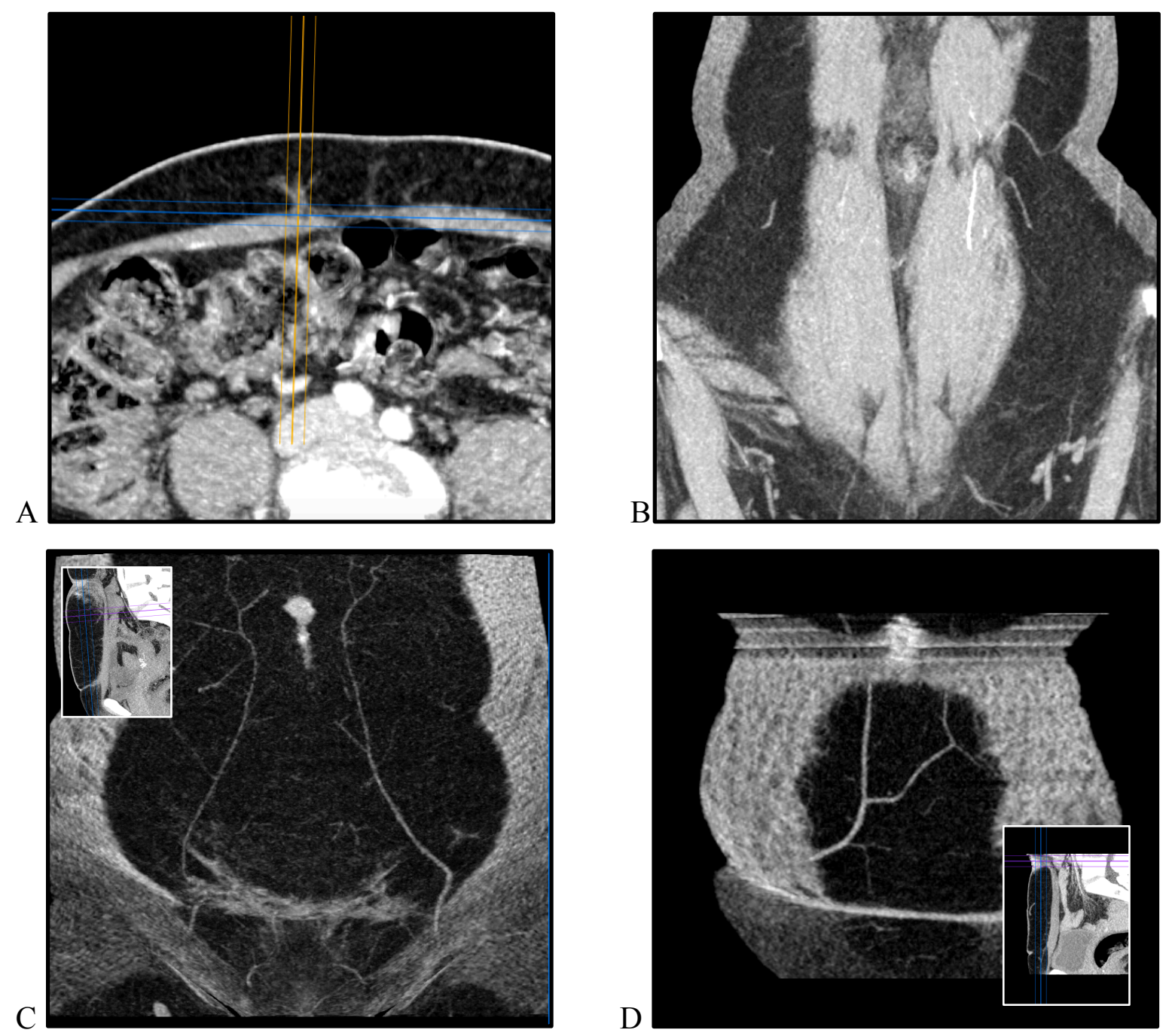

Figura 50. A: Zona de debilidad abdominal con riesgo de formación de una hernia umbilical. B: Diástasis de músculos rectos abdominales. Se observa la salida de un vaso perforante a través de una unión intermuscular izquierda.. C: Cicatriz de Pfannenstiel y su relación con el sistema venoso superficial. D: Anastomosis de ambos sistemas venosos superficiales, lo que sugiere una buena red de drenaje por parte del sistema superficial. 


\section{VARIABLES RELACIONADAS CON LA VASCULARIZACIÓN DEL COLGAJO}

Al estudiar las variables que pueden estar relacionadas con la vascularización del colgajo, éstas no se compararon con las complicaciones totales descritas. El motivo fue que muchas de estas complicaciones corresponden a la zona donante abdominal o son problemas sistémicos sin ninguna relación con la circulación del colgajo. Tampoco se compararon con las necrosis totales y parciales del colgajo, ya que aunque en este caso si pueden compartir una relación de causalidad, en nuestro estudio la frecuencia de esta complicación fue de tan sólo 3 casos y 2 casos respectivamente, de los cuales 4 casos se explicaron por problemas de los vasorreceptores o en la disección y en la anastomosis del colgajo, causas extrínsecas a la arquitectura vascular del DIEP y su vaso perforante.

\subsection{Patrón de la AEIP}

En nuestro estudio el patrón de la AEIP de la perforante en la que se basó el colgajo correspondió en 43 casos (68,9\%) al tipo 1, en 17 casos (27,9\%) al tipo 2, y únicamente en 2 casos $(3,2 \%)$ correspondió al tipo 3 (tabla 60). La elección de la perforante se realizó fundamentalmente a expensas de su calibre y el patrón no se consideró un criterio de elección de la perforante de manera preoperatoria, por lo que en nuestro estudio las perforantes de mayor calibre tienen con mayor frecuencia su origen en la AEIP formadas por un único tronco.

\begin{tabular}{ccc}
\hline $\begin{array}{c}\text { PATRÓN DE LA AEIP DEL } \\
\text { COLGAJO }\end{array}$ & $\begin{array}{c}\text { Frecuencia } \\
(\mathbf{n = 6 1 )}\end{array}$ & $\begin{array}{c}\text { Porcentaje } \\
(\mathbf{\%})\end{array}$ \\
\hline Tipo 1 & 42 & 68,9 \\
Tipo 2 & 17 & 27,9 \\
Tipo 3 & 2 & 3,2 \\
\hline
\end{tabular}

Tabla 60: Frecuencia y porcentaje del patrón de la AEIP del colgajo.

Se observó una asociación sin alcanzar la significación entre el patrón de la AEIP tipo 2 y la aparición de necrosis grasa $(\mathrm{p}$-value $=0.062)$ (tabla 61). Este hecho puede 
relacionarse con que este patrón de origen a perforantes de menor calibre, o bien a que las perforantes tengan un origen más lateral dentro de la isla diseñada de colgajo, dando así problemas de perfusión en las zonas distales del colgajo a nivel del tejido adiposo. No se observó una asociación entre el patrón de la AEIP y la línea de origen de la perforante (pvalue $=0.381)($ tabla 62$)$.

\begin{tabular}{lccc}
\cline { 2 - 3 } & \multicolumn{2}{c}{ Necrosis grasa colgajo } & \multirow{2}{*}{ Total } \\
\cline { 2 - 3 } & No necrosis & Si necrosis & \\
\hline AEIP tipo 1 & 36 & 3 & $\mathbf{3 9}$ \\
AEIP tipo 2 & 11 & 5 & $\mathbf{1 6}$ \\
AEIP tipo 3 & 2 & 0 & $\mathbf{2}$ \\
Total & $\mathbf{4 9}$ & $\mathbf{8}$ & $\mathbf{5 7}$ \\
\hline
\end{tabular}

\begin{tabular}{lccc} 
& Valor & gl & $\begin{array}{c}\text { Sig. asintótica } \\
\text { (bilateral) }\end{array}$ \\
\hline Chi-cuadrado de Pearson & 5,557 & 2 & $\mathbf{0 , 0 6 2}$ \\
\hline
\end{tabular}

Tabla 61: Distribución del patrón de la AEIP en relación con la aparición de necrosis grasa en el colgajo.

\begin{tabular}{lcccc} 
& \multicolumn{3}{c}{ Patrón AEIP } & \multirow{2}{*}{ Total } \\
\cline { 2 - 4 } & Tipo 1 & Tipo 2 & Tipo 3 & \\
\hline Línea medial & 19 & 10 & 1 & $\mathbf{3 0}$ \\
Línea lateral & 19 & 4 & 1 & $\mathbf{2 4}$ \\
Total & $\mathbf{2 8}$ & $\mathbf{1 4}$ & $\mathbf{2}$ & $\mathbf{5 4}$ \\
\hline
\end{tabular}

\begin{tabular}{cccc} 
& Valor & gl & $\begin{array}{c}\text { Sig. asintótica } \\
\text { (bilateral) }\end{array}$ \\
\hline Chi-cuadrado de Pearson & 1,929 & 2 & $\mathbf{0 , 3 8 1}$ \\
\hline
\end{tabular}

Tabla 62: Distribución del patrón de la AEIP en función de la línea de origen de la perforante.

Los 2 colgajos basados en una AEIP con patrón tipo 3 no presentaron necrosis grasa en el postoperatorio, aunque en ambos se realizó una segunda anastomosis venosa por manifestar signos de congestión venosa en el testado del colgajo previo a su autonomización. Al estudiar la aparición de problemas circulatorios en el colgajo, se 
observó una relación estadísticamente significativa ( $\mathrm{p}$-value $=0,016)$ en contra de los colgajos con una AEIP tipo 3 con respecto a las reconstrucciones que emplearon una AEIP tipo 1 y 2 (tabla 63 y gráfico 8 ).

\begin{tabular}{lccc} 
& \multicolumn{2}{c}{ Problemas circulatorios del colgajo } & \multirow{2}{*}{ Total } \\
\cline { 2 - 3 } & No problemas & Si problemas & \\
\hline AEIP tipo 1 & 32 & 6 & $\mathbf{3 8}$ \\
AEIP tipo 2 & 10 & 4 & $\mathbf{1 4}$ \\
AEIP tipo 3 & 0 & 2 & $\mathbf{2}$ \\
Total & $\mathbf{4 2}$ & $\mathbf{1 2}$ & $\mathbf{5 4}$ \\
\hline
\end{tabular}

\begin{tabular}{lccc} 
& Valor & gl & $\begin{array}{c}\text { Sig. asintótica } \\
\text { (bilateral) }\end{array}$ \\
\hline Chi-cuadrado de Pearson & 8,236 & 2 & $\mathbf{0 1 6}$ \\
\hline
\end{tabular}

Tabla 63: Distribución del patrón de la AEIP en relación con la aparición de problemas circulatorios en el colgajo.

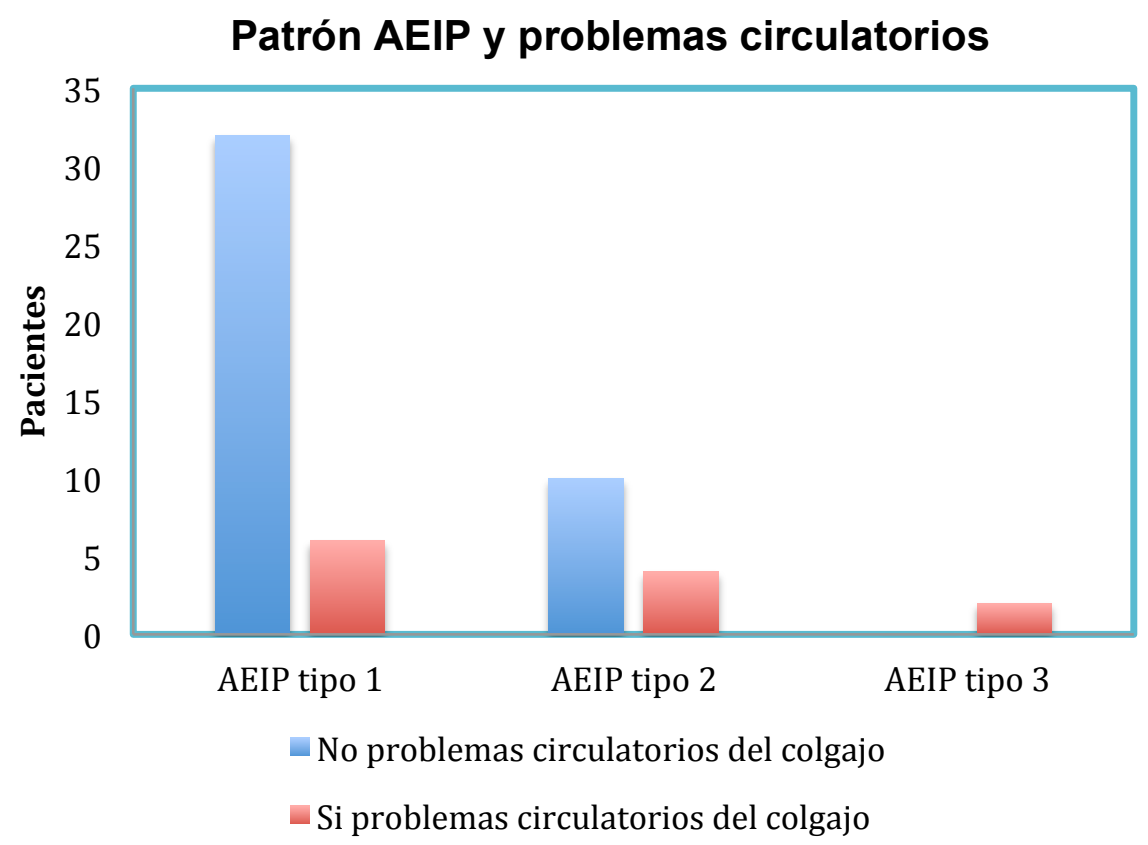

Gráfico 8: Problemas circulatorios del colgajo en función del patrón de la AEIP. 
Al estudiar los problemas circulatorios de los patrones tipo 1 y 2 , no se observó una relación significativa de la AEIP tipo $2(p$-value $=0,3)$. Este hallazgo sugiere que existen otros factores diferente al patrón de la AEIP en la aparición de problemas circulatorios del colgajo (tabla 64).

\begin{tabular}{lccc} 
& \multicolumn{2}{c}{ Problemas circulatorios del colgajo } & \multirow{2}{*}{ Total } \\
\cline { 2 - 3 } & No problemas & Si problemas & \\
\hline AEIP tipo 1 & 32 & 6 & $\mathbf{3 8}$ \\
AEIP tipo 2 & 10 & 4 & $\mathbf{1 4}$ \\
Total & $\mathbf{4 2}$ & $\mathbf{1 2}$ & $\mathbf{5 4}$ \\
\hline
\end{tabular}

\begin{tabular}{lccc} 
& Valor & gl & $\begin{array}{c}\text { Sig. asintótica } \\
\text { (bilateral) }\end{array}$ \\
\hline Chi-cuadrado de Pearson & 1,076 & 1 & $\mathbf{0 , 3}$ \\
\hline
\end{tabular}

Tabla 64: Distribución del patrón tipo 1 y 2 de la AEIP en relación con la aparición de problemas circulatorios en el colgajo.

\subsection{Trayecto muscular de la perforante}

El trayecto del vaso perforante elegido, fue corto en 20 casos (32,8\%), intermedio en 17 situaciones $(27,9 \%)$ y largo en 16 casos $(26,2 \%)$. En 8 casos $(13,1 \%)$ el trayecto de la perforante no se pudo identificar en su curso en la masa muscular del recto anterior del abdomen hasta alcanzar la AEIP en el estudio angio TC (tabla 65).

\begin{tabular}{lcc}
\hline $\begin{array}{c}\text { TRAYECTO MUSCULAR } \\
\text { DE LA PERFORANTE }\end{array}$ & $\begin{array}{c}\text { Frecuencia } \\
\text { (n=61) }\end{array}$ & $\begin{array}{c}\text { Porcentaje } \\
\mathbf{( \% )}\end{array}$ \\
\hline Corto & 20 & 32,8 \\
Intermedio & 17 & 27,9 \\
Largo & 16 & 26,2 \\
Desconocido & 8 & 13,1 \\
\hline
\end{tabular}

Tabla 65: Frecuencia y porcentaje del tipo de trayecto muscular de la perforante. 
En nuestro estudio no se observó una relación significativa entre la longitud del trayecto de la perforante y la aparición de necrosis grasa del colgajo ( $\mathrm{p}$-value $=0,323$ ) (tabla 66) o problemas circulatorios en el colgajo $(p$-value $=0,294)($ tabla 67$)$.

\begin{tabular}{lccc} 
& \multicolumn{2}{c}{ Necrosis grasa colgajo } & \multirow{2}{*}{ Total } \\
\cline { 2 - 3 } & No necrosis & Si necrosis & \\
\hline Trayecto corto & 14 & 4 & $\mathbf{1 8}$ \\
Trayecto intermedio & 14 & 3 & $\mathbf{1 7}$ \\
Trayecto largo & 14 & 0 & $\mathbf{1 4}$ \\
Desconocido & 7 & 1 & $\mathbf{8}$ \\
Total & $\mathbf{4 9}$ & $\mathbf{8}$ & $\mathbf{5 7}$ \\
\hline
\end{tabular}

\begin{tabular}{lccc} 
& Valor & gl & $\begin{array}{c}\text { Sig. asintótica } \\
\text { (bilateral) }\end{array}$ \\
\hline Chi-cuadrado de Pearson & 3,485 & 1 & $\mathbf{0 , 3 2 3}$ \\
\hline
\end{tabular}

Tabla 66: Distribución de la aparición de necrosis grasa en función del trayecto intramuscular de la perforante del colgajo.

\begin{tabular}{lccc} 
& \multicolumn{2}{c}{ Problemas circulatorios del colgajo } & \multirow{2}{*}{ Total } \\
\cline { 2 - 3 } & No problemas & No problemas & \\
\hline Trayecto corto & 12 & 5 & 17 \\
Trayecto intermedio & 12 & 3 & 15 \\
Trayecto largo & 13 & 1 & 14 \\
Desconocido & 5 & 3 & 8 \\
Total & $\mathbf{4 2}$ & $\mathbf{1 2}$ & $\mathbf{5 4}$ \\
\hline
\end{tabular}

\begin{tabular}{lccc} 
& Valor & gl & $\begin{array}{c}\text { Sig. asintótica } \\
\text { (bilateral) }\end{array}$ \\
\hline Chi-cuadrado de Pearson & $3,711^{\mathrm{a}}$ & 3 & $\mathbf{0 , 2 9 4}$ \\
\hline
\end{tabular}

Tabla 67: Distribución de la aparición de problemas circulatorios en función del trayecto intramuscular de la perforante del colgajo. 


\subsection{Características del trayecto de la perforante}

La mayoría de las perforantes seleccionadas tenían un trayecto sin ninguna peculiaridad a través del musculo recto anterior del abdomen $(42,6 \%)$ o bien atravesaban una unión intertendinosa de este músculo antes de su salida por la fascia abdominal $(45,9 \%)$. Sólo en un caso $(1,6 \%)$ su trayecto fue rodeando el musculo por su borde interno hasta alcanzar la AEIP. En tres casos $(4,9 \%)$ tuvo un trayecto subfascial, en un caso $(1,6 \%)$ combino un trayecto subfascial e intertendinoso y en 2 casos $(3,3 \%)$ no se pudo identificar correctamente en el angio TC este parámetro (tabla 68).

\begin{tabular}{lcc}
\hline $\begin{array}{c}\text { CARACTERÍSTICA DEL } \\
\text { TRAYECTO DE LA } \\
\text { PERFORANTE }\end{array}$ & $\begin{array}{c}\text { Frecuencia } \\
\text { (n=61) }\end{array}$ & $\begin{array}{c}\text { Porcentaje } \\
\text { (\%) }\end{array}$ \\
\hline Subfascial & 3 & 4,9 \\
Intertendinosa & 28 & 45,9 \\
Retromuscular & 1 & 1,6 \\
Filiforme & 2 & 3,3 \\
Intertendinosa y subfascial & 1 & 1,6 \\
Ninguna & 26 & 42,6 \\
\hline
\end{tabular}

Tabla 68: Frecuencia y porcentaje de las características del trayecto de la perforante.

En nuestro estudio no se observó una relación significativa en la aparición de necrosis grasa ( $p$-value $=0,568)($ tabla 69$)$ o problemas circulatorios en el colgajo ( $p$-value $=0,371)$ (tabla 70) en relación a si la perforante presentaba un trayecto intertendinoso dentro del músculo recto abdominal o no.

\begin{tabular}{lccc}
\cline { 2 - 3 } & \multicolumn{2}{c}{ Necrosis grasa del colgajo } & \multirow{2}{*}{ Total } \\
\cline { 2 - 3 } & No necrosis & Sí necrosis & \\
\hline Ninguna & 21 & 3 & $\mathbf{2 4}$ \\
Trayecto intertendinoso & 23 & 4 & $\mathbf{2 7}$ \\
Total & $\mathbf{4 4}$ & $\mathbf{7}$ & $\mathbf{5 1}$ \\
\hline
\end{tabular}




\begin{tabular}{lccc} 
& Valor & gl & $\begin{array}{c}\text { Sig. asintótica } \\
\text { (bilateral) }\end{array}$ \\
\hline Chi-cuadrado de Pearson & 0,057 & 1 & $\mathbf{0 , 5 6 8}$ \\
\hline
\end{tabular}

Tabla 69: Distribución de la aparición de necrosis grasa en función de las características del trayecto de la perforante.

\begin{tabular}{lccc} 
& \multicolumn{2}{c}{ Problemas circulatorios del colgajo } & \multirow{2}{*}{ Total } \\
\cline { 2 - 3 } & No problemas & Si problemas & \\
\hline Ninguna & 17 & 7 & $\mathbf{2 4}$ \\
Trayecto intertendinoso & 22 & 5 & $\mathbf{2 7}$ \\
Total & 39 & $\mathbf{1 2}$ & $\mathbf{5 1}$ \\
\hline
\end{tabular}

\begin{tabular}{llcc} 
& Valor & gl & $\begin{array}{c}\text { Sig. asintótica } \\
\text { (bilateral) }\end{array}$ \\
\hline Chi-cuadrado de Pearson &, $801^{\mathrm{a}}$ & 1 & $\mathbf{0 , 3 7 1}$ \\
\hline
\end{tabular}

Tabla 70: Distribución de la aparición de problemas circulatorios en función de la ramificación de la perforante dentro del colgajo.

\subsection{Línea de la perforante}

La perforante seleccionada correspondió a una línea de perforantes mediales en 34 casos $(55,7 \%)$ mientras que tuvo un origen en la línea lateral en 27 casos (44,3\%) (tabla $71)$.

\begin{tabular}{ccc}
\hline $\begin{array}{c}\text { LíNEA DE LA } \\
\text { PERFORANTE }\end{array}$ & $\begin{array}{c}\text { Frecuencia } \\
\text { (n=61) }\end{array}$ & Porcentaje (\%) \\
\hline Medial & 34 & 55,7 \\
Lateral & 27 & 44,3 \\
\hline
\end{tabular}

Tabla 71: Frecuencia y porcentaje de la línea de origen de la perforante del colgajo. 
En nuestro estudio, hay una asociación fuertemente significativa en la aparición de necrosis grasa cuando la perforante seleccionada pertenece a la línea lateral ( $\mathrm{p}$-value $=$ 0.013) (tabla 72 y gráfico 9). Aunque no llega a alcanzar el grado de significación estadística, se mantiene una asociación entre la aparición de problemas circulatorios del colgajo al utilizar perforantes más laterales $(\mathrm{p}$-value $=0,077)$ (tabla 73). No hemos encontrado una asociación entre los colgajos basados en la línea lateral y la necesidad de realizar un $2^{\circ}$ drenaje venoso por congestión del colgajo ( $p$-value $\left.=0,628\right)$ (tabla 74).

\begin{tabular}{lccc}
\cline { 2 - 3 } & \multicolumn{2}{c}{ Necrosis grasa colgajo } & \multirow{2}{*}{ Total } \\
\cline { 2 - 3 } & No necrosis & Si necrosis & \\
\hline Línea medial & 30 & 1 & $\mathbf{3 1}$ \\
Línea lateral & 19 & 7 & $\mathbf{2 6}$ \\
Total & $\mathbf{4 9}$ & $\mathbf{8}$ & $\mathbf{5 7}$ \\
\hline
\end{tabular}

\begin{tabular}{cccc} 
& Valor & gl & $\begin{array}{c}\text { Sig. exacta } \\
\text { (bilateral) }\end{array}$ \\
\hline $\begin{array}{c}\text { Chi-cuadrado de Pearson } \\
\text { Estadístico exacto de Fisher }\end{array}$ & 6,581 & 1 & \\
\hline
\end{tabular}

Tabla 72: Distribución de la línea de origen de la perforante en función de la aparición de necrosis grasa en el colgajo.

\begin{tabular}{lccc} 
& \multicolumn{2}{c}{ Problemas circulatorios del colgajo } & \multirow{2}{*}{ Total } \\
\cline { 2 - 3 } & No problemas & Si problemas & \\
\hline Línea medial & 26 & 4 & $\mathbf{3 0}$ \\
Línea lateral & 16 & 8 & $\mathbf{2 4}$ \\
Total & $\mathbf{4 2}$ & $\mathbf{1 2}$ & $\mathbf{5 4}$ \\
\hline
\end{tabular}

\begin{tabular}{lccc} 
& Valor & gl & $\begin{array}{c}\text { Sig. asintótica } \\
\text { (bilateral) }\end{array}$ \\
\hline Chi-cuadrado de Pearson & 3,086 & 1 & $\mathbf{0 , 0 7 7}$ \\
\hline
\end{tabular}

Tabla 73: Distribución de la línea de origen de la perforante en relación con la aparición de problemas circulatorios en el colgajo. 


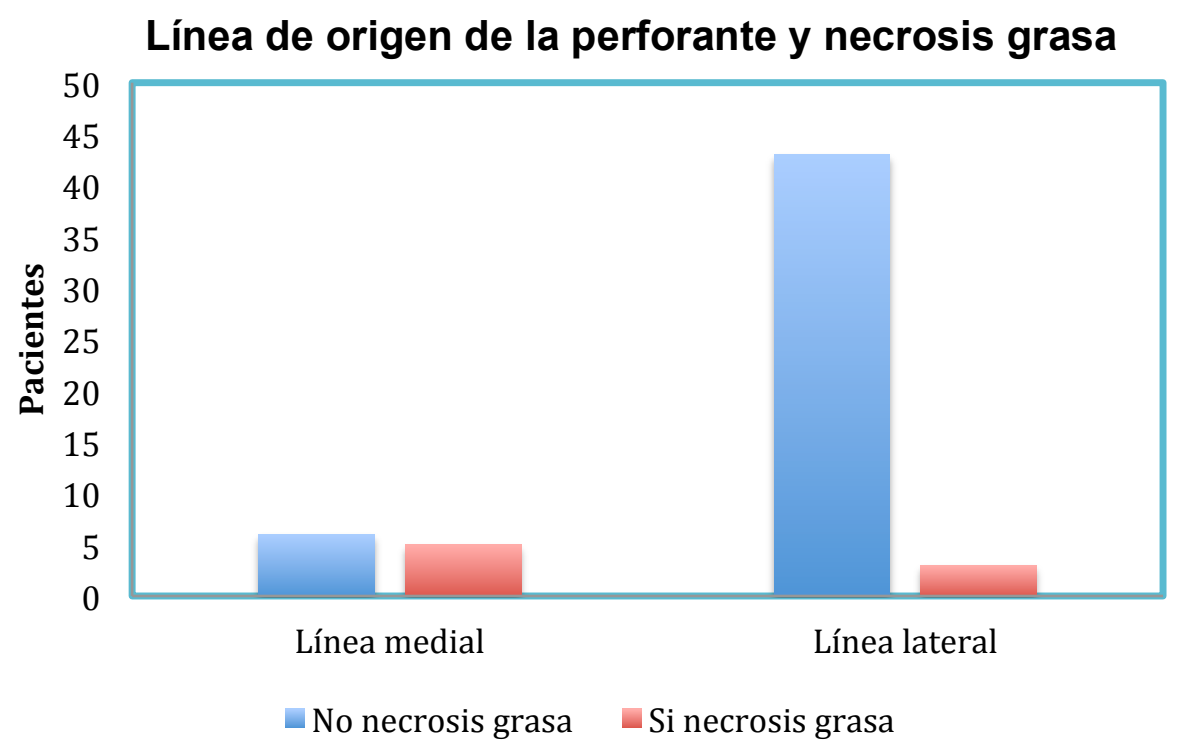

Gráfico 9: Línea de origen de la perforante en función de la aparición de problemas circulatorios en el colgajo.

\begin{tabular}{lccc}
\cline { 2 - 3 } & \multicolumn{2}{c}{ Necesidad de una 2 2 $^{\mathrm{a}}$ vena } & \multirow{2}{*}{ Total } \\
\cline { 2 - 3 } & Sí 2 ${ }^{\mathrm{a}}$ vena & No 2 $2^{\mathrm{a}}$ vena & \\
\hline Línea medial & 3 & 23 & $\mathbf{2 6}$ \\
Línea lateral & 3 & 24 & $\mathbf{4 7}$ \\
Total & 6 & $\mathbf{4 7}$ & $\mathbf{5 3}$ \\
\hline
\end{tabular}

\begin{tabular}{lccc} 
& Valor & gl & $\begin{array}{c}\text { Sig. asintótica } \\
\text { (bilateral) }\end{array}$ \\
\hline Chi-cuadrado de Pearson &, 929 & 2 & $\mathbf{0 , 6 2 8}$ \\
\hline
\end{tabular}

Tabla 74: Distribución de la realización de una $2^{\mathrm{a}}$ vena en función de la línea de origen de la perforante del colgajo.

\subsection{Localización de la salida de la perforante a nivel de fascia abdominal}

En la tabla 75 y en la figura 50 se refleja en un eje de coordenadas la localización de la salida a nivel de la fascia abdominal de los vasos perforantes seleccionados en cada reconstrucción. La salida de las perforantes en el eje X fue de media a 35,19 $\pm 14,23 \mathrm{~cm}$, 
mientras que en el eje $\mathrm{Y}$, la salida fue de media $22,78 \pm 18,39 \mathrm{~cm}$ por debajo del punto medio del ombligo.

\begin{tabular}{cccccc}
\cline { 2 - 5 } & $\mathbf{N}$ & $\begin{array}{c}\text { Media } \\
(\mathbf{m m})\end{array}$ & Desv. típ. & Mínimo & Máximo \\
\hline Eje X & 61 & 35,1967 & 14,23589 & 11,00 & 68,00 \\
Eje Y & 61 & 22,7868 & 18,39117 & $-9,00$ & 70,00 \\
\hline
\end{tabular}

Tabla 75: Localización de la salida de los vasos perforantes a nivel de fascia en un eje de coordenadas

\section{Localización de la perforante}

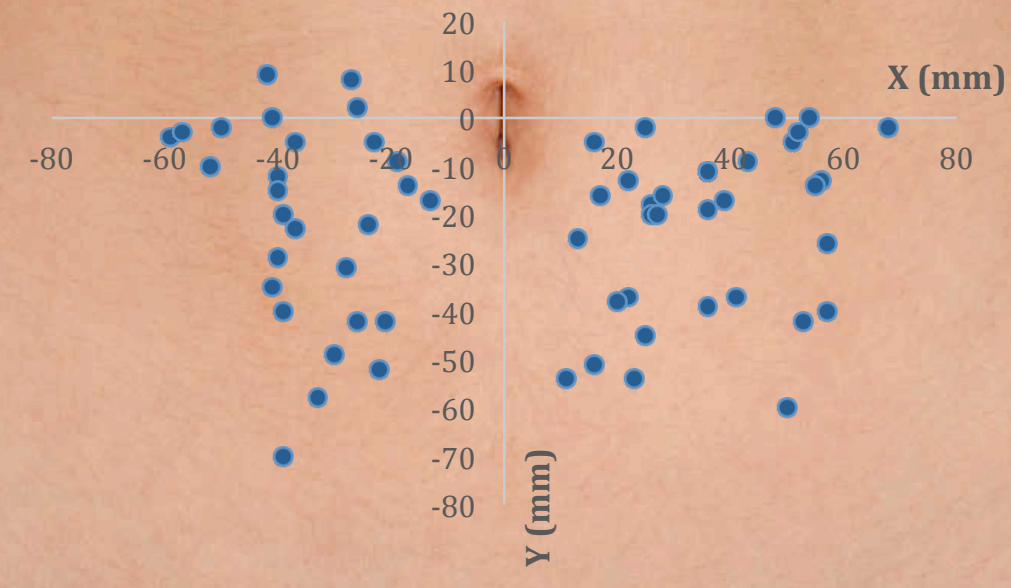

Figura 51: Localización de la salida de los vasos perforantes a nivel de fascia en un eje de coordenadas

Al comparar la localización de la salida de las perforantes a nivel de fascia abdominal en los colgajos que presentaron problemas circulatorios frente a los que no, se observa que la salida de las perforantes de los colgajos con problemas muestra una disposición más periférica que la de los colgajos no complicados.

Se observó una relación estadísticamente significativa entre la aparición de problemas circulatorios y la salida más lateral de la perforante en el eje $X(p$-value $=0,022)$. En 
cambio, no se observo que la localización de entrada de la perforante en el colgajo en el eje $Y(p$-value $=0,87)$ tuviera una influencia en la aparición de esta complicación, siendo la responsable del aumento de la diferencias entre ambos grupos ( $\mathrm{r}$ polar) el incremento de la distancia en el eje $X(p-v a l u e=0,023)($ tabla 76,77 y 78$)$.

$\mathrm{r}$ polar $=$ raíz cuadrada de $(\mathrm{X}$ al cuadrado $+\mathrm{Y}$ al cuadrado $)$

\begin{tabular}{cccccc}
\hline No complicaciones & N & Mínimo & Máximo & Media & Desviación tipica \\
\hline Eje X & 42 & 11,00 & 57,00 & 32,6905 & 12,69624 \\
Eje Y & 42 & $-9,00$ & 70,00 & 23,00 & 19,821 \\
r polar & 42 & 21,02 & 80,13 & 43,9450 & 15,19162 \\
\hline
\end{tabular}

Tabla 76: Localización de la salida de los vasos perforantes de los colgajos no complicados a nivel de fascia en un eje de coordenadas.

\begin{tabular}{cccccc}
\hline Problemas circulatorios & N & Mínimo & Máximo & Media & Desviación tipica \\
\hline Eje $X$ & 12 & 23,00 & 68,00 & 43,0000 & 15,33267 \\
Eje $Y$ & 12 &, 00 & 54,00 & 25,1667 & 19,46948 \\
r polar & 12 & 41,77 & 68,03 & 54,7170 & 7,48664 \\
\hline
\end{tabular}

Tabla 77: Localización de la salida de los vasos perforantes de los colgajos con problemas circulatorios a nivel de fascia en un eje de coordenadas.

\begin{tabular}{|c|c|c|c|c|c|c|c|c|}
\hline & $\mathrm{F}$ & Sig. $=p$ & & $\mathrm{~F}$ & Sig. $=p$ & & $\mathrm{~F}$ & Sig. $=p$ \\
\hline Eje X & 5,610 & 0,022 & Eje $Y$ & 0,027 & 0,87 & $r$ polar & 5,588 & 0,023 \\
\hline
\end{tabular}

Tabla 78: Resultados del test ANOVA.

En las figuras 51 y 52 se reflejan en un eje de coordenadas, la localización de salida de la perforante a nivel de la fascia abdominal en aquellos colgajos que no presentaron complicaciones frente aquellos que sí tuvieron problemas circulatorios. En estos últimos se observa una localización más periférica de las perforantes con respecto a aquellos sin complicaciones. 


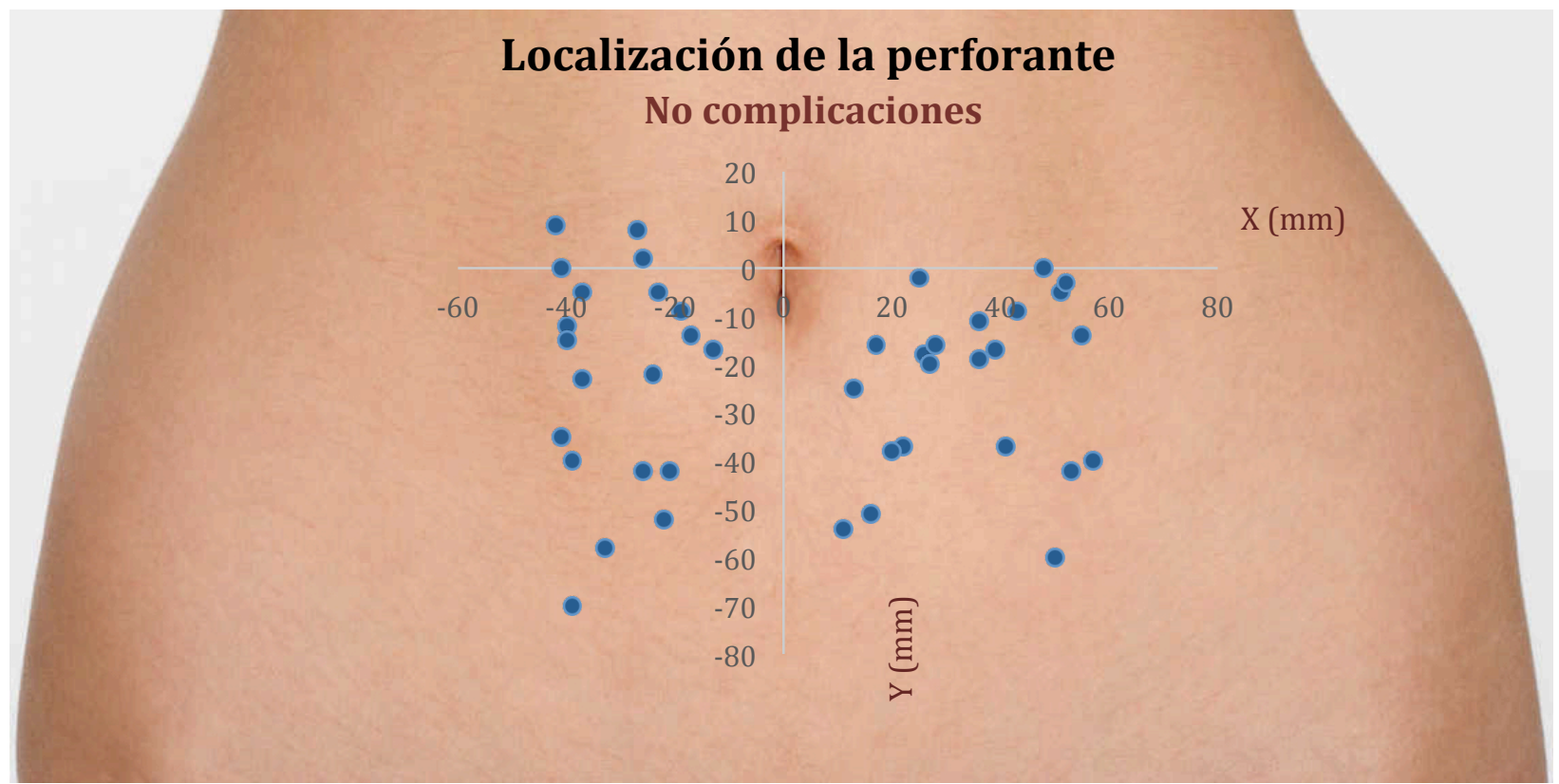

Figura 51: Localización de la salida de los vasos perforantes a nivel de fascia de los colgajos sin complicaciones circulatorias en un eje de coordenadas.

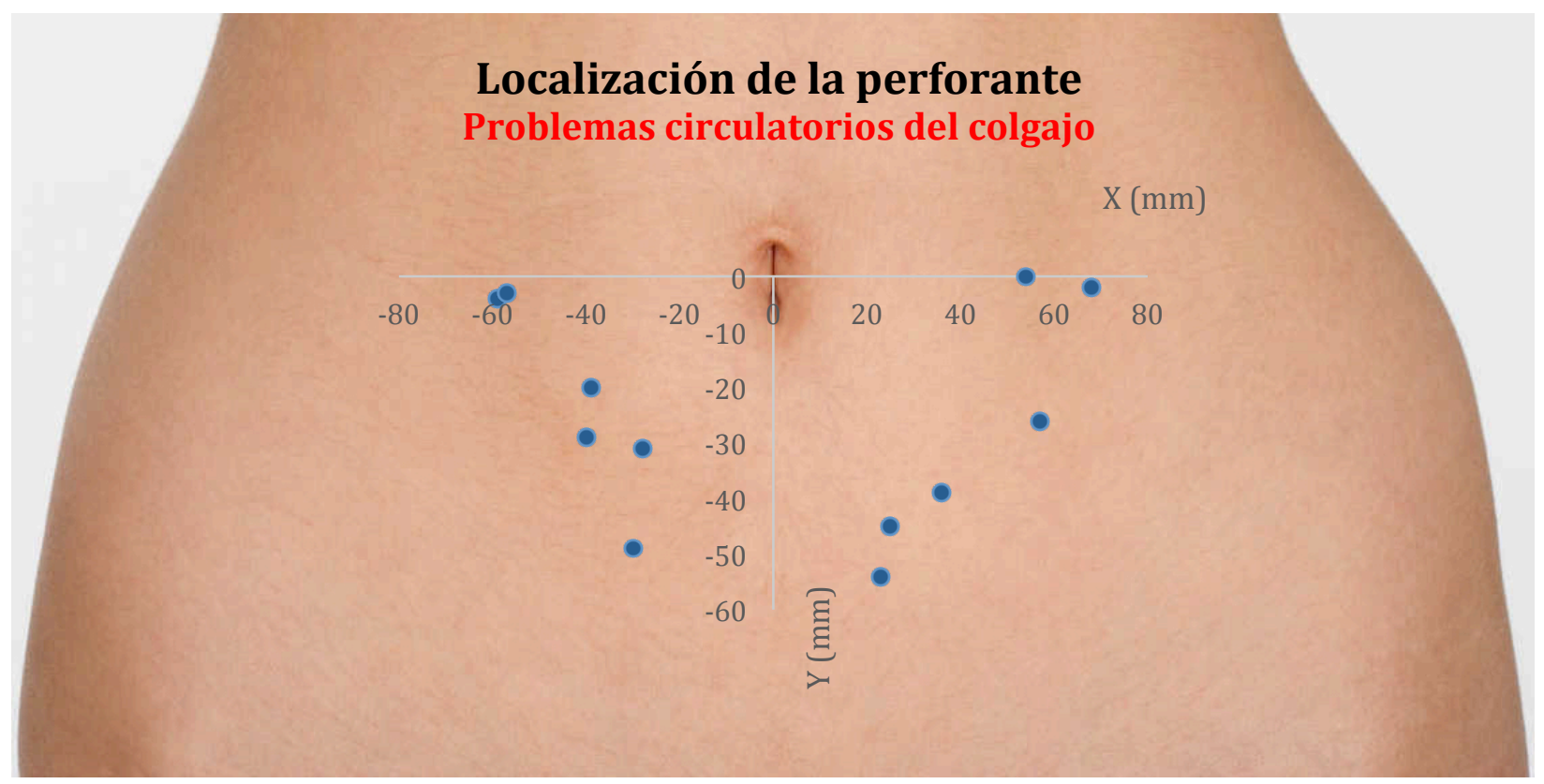

Figura 52: Localización de la salida de los vasos perforantes a nivel de fascia de los colgajos con problemas circulatorios en un eje de coordenadas.

Se estimó que por cada centímetro que aumenta la distancia de la salida de la perforante en el eje $\mathrm{X}$, el riesgo de sufrir complicaciones circulatorias en el colgajo se 
incrementa en un 5,9\% (OR: 1,059 IC 95\%: 1,006-1,115) (tabla 79). En la figura 53 se presenta un caso de un colgajo con una perforante medial y muy craneal que evolucionó sin complicaciones.

\begin{tabular}{|c|c|c|c|}
\hline \multirow[b]{3}{*}{ Distancia en el eje $X$} & \multirow{2}{*}{ Odds ratio } & \multicolumn{2}{|c|}{ Intervalo de confianza (95\%) } \\
\hline & & Inferior & Superior \\
\hline & 1,059 & 1,006 & 1,115 \\
\hline
\end{tabular}

Tabla 79: OR e intervalo de confianza de sufrir problemas circulatorios en el colgajo.
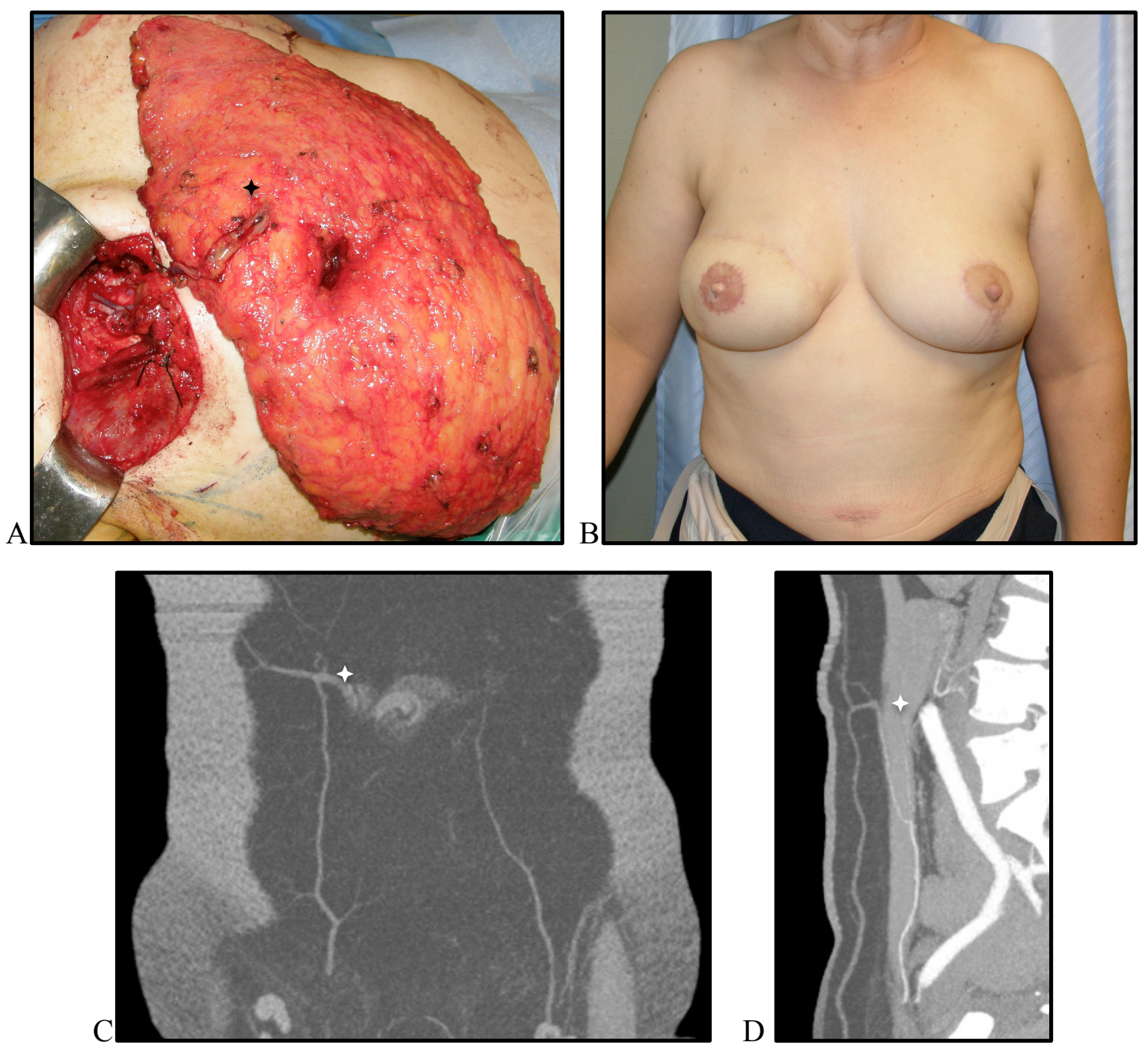

Figura 53. A: Colgajo tras la anastomosis. Se observa la entrada de la perforante en una localización medial y muy craneal (-8 mm en el eje Y) dentro del colgajo (estrella negra). B: Resultado final. La paciente no presentó ninguna complicación circulatoria en el colgajo. C y D: Imágenes MIP de proyecciones coronal y sagital en las que se observa la perforante seleccionada (estrella blanca), su conexión con el sistema venoso superficial y su trayecto intramuscular. 


\subsection{Número de perforantes del colgajo}

En 51 reconstrucciones $(83,6 \%)$ el colgajo se basó en una única perforante, en 9 casos $(14,8 \%)$ se elevo sobre dos perforantes y en un único caso $(1,6 \%)$ se emplearon tres perforantes (tabla 81).

\begin{tabular}{ccc}
\hline $\begin{array}{c}\text { NÚMERO DE } \\
\text { PERFORANTES DEL } \\
\text { COLGAJO }\end{array}$ & $\begin{array}{c}\text { Frecuencia } \\
\text { (n=61) }\end{array}$ & $\begin{array}{c}\text { Porcentaje } \\
(\%)\end{array}$ \\
\hline Una & 51 & 83,6 \\
Dos & 9 & 14,8 \\
Tres & 1 & 1,6 \\
\hline
\end{tabular}

Tabla 80: Frecuencia y porcentaje del número de perforantes disecadas con el colgajo.

No se observó una relación significativa entre el número de perforantes sobre las que se basa el colgajo y la aparición de necrosis grasa ( $\mathrm{p}$-value $=0,468$ ) (tabla 82 ) o problemas circulatorios ( $\mathrm{p}$-value $=0,261)$ (tabla 83). Esta situación no se modifica al estudiar los colgajos basados en una o dos perforantes únicamente $(\mathrm{p}$-value $=0,124)$ (tabla 84$)$.

\begin{tabular}{lccc}
\cline { 2 - 3 } & \multicolumn{2}{c}{ Necrosis grasa colgajo } & \multirow{2}{*}{ Total } \\
\cline { 2 - 3 } & No necrosis & Sí necrosis & \\
\hline Una perforante & 41 & 8 & 49 \\
Dos perforantes & 7 & 0 & 7 \\
Tres perforantes & 1 & 0 & $\mathbf{1}$ \\
Total & $\mathbf{4 9}$ & $\mathbf{8}$ & $\mathbf{5 7}$ \\
\hline
\end{tabular}

\begin{tabular}{lccc} 
& Valor & gl & $\begin{array}{c}\text { Sig. asintótica } \\
\text { (bilateral) }\end{array}$ \\
\hline Chi-cuadrado de Pearson & 1,519 & 1 & $\mathbf{0 , 4 6 8}$ \\
\hline
\end{tabular}

Tabla 81: Distribución de la aparición de necrosis grasa en función del número de perforantes del colgajo. 


\begin{tabular}{lccc} 
& \multicolumn{2}{c}{ Problemas circulatorios del colgajo } & \multirow{2}{*}{ Total } \\
\cline { 2 - 3 } & No problemas & Sí problemas & \\
\hline Una perforante & 34 & 12 & $\mathbf{4 6}$ \\
Dos perforantes & 7 & 0 & $\mathbf{7}$ \\
Tres perforantes & 1 & 0 & $\mathbf{1}$ \\
Total & $\mathbf{4 2}$ & $\mathbf{1 2}$ & $\mathbf{5 4}$ \\
\hline
\end{tabular}

\begin{tabular}{lccc} 
& Valor & gl & $\begin{array}{c}\text { Sig. asintótica } \\
\text { (bilateral) }\end{array}$ \\
\hline Chi-cuadrado de Pearson & 2,683 & 2 & $\mathbf{0 , 2 6 1}$ \\
\hline
\end{tabular}

Tabla 82: Distribución de la aparición de problemas circulatorios en función del número de perforantes del colgajo.

\begin{tabular}{lccc} 
& \multicolumn{2}{c}{ Problemas circulatorios del colgajo } & \multirow{2}{*}{ Total } \\
\cline { 2 - 3 } & No problemas & Sí problemas & \\
\hline Una perforante & 34 & 12 & $\mathbf{4 6}$ \\
Dos perforantes & 7 & 0 & $\mathbf{7}$ \\
Total & $\mathbf{4 2}$ & $\mathbf{1 2}$ & $\mathbf{5 4}$ \\
\hline
\end{tabular}

\begin{tabular}{lccc} 
& Valor & gl & $\begin{array}{c}\text { Sig. asintótica } \\
\text { (bilateral) }\end{array}$ \\
\hline Chi-cuadrado de Pearson & 2,361 & 1 & $\mathbf{0 , 1 2 4}$ \\
\hline
\end{tabular}

Tabla 83: Distribución de la aparición de problemas circulatorios en función de si el colgajo se diseca sobre una o dos perforantes

\subsection{Ramificación de la perforante}

La perforante seleccionada presentó en 47 casos (77\%) una buena ramificación dentro del panículo adiposo del colgajo, hecho que puede estar en consonancia con una mejor perfusión del tejido transferido. En 14 casos (23\%) la perforante no exhibió esta característica (tabla 85). 


\begin{tabular}{ccc}
\hline $\begin{array}{c}\text { RAMIFICACIÓN } \\
\text { DE LA } \\
\text { PERFORANTE }\end{array}$ & $\begin{array}{c}\text { Frecuencia } \\
(\mathbf{n = 6 1 )}\end{array}$ & Porcentaje (\%) \\
\hline No & 14 & 23,0 \\
Sí & 47 & 77,0 \\
\hline
\end{tabular}

Tabla 84: Frecuencia y porcentaje de la ramificación de la perforante dentro del colgajo.

En nuestro estudio se observa una asociación que no llega a ser significativa entre la división en varias ramas de la perforante seleccionada y la no aparición de necrosis grasa $(\mathrm{p}$-value $=0.070)($ tabla 86 y gráfico 10). Con una muestra mayor es posible que se alcanzase una relación significativa. En cambio, si que se observó una clara asociación estadística en la no aparición de problemas circulatorios del colgajo cuando se escoge una perforante con ramificaciones en el tejido subcutáneo del colgajo (p-value $=0.000)$ (tabla 87 y gráfico 11).

\begin{tabular}{lccc}
\cline { 2 - 3 } & \multicolumn{2}{c}{ Necrosis grasa del colgajo } & \multirow{2}{*}{ Total } \\
\cline { 2 - 3 } & No necrosis & Sí necrosis & \\
\hline No ramificación & 9 & 4 & 13 \\
Sí ramificación & 40 & 4 & 44 \\
Total & 49 & 8 & 57 \\
\hline
\end{tabular}

\begin{tabular}{cccc} 
& Valor & gl & $\begin{array}{c}\text { Sig. exacta } \\
\text { (bilateral) }\end{array}$ \\
\hline $\begin{array}{c}\text { Chi-cuadrado de Pearson } \\
\text { Estadístico exacto de Fisher }\end{array}$ & 3,909 & 1 & \\
\hline
\end{tabular}

Tabla 85: Distribución de la aparición de necrosis grasa en función de si la perforante se ramifica dentro del colgajo. 


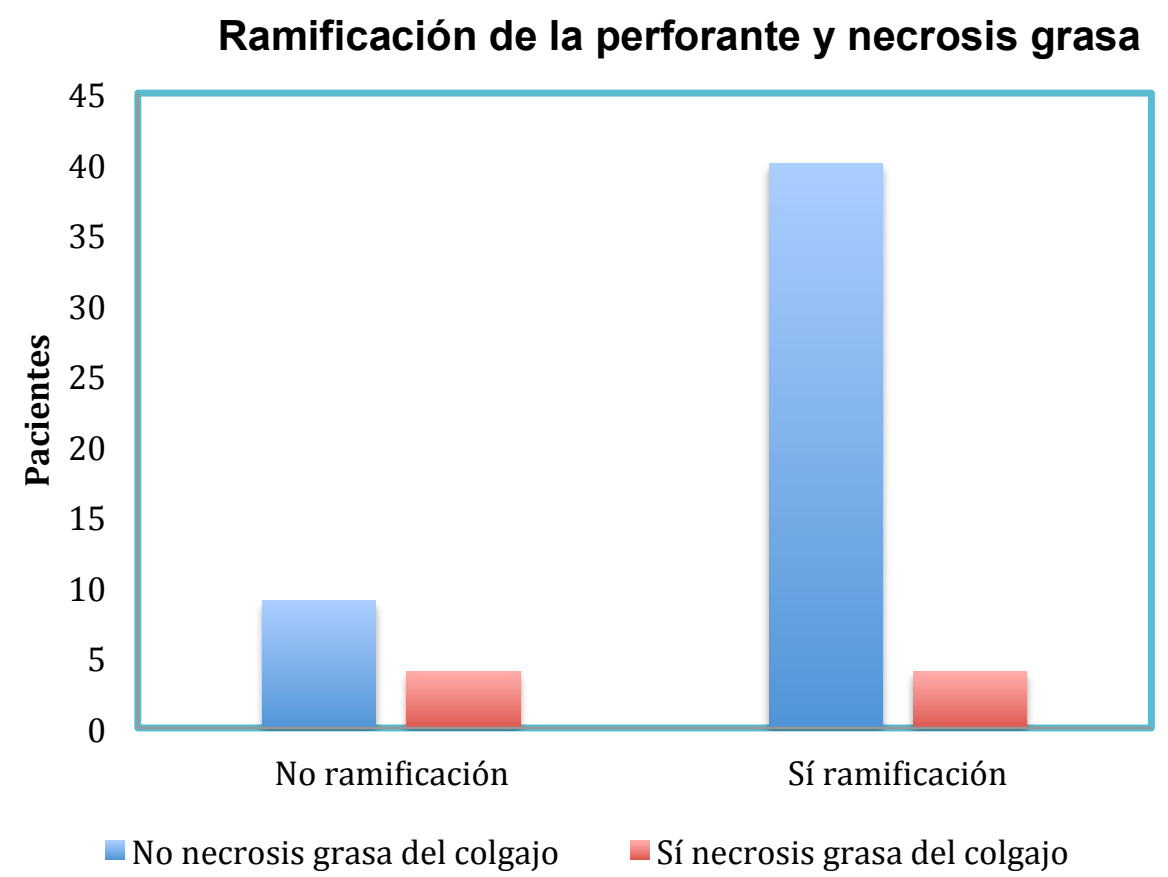

Gráfico 10: Aparición de necrosis grasa en el colgajo en función de la ramificación de la perforante.

\begin{tabular}{lccc} 
& \multicolumn{2}{c}{ Problemas circulatorios del colgajo } & \multirow{2}{*}{ Total } \\
\cline { 2 - 3 } & No problemas & Si problemas & \\
\hline No ramificación & 5 & 8 & 13 \\
Sí ramificación & 37 & 4 & 41 \\
Total & $\mathbf{4 2}$ & $\mathbf{1 2}$ & $\mathbf{5 4}$ \\
\hline
\end{tabular}

\begin{tabular}{lccc} 
& Valor & gl & $\begin{array}{c}\text { Sig. asintótica } \\
\text { (bilateral) }\end{array}$ \\
\hline Chi-cuadrado de Pearson & 15,313 & 1 & $\mathbf{0 , 0 0 0}$ \\
\hline
\end{tabular}

Tabla 86: Distribución de la aparición de problemas circulatorios en función de la ramificación de la perforante dentro del colgajo. 


\section{Ramificación de la perforante y problemas circulatorios}

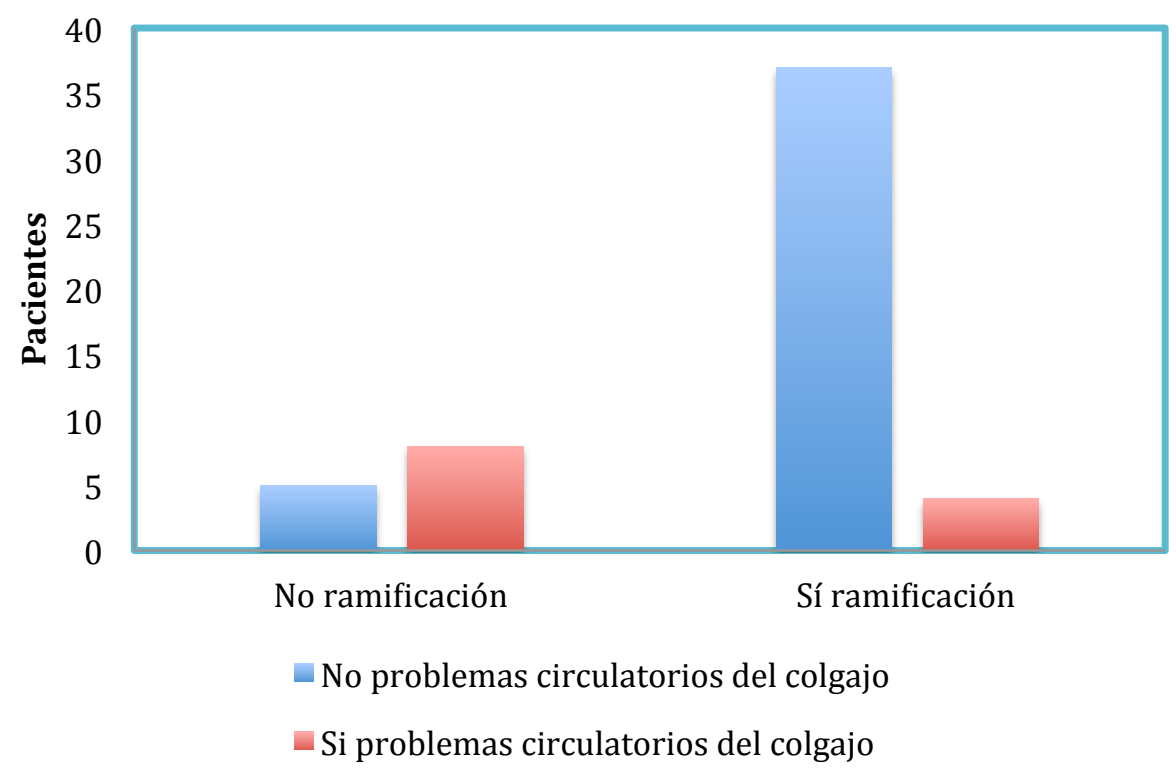

Gráfico 11: Aparición de problemas circulatorios en el colgajo en función de la ramificación de la perforante.

\subsection{Mejor perforante sobre la que basar el colgajo}

Tras el análisis retrospectivo de todos los angio TC, se concluyó que la perforante en la que se basó el colgajo fue la mejor en 48 casos $(78,7 \%)$ de acuerdo a los parámetros establecidos. Sin embargo, las posibilidades en el postprocesamiento de imágenes que ofreció el método de estudio elegido recomendó la elección de una perforante diferente a la escogida en 13 casos (21,3\%) (tabla 88$)$

\begin{tabular}{ccc}
\hline $\begin{array}{c}\text { MEJOR } \\
\text { PERFORANTE }\end{array}$ & $\begin{array}{c}\text { Frecuencia } \\
(\mathbf{n = 6 1 )}\end{array}$ & Porcentaje (\%) \\
\hline No & 13 & 21,3 \\
Sí & 48 & 78,7 \\
\hline
\end{tabular}

Tabla 87: Frecuencia y porcentaje de la mejor perforante del colgajo . 
En nuestro estudio se observa una clara asociación estadística en la aparición de necrosis grasa $(\mathrm{p}$-value $=0.007)$ y problemas circulatorios del colgajo cuando no se escoge la mejor perforante del angio TC (p-value $=0.000)($ tablas 89 y 90; gráfico 12 y 13).

\begin{tabular}{lccc}
\cline { 2 - 3 } & \multicolumn{2}{c}{ Necrosis grasa del colgajo } & \multirow{2}{*}{ Total } \\
\cline { 2 - 4 } & No necrosis & Sí necrosis & \\
\hline No mejor perforante & 7 & 5 & $\mathbf{1 2}$ \\
Sí mejor perforante & 42 & 3 & $\mathbf{4 5}$ \\
Total & $\mathbf{4 9}$ & $\mathbf{8}$ & $\mathbf{5 7}$ \\
\hline
\end{tabular}

\begin{tabular}{cccc} 
& Valor & gl & $\begin{array}{c}\text { Sig. exacta } \\
\text { (bilateral) }\end{array}$ \\
\hline $\begin{array}{c}\text { Chi-cuadrado de Pearson } \\
\text { Estadístico exacto de Fisher }\end{array}$ & 9,619 & 1 & \\
\hline
\end{tabular}

Tabla 88: Distribución de la aparición de necrosis grasa en función de si la perforante en la que se basó el colgajo se consideró la mejor.

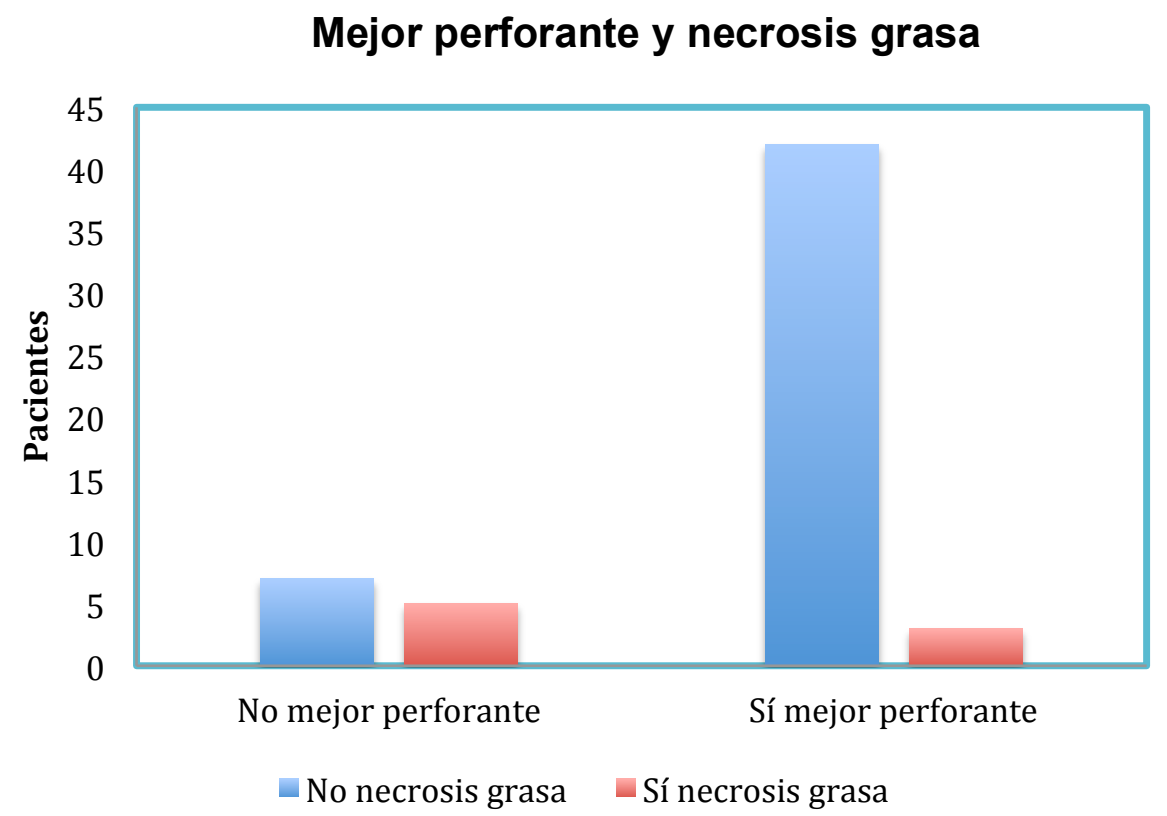

Gráfico 12: Aparición de necrosis grasa en el colgajo en función de si la perforante en la que se basó el colgajo se consideró la mejor. 


\begin{tabular}{lccc} 
& \multicolumn{2}{c}{ Problemas circulatorios del colgajo } & \multirow{2}{*}{ Total } \\
\cline { 2 - 3 } & No problemas & Si problemas & \\
\hline No mejor perforante & 3 & 9 & $\mathbf{1 2}$ \\
Sí mejor perforante & 39 & 3 & $\mathbf{4 2}$ \\
Total & $\mathbf{4 2}$ & $\mathbf{1 2}$ & $\mathbf{5 4}$ \\
\hline
\end{tabular}

\begin{tabular}{lccc} 
& Valor & gl & $\begin{array}{c}\text { Sig. asintótica } \\
\text { (bilateral) }\end{array}$ \\
\hline Chi-cuadrado de Pearson & 24,865 & 1 & $\mathbf{0 , 0 0 0}$ \\
\hline
\end{tabular}

Tabla 89: Distribución de la aparición de problemas circulatorios en función de si la perforante en la que se basó el colgajo se consideró la mejor.

\section{Mejor perforante y problemas circulatorios}

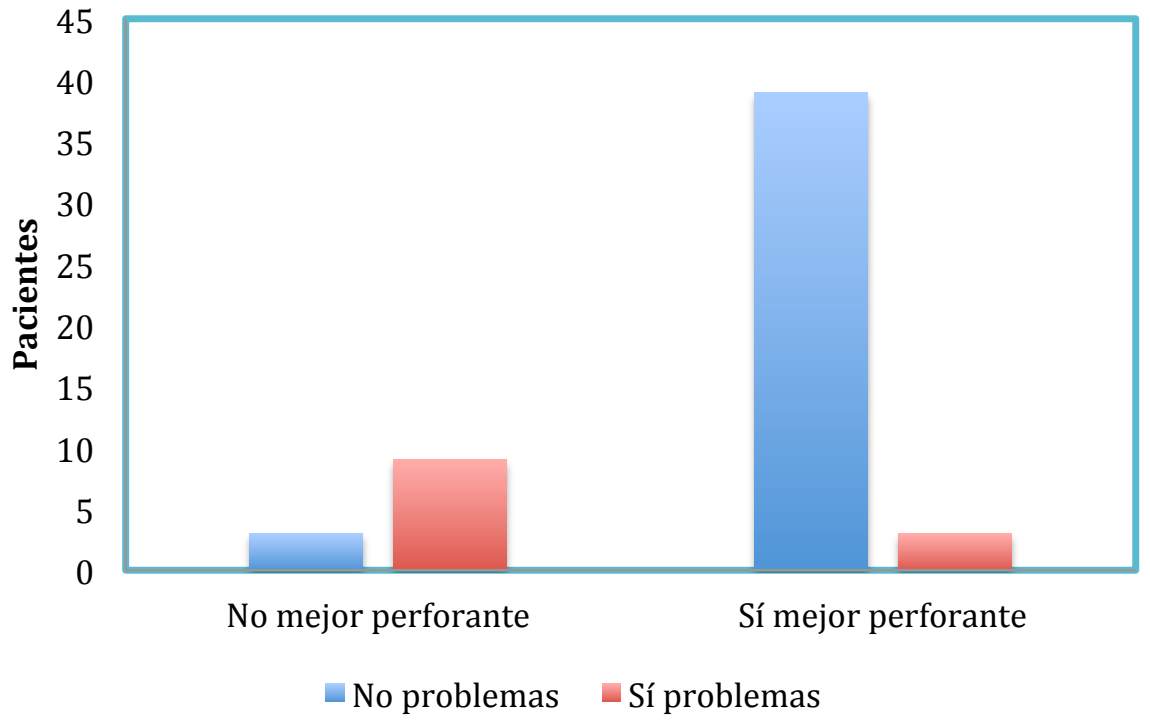

Gráfico 13: Aparición de problemas circulatorios en el colgajo en función de si la perforante en la que se basó el colgajo se consideró la mejor.

\subsection{Conexión de la perforante al sistema venoso superficial}

La conexión de la perforante seleccionada mostró conexión con el sistema venoso superficial en 49 casos (80,3\%), mientras que los 12 casos restantes (19,7\%) no se observó esta anastomosis (tabla 91). 


\begin{tabular}{ccc}
\hline $\begin{array}{c}\text { CONEXIÓN AL } \\
\text { SISTEMA VENOSO }\end{array}$ & $\begin{array}{c}\text { Frecuencia } \\
(\mathbf{n = 6 1 )}\end{array}$ & Porcentaje (\%) \\
\hline No & 12 & 19,7 \\
Sí & 49 & 80,3 \\
\hline
\end{tabular}

Tabla 90: Frecuencia y porcentaje de los vasos perforantes que tienen conexiones con el sistema venoso superficial del colgajo.

En nuestro estudio se observa que cuando se seleccionó una perforante que no estaba conectada al sistema venoso superficial, la aparición de necrosis grasa en el colgajo aumento de forma significativa ( $\mathrm{p}$-value $=0,005$ ) (tabla 92 y gráfico 14). Esta asociación también es significativa para en la aparición de problemas circulatorios en el colgajo (pvalue $=0.000)($ tabla 93 y gráfico 15$)$.

\begin{tabular}{lccc}
\cline { 2 - 3 } & \multicolumn{2}{c}{ Necrosis grasa en el colgajo } & \multirow{2}{*}{ Total } \\
\cline { 2 - 4 } & No necrosis & Si necrosis & \\
\hline No conexión & 6 & 5 & $\mathbf{1 1}$ \\
Sí conexión & 43 & 3 & $\mathbf{4 6}$ \\
Total & $\mathbf{4 9}$ & $\mathbf{8}$ & $\mathbf{5 7}$ \\
\hline
\end{tabular}

\begin{tabular}{cccc} 
& Valor & gl & $\begin{array}{c}\text { Sig. exacta } \\
\text { (bilateral) }\end{array}$ \\
\hline $\begin{array}{c}\text { Chi-cuadrado de Pearson } \\
\text { Estadístico exacto de Fisher }\end{array}$ & 11,152 & 1 & \\
\hline
\end{tabular}

Tabla 91: Distribución de la conexión de la perforante con el sistema venoso superficial en relación de la aparición de necrosis grasa en el colgajo. 
Conexión al sistema superficial y necrosis grasa

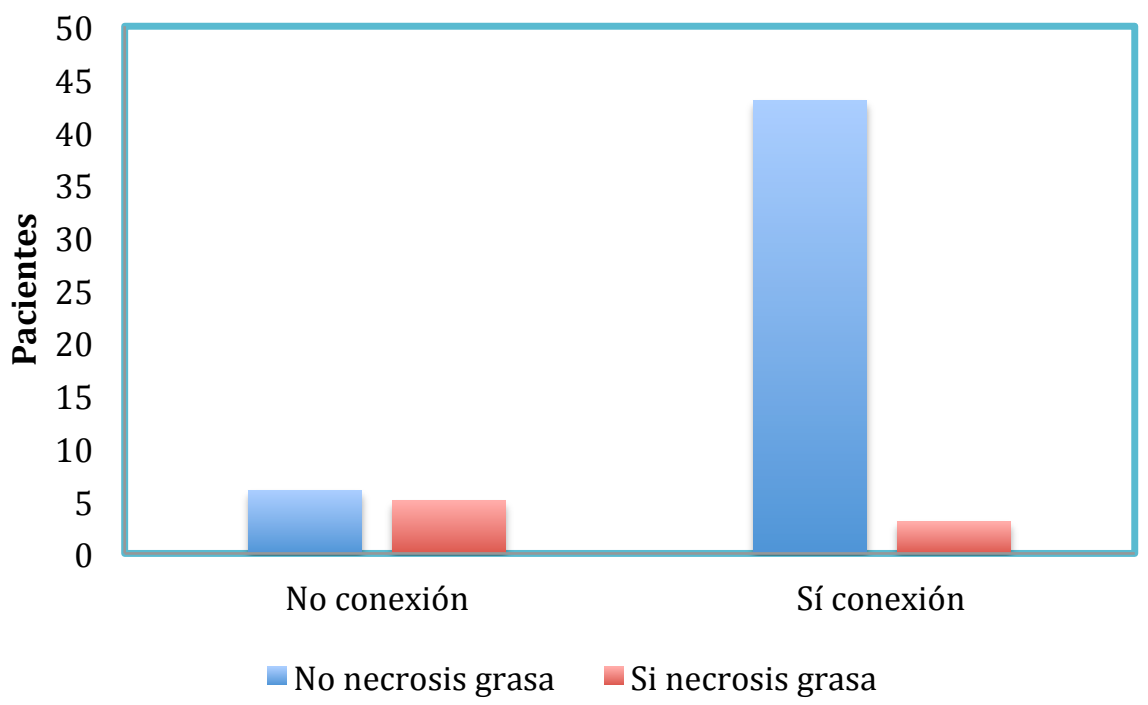

Gráfico 14: Aparición de necrosis grasa en el colgajo en función de si la perforante estaba conectada con el sistema superficial.

Esta asociación también es significativa para en la aparición de problemas circulatorios en el colgajo $(\mathrm{p}$-value $=0.000)($ tabla 93 y gráfico 15$)$.

\begin{tabular}{lccc} 
& \multicolumn{2}{c}{ Problemas circulatorios del colgajo } & \multirow{2}{*}{ Total } \\
\cline { 2 - 3 } & No problemas & Si problemas & \\
\hline No conexión & 2 & 9 & 11 \\
Sí conexión & 40 & 3 & 43 \\
Total & $\mathbf{4 2}$ & $\mathbf{1 2}$ & $\mathbf{5 4}$ \\
\hline
\end{tabular}

\begin{tabular}{lccc} 
& Valor & gl & $\begin{array}{c}\text { Sig. asintótica } \\
\text { (bilateral) }\end{array}$ \\
\hline Chi-cuadrado de Pearson & 28,386 & 1 & $\mathbf{0 , 0 0 0}$ \\
\hline
\end{tabular}

Tabla 92: Distribución de la conexión de la perforante con el sistema venoso superficial en relación de la aparición de problemas circulatorios en el colgajo. 


\section{Conexión al sistema superficial y problemas circulatorios}

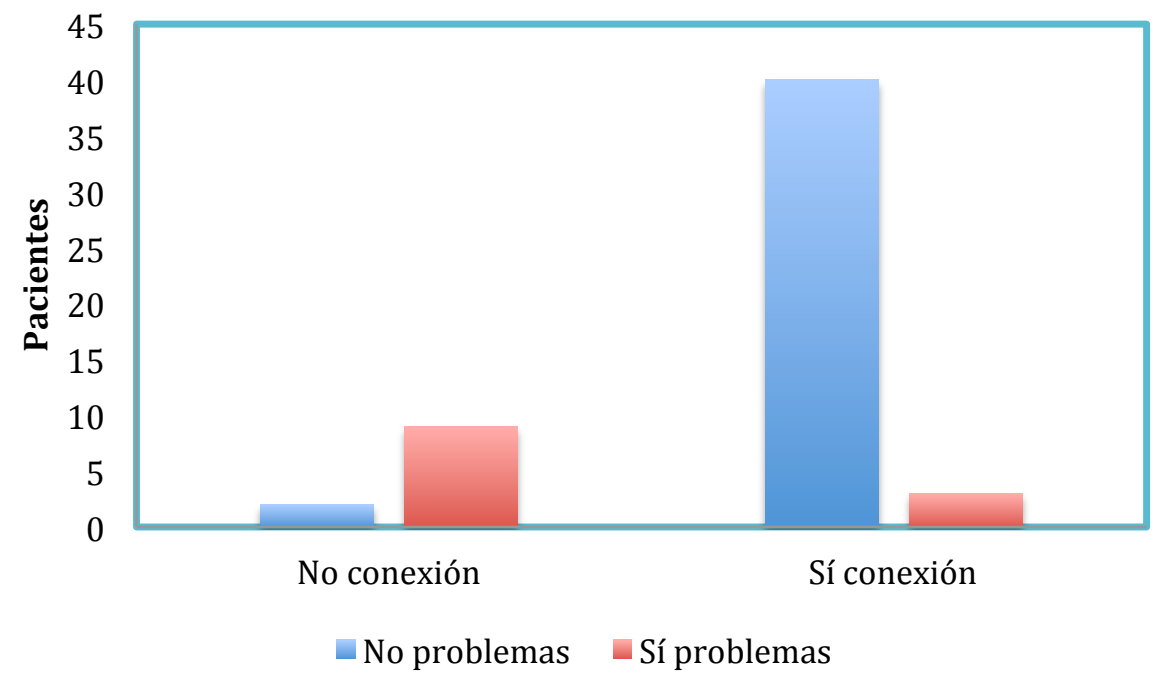

Gráfico 15: Aparición de problemas circulatorios en el colgajo en función de si la perforante estaba conectada con el sistema superficial.

El 96,6\% de las perforantes seleccionadas que presentaron ramificaciones amplias dentro del colgajo también demostraron una conexión directa con el sistema venoso superficial, lo que pone de manifiesto la estrecha relación entre ambos parámetros ( $\mathrm{p}$-value $=0.000$ ) (tabla 94).

\begin{tabular}{lccc}
\cline { 2 - 3 } & \multicolumn{2}{c}{ Ramificación de la perforante } & \multirow{2}{*}{ Total } \\
\cline { 2 - 3 } & No ramificación & Si ramificación & \\
\hline No conexión & 0 & 2 & 2 \\
Sí conexión & 4 & 55 & 59 \\
Total & 4 & 57 & 61 \\
\hline
\end{tabular}

\begin{tabular}{lccc} 
& Valor & gl & $\begin{array}{c}\text { Sig. asintótica } \\
\text { (bilateral) }\end{array}$ \\
\hline Chi-cuadrado de Pearson & 42,210 & 1 & $\mathbf{0 , 0 0 0}$ \\
\hline
\end{tabular}

Tabla 93: Distribución de la conexión de la perforante con el sistema venoso superficial en relación con la ramificación de la perforante. 


\subsection{Realización de una anastomosis venosa superficial}

En nuestra muestra, fue preciso realizar una anastomosis de una vena epigástrica inferior superficial del colgajo a una vena cefálica o a una vena del eje subescapular en 10 reconstrucciones $(16,4 \%)$, frente a 51 ocasiones $(83,6 \%)$ en las que no fue realizada (tabla 95).

La indicación para realizar esta anastomosis fue en 9 casos $(14,8 \%)$ para resolver un problema de congestión venosa del colgajo como un segundo drenaje venoso de refuerzo a la anastomosis principal [por problemas intrínsecos al colgajo en 7 casos $(11,5 \%)$ y por mala calidad del vasorreceptor en 2 casos $(3,3 \%)]$. En una intervención $(1,6 \%)$ se utilizó como único drenaje venoso del colgajo por la lesión iatrogénica de la vena mamaria interna.

\begin{tabular}{lcc}
\hline ANASTOMOSIS VENOSA SUPERFICIAL & $\begin{array}{c}\text { Frecuencia } \\
(\mathrm{n}=\mathbf{6 1})\end{array}$ & $\begin{array}{c}\text { Porcentaje } \\
(\%)\end{array}$ \\
\hline NO ANASTOMOSIS VENOSA SUPERFICIAL & $\mathbf{5 1}$ & $\mathbf{8 3 , 6}$ \\
Sí ANASTOMOSIS VENOSA SUPERFICIAL & 10 & $\mathbf{1 6 , 4}$ \\
Congestión venosa del colgajo & 9 & 14,8 \\
Lesión iatrogénica del vasorreceptor principal & 1 & 1,6 \\
\hline
\end{tabular}

Tabla 94: Frecuencia y porcentaje de la realización de una segunda anastomosis venosa.

No se observó una relación significativa entre la realización de este drenaje venoso del sistema superficial y un efecto protector en la aparición de necrosis grasa en el colgajo (pvalue $=0,783)$ (tabla 96). De los pacientes estudiados, sólo hubo un caso en el que apareció necrosis grasa en el colgajo con una vena del sistema superficial anastomosada. Este caso corresponde a una reconstrucción inmediata con una mastectomía ahorradora de piel. El problema de congestión se detectó a las 4 horas del fin de la intervención y se realizó un drenaje venoso accesorio superficial. A pesar de la falta asociación en este estudio sería aconsejable evaluar esta variable con una muestra mayor, debido a que varios 
autores consideran el sistema venoso superficial como el principal retorno venoso de la pared cutáneo adiposa abdominal.

\begin{tabular}{lccc}
\cline { 2 - 3 } & \multicolumn{2}{c}{ Necrosis grasa en el colgajo } & \multirow{2}{*}{ Total } \\
\cline { 2 - 3 } & No necrosis & Sí necrosis & \\
\hline No anastomosis superficial & 41 & 7 & $\mathbf{4 8}$ \\
Sí anastomosis superficial & 8 & 1 & $\mathbf{9}$ \\
Total & $\mathbf{4 9}$ & $\mathbf{8}$ & $\mathbf{5 7}$ \\
\hline
\end{tabular}

\begin{tabular}{cccc} 
& Valor & gl & $\begin{array}{c}\text { Sig. asintótica } \\
\text { (bilateral) }\end{array}$ \\
\hline Chi-cuadrado de Pearson & 0,076 & 1 & $\mathbf{0 , 7 8 3}$ \\
\hline
\end{tabular}

Tabla 95: Distribución de la conexión de la perforante con el sistema venoso superficial en relación de la aparición de necrosis grasa en el colgajo. 


\section{PROCEDIMIENTOS DE SIMETRIZACIÓN MAMARIA Y RECONSTRUCCIÓN DEL COMPLEJO AREOLA-PEZÓN}

\subsection{Simetrización de la mama contralateral}

Del total de reconstrucciones revisadas en este trabajo, en 40 casos $(65,57 \%)$ hubo que realizar alguna técnica de simetrización en la mama contralateral para obtener el mayor grado de simetría posible. Mientras que en las 12 primeras reconstrucciones de nuestra serie $(30 \%)$ se realizó de forma diferida, en las 28 restantes $(70 \%)$ se realizó en el mismo tiempo que la reconstrucción con el colgajo DIEP. En 21 casos (52,5\%) el procedimiento realizado fue una mastopexia, el 15 casos $(37,5)$ una mamoplastia de reducción, en 4 casos (10\%) una reconstrucción mamaria (de los cuales 2 corresponden al DIEP bilateral y los otros 2 a una reconstrucción con colgajo de dorsal ancho). Las técnicas empleadas en la reducción y en la pexia mamaria fueron muy diversas y dependieron de las características de la mama contralateral así como de las preferencias del cirujano (tabla 97).

\begin{tabular}{lcc}
\hline SIMETRIZACIÓN MAMA CONTRALATERAL & $\begin{array}{c}\text { Frecuencia } \\
(\mathbf{n = 6 1 )}\end{array}$ & $\begin{array}{c}\text { Porcentaje } \\
(\%)\end{array}$ \\
\hline NO FUE PRECISO NINGÚN PROCEDIMIENTO & $\mathbf{2 1}$ & $\mathbf{3 4 , 4}$ \\
SE REALIZÓ CIRUGÍA SIMETRIZADORA & $\mathbf{4 0}$ & $\mathbf{6 5 , 6}$ \\
\hline SEGÚN EL MOMENTO DE LA SIMETRIZACIÓN & 40 & $\mathbf{1 0 0}$ \\
De manera diferida & 12 & 30 \\
A la vez que la RM con colgajo DIEP & 28 & 70 \\
& & 100 \\
\hline SEGÚN LA TÉCNICA EMPLEADA & 40 & 52,5 \\
Mastopexia & 21 & 37,5 \\
Mamoplastia de reducción & 15 & 10 \\
Reconstrucción mamaria & 4 &
\end{tabular}

Tabla 96: Simetrización de la mama contralateral. 


\subsection{Procedimiento sobre la mama reconstruida}

De las 61 revisadas en nuestro estudio, 47 pacientes $(77,1 \%)$ recibieron algún procedimiento complementario sobre la mama reconstruida. De las 18 reconstrucciones restantes $(22,9 \%), 5$ pacientes $(8,1 \%)$ no desearon realizar ningún procedimiento adicional, en 4 casos $(6,6 \%)$ fue por necrosis completa del colgajo, en $3(4,9 \%)$ por exitus de la paciente durante el seguimiento y 2 casos $(3,3 \%)$ fueron pospuestos por recidiva $o$ aparición de un nuevo tumor (tabla 98).

Los procedimientos realizados consistieron en la liposucción del colgajo [realizado en 13 casos (27,7\%)], lipoinfiltración del colgajo [29 casos $(61,7 \%)]$, o remodelado del colgajo [en 16 casos, (34,0\%)]. En algunas reconstrucciones se combinaron varios procedimientos para alcanzar el resultado deseado. En el caso de la lipoinfiltración, el volumen medio de tejido adiposo injertado fue de 117,1cc \pm 68 ,2cc (rango 10271cc)(figura 54).

Independientemente de estas correcciones, en 40 casos $(85,1 \%)$ se realizó la reconstrucción del complejo areola-pezón mediante un autoinjerto de piel total para recrear la areola con un colgajo local para la reconstrucción del pezón. Algunas pacientes decidieron realizarse esta reconstrucción mediante la técnica de tatuaje de manera independiente a nuestro centro.

\begin{tabular}{lcc}
$\begin{array}{c}\text { PROCEDIMIENTOS COMPLEMENTARIOS A A } \\
\text { LA RECONSTRUCCIÓN MAMARIA }\end{array}$ & $\begin{array}{c}\text { Frecuencia } \\
(\mathbf{n = 6 1 )}\end{array}$ & $\begin{array}{c}\text { Porcentaje } \\
(\%)\end{array}$ \\
\hline SI SE REALIZÓ CIRUGÍA COMPLEMENTARIA & $\mathbf{4 7}$ & $\mathbf{7 7 , 1}$ \\
NO SE REALIZÓ CIRUGÍA COMPLEMENTARIA & $\mathbf{1 4}$ & $\mathbf{2 2 , 9}$ \\
\hline PACIENTES INTERVENIDAS & & \\
\hline Liposucción del colgajo & 47 & $\mathbf{1 0 0}$ \\
Lipoinfiltración del colgajo & 13 & 27,7 \\
Remodelado del colgajo & 29 & 61,7 \\
Reconstrucción del complejo areola-pezón & 16 & 34,0 \\
\hline
\end{tabular}

Tabla 97: Procedimientos complementarios a la reconstrucción mamaria. 
Entre las pacientes que se sometieron a algún procedimiento complementario, el número de cirugías realizadas por paciente fue de 1,25 \pm 0,269 (rango 1-2 cirugías adicionales).
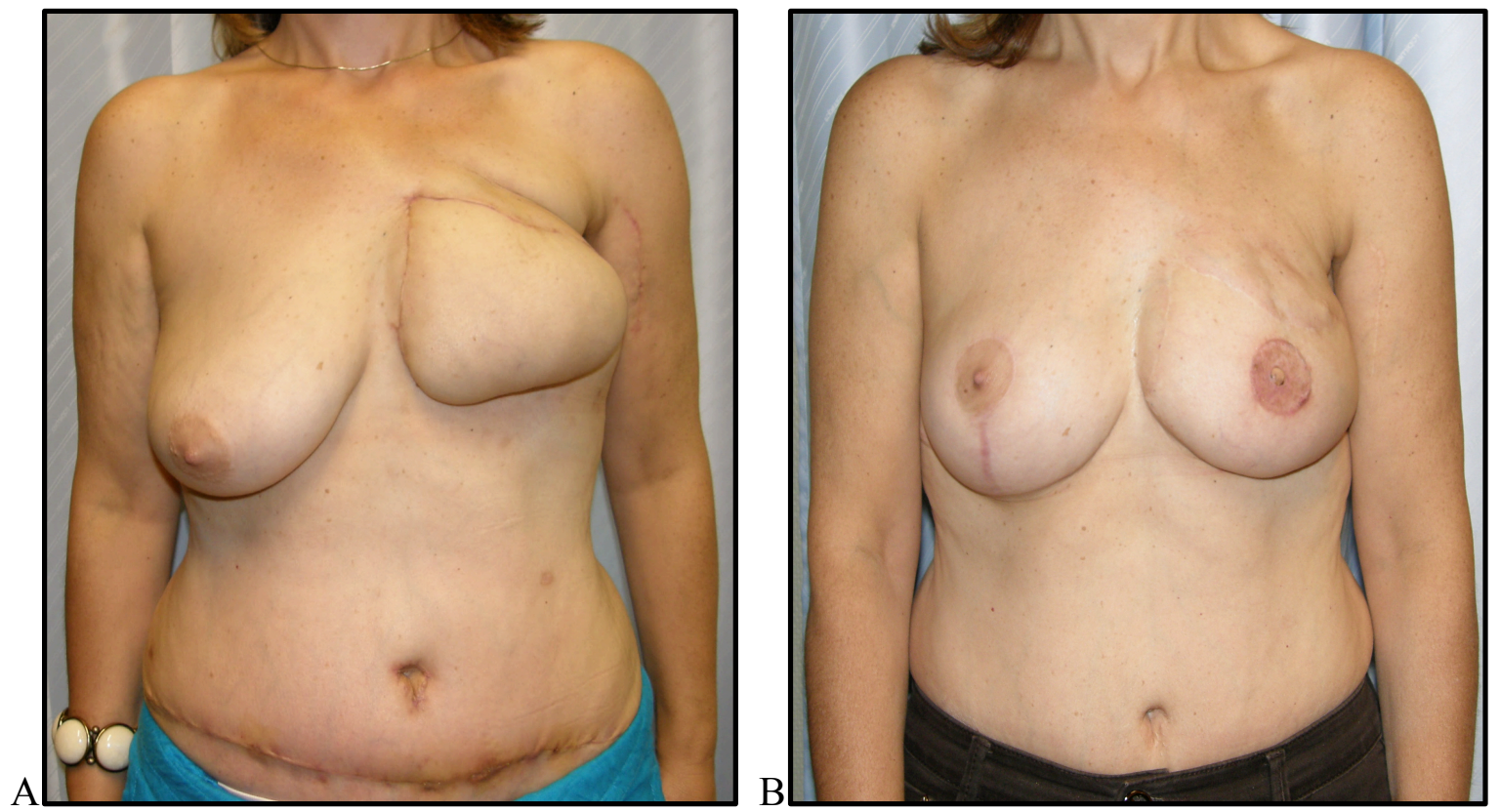

Figura 54: A: Paciente con una reconstrucción mamaria diferida izquierda con un colgajo DIEP con importante asimetría. B: Misma pacientes después de realizarse una mastopexia derecha y un remodelado del colgajo izquierdo con una lipoinfiltración de $83 \mathrm{cc}$ de en cuadrante supero externo en un tiempo y una reconstrucción del complejo areola-pezón en un segundo tiempo. 
DISCUSIÓN 



\section{INTRODUCCIÓN}

El cáncer de mama representa el tipo de cáncer más frecuente en la mujer en el mundo occidental, con una incidencia anual de más de 16.000 casos en España (5). La gravedad y frecuencia de esta enfermedad la han convertido en una preocupación social de primera magnitud y una prioridad para el sistema sanitario. Los esfuerzos realizados desde diferentes campos de la medicina han desembocado en importantes avances en su tratamiento, modificando el pronóstico vital y permitiendo un notable aumento de la supervivencia en los últimos 20 años. Entre estos progresos se incluyen el mejor conocimiento de los factores de riesgo así como de aquellos genes con susceptibilidad de desarrollar la enfermedad, la mejora de las técnicas diagnósticas, la reducción de la morbilidad del tratamiento quirúrgico derivado del desarrollo de técnicas conservadoras de mama, mastectomías preservadoras de piel y el desarrollo de la biopsia del ganglio centinela, la mejora de los protocolos de indicación y tratamiento radioterápico y el desarrollo de nuevos fármacos mejor tolerados que en algunos casos actúan como dianas biológicas y que han contribuido de forma global a la reducción de su mortalidad. Esto ha obligado a la creación de grupos multidisciplinares con el fin de maximizar los beneficios que cada profesional puede aportar dentro de su ámbito para ofrecer de manera individualizada el mejor diagnóstico y tratamiento posible en el cáncer de mama. De forma paralela también han pasado a formar parte de estos grupos aquellos especialistas en procedimientos y terapias que ayuden a paliar los efectos adversos de los tratamientos oncológicos, como es el caso del linfedema o la reconstrucción mamaria.

El progreso del mundo occidental acontecido en el último siglo ha propiciado un cambio en la forma de vida de la sociedad actual, cada vez más sensibilizada con la salud, las relaciones personales y los estilos de vida. Es por ello que los procedimientos terapéuticos no van a ir únicamente encaminados a erradicar la enfermedad, sino que estos esfuerzos también deben ir dirigidos a ayudar a estas personas a recuperar el equilibrio personal, social y psicológico tras un evento tan traumático como es el cáncer de mama. En este aspecto juega un papel fundamental la reconstrucción mamaria, ya que la recuperación de la imagen corporal y la autoestima perdida son un paso previo e indispensable para 
superar la enfermedad y permitir a la persona su reincorporación plena y satisfactoria en todos los ámbitos de su vida.

Este hecho a facilitado la integración cada vez mayor del cirujano plástico reconstructor dentro de las unidades multidisciplinares de cáncer de mama. Hoy en día nadie discute los beneficios que reporta para la paciente la reconstrucción mamaria, con un papel cada vez más preponderante de la reconstrucción inmediata. Como máximos exponentes de estas ventajas son el evitar a la paciente el trance de verse con una mama amputada con el daño psicológico parejo, y de costes, al reducir el número de intervenciones y acortar los periodos de convalecencia, sin que este hecho repercuta de manera negativa en la evolución de la enfermedad ni de los tratamientos concomitantes.

Los fracasos en los procedimientos reconstructivos son mal tolerados por las pacientes, aflorando de nuevo las heridas abiertas durante el tratamiento oncológico siendo vividas incluso con un sentimiento de culpabilidad. De ahí la importancia de dedicar todos nuestros esfuerzos a hacer que nuestros procedimientos sean lo más seguros posible, intentado que esta enfermedad quede como un recuerdo en el pasado de nuestras pacientes. 


\section{ANÁLISIS DE LAS COMPLICACIONES}

En nuestro estudio se constató algún tipo de complicación en 34 reconstrucciones mamarias $(55,7 \%)$ siendo a priori una cifra relativamente alta. Clasificándose por zonas, 18 reconstrucciones mamarias (29,5\%) presentaron complicaciones sobre el colgajo y 21 casos $(34,4 \%)$ en la zona donante abdominal. A pesar de este elevado porcentaje la reconstrucción se consideró exitosa cuando no hubo una necrosis total o parcial del colgajo, situación que ocurrió en 56 casos $(91,8 \%)$. Esto traduce que en la mayoría de las pacientes se consiguió el objetivo propuesto, siendo muchas de las complicaciones surgidas relativamente menores. En muchos casos estos problemas no comprometieron el resultado o dejaron secuelas, implicando un aumento del tiempo de ingreso o bien precisando una intervención quirúrgica $(26,2 \%)$ para solucionar la complicación.

Otros autores han presentado porcentajes de complicaciones totales entre el $21,7 \%$ y el $50 \%$ de las reconstrucciones, con complicaciones del 23,8\% en la zona del colgajo y del $25,8 \%$ en la zona abdominal $(165,170,172,173)$. Estos valores son sensiblemente inferiores a los de nuestro estudio. Este hecho puede ser explicado a que en nuestro estudio se registraron y contaron como complicaciones todos los eventos, incluso los menores. Además, la mayoría de los cirujanos tuvieron que superar una curva de aprendizaje que en el caso de la reconstrucción con colgajo DIEP es cuanto menos ardua y compleja, ya que sólo uno de los ocho miembros que han participado estaba ampliamente familiarizado con la técnica, con 70 intervenciones aproximadamente como médico especialista de manera previa, mientras que el resto de los cirujanos habían tenido escaso contacto con el procedimiento y 6 de ellos acaban de finalizar su período de residencia o llevaban sólo 2 años como especialistas. Este hecho "amortiguó" el impacto de esta curva de aprendizaje, siendo destacablemente menor a la de otros grupos que se inician en esta técnica.

Thorarinsson y cols. (173) han revisado recientemente la incidencia de las complicaciones en reconstrucción mamaria diferida con diferentes técnicas. En su trabajo concluye que las reconstrucciones con colgajo DIEP presentan una incidencia de complicaciones totales tempranas $(50.0 \%)$ significativamente mayores con respecto a las 
reconstrucciones con colgajo de dorsal ancho, toracodorsal o prótesis inmediata, siendo la reconstrucción con expansor y prótesis la que presenta un índice menor. Sin embargo, el número de intervenciones tardías para realizar correcciones estéticas en el colgajo DIEP es significativamente menor frente al resto de las técnicas, a pesar de haber recibido tratamiento con radioterapia preoperatoria en el $82,7 \%$ frente al $16,1 \%-31,1 \%$ de las técnicas basadas en implantes.

Con respecto a la necesidad de reintervenciones, en nuestro estudio ascendió al 26,2\% de las reconstrucciones realizadas (tempranas 19,6\% y tardías 6,6\%). Thorarinsson y cols. (173) reintervenieron por complicaciones al $26,9 \%$ de sus reconstrucciones con colgajo DIEP en manera temprana, y 40,4\% tardías aunque en este caso incluyó también la realización de correcciones estéticas. De acuerdo con este y otros autores, es cuestionable que esta ventaja inicial del resto de métodos reconstructivos compensen una mayor incidencia de complicaciones y reintervenciones tardías con un numero adicional de días de estancia hospitalaria (174-176), más aún teniendo en cuenta que esta tasa de complicaciones de las reconstrucciones basadas en implantes sería mucho mayor si se utilizase de forma sistemática sobre tejidos radiados $(177,178)$.

Además y a pesar de todos estos contratiempos, la reconstrucción con tejidos autólogos y especialmente el colgajo DIEP goza entre las pacientes de los índices más altos de satisfacción dentro de las diferentes técnicas reconstructivas (179-181), siendo cada vez más demandadas entre aquellas pacientes que buscan una reconstrucción lo más natural y perdurable en el tiempo.

\subsection{Necrosis total y parcial del colgajo}

En este estudio se produjo una necrosis completa del colgajo en el $4,9 \%$ de las reconstrucciones. El motivo en estos 3 casos fueron problemas con el pedículo del colgajo o la microanastomosis, en correlación con las observaciones de Lie y cols. (171). 
La mayoría de los autores presentan porcentajes de necrosis totales entre el $1 \%$ y el $2,6 \%(165,170,182-185)$ con un porcentaje total del 1,1\% sobre 17.096 colgajos DIEP en una revisión total de 693 publicaciones (171). Al igual que en el caso de las complicaciones totales, nuestra serie acusó la larga curva de aprendizaje asociada a la técnica. A pesar de este dato negativo, 2 fracasos se produjeron en las primeras 9 pacientes intervenidas mientras que en las últimas 52 reconstrucciones sólo se perdió un colgajo $(1,9 \%)$, por lo que nuestro trabajo nos sitúa actualmente en el camino de los grupos con grandes series publicadas.

Nuestro porcentaje de necrosis parcial del colgajo fue del 3,3\%. En la literatura se recogen valores que oscilan entre el $0 \%$ y el $11,5 \%$ en la mayoría de las series, llegando en algún caso a alcanzar el 22,1\% (165,171,173,182,183,185-188).

La necrosis parcial del colgajo suelen traducir una inadecuada microcirculación en zonas limitadas del colgajo en relación con un diseño subóptimo del colgajo y la falta de consideración a las diferentes zonas que conforman su arquitectura microvascular (171). Nuestra serie se encuentra dentro del limite bajo de la horquilla observada en la literatura, lo que traduce una buena sistemática en el diseño de los colgajos y en la elección del vaso perforante. La planificación con ayuda de la angio TC tuvo una contribución determinante en este aspecto.

\subsection{Necrosis grasa del colgajo}

Esta complicación tiene dos implicaciones importantes. Por un lado, un área de necrosis grasa puede generar molestias con dolor, tirantez y alteraciones en la forma y volumen de la mama reconstruida. Por otro lado, esta complicación puede mimetizar una recidiva tumoral, con la consiguiente ansiedad que esta incertidumbre genera en la paciente y la necesidad de realizar procedimientos diagnósticos adicionales para estudiar la neoformación. 
El rango de porcentaje publicados en la literatura de necrosis grasa en una mama reconstruida con el colgajo DIEP es muy amplio, con valores que oscilan desde el 1,8\% al $42,9 \%$, aunque en la mayoría de las series este valor varía entre el $9,7 \%$ y el $18,8 \%$ $(170,171,188-191)$. En el caso de que el diagnóstico de esta complicación se apoye en estudios ecográficos y debido a la mayor sensibilidad de esta prueba con respecto al examen clínico, este valor puede alcanzar el 35\% de las reconstrucciones (192).

En nuestro estudio, esta aparición se observó en el 13,1\% de las reconstrucciones, totalmente acorde con la gran mayoría de los trabajos publicados.

De forma similar a la necrosis parcial, esta complicación es la respuesta a un problema en la arquitectura vascular del colgajo diseñado. En muchos casos su aparición esta sujeta al desconocimiento de los diferentes territorios circulatorios que conforman el colgajo DIEP (193), lo que explicaría que diferentes autores reflejen una incidencia de necrosis grasa 2 veces superior con el colgajo DIEP con respecto al TRAM $(188,193)$, con un porcentaje de 10,1\% en una revisión sobre 1.872 colgajos estudiados. En este sentido son interesantes las apreciaciones del grupo de Wong y Saint-Cyr en su teoría de los perforasomas $(135,148)$, en las que explican que cada perforante tiene su perfarosoma y es por ello que las cifras de la aparición de necrosis grasa sean tan variables dentro de la literatura.

Diferentes variables como la radioterapia o el tabaco se han relacionado con esta complicación con resultados contrapuestos en la literatura, y que serán analizadas más adelante.

Lee y cols. (194) han informado que un tiempo de isquemia del colgajo superior a los 99 min incrementa el porcentaje de aparición de necrosis grasa desde el 7,3\% hasta el $35,5 \%$ independientemente de otros factores. Aunque en nuestro trabajo no se recogió este tiempo de isquemia, este nunca superó los 100 min ya que la microanastomosis se realizó inmediatamente a continuación de la autonomización con el objetivo expreso de reducir este tiempo de isquemia. 
Otros autores han especulado sobre si reconstrucciones mamarias de mayor tamaño y por ende colgajos más grandes están relacionados con la aparición de esta complicación. Sin embargo, hasta el momento no se ha comprobado una asociación significativa entre estos dos factores $(195,196)$.

\subsection{Problemas circulatorios del colgajo}

En nuestro trabajo hemos introducido una forma no relatada antes en la literatura, de estudiar las complicaciones asociadas a la arquitectura microvascular del colgajo. Mientras analizábamos nuestras complicaciones observamos que algunas reconstrucciones que, debido a las características del colgajo y a los problemas surgidos durante la intervención tenían que haber presentado una necrosis grasa o una necrosis parcial, terminaban siendo exitosas. Estas reconstrucciones se caracterizaron por manifestar un problema de congestión venosa durante la intervención o en el postoperatorio inmediato que en la mayoría de los casos se resolvió favorablemente con el refuerzo del drenaje venoso mediante la realización de una segunda anastomosis venosa, habitualmente entre una vena epigástrica inferior superficial del colgajo y la vena cefálica homolateral a la reconstrucción.

De este modo y para poder estudiar la repercusión que han tenido diferentes variables anatómicas y circulatorias del colgajo sobre su perfusión, se agruparon juntas todas aquellas reconstrucciones que presentaron una necrosis grasa o una necrosis parcial del colgajo o bien presentaron un problema de congestión venosa que se resolvió o no con una segunda anastomosis venosa. Se excluyeron aquellos casos de necrosis completa al asociarse esta complicación, como se ha relatado antes, con problemas técnicos en la disección del pedículo o en la anastomosis. También se excluyeron aquellos casos que presentaron unos vasorreceptores inadecuados, fundamentalmente a expensas de una vena mamaria interna filiforme, debido al ser la fibrosis perivascular el causante real de estos problemas circulatorios. Otra causa de exclusión fue la realización de una anastomosis venosa a flujo inverso o una única anastomosis venosa del colgajo a partir del sistema venoso superficial debido a la lesión iatrogénica de los vasorreceptores. Todas estas 
exclusiones se describen en el apartado de resultados. En total se compararon 12 reconstrucciones asociadas a uno de los problemas descritos anteriormente frente a 42 que no presentaron ninguna de estas complicaciones.

La creación de este parámetro se fundamenta en que la aparición de una necrosis grasa, los signos de congestión o insuficiencia venosa y la necrosis parcial en el colgajo son diferentes grados de severidad de un mismo problema relacionado con la trama circulatoria interna del colgajo. De hecho, la aparición de una necrosis grasa traduciría un problema circulatorio de menor gravedad y sin repercusiones a nivel cutáneo, mientras que en el caso de una congestión venosa implicaría un problema mayor que en caso de no resolverse se convertiría en una necrosis parcial a consecuencia del aumento de la presión local, originando edema, liberación de mediadores de la inflamación y finalmente un fallo circulatorio mixto.

En este sentido Lie y cols. (171) han propuesto una escala para ayudar en la descripción de este tipo de complicaciones que van desde el grado I para las necrosis grasas $<5 \%$ hasta el grado IV que incluye necrosis $>50 \%$ con defecto cutáneo asociado. Se ha definido también un grado $\mathrm{V}$ en el caso de que se produzca una necrosis completa del colgajo.

Esta ampliamente referenciada en la literatura el empleo del refuerzo del drenaje venoso a expensas del sistema superficial del colgajo DIEP como método de resolución de las problemas de congestión venosa $(138,165,183,186,187,197-200)$. Aunque hasta la fecha no se ha conseguido demostrar que la realización de una segunda anastomosis venosa a partir de la VEIS reporte un descenso significativo de necrosis grasa y/o parcial del colgajo, en una revisión sobre 1.376 casos (de los cuales 842 tenían un doble drenaje venoso) se observó un efecto protector con un RR de 0,87 (IC al 95\%: 0,58-1,30) y 0,59 (IC al 95\%: 0,18-1,94) respectivamente en la aparición de estas complicaciones. En cambio, no se observó una relación con la formación de una necrosis completa del colgajo (RR: 0,97, IC al 95\%: 0,36-2,57) (186). Los autores (186) concluyen que a pesar de no encontrar resultados significativos, el análisis estadístico expresa la necesidad de una muestra de 2.624 casos en cada grupo para obtener conclusiones sólidas. 
De manera similar a lo observado en la literatura, en nuestro estudio tampoco se observó un efecto protector significativo en la realización de un $2^{\circ}$ drenaje venoso con respecto a la formación de necrosis grasa en el colgajo. Sin embargo, sólo uno de los ocho casos con un segundo refuerzo venoso presentó esta complicación. El problema de congestión se detectó a las 4 horas del fin de la intervención y se realizó un drenaje venoso accesorio superficial, lo que no evitó la formación de la necrosis grasa durante el postoperatorio. Esto sugiere que pueden existir otros parámetros implicados en la aparición de estas complicaciones circulatorias, posiblemente relacionados con las características de la perforante seleccionada, los cuales serán estudiados más adelante.

\subsection{Competencia de la pared abdominal}

Desde el inicio de la reconstrucción autóloga con colgajos abdominales ha habido un interés constante en la reducción de la morbilidad de la pared abdominal. Ya con las primeras series que emplearon el colgajo TRAM en su modalidad pediculada se puso de manifiesto dos inconvenientes. Por un lado, la precaria vascularización de este colgajo cuando su nutrición se basaba en el pedículo epigástrico superior profundo, con elevados porcentajes de necrosis parciales, demostrándose posteriormente por Moon y Taylor (124) que el aporte vascular más robusto procedía de los vasos epigástricos inferiores profundos. Por otro lado, la recolección del músculo recto anterior para vehicular el pedículo suponía una pérdida de su función de contención abdominal con el consiguiente aparición de hernias y alteraciones del contorno abdominal, con porcentajes de hernias tan altos como el $16 \%$ de las pacientes (201).

Con el desarrollo de las técnicas microquirúrgicas pronto se puso de manifiesto los beneficios del TRAM libre frente a su homólogo pediculado en términos de seguridad circulatoria del colgajo $(202,203)$, aunque aún quedaba pendiente los problemas de continencia abdominal (107). Diferentes técnicas de cierre del defecto abdominal (204) y colocación de mallas se preconizaron, sin llegar a ofrecer una solución definitiva. En aras de reducir este tipo de complicaciones fueron surgiendo diferentes técnicas preservadoras de músculo como el TRAM MS-1, MS-2 y el MS-3, en los que únicamente se recolectaba 
una pequeña porción o una tira del músculo, en donde iban incluidas las perforantes de la AEIP. Sin embargo no sería hasta la llegada de los colgajos de perforantes, en los que hay una preservación completa de la musculatura abdominal y su inervación, cuando los porcentajes de este tipo de complicaciones se han reducido al máximo.

Man y cols. (193) han presentado una revisión en la que comparan 1920 colgajos DIEP con 3.185 colgajos TRAM libres. En su estudio concluyen que aunque las reconstrucciones con colgajo DIEP tienen el doble de riesgo de presentar necrosis grasa o pérdida del colgajo, el riesgo de aparición de hernias o debilidad de la pared abdominal se reduce a la mitad con respecto al TRAM. Estos datos son similares a los de otro meta-análisis (205) Grandes series como las de Ochoa, Gills o Nahabedian y cols. $(170,191,206)$ presentan porcentajes de abultamiento abdominal de entre el $0,7 \%$ y el $4,5 \%$. Con respecto a la aparición de hernias abdominales, los valores oscilan entre el $0 \%$ y el 1,4\%, mientras que otros grupos de trabajo presentan porcentajes de entre el $8 \%$ y el $11,1 \%$ para el abultamiento abdominal $(201,207,208)$.

En consonancia con la mayoría de los trabajos publicados, nuestra serie presentó un caso de hernia abdominal $(1,6 \%)$ que precisó ser reintervenida para su corrección con ayuda de una malla sintética. En cambio, el porcentaje de abultamiento abdominal se elevó hasta el 9,8\% (6 casos), colocándonos en el límite de los estudios descritos en la literatura.

Mientras que la hernia se define como un fallo abdominal con defecto de la fascia asociado, en el caso del abultamiento la laxitud abdominal no incluye esta falta de cobertura de la fascia (189). Diferentes autores han buscado una relación entre la línea de los vasos perforantes del colgajo u otros parámetros como el IMC, comorbilidades o cirugías previas sin llegar a observar una asociación significativa $(170,209,210)$. La formación de una hernia tras una reconstrucción con el colgajo DIEP se relaciona con una mala técnica en el cierre abdominal. Sin embargo el abultamiento abdominal tiene más que ver con una lesión de la inervación abdominal durante la disección del colgajo, dejando zonas del músculo recto anterior paréticas que traducen una pérdida de competencia sin que se trate de una hernia. De nuevo, nuestros resultados están en consonancia con los de otros autores durante su curva de aprendizaje. 


\subsection{Otras complicaciones}

En nuestra serie se presentaron otras complicaciones como la aparición de dehiscencia, hematoma o infección en la mama reconstruida y seroma en la zona abdominal, en porcentaje similar a las de otros grupos de trabajo $(170,173,191)$. La baja frecuencia de aparición de estas complicaciones en nuestro trabajo imposibilitó buscar una asociación con otras variables a estudio.

Una paciente sufrió un tromboembolismo pulmonar que se resolvió satisfactoriamente con tratamiento médico. A pesar de que existe un protocolo para prevenir este tipo de complicaciones (ver anexo 1), el traslado a una nueva planta de hospitalización hizo que no se siguiese el procedimiento (movilización precoz, medias de compresión,...) con la aparición del episodio al $3^{\circ}$ día de ingreso. Esta complicación, a pesar de ser infrecuente, está referida en la literatura $(211,212)$ y de ahí que dispongamos de un protocolo para su prevención.

Otra paciente presentó un neumotórax por la lesión inadvertida de la pleural parietal durante la disección de los vasorreceptores mamarios internos, que se resolvió favorablemente con la colocación de un drenaje torácico. Aunque se trata de una complicación poco frecuente, está descrita en relación con el uso de los vasos mamarios internos como vasorreceptores en reconstrucciones con colgajos microvascularizados (213).

\subsection{Estancia hospitalaria}

El tiempo medio de estancia hospitalaria de nuestra serie fue de 5,72 $\pm 2,543$ días. El $72,2 \%$ de las reconstrucciones permanecieron ingresadas 4 ó 5 días. Las complicaciones más frecuentes como la necrosis parcial o total del colgajo, la necrosis grasa o la dehiscencia del cierre abdominal conllevaron un aumento de la estancia media, sin que en ningún caso llegase a ser significativo. En el caso de las necrosis parcial y/o total la 
estancia media subió hasta los 10,4 días pero a consecuencia del bajo tamaño de la muestra así como en el número de complicaciones no se observó una asociación significativa.

Existen pocos trabajos publicados que consideren el tiempo de ingreso hospitalario, aunque algunos trabajos presentan estancias medias de 4 días $(138,201)$ y 5,8 $\pm 2,7$ días (173), un valor casi idéntico al de nuestro estudio. Considerando la duración del procedimiento, las potenciales complicaciones severas en el postoperatorio inmediato y que la formación de endotelio a nivel de la anastomosis se produce a partir del $5^{\circ}$ día, no parece recomendable estancias inferiores a 4 días para este tipo de reconstrucciones. 


\section{VARIABLES EPIDEMIOLÓGICAS Y FACTORES DE RIESGO CIRCULATORIO}

\subsection{Edad}

La edad media de las pacientes reconstruidas en nuestro trabajo fue de 47,10 $\pm 7,76$ años, en consonancia aunque discretamente inferior a la de las mayoría de las series, que se sitúan en una horquilla comprendida entre los 48,9 y 54 años de edad $(165,170,173,182,186,191,201)$.

La reconstrucción mamaria con tejido autólogo demuestra sus beneficios con el paso de los años. La perdurabilidad de los resultados, la baja incidencia de revisiones tardías y la naturalidad obtenida y mantenida en el tiempo hacen que el grupo que mayor beneficio extrae de esta técnica sea el de las pacientes jóvenes. Una vez completada la reconstrucción con tejido autólogo, la paciente probablemente no tendrá que someterse a nuevas intervenciones con el paso de los años, a diferencia de las reconstrucciones basadas en implantes, donde es frecuente practicar revisiones por recambio de implantes, asimetría, contractura capsular,... Este hecho hace que la reconstrucción con tejido autólogo sea una técnica coste-efectiva en comparación con los implantes (214).

En nuestra serie no se encontró una relación estadísticamente significativa entre la edad de las pacientes y la aparición de complicaciones. No se estudiaron relaciones de causalidad con otras variables de acuerdo con la literatura existente ya que existen otros factores de más peso que la edad en la aparición de complicaciones.

\section{2. Índice de masa corporal}

El índice de masa corporal medio de nuestra muestra fue $25,49 \pm 3,21$, en concordancia con el de otros grupos de trabajo $(170,173,182)$. Se evitó incluir pacientes con un IMC 
extremadamente bajo con el fin de evitar colgajos con un volumen insuficiente para realizar un reconstrucción, así como pacientes con obesidad severa que hiciese más dificultosa la intervención.

Ochoa y cols. (170) estudiaron la influencia del IMC en un trabajo sobre 639 reconstrucciones mamarias con el colgajo DIEP. Entre sus conclusiones resaltan que la presencia de obesidad severa se relaciona con el retraso en la curación de las heridas tanto en la zona donante como del colgajo, mientras que la obesidad mórbida también se asocia al aumento en el número total de complicaciones en la zona abdominal. No se observó una relación entre el IMC y la aparición de abultamiento y hernias abdominales.

Grover y cols. (215) han informado de un aumento de colgajos perdidos en pacientes con IMC superior a 30 puntos, sin observar una relación con la aparición de necrosis grasa (216). Otros autores tampoco han observado un aumento de las complicaciones en pacientes con un IMC inferior a 30.

En nuestro estudio no se observó una relación estadísticamente significativa entre el IMC y la aparición de una dehiscencia del cierre abdominal, un seroma o un abultamiento abdominal. Considerando que más del 95\% de las pacientes de nuestra muestra tenían un IMC inferior a 30, nuestros resultados están en concordancia con la literatura publicada.

\subsection{Tabaquismo}

El hábito tabáquico y su relación con las complicaciones de los colgajos microvascularizados están ampliamente documentadas en la bibliografía médica.

Los efectos del consumo de tabaco son bien conocidos y consisten fundamentalmente en un incremento de los índices de trombosis a través de un aumento del fibrinógeno plasmático, mayor tendencia a la vasoconstricción por el descenso en la síntesis de óxido nítrico y una prevalencia superior de ateroesclerosis respecto a los no fumadores (182). 
Con respecto a la RM con colgajo DIEP, diferentes autores no han encontrado relación entre el tabaquismo y un aumento de la incidencia de fracasos por trombosis vascular $(182,217)$. Sin embargo, la mayoría de las publicaciones relacionan el tabaquismo con el aumento de complicaciones en la mama, mayores índices de necrosis grasa en el colgajo, retardo en la curación de heridas, dehiscencias y complicaciones en la zona donante $(182,190,191,195,218)$.

En nuestra serie, el $15 \%$ de las pacientes eran fumadoras activas en la fecha de la intervención quirúrgica. A pesar de que el 33\% de las pacientes con tabaquismo activo presentaron dehiscencia en el cierre abdominal o necrosis grasa en el colgajo frente al $13,3 \%$ y al 11,9\% respectivamente de las no fumadoras, hallamos una asociación no significativa probablemente debido al bajo tamaño de la muestra. En cambio, al analizar los problemas circulatorios del colgajo si que se observó una relación significativa. De estos resultados se desprende que el consumo de tabaco se asocia con aumento del riesgo de presentar problemas en la perfusión de los tejidos, con mayor tendencia a la aparición de insuficiencia venosa que de no resolverse pueden derivar en necrosis parciales del colgajo.

Nuestros hallazgos se muestran concordantes con la literatura publicada. De acuerdo con estos hallazgos, las pacientes que deseen una RM con colgajo DIEP deben abandonar previamente el hábito tabáquico, ya que su consumo se asocia a la aparición de complicaciones circulatorias en el colgajo o en el cierre abdominal, que pueden condicionar el resultado de la reconstrucción y la necesidad de reintervenciones correctoras.

\subsection{Cirugía abdominal}

En nuestro trabajo el $25 \%$ de las pacientes presentaban algún antecedente de cirugía abdominal de las cuales el 10\% tenían una cicatriz de Pfannenstiel por histerectomía o cesárea, el 6,7\% habían sufrido una apendicectomía, el 5\% tenían pequeñas cicatrices de laparoscopia y el 3,3\% habían tenido una laparotomía media. 
La importancia de este factor ha sido estudiado por diferentes autores. La existencia de una cicatriz de Pfannenstiel no se ha relacionado con un aumento en la formación de necrosis grasa o un descenso en el número de perforantes observadas en la angio TC $(194,219)$.

Roostaeian y cols. (210) revisaron la importancia de una cirugía previa abdominal en un estudio sobre 692 colgajos libres abdominales, concluyendo que este antecedente no tenía influencia sobre la aparición de complicaciones importantes en el colgajo o en la zona donante abdominal.

Casado Sánchez y cols. (182) no consideran que una cicatriz de Pfannenstiel, de McBurney o de Kocher supongan una contraindicación. Estos autores defiende como una contraindicación relativa la liposucción abdominal y la laparotomía media y absoluta la abdominoplastia al seccionarse las perforantes abdominales durante el despegamiento dermograso. Posteriormente, diferentes autores han conseguido realizar reconstrucciones con un colgajo DIEP en pacientes con una laparotomía media, una abdominoplastia o una liposucción abdominal previa (220-222). En este aspecto la planificación con angiotomografía expone una de sus máximas virtudes, al ser capaz de poner de manifiesto la existencia de vasos perforantes conectados al pedículo epigástrico inferior profundo.

Tener un antecedente de cirugía abdominal no supuso en nuestro estudio un factor de riesgo en la aparición de dehiscencia del cierre abdominal, en la formación de seroma, en la aparición de debilidad con abultamiento de la pared abdominal o en la presencia de hernias postquirúrgicas. Estos colgajos tampoco presentaron una mayor incidencia de problemas circulatorios.

Dos pacientes con una cicatriz de laparotomía media fueron intervenidas. Su inclusión para la RM quedó condicionada al estudio de la angio TC, que confirmó la presencia de un eje circulatorio que permitía disecar un colgajo DIEP con seguridad. En ambos casos se utilizó un hemiDIEP, desechando todo el tejido más allá de la cicatriz. Ninguno de los 2 casos presentó complicaciones circulatorias en el colgajo. 
Se valoró la posibilidad de que una cicatriz de Pfannenstiel pudiese reducir la aparición de problemas circulatorios en el colgajo. Está aceptado que el sistema venoso superficial es el principal drenaje de la porción cutáneo adiposa de la pared abdominal, por lo que nos preguntamos si una sección del mismo podría reforzar el drenaje a través del sistema profundo de acuerdo con el principio de retardo de los colgajos (137). Previamente se ha descrito un efecto protector de las cirugías abdominales en la aparición de congestión venosa en el colgajo debido a la disrupción que producen estas cirugías en el sistema venoso superficial, redirigiendo y potenciando el retorno venoso por el sistema profundo (138).Aunque nuestras impresiones están de acuerdo con esta hipótesis, en nuestro trabajo no fue posible corroborarla, observando en la angio TC que en algunos casos este tipo de abordaje no había llegado a seccionar el sistema venoso superficial, o bien el drenaje se realizaba a través de vasos colaterales, de modo que es aconsejable realizar futuros estudios con una selección individualizada de los pacientes para ayudar a clarificar esta cuestión.

\subsection{Otros factores de riesgo circulatorios}

En nuestro trabajo se recogieron la incidencia de otros factores de riesgo circulatorio, como la diabetes mellitus (5\%), la hipertensión arterial $(11,7 \%)$ y la dislipemia $(8,3 \%)$. La baja frecuencia de esta variable imposibilitó estudiar su relación con las diferentes complicaciones descritas

Estas factores han sido estudiado por varios autores. En una revisión de 758 colgajos DIEP, Gill y cols. (191), observaron una relación significativa entre la HTA y la aparición de complicaciones en el colgajo mientras que la diabetes sólo mostró una asociación no significativa. No se encontró correlación entre estas patologías y cada una de las complicaciones de manera individualizada, por lo que el autor se cuestionó si esta asociación estaba en relación con el daño que estas patologías causan en la microcirculación o mas bien traducen un pobre estado de salud y la presencia de otras comorbilidades. 


\section{TRATAMIENTO ONCOLÓGICO ADYUVANTE}

\subsection{Radioterapia}

En nuestro estudio, el 55,7\% de las reconstrucciones se practicaron sobre un lecho radiado previamente. En todos los casos el tratamiento había finalizado al menos 1 año antes de la intervención. No hemos observado que la administración de RT esté relacionado con un aumento en la aparición de problemas circulatorios o necrosis grasa en el colgajo, ni en la necesidad de realizar una segunda anastomosis venosa para aumentar el retorno venoso.

Los efectos nocivos de la RT sobre el futuro lecho de la reconstrucción son bien conocidos. Este tratamiento puede causar de zonas de radiodermitis, hiperpigmentación, telangiectasias y fibrosis tisular. A nivel de los vasorreceptores producen fibrosis perivascular, sufrimiento endotelial y trombosis microvascular, siendo este daño dosis dependiente, con repercusiones venosas a dosis altas (65-70 Gy) aunque no a dosis fraccionadas bajas (40-50 Gy) (182).

Una de las grandes ventajas de la RM con tejido autólogo es el aporte de tejido vascularizado, mejorando sustancialmente los campos radiados. En el caso del colgajo DIEP y debido a la transferencia de un volumen considerable de piel y grasa, es posible prescindir de aquellos tejidos especialmente dañados o bien dejarlos enterrados, lo que se traduce en una gran ventaja para el cirujano plástico, que no condiciona la reconstrucción a los problemas locales que puedan existir.

Actualmente existe un consenso en la comunidad científica con respecto a que la aplicación de RT de manera previa a una reconstrucción con colgajo abdominal no se asocia a una mayor incidencia de necrosis grasa en la reconstrucción ni a la aparición de otras complicaciones en la mama reconstruida $(182,191,192,223)$. En cambio, cuando se trata de una RMI con colgajo DIEP que posteriormente se somete a RT, si que se ha 
documentado un aumento de la incidencia de necrosis grasa, aunque no de necrosis parcial o total del colgajo (191), sin que haya uniformidad de criterio en la literatura a este respecto (100). A pesar de que diferentes estudios destacan que no hay una pérdida significativa en el resultado estético de la reconstrucción tras la aplicación de la RT (224) o bien que el beneficio de realizar una RMI sobre una mastectomía ahorradora de piel compensa el perjuicio de someter la reconstrucción a este tratamiento adyuvante, muchos otros autores recomiendan retrasar la reconstrucción un mínimo de 6 meses cuando se sospeche que va a ser necesario aplicar RT (225). Una solución intermedia es la RM inmediata-diferida en la que se preserva la envoltura cutánea con ayuda de un expansor hasta que se concluyen los tratamientos adyuvantes y se sustituye por tejido autólogo, aunque este método no esta exento tampoco de inconvenientes (226).

En nuestro trabajo no hemos observado un aumento de las complicaciones con la aplicación de RT preoperatoria, con resultados similares al resto de la literatura publicada. Sin embargo, es posible también que los efectos negativos de la RT sobre los vasorreceptores queden ocultos por una influencia mayor de otros factores en la aparición de las complicaciones estudiadas, siendo necesario una muestra mucho mayor y una selección individualizada de los pacientes para llegar a unas conclusiones sólidas.

En este sentido hay que reseñar que 4 de las 58 reconstrucciones en las que se utilizaron los vasos mamarios internos como vasorreceptores, se observó una vena mamaria interna de un calibre muy fino con respecto a la arteria mamaria interna. En 2 casos fue imperativo realizar una segunda anastomosis venosa, lo que permitió salvar el colgajo, en otro caso no fue posible lo que desembocó en una necrosis parcial del colgajo y en el último caso se realizó una anastomosis a flujo inverso de la VMI, que mostraba un calibre superior, lo que permitió salvar el colgajo pero con aparición de una zona de necrosis grasa en el postoperatorio. Todos estos casos, unidos a dos reconstrucciones en las que se desestimó la VMI en favor del eje subescapular como vasorreceptor por el mismo motivo, tenían el antecedente de haber recibido tratamiento radioterápico previo. Como hemos explicado, los efectos deletéreos de la RT a nivel circulatorio incluyen la fibrosis perivascular y hialinosis, lo que puede conllevar una reducción del calibre de los vasos 
sanguíneos (182). A este respecto, la vena mamaria interna podría afectarse con mayor severidad que la arteria, al presentar una pared más fina.

En nuestra serie, el 17,6\% de los vasos mamarios internos radiados no se consideraron adecuados para utilizarse como receptores, precisando realizar otros procedimientos como aumentar el drenaje venoso o cambiar la elección de los vasorreceptores. El factor limitante en todos los casos fue el hallazgo de una vena mamaria interna con fibrosis perivascular y extremadamente fina en comparación con la AMI.

Para comprender los efectos de una vena mamaria interna de menor calibre que su arteria homónima hay que recordar que la circulación sanguínea se rige por la ley de Poiseuille:

$$
\Phi \mathrm{V}=\frac{\pi \mathrm{r}^{4}}{8 \eta} \frac{\Delta \mathrm{p}}{1}
$$

$$
\begin{aligned}
& \Phi \mathrm{v}=\text { Volumen de flujo sanguíneo } \\
& \mathrm{r}=\text { radio del vaso } \\
& \Delta \mathrm{p}=\text { Gradiente de presiones } \\
& \eta=\text { Viscosidad } \\
& 1=\text { longitud del vaso }
\end{aligned}
$$

Para evitar edema y congestión venosa en un colgajo, el flujo sanguíneo de entrada ha de ser igual al de salida. Partiendo de la base de que la longitud del vaso y la viscosidad de la sangre se mantienen constante, dado que la presión arterial es mayor que la venosa, es necesario que la vena tenga un radio mayor que la arteria. Considerando que las venas tienen una pared más fina que las arterias y que su relación en la fórmula se encuentra elevada a la cuarta potencia, un radio ligeramente superior de la vena es capaz de compensar la diferencia de presión con respecto a la arteria (227). Si la RT produce una estenosis en el calibre de la vena superior al de la arteria, esta relación se invierte, 
apareciendo una insuficiencia venosa al ser incapaz de dar salida a todo el flujo sanguíneo que ha entrado en el colgajo.

Esta situación explicaría los problemas asociados a utilizar una VMI muy fina en relación con la AMI, o bien el uso de vasos perforantes muy finos, donde el componente venoso es de menor calibre que el arterial. También explicaría por qué al estudiar la variable definida en nuestro estudio como problemas circulatorios del colgajo se han excluido aquellos casos con una VMI de menor calibre que la AMI, con el fin de evitar que problemas a nivel de los vasorreceptores impidan sacar conclusiones adecuadas sobre los distintos parámetros relacionados con la circulación del colgajo. Al revisar la bibliografía de este trabajo no hemos observado que otros autores tengan en consideración este aspecto, pudiendo dar lugar origen a sesgos de selección y conclusiones equivocadas sobre los factores etiológicos implicados en la necrosis parcial y/o grasa del colgajo así como en la congestión venosa.

Hemos observado esta diferencia de calibre en contra de la VMI en el 17,6\% de los lechos radiados y en el $0 \%$ de los no radiados. A pesar que en la literatura se ha considerado que el pedículo mamario interno tiene una buena resistencia a los efectos de la RT, sería interesante realizar futuros trabajos en los que se estudiasen de manera aislada estos parámetros, con el fin de ayudar a esclarecer la etiología de las complicaciones circulatorias de los colgajos.

Varios autores han propuesto el estudio preoperatorio de los vasos mamarios internos con ayuda de la angio TC, lo que proporciona información en varios sentidos $(145,146)$. Por un lado permite conocer de manera preoperatoria tanto el calibre como la localización de los vasos mamarios internos. Por otro lado permite elegir el espacio intercostal mayor con el fin de facilitar la microanastomosis y evitar la resección de cartílago costal que se ha asociado en un 15\% a depresiones en la zona de la reconstrucción $(228,229)$. Sin embargo, dado que la mayoría de los estudios se centran en el estudio de la AMI, sería interesante conocer si esta prueba es capaz de predecir problemas de insuficiencia venosa y si resulta ser un estudio coste-efectivo, considerando que se puede asociar al estudio de planificación 
abdominal y también puede tener validez como estudio de seguimiento del proceso oncológico.

\subsection{Quimioterapia}

En nuestra serie, el $82 \%$ de las RM habían recibido quimioterápicos como parte del tratamiento oncológico. No hemos hallado una relación entre el tratamiento quimioterápico y la aparición de complicaciones totales, necrosis grasa o dehiscencia del cierre abdominal. Este hecho probablemente fue debido a que el tiempo transcurrido entre la cirugía reconstructiva mamaria y el fin de este tratamiento adyuvante fue superior a un año en todos los casos, lo que permitió una adecuada recuperación de las capacidades regenerativas de los tejidos en el momento de nuestra intervención.

Los efectos tóxicos de la quimioterapia sobre la curación de las heridas y cualquier proceso regenerativo en general son de sobra conocidos, con mayor incidencia de infecciones, necrosis grasa en zonas intervenidas, dehiscencia de heridas y complicaciones en general. Es por este motivo que esta aceptado espaciar hasta un año este tratamiento de un procedimiento reconstructivo o cualquier cirugía electiva $(9,39,53)$. En cambio, otros autores no han encontrado un aumento de complicaciones en aquellas RMI que han recibido tratamiento quimioterápico neoadyuvante (230).

De acuerdo con nuestros resultados, creemos prudente espaciar las reconstrucciones mamarias diferidas, para garantizar que la paciente se encuentra en las mejores condiciones para enfrentarse a una nueva cirugía. Debido a que existe una amplia variedad de pautas de tratamiento y fármacos, podría ser motivo de futuros estudios conocer si este tiempo se puede reducir en algunos casos. 


\subsection{Hormonoterapia}

En nuestra serie se prescribió tratamiento hormonal en el 77,0\% de los casos, estando bajo tratamiento en el momento de la intervención quirúrgica. El tamoxifeno fue el fármaco que más veces se indicó.

No hemos observado una relación significativa entre los inhibidores hormonales y la aparición de complicaciones. Se especuló si la capacidad trombogénica de estos fármacos podían condicionar un aumento en la aparición de necrosis grasa, no encontrando una relación en nuestro estudio. En cambio si hemos observado un efecto protector en la aparición de dehiscencia en la zona abdominal. Después de revisar la ficha técnica de estos fármacos no se ha encontrado una efecto que justifique este resultado.

Es de sobra conocido el aumento del riesgo de aparición de trombosis arterial y venosa asociada en pacientes a tratamiento con tamoxifeno. Jokuszies y cols. (211) estudiaron si el tamoxifeno podía significar un incremento en el riesgo de complicaciones tromboembólicas en pacientes sometidas a una reconstrucción mamaria microquirúrgica. Estos autores no observaron un aumento ni de las complicaciones totales ni en la aparición de trombosis del colgajo, aunque habían pausaron el tratamiento un mes antes a la intervención quirúrgica. En contraposición, Kelley y cols. (231) si han detectado un aumento de las complicaciones en la reconstrucción y en la pérdida de colgajos en pacientes sometidas a tratamiento con tamoxifeno, pero sin observar un aumento en la aparición de tromboembolismo pulmonar.

En nuestra serie sólo presentamos un caso de tromboembolismo pulmonar. Aunque esta paciente estaba a tratamiento con tamoxifeno, el motivo de esta complicación se relacionó con el no cumplimiento del protocolo postoperatorio que tenemos para esta intervención.

A pesar de que no hemos encontrado relación entre los inhibidores hormonales y la aparición de complicaciones, son necesarios más estudios que clarifiquen estas cuestiones y otras como si es aconsejable pausar este tratamiento y durante cuanto tiempo. 


\section{VARIABLES RELACIONADAS CON LA INTERVENCIÓN}

\subsection{Frecuencia de los vasorreceptores seleccionados}

Los vasos mamarios internos fueron los vasorreceptores de elección al inicio de todas las intervenciones, utilizándose finalmente en 58 reconstrucciones (95,1\%). En las situaciones en las que al concluir la exposición de estos se observó un calibre excesivamente pequeño, fundamentalmente de la vena, o bien presentaban una importante fibrosis o daño inducido por la radioterapia, se optó por emplear en su lugar vasos del eje subescapular. De esta forma, en 1 caso $(1,6 \%)$ se empleó la arteria y vena toracodorsales y en otro caso $(1,6 \%)$ los vasos del pedículo del serrato. En otra paciente $(1,6 \%)$ se utilizó como vasorreceptor una arteria y vena perforante de los vasos mamarios internos al presentar un calibre destacable, probablemente debido a que con anterioridad se había practicado una reducción mamaria, reforzándose la vascularización según los principios de los colgajos diferidos (137).

Nuestra práctica ha seguido la tendencia actual, siendo los vasos mamarios internos aceptados por la mayoría de los autores como los vasorreceptores de referencia en el campo de la reconstrucción microquirúrgica de mama $(122,142-144,185,232,233)$. Las múltiples ventajas que presentan han desplazado progresivamente a los vasos toracodorsales como vasos de referencia, siendo utilizados únicamente por algunos autores en casos de RMI con buena exposición de estos vasos tras una disección axilar. Estas ventajas se resumen en su constancia anatómica; su seguridad de tamaño y calibre similar al pedículo epigástrico inferior profundo; tienen una localización más centrada en la zona de la reconstrucción lo que repercute en una mayor libertad de movimiento para la colocación del colgajo; son resistentes a la arterioesclerosis; suelen estar preservados tras la administración de RT y/o cirugía axilar y por último permite reservar los vasos toracodorsales para usar con el colgajo de LD en caso de una reconstrucción fallida del colgajo DIEP. 


\subsection{Tiempo operatorio}

El tiempo medio necesario para realizar una RM unilateral en nuestra serie fue de 413,39 \pm 72,667 minutos, mientras que en el único caso de reconstrucción bilateral la intervención duró 720 minutos. Hemos observado que aquellas RM que presentaron algún tipo de complicación fueron 15 minutos más largas, sin que esta diferencia llegase a resultar estadísticamente significativa.

Los grupos de referencia en RM con colgajo DIEP han presentado tiempos quirúrgicos comprendidos entre 248 - 385 min, significativamente menores a los de nuestra serie $(165,170,183,187,191)$. Estos tiempos operatorios medios corresponden a grupos con series superiores a los 600 colgajos DIEP compuestos por especialistas en microcirugía de prestigio mundial y con muchos años de desarrollo profesional. En cambio, como he explicado anteriormente, nuestro grupo ha estado compuesto por cirujanos que en la mayoría de los casos acababan de terminar su periodo de formación y que tenían relativamente poca experiencia clínica en microcirugía aunque sí una buena base experimental. Nuestros tiempos medios se han reducido desde las primeras cirugías aunque no de forma drástica. Esto se explica por la rotación de profesionales de nuestro servicio en los años que se ha llevado a cabo este estudio unido a que la adquisición de responsabilidades en la cirugía por parte de los diferentes miembros ha sido progresiva, de modo que a medida que unos especialistas ganaban técnica de disección y habilidades microquirúrgicas se daba paso a cirujanos menos experimentados.

Acosta y cols. informaron que en sus inicios con esta técnica en el año 2000, el tiempo medio empleado fue de 438 min, similar al nuestro, aunque en aquellas fechas no se había descrito la aplicación de la angio TC como método útil en la planificación y en la reducción del tiempo operatorio (165). Otros autores ha presentado tiempos medios de 407,7 $\pm 88,4$ min en sus primeros 104 RM con colgajo DIEP, mucho más en consonancia con los resultados de nuestra serie (173).

Ha sido sorprendente detectar que el tiempo medio de cirugía de aquellos colgajos que han presentado una necrosis grasa ha sido 22 minutos inferior a los que no han presentado 
esta complicación. Esta diferencia puede ser explicada al azar debido a la falta de significación en nuestro estudio, aunque la muestra es escasa para poder realizar esa afirmación con rotundidad. Debido a que esta complicación se comporta de manera "silente" durante la intervención y no se detecta hasta varios días y/o semanas después, no debería suponer una diferencia de tiempo operatorio. Una explicación podría ser que en los colgajos que no han presentado necrosis grasa se haya realizado algún procedimiento protector de esta complicación. La ejecución de la técnica quirúrgica ha sido uniforme en todo el estudio, únicamente cambiando la habilidad técnica y rapidez de cada cirujano en la disección del colgajo, y el aumento del retorno venoso mediante la realización de una segunda anastomosis venosa. Mientras que no se ha recogido información de la primera posibilidad, el consumo de tiempo en la realización de una segunda vena han sido $82 \mathrm{~min}$, suponiendo un incremento significativo.

Este incremento de tiempo ha sido tan importante por dos motivos. El primero porque la congestión venosa en el colgajo no se ha podido anticipar en ocasiones hasta la finalización de la anastomosis a los vasorreceptores principales, siendo necesario no sólo realizar la segunda anastomosis venosa, sino disecar también el vasorreceptor accesorio. El segundo porque una vez perfundido el colgajo y sin los efectos deletéreos de la isquemia, la ejecución de esta anastomosis se reservaba a los miembros menos experimentados para incrementar sus habilidades ya que se puede rehacer fácilmente por otro cirujano si el primero comete algún error técnico. De hecho, los picos más pronunciados de la gráfica del tiempo operatorio se corresponden con la realización de este procedimiento adicional.

Lee y cols. (186) observaron en una revisión de publicaciones que la realización de una segunda anastomosis aumentaba el tiempo quirúrgico alrededor de $15 \mathrm{~min}$, sin encontrar diferencias significativas con respecto a la no realización de este procedimiento. En cambio, Ochoa y cols. (138) observaron un aumento estadísticamente significativo en la duración de sus intervenciones al realizar esta segunda vena, cuantificándolo en 61 min de media. Estas diferencias se explican porque mientras que la mayoría de los autores emplean "couplers" o sistemas automáticos para realizar sus anastomosis venosas lo que reduce significativamente el tiempo $(183,199)$, en la serie de Ochoa y cols. la sutura se realizó "a mano", de forma análoga a como se ha realizado en nuestro estudio. 
A pesar de que en base a estos datos no podemos asegurar que existe una relación entre hacer un drenaje venoso adicional y la no aparición de necrosis grasa, estos dos parámetros serán objeto de estudio con más detenimiento en este trabajo. 


\section{CONTRIBUCIÓN DE LA ANGIO TC EN LA PLANIFICACIÓN DE COLGAJOS DE PERFORANTES ABDOMINALES}

La anatomía de la arteria epigástrica inferior profunda varía ampliamente en su localización, patrón de división, en el curso intramuscular, número y localización de vasos perforantes entre diferentes individuos, e incluso de un hemiabdomen a otro dentro del mismo individuo, por lo que es imperativo realizar una aproximación preoperatoria que facilite la localización intraoperatoria de la perforante adecuada. Inicialmente, la ecografía doppler color se presentó como un buen método de estudio de los vasos perforantes. Cirujanos plásticos como Blondeel y Hallock $(127,150,234)$ fueron precursores en utilizar esta técnica para planificar su colgajos de perforantes. El doppler color tiene la ventaja de ser una prueba barata, no invasiva, que no utiliza radiación y no sólo ofrece información sobre el vaso analizado sino también de la anatomía perivascular. Por el contrario, destacan su difícil reproducibilidad, la necesidad de un largo tiempo de exploración y el ofrecer imágenes difíciles de interpretar por el cirujano plástico. Su valor predictivo positivo entre la perforante seleccionada por el radiólogo y la elegida de forma intraoperatoria por el cirujano varía entre el 46,1\% y el 100\% según diferentes estudios $(153,235)$, por lo es una técnica operador dependiente. Estos inconvenientes la han desplazado a un segundo plano con el desarrollo de la angiotomografía. Sin embargo, sigue siendo una técnica valiosa gracias a su utilidad en pacientes en los que esta contraindicado la realización de un angio TC y a la información hemodinámica que ofrece sobre los vasos en zonas que han recibido un traumatismo previo como en las reconstrucciones de miembro inferior o cuando han sufrido una liposucción abdominal en el caso del colgajo DIEP (235).

Este trabajo de tesis sienta sus bases en la utilización de técnicas radiológicas, en concreto en el estudio de la pared abdominal mediante angiotomografía computerizada, como método para planificar las reconstrucciones mamarias con el colgajo DIEP y analizar las implicaciones de las diferentes características anatómicas de los vasos perforantes en la irrigación del tejido transferido y su repercusión en la complicaciones circulatorias de estos colgajos. 
Las ventajas de la angio TC en la planificación del colgajo DIEP están ampliamente referenciadas en la literatura, siendo su utilización aceptada por la mayoría de las unidades de reconstrucción mamaria microquirúrgica. Masiá y cols., pioneros en esta técnica, presentaron en 2006 un estudio en 66 pacientes en las que utilizó la tomografía computerizada por multidetectores en la localización de los vasos perforantes de manera preoperatoria a la reconstrucción mamaria con un colgajo DIEP (236). Esta técnica demostró un valor predictivo positivo y una concordancia anatómica de los vasos perforantes entre el estudio preoperatorio y los hallazgos intraoperatorios del $100 \%$, siendo este hecho confirmado posteriormente por otros autores (153,237-240). En nuestro estudio hemos podido evidenciar esta correlación, visualizando durante la intervención quirúrgica todas aquellas perforantes seleccionadas en la planificación preoperatoria. También hemos podido comprobar la existencia de una concordancia entre el calibre de las perforantes seleccionadas en la prueba diagnóstica con el demostrado en el quirófano.

Otra de las ventajas referidas por el angio TC es la reducción en el tiempo operatorio. Un criterio de exclusión en este estudio ha sido el no disponer de esta prueba diagnóstica para su estudio preoperatorio. Esta circunstancia sólo sucedió en una ocasión en nuestra población por lo que no ha sido posible analizar este parámetro. Hemos podido comprobar sin embargo, una serie de hechos. Conocer la localización de la perforante elegida ha permitido realizar una disección más dirigida y menos dubitativa, evitando el miedo a lesionar un vaso perforante adecuado sobre la que basar el colgajo por una aparición inadvertida en el campo operatorio; esto ha facilitado un marcaje más preciso de la isla cutánea con una ubicación mas centrada de la perforante dentro del colgajo. A medida que se ampliaron nuestros conocimientos en el postprocesamiento de imágenes se pudo realizar renderizados en 3D, fundamentalmente en los últimos casos de nuestra serie, lo que nos dió la ubicación relativa de la perforante seleccionada con respecto a otras perforantes y al ombligo, de tal manera que se pudo realizar una rápida disección hasta las perforantes menores tomadas como referencia y luego una más cuidadosa hasta la seleccionada; esta información tuvo su mayor beneficio en pacientes con importante grosor del panículo adiposo abdominal, en las que a pesar del marcaje del vaso seleccionado en la piel, la tracción del colgajo durante su separación podía inducir a errores en su localización exacta. En la mayoría de nuestros estudios se observó el trayecto del vaso perforante a través del 
músculo recto anterior del abdomen, lo que permitió anticipar una localización subfascial y conocer de antemano la dirección que llevaba, realizándose una disección más rápida y segura. El marcaje de las venas epigástricas inferiores superficiales también permitió al igual que en el caso del vaso perforante, una disección más dirigida y rápida. Diferentes autores han intentado trasladar en tiempo el valor de esta información, comparando los tiempos de disección previos en sus series utilizando planificaciones con eco doppler color o doppler portátil con los tiempos al introducir la angio TC. Así, el grupo de Masiá informó de una reducción del tiempo operatorio de 100 minutos $(163,236)$, mientras que Uppal y cols. lo cuantificó en 72 minutos (238), Gacto-Sanchez y cols. en 128 minutos (241), Minquiang y cols. en 96 minutos (242) y Casey y cols. en 99 minutos (243). Todas estas series demostraron una reducción significativa en la reducción del tiempo operatorio. Además, Casey presentó una reducción no significativa en la aparición de necrosis grasa, complicaciones anastomóticas, colgajos fallidos y dehiscencia abdominal, aunque en la serie de Gacto-Sanchez hubo una reducción generalizada y significativa de todas las complicaciones en aquellos pacientes con un estudio angio TC preoperatorio. Estos datos han sido corroborados en un meta análisis sobre 6 estudios realizado por Teunis y cols. (244).

El desarrollo de tomógrafos computerizados cada vez mas avanzados y con mayor número de detectores ha permitido obtener estudios con más grado de detalles en un tiempo de adquisición cada vez menor. Estos tiempos ya de por si bajos y menores a 10 segundos, permiten completar el estudio en un tiempo de apnea, reduciendo los artefactos en la adquisición de las imágenes. En nuestro estudio se emplearon tres tomógrafos diferentes en la realización de los estudios, con unas prestaciones y unos parámetros de adquisición en consonancia con la mayoría de las publicaciones $(162,163)$. En algunos trabajos se ha relatado el uso de contrastes yodados de una densidad mayor $(370 \mathrm{mg} / \mathrm{ml})$ frente a la empleada en este trabajo $(300 \mathrm{mg} / \mathrm{ml})(161,245)$ con el fin de obtener una mayor realce de los pedículos vasculares estudiados. El tomógrafo inició de manera automática la captura de imágenes al alcanzar un nivel de atenuación en la aorta abdominal por encima de $100 \mathrm{HU}$, de acuerdo al artículo original de Clavero y cols. (163) y Phillips y cols. (162), con una demora habitualmente inferior a los $10 \mathrm{seg}$. desde la inyección del contraste hasta el inicio en la adquisición de las imágenes. Con posterioridad, varios autores han 
recomendado usar tiempos de latencia mayores, en torno a $12-15$ s y $180 \mathrm{HU}$, con el fin de obtener las imágenes en una fase arterial tardía o venosa precoz $(154,165)$, debido a la importancia del estudio de las venas para la viabilidad del colgajo. A pesar de estas recomendaciones, nuestros estudios mostraron una adecuada captación del sistema venoso superficial y sus conexiones con las perforantes del colgajo.

Existen diferentes paquetes de software que se pueden utilizar en el postprocesamiento de los archivos obtenidos en formato DICOM. Aunque en las estaciones de trabajo de los servicios de radiología se usó la aplicación Siemens Syngo web-space, existen una gran variedad de programas capaces de manejar archivos DICOM y realizar reconstrucciones en 2D y 3D. Para este estudio se utilizó la herramienta OsiriX. Los motivos fueron su fácil disponibilidad, la existencia de una versión homologada por la FDA para uso clínico e investigador, sus altas prestaciones, la posibilidad de encontrar tutoriales para aprender el manejo en la red y el funcionar en ordenadores domésticos que trabajen bajo el sistema operativo Mac OsX. Su utilidad en el campo médico esta avalada por la existencia de más de 200 referencias en el motor de búsqueda PubMed.

Rodríguez-Vegas y cols. (161) ha publicado una relación de los modos de reconstrucción de imágenes con el software OsiriX útiles en el análisis de diferentes parámetros en la planificación de colgajos de perforantes. Aunque este autor propone diferentes modos en función de la estructura analizada, en nuestro estudio siempre se empleó el modo 3D MPR. Este modo permite hacer una rotación de las imágenes en la orientación adecuada y recoger toda la información precisa en un solo modo, simplificando esta labor. En nuestro estudio no se utilizó el modo 3D MPR curvo, el cual permite recoger información sobre la longitud del pedículo, debido a la falta de relevancia ya que esta longitud no es un factor limitante en el colgajo DIEP, ni la medición calibre de los vasos, debido a que se trata de una medida imprecisa cuando se trata de estudiar vasos de menos de $2 \mathrm{~mm}$ de diámetro, hecho este último en la que coincidimos con estos autores (161). Se ajustó el parámetro "grosor de corte" de acuerdo a las necesidades del análisis realizado. Así, mientras para la toma de distancias se emplearon los cortes más finos de los que disponía el estudio con el fin de alcanzar el mayor grado de precisión, se aumento el grosor de corte para facilitar el estudio del trayecto de los vasos perforantes y su relaciones con la 
AEIP, su distribución en el parénquima del colgajo y sus relaciones con el sistema venoso superficial. Únicamente se utilizó el modo 3D VR cuando se quiso hace una representación de las diferentes perforantes disponibles a nivel de su salida a través de la fascia abdominal.

El tiempo utilizado en el procesamiento de las imágenes y planificación del colgajo con OsiriX ha sido de entre 10 a 15 minutos, similar al tiempo empleado por otros autores con otros software $(154,239)$. Fue posible realizar capturas de imágenes con sus medidas y representar una secuencia de cortes en formato de vídeo para ser revisados justo antes de iniciar la intervención.

Nuestra experiencia en el uso del programa OsiriX en el estudio de los angio TC para la realización de este trabajo así como en los últimos casos de nuestra serie nos permite certificar que se trata de una aplicación sencilla al alcance de cualquier cirujano plástico que permite hacer una adecuada planificación del colgajo DIEP.

Otra de las ventajas de la angio TC es el elevado nivel de detalle en los estudios, que permite visualizar vasos de hasta un diámetro de $0,3 \mathrm{~mm}$ y realizar reconstrucciones $3 \mathrm{D}$ de excelente calidad, incluso superior a la definición de la angioresonancia, que permite visualizar vasos de hasta $1 \mathrm{~mm}$ de diámetro $(156,246)$. Nuestra experiencia ha sido similar a la relatada en la literatura y únicamente la calidad de detalles descendió en los estudios realizados en el Hospital de El Bierzo debido a que la captura de imágenes se realizó con un grosor mayor. Esto dificultó la visualización de las perforantes de menor calibre, pero permitió estudiar perfectamente las perforantes de mayor calibre y su relación con el resto de estructuras anatómicas, siendo válidos estos estudios en la planificación del colgajo DIEP.

La motivación que nos ha llevado progresivamente a intervenir en la planificación de nuestros colgajos DIEP ha sido la variabilidad en la información ofrecida por los diferentes radiólogos que han estudiado los angio TC de las pacientes de esta serie. La elección de la perforante adecuada implica una larga curva de aprendizaje y muchos detalles que con la experiencia y la actualización científica hemos observado como relevantes (conexiones 
con el sistema venoso superficial, ramificación, trayecto de la perforante, patrón de la AEIP) no suelen ser percibidos por los radiólogos al no participar activamente en la cirugía si no existe una continua y estrecha comunicación entre éste y el cirujano. Esto se traduce en que mientras algunos autores han presentado concordancias en la elección de la perforante entre el radiólogo y el cirujano del 95,2\% (245), otros autores han reducido esta coincidencia al 33\% (247). Aunque creemos que la labor del radiólogo sigue siendo insustituible debido a sus conocimientos técnicos y su capacidad de análisis de la imagen radiológica, la reconstrucción mamaria con el colgajo DIEP es una técnica altamente compleja que hace recomendable que el cirujano plástico participe activamente en su planificación preoperatoria para obtener el máximo beneficio de esta prueba diagnóstica.

Los principales inconvenientes descritos en la planificación de colgajos con la angiotomografía son el potencial efecto nefrotóxico derivado del uso de contrastes iodados $(242,248)$ y el uso de radiaciones ionizantes con una dosis alrededor a los $5.6 \mathrm{mSv}(236)$, no siendo sin embargo superior a la dosis de una tomografía abdominal convencional (249).

Aunque en este trabajo la planificación se realizó siempre mediante angio TC, se empleó un doppler portátil antes de iniciar la intervención para confirmar la localización de la perforante seleccionada y de manera intraoperatoria cuando se deseó testar el flujo de un vaso. Se trata de un método muy sensible pero poco específico y con alto índice de falsos positivos en comparación con las otras técnicas descritas, por lo que su utilidad esta limitada como complemento a dichas técnicas por su facilidad de uso y su disponibilidad intraoperatoria $(248,250-252)$.

\subsection{Estudio circulatorio de la pared abdominal}

La principal clasificación de la arteria epigástrica inferior profunda según su patrón de ramificación corresponde a la realizada por Moon y Taylor en 1988 (124). En esta clasificación el tipo 1 corresponde a un tronco único (29\%), el tipo 2 a un tronco bifurcado (57\%) y el tipo 3 a un tronco trifurcado (14\%). En nuestro estudio se registró el patrón de 
la AEIP de acuerdo a esta clasificación, observándose un porcentaje inverso entre los tipos 1 y 2. En nuestro registro se diferenciaron el lado derecho y el lado izquierdo, con una frecuencia del patrón tipo 1 de 60,7 y 63,9 \% respectivamente. El patrón tipo 2 se observó en el $36,1 \%$ en el lado derecho y en 32,8\% en el izquierdo y el patrón tipo 3 en el 3,3\% en ambos lados por igual.

Otros autores han estudiado el patrón de la AEIP en cadáver o bien con ayuda del eco doppler color, observando un patrón tipo 2 en el $58 \%$ al $82 \%$ de los casos mientras que el tipo 1 estuvo presente en el 26,5\% al 28\% de los mismos $(126,127,253)$. Recientemente Rozen y cols. $(125,254)$ han introducido dos patrones a esta clasificación; el tipo 0 cuando el tronco de la AEIP está ausente y el tipo 4 cuando este tronco presenta cuatro divisiones. En una revisión de 500 angio TC observó una mayor frecuencia del tipo 1 con respecto a las series publicadas anteriormente (tipo 0: $<1 \%$; tipo 1: 43\%; tipo 2: $48 \%$; tipo 3: $9 \%$ y tipo 4: $<1 \%)$.

Nuestras observaciones discrepan de otras publicadas en la literatura, aunque se aproximan a este último trabajo, posiblemente porque comparten la misma metodología de estudio . La importancia del patrón de la AEIP en el que se basa el colgajo radica en que mientras las perforantes del tipo 3 tienen un trayecto intramuscular más largo, aquellos vasos que nacen de la rama lateral del patrón tipo 2 tienen el trayecto más corto, lo que facilita y reduce el tiempo de disección y produce menor grado de lesión en músculo recto anterior del abdomen, por lo que Rozen y cols. han considerado el patrón tipo 2 como el óptimo sobre el que basar el colgajo DIEP, desaconsejando el tipo 3 (253).

En las pacientes de nuestro estudio se realizó un recuento de las perforantes abdominales de un calibre suficiente para ser patentes en el angio TC. El número medio de perforantes abdominales correspondiente al lado derecho fue de 2,72 $\pm 1,240$ (rango 1-6) frente al lado izquierdo que fue de 2,84 \pm 1,067 (rango 1-5). En todos los estudios se visualizó al menos 1 perforante, siendo habitual localizar 2 ó 3 perforantes (32,8\% y 31,1\% en el lado derecho frente a $26,2 \%$ y $34,4 \%$ respectivamente). Con respecto a estos valores hay que considerar que en una disección anatómica el número de perforantes puede ser mayor, sin embargo en nuestro trabajo sólo hemos recogido aquellas de calibre mediano o 
grande, que son sobre las que interesa basar un colgajo DIEP. Estos hallazgos son similares a otros referidos en la literatura. Masiá y cols. (249) encontraron una media de 2,3 perforantes en cada hemiabdomen útiles para esta cirugía con una única perforante disponible en el 4,9\% de los casos. En un estudio en 40 cadáveres Heitmann y cols. (130) comprobaron que entre una y dos perforantes de un calibre superior a $1 \mathrm{~mm}$ pueden observarse en relación con cada pedículo epigástrico inferior profundo en un radio de $8 \mathrm{~cm}$ alrededor del ombligo. Otros autores en cambio han descrito una media de entre 5,04 y 6,4 perforantes por colgajo en disecciones en cadáver o con ayuda de angio TC, registrando todas las perforantes de un grosor superior a $0,8 \mathrm{~mm}(253,255)$.

En nuestro trabajo se observó un gran variabilidad anatómica en la localización de las VEIS con un rango que fue desde los $7 \mathrm{~mm}$ a los $78 \mathrm{~mm}$ con respecto a la línea media. Además en el 3,3\% de los casos en el lado izquierdo y en el 1,6\% de los casos en el lado derecho, la VEIS estuvo ausente. También se observaron diferentes variantes anatómicas, como VEIS bifurcadas, VEIS que drenaban al lado contralateral o importantes conexiones entre ambos sistemas, sin que la frecuencia de estas variaciones superase el 3,3\% de los casos. Este hecho refuerza la importancia de la planificación de la angio TC, ya que la variabilidad anatómica que muestra la localización y calibre de los vasos perforantes se extiende también al sistema venoso superficial. Dado el papel tan relevante que juega en el drenaje del colgajo DIEP y su utilidad como método de salvamento, es de vital importancia su estudio preoperatorio.

\subsection{Hallazgos complementarios del angio TC}

La finalidad del mapeo abdominal con angio TC fue estudiar las cualidades circulatorias de la pared abdominal de cara a la disección del colgajo DIEP, lo cual se logró en todos los casos. Sin embargo, esta prueba es capaz de aportar otros datos que pueden resultar ser tremendamente útiles en la planificación quirúrgica.

La angio TC permite aportar información sobre: 
- Continencia de la pared abdominal. En el estudio se puede visualizar hernias umbilicales, zonas de labilidad de la pared o bien diástasis de rectos, que si no son tomadas en consideración durante el acto quirúrgico que puede dar lugar a una debilidad abdominal e incluso eventraciones tras la disección del colgajo DIEP.

- Estudio de las cicatrices abdominales originadas en cirugía previas y su relación con los pedículos vasculares utilizados en la extracción del colgajo.

- Variaciones anatómicas de diferente relevancia.

Toda esta información conocida de antemano nos permitió, por ejemplo, coordinarnos con el Servicio de Cirugía General en aquellos casos en los que la existencia previa de una hernia o un fallo en la pared abdominal aconsejase su actuación, ahorrando morbilidad y futuras intervenciones a la paciente. También se pudo valorar la idoneidad de la indicación en aquellas pacientes con una laparotomía media previa, comprobando la existencia de una arquitectura vascular adecuada sobre la que realizar un colgajo DIEP.

En definitiva, toda esta información no sólo reduce la morbilidad y el tiempo operatorio a la vez que optimiza los resultados de la RM, sino que ofrece al cirujano algo intangible y difícil de valorar como es la sensación de seguridad y control absoluto en todo momento del procedimiento permitiendo una rápida y adecuada toma de decisiones ante la aparición de situaciones inesperadas. 


\section{ESTUDIO DE LA ARQUITECTURA CIRCULATORIA DEL COLGAJO}

Actualmente las opciones reconstructivas disponibles en el campo de la Cirugía Plástica y Reparadora son tan amplias que uno de los objetivos que tiene mayor relevancia a la hora de indicar una técnica es generar el menor daño posible sobre la zona de donde se extrae el tejido utilizado para reparar un defecto. En este sentido, el desarrollo de los colgajos de perforantes ha supuesto una revolución sustancial al permitir transferir tejidos prescindiendo de ejes vasculares de importancia y de estructuras intermedias como músculos para vehicular los vasos que nutren el colgajo, dejando como única secuela en muchos casos una cicatriz. Sin embargo, el precio a pagar por estos beneficios ha sido un aumento de las complicaciones circulatorias con resultado de pérdidas parciales o totales de los colgajos como consecuencia de la labilidad de los vasos perforantes que los nutren. Muchos equipos de cirujanos plásticos han estudiado estas complicaciones y su relación con diferentes factores clínico-epidemiológicos con el fin de hacer una adecuada selección de los pacientes candidatos a este tipo de reconstrucciones y reducir el riesgo de aparición de estos problemas.

El colgajo DIEP no se ha librado de este minucioso estudio, describiendo diferentes factores de riesgo. Sin embargo, al tratarse de un procedimiento relativamente largo y complejo cuyo objetivo último es una mejora en la calidad de vida, la indicación de este tipo de reconstrucción se suelen condicionar a que el paciente tenga un buen estado de salud. A medida que ha crecido la experiencia con este colgajo, los grupos más punteros han observado la transcendencia de diferentes detalles anatómicos, como el uso de perforantes de buen calibre, y su relación con el éxito de la reconstrucción. De este modo, se ha iniciado una carrera en el estudio de diferentes características circulatorias y su relación con estas complicaciones. Muchos de estos estudios han sido realizados inicialmente en cadáveres mediante la inyección de colorantes en los vasos perforantes con la intención de conocer sus angiosomas correspondientes. Estos estudios, aunque muy interesantes, fallaban en el modelo utilizado al ser incapaz de considerar factores nerviosos, hormonales y locales no presentes en el cadáver y que son de vital importancia en la regulación circulatoria, quedando reservados para descripciones anatómicas o en la 
formulación de nuevas hipótesis. Aunque no de fácil realización, diferentes estudios clínicos apoyados en técnicas de fluorescencia y espectrofotometría han permitido considerar estos factores y conocer los territorios de irrigación de los vasos perforantes del colgajo DIEP $(134,135,256)$. Sin embargo, el desarrollo de las técnicas radiológicas, sobre todo la angio TC y la angio RNM, unido al descubrimiento de su utilidad en la planificación del colgajo DIEP, ha facilitado enormemente esta labor a la vez que ha expandido considerablemente los parámetros relacionados con la arquitectura vascular que se pueden estudiar $(221,253,257-261)$. Este trabajo de tesis ha intentado desentrañar que características tienen un papel más preponderante en la vascularización de este colgajo que permitan realizar nuestras reconstrucciones lo más exitosas posibles.

\subsection{Patrón de la AEIP}

En nuestra serie, el patrón de la AEIP de la perforante en la que se basó el colgajo correspondió en 43 casos $(68,9 \%)$ al tipo 1, en 17 casos (27,9\%) al tipo 2, y únicamente en 2 casos $(3,2 \%)$ correspondió al tipo 3. La elección de la perforante se realizó fundamentalmente a expensas de su calibre y el patrón no se consideró un criterio de elección de la perforante de manera preoperatoria, por lo que en nuestro estudio las perforantes de mayor calibre tienen con mayor frecuencia su origen en la AEIP formadas por un único tronco. No se observaron los patrones tipo 0 y 4 recientemente descritos por Rozen y cols. (254).

En este estudio no se ha observado una relación significativa entre el patrón de la AEIP y la aparición de necrosis grasa, aunque si que hubo una tendencia en el caso del patrón tipo $2(\mathrm{p}$-value $=0.062)$. Este hecho puede relacionarse con que este patrón dé origen a perforantes de menor calibre, o bien a que las perforantes tengan un origen más lateral dentro de la isla diseñada del colgajo, dando así problemas de perfusión en las zonas distales del colgajo a nivel del tejido adiposo. Sin embargo esta relación no se confirmó, siendo más frecuente utilizar perforantes de la línea medial frente a la lateral (10 y 4 respectivamente) en el patrón tipo 2. Al considerar la aparición de problemas circulatorios del colgajo, no se sostuvo esta tendencia, aunque las 2 reconstrucciones con un patrón tipo 
3 presentaron problemas de congestión venosa que se resolvieron mediante la realización de una $2^{\mathrm{a}}$ anastomosis venosa, existiendo una relación significativa para el patrón tipo 3. Cabe decir que en ambos casos el vaso perforante no presentaba conexión con el sistema venoso superficial ni una ramificación significativa en el interior del colgajo, lo que como veremos más adelante parece tener una vital importancia en la circulación del colgajo, siendo realmente la relación significativa a expensas de estos parámetros y no del patrón de la AEIP.

En la literatura existen pocos autores que hayan estudiado el patrón de la AEIP y no se encontró ninguna publicación que relacione este parámetro con la aparición de complicaciones circulatorias. Aunque una AEIP con más divisiones suele tener un menor calibre, el factor limitante se localiza a nivel de la perforante, donde su calibre es aún menor. En el caso de los problemas observados en las RM con el patrón tipo 3, parece estar más en relación con otras variables. En nuestro estudio no se ha observado una relación entre estos dos parámetros $\mathrm{y}$, a pesar de que parece improbable, sería preciso realizar estudios con muestras mucho mayores para descartar esta asociación.

\subsection{Trayecto muscular de la perforante}

En el presente trabajo no se observó una relación significativa entre la longitud del trayecto de la perforante y la aparición de necrosis grasa o problemas circulatorios en el colgajo (p-value $=0,294)$.

No existen publicaciones que hayan valorado este parámetro. Parece lógico pensar en función es estos resultados que una perforante de mayor longitud únicamente condiciona una disección más tediosa dentro del vientre muscular, lo que se traduce en un consumo de tiempo mayor, sin que este factor tenga una relación con la perfusión del colgajo. Sí está reseñado en la literatura que las perforantes con un patrón de AEIP tipo 2 que se originan en la bifurcación lateral tienen un trayecto intramuscular más corto, aunque esta ventaja queda ensombrecida por su estrecha relación con los nervios motores del músculo recto 
anterior, haciendo más probable su lesión durante la esqueletización de la perforante $(253,262)$.

\subsection{Características del trayecto de la perforante}

La mayoría de las perforantes seleccionadas tenían un trayecto a través del musculo recto anterior del abdomen sin ninguna característica especial $(42,6 \%)$ o bien atravesaban una unión intertendinosa de este músculo antes de su salida por la fascia abdominal $(45,9 \%)$, mientras que el resto de características (retromuscular y subfascial tuvieron una escasa frecuencia de aparición). En nuestro estudio no se observó una relación significativa en la aparición de necrosis grasa o problemas circulatorios en el colgajo en relación a si la perforante presentaba un trayecto intertendinoso dentro del músculo recto abdominal.

Parece lógico que las interrelaciones de la perforante con otras estructuras anatómicas no tengan una repercusión sobre la vascularización del colgajo. Tampoco se han encontrado referencias en la bibliografía publicada que relacionen estos parámetros. Sin embargo hay que tener en cuenta una serie de consideraciones. La salida de la perforante a través de una unión intertendinosa del músculo recto anterior del abdomen hace que su disección sea más difícil debido a que este tejido tiene características fibróticas y se imbrica con el vaso, precisando más tiempo en su esqueletización y aumentando el riesgo de lesionarla. Las perforantes retromusculares circunvalan el musculo recto anterior por su borde medial hasta alcanzar la AEIP, por lo que al no tener trayecto intramuscular su disección es considerada más sencilla. Un trayecto subfascial largo del vaso perforante se ha asociado con un trayecto intramuscular corto y de más sencilla disección (152). Sin embargo se corre el riesgo de lesionarla al abrir la fascia muscular si se desconoce esta relación.

Vandevoort y cols. (263) describieron estas características en una serie de 100 colgajos DIEP, encontrando un trayecto subfascial en el $5 \%$ de sus perforantes mientras que en el $16 \%$ el vaso atravesaba una intersección tendinosa. Aunque la frecuencia de aparición de 
cada una de estas características fueron muy diferente a las nuestras, coincidimos en sus apreciaciones sobre el significado de cada una de ellas.

\subsection{Línea de la perforante}

La línea de origen del vaso perforante en el que se basa el colgajo ha sido recientemente motivo de estudio por diferentes autores, cobrando una gran relevancia en los últimos años.

Holm y cols. (134) publicaron en 2006 un estudio prospectivo y clínico sobre 15 colgajos DIEP en el que se redefinían las zonas clásicas de perfusión del colgajo DIEP popularizadas por Hartrampf (80). En este estudio observaron mediante fluorescencia que el índice medio de perfusión para la zona I era un $76 \%$ con respecto al control, la zona II recibía un $25 \%$ y la zona III un $47 \%$, mientras que la zona IV no estaba perfundida en el $33 \%$ de los pacientes mientras que el índice medio era del 13\%. Este trabajo concluía que los vasos de conexión entre los diferentes territorios vasculares eran más consistentes en el lado ipsilateral con respecto al lado contralateral a la línea media, de modo que las zonas II y III clásicas debían intercambiar su posición mientras que la zona IV debe ser descartada siempre debido a que sus índices de perfusión hacen improbables la supervivencia del tejido de esta zona. La mala vascularización de la zona IV ha sido refrendada por otros autores $(256,264)$. Sin embargo este estudio ha sido cuestionado con posterioridad ya que de los 15 colgajos, 2 se basaron en perforantes de la línea medial, 8 en vasos laterales y en los 5 restantes en una combinación de ambos por lo que la validez de los resultados corresponderían a la línea lateral de perforantes.

En 2008 Schaverien y cols. (264) estudiaron la circulación de 10 colgajos DIEP disecados en cadáver, empleando inyección de contraste y análisis con angio TC. En su trabajo concluyen que las perforantes mediales perfunden el colgajo mediante un patrón elíptico abdominal central, mientras que las laterales se distribuyen predominantemente en la lado ipsilateral del colgajo. También observan que la perfusión entre diferentes zonas ocurre mediante pequeños vasos a nivel del plexo subdérmico. 
Con el desarrollo de la teoría de los perforasomas y su aplicación al colgajo DIEP $(135,148)$ se define una nueva distribución de las zonas de perfusión del colgajo DIEP en función de la línea de origen de la perforante. La perfusión de los colgajos compuestos por las 3 zonas mas próximas a la perforante se consideran muy seguros, los que incluyen las 4 zonas más próximas seguros mientras que con más zonas los colgajos se vuelven variables o poco seguros (fig. 55). En un trabajo publicado en 2010 con una metodología similar al de Schaverien y cols. (264), Wong y cols. (135) observaron los siguientes hechos: existen unas conexiones directas entre vasos de la misma línea, mientras que entre vasos de diferentes líneas de perforantes estas conexiones son indirectas (de un calibre menor); el contraste inyectado en una perforante medial alcanza primero la zona II de Hartrampf y se distribuye por un área mayor comparado con la zona III, mientras que en el caso de las perforantes laterales esta relación se invierte; los colgajos basados en perforantes mediales ocasionalmente presentan conexiones indirectas que alcanzan la zona IV de Hartrampf, hecho que no ocurre con las perforantes laterales. Los autores concluyen que las perforantes laterales deben emplearse en colgajos hemiabdominales donde tienen una disposición más central, siendo ideales para reconstruir mamas de pequeño a mediano tamaño o bien en RM bilateral, mientras que en mamas grandes es mejor emplear las perforantes mediales o una combinación de ambas. También afirman que el aumento de la incidencia de necrosis grasa y otras complicaciones en el colgajo DIEP con respecto al TRAM descrito en la mayoría de los trabajos se debe probablemente a un desconocimiento en la anatomía y territorios vasculares de las líneas de perforantes denominados perforasomas.

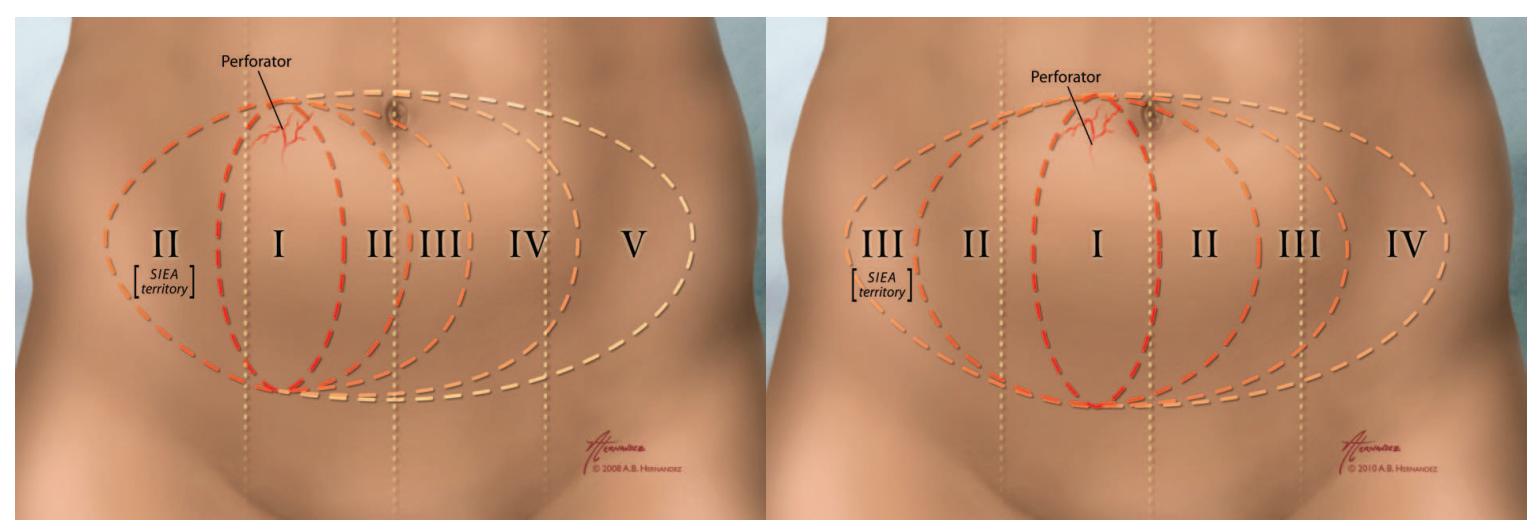

Figura 55: Nuevas zonas de perfusión del colgajo DIEP en función de si la salida de la perforante es en la línea medial (a la izquierda) o de la línea lateral (a la derecha). Fuente: Wong C, Saint-Cyr M, Mojallal A, Schaub T, Bailey SH, Myers S, et al. Perforasomes of the DIEP flap: vascular anatomy of the lateral versus medial row perforators and clinical implications. Plast Reconstr Surg. 2010;125(3):772-82. 
Al mismo tiempo que el trabajo anterior, Rozen y cols. (265) conducen un estudio de las líneas de perforantes en 155 cadáveres y en 145 angio $\mathrm{TC}$, en el que definen el concepto de "angiosoma de perforante", con similares implicaciones al artículo de Wong y cols. (135). Además observan que las perforantes de la línea medial tiene un calibre medio mayor (1,3 mm), un trayecto más directo en el colgajo, una ramificación más extensa y en el $98 \%$ de los casos presentan conexiones que cruzan la línea media. En cambio, las perforantes laterales son de menor calibre $(1 \mathrm{~mm})$, su trayecto en la isla del colgajo es más lateral, presentan una ramificación más limitada y sólo en un $2 \%$ de los casos tienen conexiones que cruzan la línea media. Concluyen afirmando que las perforantes mediales son mas ventajosas en términos de calibre, ramificación y disposición más central en el colgajo abdominal, además de que permiten preservar con mayor facilidad los nervios motores durante su disección intramuscular con respecto a las laterales.

En 2011 Rashmanian-Schwarz y cols. (256) publican un estudio donde analizan mediante espectrometría la saturación de oxígeno según la línea de la perforante elegida en 16 reconstrucciones con colgajo DIEP y mediante simulación de perfusión en cadáver 11 cadáveres en el que concluyen que las perforantes mediales tienen una mejor perfusión en la zona II clásica y peor en la III, mientras que las perforantes laterales tienen una mejor perfusión en el hemiabdomen ipsilateral.

Estas observaciones han sido corroboradas por otros autores de renombre y hoy en día han sido aceptadas dentro del campo de la Cirugía Plástica y Reparadora $(266,267)$.

En concordancia con todo lo relatado anteriormente, en el presente trabajo hemos observado una fuerte asociación en la aparición de necrosis grasa en el colgajo y la elección de perforantes laterales $(p$-value $=0.013)$. Cuando estudiamos la aparición de problemas circulatorios se pierde esta relación, aunque se mantiene una tendencia en el mismo sentido ( $p$-value $=0,077$ ). A pesar de que en nuestro estudio no hemos descritos las zonas de colgajo empleadas de manera individualizada, hemos seguido una sistemática en todas las reconstrucciones, prescindiendo de entre un tercio a la mitad de las zonas II y III de Hartrampf y de la totalidad de la zona IV de acuerdo a las recomendaciones de varios autores $(122,264)$. Esto significa que cuando se utilizaron las perforantes de la línea lateral 
nuestros colgajos estaban incluyendo toda la zona III y parte de la zona IV de la nueva clasificación, zonas con una perfusión mucho menos segura. A pesar de la evidencia científica que hay sobre los diferentes patrones circulatorios del colgajo DIEP en función de la línea de la perforante, hasta la fecha no hemos encontrado ningún estudio que aborde la relación del origen de la perforante con la aparición de complicaciones, siendo este uno de los primeros trabajos al respecto que corroboran las observaciones de los trabajos anatómicos y clínicos mencionados anteriormente.

\subsection{Localización de la salida de la perforante a nivel de fascia abdominal}

Al comparar la localización de la salida de las perforantes a nivel de la fascia abdominal en colgajos que presentaron problemas circulatorios frente a los que no, se observó una relación significativa entre la aparición de problemas circulatorios y la salida más periférica de la perforante en el eje $X(p$-value $=0,022)$ sin observarse esta asociación con el eje Y (p-value $=0,87)$. Estos resultados están en consonancia con lo relatado anteriormente. Una salida más lateral de la perforante va a dar como resultado una perfusión mucho peor de la porción del colgajo correspondiente al hemiabdomen contralateral y una mayor incidencia de las complicaciones relatadas. Se realizó una estimación de modo que por cada centímetro que se localiza más lateralmente la salida de la perforante, el riesgo de sufrir estas complicaciones aumenta en un 5,9\% (intervalo 0,6$15 \%)$.

En cambio, ha sido sorprendente el hallazgo de que esta correlación no se mantenga también en sentido cráneo-caudal, es decir, que las perforantes situadas en el borde superior del colgajo no presenten más complicaciones que las localizadas en una disposición más central.

En relación con este hallazgo, Blondeel, Rozen, Schaverien, Hallock y cols. $(136,199,264,267)$ han confirmado que un drenaje venoso inadecuado puede ser en realidad el factor limitante en la perfusión de los colgajos DIEP, debido a la elección de una perforante con un componente venoso demasiado pequeño, a la ausencia de 
conexiones venosas directas que sobrepasen la línea media o a que las conexiones entre los sistemas venosos superficiales y profundos sean demasiado finas. Estos autores a su vez han reflejado una progresión horizontal de la perfusión en la región abdominal inferior como se puede ver en la fig. 55, aunque Keller y cols. (268) también ha informado de un descenso en la saturación de oxígeno y en la perfusión del colgajo en sus secciones inferiores. Según las apreciaciones de Hallock, la configuración vascular óptima de cada colgajo DIEP es variable y depende de la combinación de los sistemas circulatorios superficiales y profundos según su dominancia en cada caso.

En nuestro trabajo se aceptó el "riesgo" de emplear perforantes localizadas en el borde superior del colgajo cuando estas demostraron una dominancia clara de calibre con respecto al resto, una amplia ramificación dentro del colgajo y una conexión directa con la VEIS en la angio TC, de modo que se respetó el perforasoma de la perforante seleccionada. Nuestros hallazgos sugieren que una perforante ha de estar centrada en la isla del colgajo en el plano horizontal, aunque no tiene tanta relevancia su ubicación periférica en el eje vertical, siempre y cuando se respete el perforasoma medial o lateral del colgajo DIEP.

De nuevo, no hemos encontrado otras publicaciones que hayan relacionado la aparición de complicaciones con la localización de salida de la perforante, aunque como hemos explicado previamente, nuestros hallazgos están en concordancia con las nuevas zonas de perfusión descritas recientemente.

\subsection{Número de perforantes del colgajo}

La influencia del número de perforantes que incluye un colgajo en la aparición de complicaciones ha sido y es en la actualidad motivo de debate, sin que exista actualmente un consenso al respecto. Diferentes autores han informado de resultados contrapuestos.

Gill y cols. presentaron en 2004 un estudio retrospectivo sobre 758 colgajos DIEP en RM, analizando diferentes parámetros. Entre sus resultados informan de un aumento en la 
incidencia de todas las complicaciones a medida que se incrementa el número de perforantes reclutadas con el colgajo. Los colgajos elevados sobre cinco perforantes muestron una relación significativa como factor de riesgo independiente en la aparición de cualquier tipo de complicación, y en las necrosis parciales del colgajo. Los colgajos basados en una perforante presentaron menos complicaciones de manera significativa con respecto a aquellos basados en dos o más perforantes. Con respecto a la aparición de necrosis grasa, aunque los resultados no fueron estadísticamente significativos, su incidencia aumento con el número de perforantes (191). La explicación dada por los autores fue que se emplearon colgajos con más perforantes en pacientes con más factores de riesgo circulatorios. Además, cuando se usaron colgajos basados en una o dos perforantes, éstas fueron de un calibre considerable lo que permitió una adecuada nutrición del colgajo, mientras que en los casos que se emplearon cuatro o cinco perforantes estas fueron de pequeño calibre sin que abastecieran al colgajo de un aporte sanguíneo fuerte y centralizado.

En 2009 Peeters y cols., en un estudio sobre la aparición de necrosis grasa en los colgajos DIEP consideran que es el calibre y el flujo a través de la perforante y su patrón de distribución dentro del colgajo como el factor más importante en la aparición de esta complicación por encima del número de perforantes incluidas en la disección (188).

Baumann y cols. (195) fueron los autores de un trabajo prospectivo presentado en 2010 que intentaba demostrar que el número de perforantes del colgajo TRAM y DIEP es un predictor de la aparición de necrosis grasa. La incidencia de esta complicación en los colgajos con 1 ó 2 perforantes fue del 25\%, en los colgajos con 3 a 5 perforantes del 5\% mientras que aquellos con más de 5 perforantes presentaron un 19\% de necrosis grasa. Además asignaron una puntuación en función del calibre del vaso, sin encontrar una diferencia de esta puntuación entre los colgajos con necrosis grasa con respecto a los no complicados. Los autores justifican estos resultados en que los colgajos con muchas perforantes no tenían una perforante de un gran calibre sino que usaron perforantes muy pequeñas siendo más importante una adecuada distribución del flujo sanguíneo dentro del colgajo a través de uno o varios angiosomas de la perforante que el flujo total aportado a través de las perforantes. 
Otros autores han demostrado que un aumento en el número de perforantes no previene la aparición de congestión venosa en el colgajo, y que incluso se asocia a la aparición de esta complicación. De nuevo la explicación ofrecida es que sin una perforante de gran calibre se tiende a disecar el colgajo reclutando mayor número de perforantes y que aunque el efecto acumulativo de estas es suficiente para perfundir el colgajo, su componente venoso es demasiado pequeño para permitir un adecuado drenaje del colgajo $(138,269,270)$.

En un trabajo presentado en 2014 sobre 310 colgajos DIEP, Grover y cols. afirman que los colgajos con menos perforantes tienen mayor incidencia de necrosis grasa, con porcentajes del 10,2\% en el grupo de una perforante frente a 3,1\% en el grupo de múltiples perforantes, sugiriendo que estos colgajos tienen una perfusión mas robusta que nutre más fácilmente las zonas periféricas del colgajo.

La mayoría de estos estudios fallan al estudiar de forma aislada el número de perforantes sin considerar otros factores como la línea de la perforante de origen del colgajo, su distribución dentro del colgajo, cuantificar su flujo y no considerar únicamente su calibre externo o el estudio del drenaje venoso del colgajo. En nuestro trabajo no se observó una relación significativa entre la aparición de necrosis grasa o problemas circulatorios del colgajo y el número de perforantes. Sin embargo es destacable que todas las complicaciones se presentasen en aquellos colgajos basados en una sola perforante. Como hemos observado, otros autores han presentado resultados antagónicos con muestras mucho mayores. Nuestras observaciones van en la línea de algunos de estos autores, no siendo tan significativo el número de perforantes como la adecuada distribución del flujo sanguíneo y el drenaje venoso dentro de toda la extensión del colgajo. Esto puede conseguirse en ocasiones con una sola perforante o pueden ser necesarias varias según el caso, debido a la gran variabilidad que han demostrado estos vasos. De nuevo parece que un adecuado estudio preoperatorio de la anatomía circulatoria de cada colgajo es imperativo si se quiere seleccionar aquellos vasos perforantes que aporten una adecuada nutrición al colgajo diseñado. 


\subsection{Ramificación de la perforante}

En este estudio la perforante sobre la que se basó el colgajo presentó en un 77\% de los casos una buena ramificación dentro del panículo adiposo del colgajo. En nuestro estudio se observó una asociación próxima a la significación al relacionar este parámetro con la aparición de necrosis grasa, mientras que la significación fue máxima al confrontarlo con los problemas circulatorios del colgajo.

Parece lógico que la visualización de una división de la perforante en múltiples ramas esté en consonancia con una mejor perfusión del tejido transferido.

Diferentes autores han estudiado la división de la perforante dentro del colgajo. ElMrakby y cols. (271) demostraron en sus disecciones en cadáveres que las perforantes de mayor calibre tenían un curso directo dentro del tejido adiposo del colgajo hasta alcanzar la piel, donde se distribuían a través del plexo subdérmico, optimizando la perfusión del colgajo, a diferencia de las perforantes con un grosor inferior a $0,5 \mathrm{~mm}$, que terminaban en la capa adiposa profunda bajo la fascia de Scarpa. Además, las perforantes de mayor calibre estaban asociadas a venas concomitantes que drenaban el plexo subdérmico siendo la elección de estas perforantes critica no sólo en la perfusión del colgajo sino también en el drenaje venoso.

Por otra parte Rozen y cols. $(265,272)$ demostraron en varios trabajos que la perforantes de la línea medial tenían unas ramificaciones más amplias y un calibre medio mayor que las perforantes de la línea lateral. Además, las perforantes se ramifican en dos localizaciones: justo superficial a la fascia de Scarpa (plexo fascial) que posteriormente emite ramas para nutrir el tejido adiposo profundo y a nivel del plexo subdérmico. Ambos plexos establecen conexiones con los plexos de perforantes anexas siguiendo el concepto de angiosoma descrito por Taylor y Palmer (89), mediante los vasos de "estrangulamiento".

Nuestros hallazgos están de nuevo en consonancia con estos trabajos, siendo aconsejable seleccionar perforantes con múltiples ramificaciones en el tejido adiposo 
debido a que proporcionan una mejor perfusión del colgajo. Además, estas ramificaciones se observan más frecuentemente en perforantes de mayor calibre y localización en la línea medial, ambos factores con connotaciones circulatorias favorables para el colgajo.

\subsection{Mejor perforante sobre la que basar el colgajo}

En nuestro estudio se observa una fuerte asociación estadística en la aparición de necrosis grasa $(\mathrm{p}$-value $=0.007)$ cuando no se escoge la mejor perforante de la angio TC . Cuando se analizó este parámetro con respecto a los problemas circulatorios del colgajo se observó que esta relación estadística era, si cabe, máxima ( $\mathrm{p}$-value $=0.000)$.

En este trabajo, se ha utilizando la aplicación OsiriX en el postprocesamiento de las imágenes capturadas por la angio TC. Se consideró como mejor perforante el vaso de mayor calibre a nivel de su salida de la fascia abdominal que a la vez tuviera una conexión directa con el sistema venoso superficial y una ramificación importante dentro del colgajo, sin considerarse otros parámetros como la localización de la perforante o su trayecto. Hay que tener en cuenta que los criterios de elección de la perforante de forma preoperatoria a la cirugía cambiaron con la evolución de nuestra experiencia. Inicialmente sólo se estudiaban los cortes axiales y se buscaba la perforante de mayor calibre y lateral preferiblemente, al gozar de un curso intramuscular más corto. Posteriormente se fue considerando sus conexiones con el sistema superficial, aunque no siempre fue posible evidenciar este aspecto al trabajar con cortes axiales simples, si no nos proporcionaba esta característica el radiólogo. En los últimos casos se empleó la herramienta OsiriX y se siguieron las recomendaciones de los criterios de Navarra (152).

Estos resultados demuestran dos hechos. Por un lado, la utilidad de la aplicación OsiriX y el protocolo seguido como método de planificación preoperatoria de los colgajos DIEP. Por otro lado, los parámetros elegidos para declarar una perforante como la mejor (conexión directa con el VEIS, ramificación intracolgajo y mayor calibre) han demostrado ser adecuados en el objetivo de elegir aquella perforante que mejor perfunda el colgajo. Sin embargo, en esta elección no se ha considerado la línea de la perforante, que como hemos observado previamente, también está relacionada con la circulación del colgajo. De 
acuerdo con las observaciones de Rozen y cols. (265) estos parámetros que seleccionan a la mejor perforante son más característicos de las perforantes de la línea medial, lo que de manera indirecta también se ha tenido en cuenta este factor.

Otros autores han apoyado estos parámetros como muy importantes a la hora de elegir la perforante adecuada sobre la que basar el colgajo, considerando que la adquisición de un juicio preciso a la hora de valorar cada perforante están influidos por una curva de aprendizaje $(135,136,152,163,199,236,264,265,267,270-272)$.

\subsection{Conexión de la perforante al sistema venoso superficial}

Entre los reglas que rigen la fisiología de los colgajos existe una máxima fundamental que determina la supervivencia de cualquier transferencia tisular vascularizada y su funcionamiento hemorreológico adecuado: un colgajo necesita recibir un aporte sanguíneo suficiente a la vez que toda la sangre que entra en un colgajo debe salir. Mientras que la consecuencia de un fallo arterial es la muerte celular por isquemia del colgajo, una insuficiencia venosa se traduce en un estasis sanguíneo y un edema intersticial por extravasación que desemboca finalmente en un fallo mixto con isquemia y necrosis tisular.

Diferentes autores han estudiado la circulación de la pared abdominal infraumbilical demostrando que mientras la perfusión arterial depende principalmente del sistema epigástrico inferior profundo, el retorno venoso se produce fundamentalmente a expensas del sistema epigástrico inferior superficial $(128,129,199)$. Durante la disección de un colgajo DIEP, el retorno venoso es redireccionado desde el sistema venoso superficial (dominante) al profundo a través de una red de conexiones venosas. Si estas conexiones no existen o son de un calibre inadecuado puede instaurarse una insuficiencia con resultado de congestión venosa del colgajo (138). La gravedad de este cuadro puede ir desde leve, en el caso de que la insuficiencia venosa comprometa a una pequeña zona de tejido adiposo profundo sin apreciarse manifestaciones clínicas de congestión venosa y desembocando en la formación de una necrosis grasa, hasta severas, cuando el déficit de retorno venoso 
engloba a una porción cutáneo adiposa mayor del colgajo, lo que puede conducir a una necrosis parcial e incluso total del mismo (270).

Kroll (188) fue el primero en hacerse eco de este hecho, proponiendo que la selección de una perforante con una vena de un calibre superior a $1 \mathrm{~mm}$ era importante a la hora de reducir la aparición de complicaciones en el colgajo DIEP. Posteriormente, Blondeel y cols. (136) observaron cuadros de insuficiencia venosa difusa relacionados con el hallazgo de VEIS de un calibre superior al habitual, mientras que Tran y cols. (273) midieron este calibre de la VEIS sugiriendo que un valor superior a 1,5 $\mathrm{mm}$ se asociaba a un aumento en el riesgo de congestión venosa. Otros autores en cambio han desmentido esta relación $(270,274)$.

Rozen ha sido uno de los autores que más ha estudiado la anatomía circulatoria del colgajo DIEP. En uno de estos trabajos con apoyo de la angio TC (199), concluye que sólo en un $90 \%$ de los casos observó conexiones entre el sistema venoso superficial y profundo y que estas conexiones estaban únicamente presentes de 1 a 3 perforantes en cada paciente. Comprobó que estas conexiones venosas carecían de valvas lo que permitían el redireccionamiento del flujo venoso del sistema superficial al profundo en el caso de que el primero fuese anulado, como ocurre durante la disección de este colgajo. También demostró la existencia de shunt arteriovenosos macrovasculares de hasta $1 \mathrm{~mm}$ entre las arterias perforantes y la VEIS, abriendo el campo a futuras investigaciones y especulando sobre el beneficio que supondría el desarrollo de fármacos que permitan su regulación.

Schaverien y cols. demostraron en 2010 que una conexión inadecuada entre las venas concomitantes de la perforante elegida y el sistema venoso superficial podía explicar los cuadros de congestión venosa difusa observada en algunos colgajos DIEP. En un estudio retrospectivo sobre 54 colgajos DIEP a los que se les practicó un estudio preoperatorio abdominal con angio RNM observó que de los 8 colgajos que habían manifestado un fenómeno de congestión venosa, 7 no presentaban una conexión directa entre ambos sistemas venosos $(\mathrm{p}<0,0001)$, sin que se comprobase una relación entre la congestión venosa y el número de perforantes sobre las que se elevó el colgajo. En su trabajo también comprobó que el $68 \%$ de las 201 perforantes estudiadas tenían conexiones directas con la 
VEIS, en contraposición con el $32 \%$ que no tenían conexiones o bien se catalogaron como indirectas (de escaso calibre), mientras que en 1,5\% de los pacientes no mostraban ningún tipo de conexión. Además el grosor de las perforantes con conexiones directas era mayor $(2,6 \mathrm{~mm}$ vs $2,3 \mathrm{~mm} ; \mathrm{p}=0,02)$, su localización mas frecuente era la línea medial $(\mathrm{p}<0,01)$ y el grosor de la vena concomitante de la perforante era mayor. El autor concluye que la elección de perforantes de la línea medial con conexiones venosas directas mejora la perfusión y el drenaje venoso del colgajo y que un colgajo basado en múltiples perforantes con conexiones venosas indirectas tambien pueden proveer un adecuado drenaje venoso del colgajo (270). Esto explicaría la menor incidencia de aparición de necrosis grasa en los colgajos TRAM, ya que la inclusión de varias perforantes le permite tener múltiples puntos de drenaje venoso profundo (264).

En nuestro trabajo hemos observado una fuerte asociación entre la aparición de necrosis grasa en el colgajo y la ausencia de estas conexiones entre el sistema venoso superficial y profundo ( $\mathrm{p}$-value $=0,005$ ), lo que pone de manifiesto que la base etiopatogenia de la necrosis grasa en el colgajo DIEP es una insuficiencia venosa, más que un déficit de perfusión arterial. Al considerar los problemas circulatorios del colgajo, que incluye aquellos colgajos que han presentado manifestaciones de congestión venosa, observamos unos resultados casi idénticos a los de Schaverien y cols., siendo éste el único estudio publicado en la literatura que relacione las conexiones venosas con complicaciones circulatorias en el colgajo. En nuestra serie, el 75\% de los colgajos que presentaron esta complicación carecían de conexiones directas $(p$-value $=0.000)$, lo que confirma la importancia de que las perforantes seleccionadas incluyan estas conexiones para un adecuado funcionamiento hemorreológico del colgajo DIEP. También hemos observado que el $96,6 \%$ de las perforantes seleccionadas que presentaban ramificaciones amplias dentro del colgajo también mostraban estas conexiones directas con la VEIS, lo que muestra que la relación entre ambos parámetros.

\subsection{Realización de una anastomosis venosa superficial}

Como hemos explicado en el apartado anterior, un adecuado retorno venoso del colgajo puede prevenir la mayoría de las problemas circulatorios que acontecen con esta técnica 
reconstructivas. La congestión venosa sobreviene cuando hay un drenaje insuficiente del colgajo, poniendo en peligro su supervivencia. La incidencia de esta complicación en la literatura oscila entre el 2 y el 19\% (136,138,183,269,270,275,276). Diferentes causas se han postulado en la etiopatogenia de la congestión venosa (138): inadecuada selección de la perforante, insuficiente flujo venoso a través de una anastomosis venosa del sistema profundo competente o una red de conexiones entre los sistemas venosos superficial y profundo poco desarrollada. Clínicamente se manifiesta como un relleno capilar muy rápido acompañado de un cambio de color del colgajo a morado-violáceo por el estasis venoso y un sangrado venoso importante por los bordes del colgajo con formación de hematomas si se continúa con la inserción del colgajo en la zona receptora. Estas manifestaciones mejoran al permitir la salida de sangre a través de la VEIS. Aunque diferentes autores han defendido la conversión intraoperatoria del colgajo DIEP a TRAM libre o la inclusión de un mayor número de perforantes cuando su diámetro es inferior a 1,5 mm $(134,216)$, ha sido la realización de una segunda anastomosis venosa el método más popular para revertir esta complicación, lo que ha hecho que la VEIS se gane el apelativo de "bote salvavidas" (277). Diversos autores han propuesto una amplia variedad de modalidades con el fin de mejorar el retorno venoso del colgajo. Se ha empleando las VEIS o VEIP homolateral o contralateral anastomosada a la vena cefálica, toracodorsal, toracoacromial, torácica lateral o intercostal entre otras. Incluso esta referenciada la anastomosis de la VEIS a la VEIP cuando la causa de la congestión es una deficiente conexión de ambos sistemas venosos en el interior del colgajo (183,275,278-281).

Considerando el origen multifactorial de la congestión venosa, Ochoa y cols. (138) han propuesto un protocolo de detección y actuación ante esta complicación. De este modo, si la insuficiencia venosa del colgajo aparece al finalizar su disección y antes de su autonomización, se entiende que ha habido una mala selección de la perforante o una ausencia de conexiones con el sistema venoso superficial, por lo que se puede realizar una anastomosis entre la VEIS y una VEIP u otro vasorreceptor con el fin de suplir la ausencia de esta conexión en el interior del colgajo. En cambio, cuando la congestión venosa se manifiesta tras la anastomosis venosa se presupone que es el vasorreceptor el factor limitante, por lo que se recomienda realizar una segunda anastomosis de la VEIP a la vena mamaria interna a flujo inverso o bien a otro vasorreceptor. 
En nuestra serie se realizó una anastomosis de la VEIS a la vena cefálica en un 16,4\% de las reconstrucciones. Nuestras indicaciones para la realización de esta anastomosis fue como único drenaje en un caso por la lesión de la vena mamaria interna durante la disección, en 2 casos $(3,3 \%)$ de manera preventiva por observarse una vena mamaria interna de un calibre extremadamente fino y probablemente incompetente para evacuar todo el flujo venoso del colgajo y en los 7 casos restantes $(11,5 \%)$ por congestión venosa del colgajo. De estos 7 últimos casos, el 71,4\% no tenían conexiones venosas directas entre los sistemas venosos superficial y profundo, lo que vuelve a poner de manifiesto la importancia de estas uniones en la adecuada perfusión del colgajo.

Estas indicaciones son compartidas por otros autores y en la actualidad esta aceptado que un segundo drenaje venoso puede solucionar de manera efectiva los problemas de congestión venosa. Además se trata de una medida coste efectiva, con baja morbilidad y que no aumenta el tiempo operatorio de una manera significativa cuando se realiza mediante dispositivos automáticos $(183,186,197,199)$.

Sólo una paciente de entre las que se extrajo la vena cefálica para mejorar el retorno venoso desarrollo un linfedema de carácter leve $(10 \%)$. Hay que decir que esta paciente había sido sometida radioterapia y linfadenectomía axilar como parte de su tratamiento oncológico, y que durante la intervención también se reclutó la vena toracodorsal como vasorreceptor de la vena circunfleja ilíaca superficial debido a un problema de insuficiencia venosa severa como consecuencia de un mal planteamiento en las anastomosis venosas realizadas. En este colgajo se anastomosaron una VEIP a la mamaria interna (con importante daño por la RT) y la otra VEIP a la vena cefálica. Todas las anastomosis se realizaron en el mismo tiempo quirúrgico y la evolución fue favorable y sin complicaciones, lo que pone otra vez de manifiesto el papel crucial de un adecuado drenaje venoso para prevenir complicaciones como la necrosis grasa y/o parcial del colgajo.

En un metaanálisis realizado por Lee y Mun (186) sobre 1376 colgajos DIEP de los cuales en 842 se les practicó un segundo drenaje venoso con la VEIS, no pudieron demostrar que esta práctica se tradujese en un efecto protector en la aparición de complicaciones relacionadas con la perfusión del colgajo. Mientras que el porcentaje de 
necrosis total se mantuvo invariable, si se observó una tendencia a la reducción del riesgo de necrosis parcial del colgajo $(\operatorname{RR} 0,59 ; \mathrm{p}$-value $=0,39)$ y necrosis grasa $(\operatorname{RR~} 0,87 ; \mathrm{p}$ value $=0,49)$ sin que las diferencias alcanzasen la significación. En cambio, hubo una reducción significativa de los índices de congestión venosa con resultados de supervivencia del colgajo similares a los del grupo control. Los autores explican estos resultados con la hipótesis de que la elevada incidencia de congestión venosa con resultados similares de supervivencia en el grupo en el que se practicó la segunda anastomosis venosa podría haber dejado como secuela de esta complicación una necrosis parcial o grasa, enmascarando el efecto beneficioso que implica la realización de un drenaje venoso adicional en estas situaciones. Los autores concluyen que a pesar del elevado número de casos analizados su muestra es insuficiente desde el punto estadístico, siendo preciso estudiar aproximadamente cerca de 2.600 colgajos en cada grupo para obtener conclusiones sólidas.

En nuestra serie, de manera similar al trabajo de estos autores, hemos observado un porcentaje de aparición de necrosis grasa del 19,5\% en aquellos colgajos en los que no se realizó una anastomosis de la VEIS frente al 14,2\% en aquellos en los que sí se realizó, con una reducción del 5,2\% sin que ésta alcanzase la significación. Sin embargo, nuestro trabajo tiene una muestra muy escasa para evaluar adecuadamente este parámetro.

A pesar de estos resultados, estudios experimentales en animales han demostrado un aumento en los porcentajes de supervivencia del colgajo así como del área viable cuando se ha aumentado el retorno venoso con ayuda de la VEIS. De estos hallazgos se desprende que esta técnica es efectiva en la reducción de los porcentajes de necrosis parcial y total de los colgajos así como permite ampliar el territorio vascular seguro que se puede transferir con el colgajo DIEP $(282,283)$.

La falta de significación que se observa en los trabajos publicados hasta la fecha puede deberse a la multitud de factores implicados en la congestión venosa, a la falta de homogeneidad de los estudios y a que todos los publicados hasta la fecha sean retrospectivos. Considerando los trabajos que se describen a continuación, es comprensible que no exista una evidencia sólida a día de hoy. 
Rothenberger y cols. (198) demostraron la importancia de la lateralidad de la VEIS utilizada, siendo mejor el drenaje cuando se empleaba la VEIS del lado contralateral a la perforante seleccionada.

Otro factor importante es la variabilidad anatómica de la VEIS, que puede estar formada por un único tronco $(82 \%)$ o bien encontrase bifurcada $(17 \%)$ o trifurcada $(1 \%)$. Además, en el $86 \%$ se encuentra un rama medial por debajo del ombligo que conecta el sistema venoso superficial de ambos lados (199). La ausencia de esta conexión puede influir en la efectividad de aumentar el retorno venoso empleando la VEIS.

Por último, otro factor a tener en cuenta es el momento en el que se aumenta el drenaje venoso. Reconocer de forma precoz un cuadro de congestión venosa es fundamental para minimizar los daños sobre el colgajo. Mientras que la realización de esta anastomosis en el mismo tiempo operatorio no aumenta la morbilidad del colgajo, Ali y cols. (276) informaron de un riesgo hasta 4 veces mayor en la aparición de necrosis grasa cuando el rescate utilizando una VEIS se difiere al momento postoperatorio, además de los inconvenientes resultantes de tener que volver a llevar a la paciente a quirófano.

Cabe decir que en nuestra serie todas las anastomosis de la VEIS se realizaron durante el tiempo operatorio de la reconstrucción mamaria, salvo en un caso en el que la congestión venosa se realizó a las 7 horas de haber finalizado la intervención. Este fue el único caso de nuestra serie a las que se le realizó una anastomosis del sistema venoso superficial que desarrollo una necrosis grasa en el postoperatorio, siendo nuestros resultados consistentes con los descritos por Ali y cols.

En definitiva, el aumento del drenaje venoso de los colgajos empleando el sistema venoso superficial es capaz de resolver los cuadros de congestión venosa, y aunque falta evidencia científica, parece reducir también la incidencia de complicaciones circulatorias de los colgajos. La baja morbilidad asociada y el poco tiempo requerido en su realización hacen que la realización de este procedimiento sea altamente recomendable ante el más mínimo signo de insuficiencia venosa del colgajo. 


\section{SIMETRIZACIÓN}

En nuestro trabajo, al 65,6\% de las pacientes se le indicó algún procedimiento sobre la mama contralateral con el fin de obtener un buen resultado estético. Diferentes autores han resaltado entre las ventajas del colgajo DIEP, la posibilidad que tiene éste para adaptarse a la mama contralateral en el momento de su modelado(2,122,167,284). Desde este punto de vista, podría parecer que el número de pacientes que han recibido actuaciones sobre la mama contralateral ha sido excesivo.

Nuestros resultados se pueden explicar porque en nuestra serie la edad media de las pacientes fue de 47 años. A esta edad es habitual que exista cierto grado de laxitud cutánea que se manifiesta significativamente a nivel de la mama, donde se puede encontrar un polo superior vacío con una disposición de la areola por debajo del surco submamario. A su vez, el tejido mamario ha comenzado a sustituirse por tejido adiposo acompañándose de un aumento de volumen con respecto a etapas anteriores de la vida. Nuestra indicación no ha sido tanto por la incapacidad de moldear el colgajo DIEP para que presentase una adecuada simetría con la mama sana contralateral, sino dotar a ésta de un aspecto rejuvenecido y lograr un resultado no sólo simétrico, sino acorde a las proporciones corporales de la paciente y a los cánones estéticos actuales.

El $77,1 \%$ de las pacientes de nuestra serie recibieron algún procedimiento complementario sobre la mama reconstruida. El motivo de estas intervenciones fue en muchos casos la realización de correcciones de volumen y forma para lograr un resultado de la reconstrucción lo más refinado posible.

Hay que tener en cuenta que el comportamiento de los tejidos que conforman la mama reconstruida puede ser muy variable en los meses posteriores a la intervención, siendo muy difícil afinar en un sólo tiempo quirúrgico el resultado que la mama adquirirá finalmente, sobretodo si hay que tener en cuenta que debe ser lo más simétrico posible a una mama contralateral que también puede haber sido modificada. 
De estas pacientes intervenidas, al $85,1 \%$ se les practicó una reconstrucción de CAP en nuestro centro, aprovechando el mismo acto para realizar las correcciones que se estimaron oportunas, por lo que estos procedimientos no alargaron de forma importante la necesidad de tiempos quirúrgicos para completar la reconstrucción. Acorde con esta explicación, las pacientes de nuestro estudio recibieron 1,25 intervenciones (rango 1-2 cirugías), muy acorde a la presentada por otros autores $(1,7 \pm 1,0)$ y significativamente menor frente al resto de técnicas reconstructivas, siendo las técnica con expansor y prótesis la que habitualmente necesita mayor numero de revisiones tardías $(2,5 \pm 0,9)(173)$. 


\section{LIMITACIONES DE ESTE ESTUDIO}

En este trabajo hemos revisado las complicaciones asociadas a la reconstrucción mamaria con el colgajo DIEP y su relación con diferentes factores poniendo especial interés en los problemas de perfusión del colgajo. A pesar del esfuerzo dedicado creemos que este estudio presenta una serie de limitaciones que paso a describir.

La tamaño de la muestra es relativamente pequeño. Aunque en la bibliografía revisada hemos encontrado autores con grandes series publicadas, es difícil lograr alcanzar estos números en nuestro medio ya que los Servicios de Cirugía Plástica y Reparadora de nuestro Sistema Nacional de Salud no son monográficos, siendo la reconstrucción mamaria una parte dentro de la patología que debemos atender en nuestra labor asistencial diaria. A esto se le une la elevada complejidad de la técnica unida a su duración, no siendo adecuado estandarizar su indicación a toda la población que desea someterse a una reconstrucción mamaria. A pesar de haber demostrado ser un procedimiento coste-eficiente, seguimos sintiendo las reticencias iniciales de algunas direcciones hospitalarias a potenciar una técnica que inicialmente precisa de más medios y es más costoso.

El que estemos ante un estudio retrospectivo ha impedido disponer de una serie de datos que no fueron recogidos y que hubiera sido interesante estudiar:

- No hemos tenido acceso el volumen de cada colgajo transferido. Aunque algunos han descrito que no esta relacionado con la aparición de problemas de perfusión en el colgajo (191), hubiera sido interesante corroborar este hecho en nuestro trabajo.

- No se reflejaron en el protocolo quirúrgico las zonas de perfusión del colgajo empleadas en cada caso. Aunque el remodelado del colgajo fue muy homogéneo en cada caso, hubiera sido interesante conocer este dato debido a la influencia que hemos observado que tienen las diferentes líneas de perforantes en la perfusión del colgajo. 
- No se detallaron los tiempos de isquemia. Aunque estos nunca sobrepasaron los 100 min, hubiera sido interesante relacionar este dato con la aparición de necrosis grasa.

- Tampoco conocemos la lateralidad de la VEIS cuando se usó para aumentar el retorno venoso, hecho que puede tener relevancia según la bibliografía revisada (198).

- Debido al bajo tamaño de la muestra no hemos considerado los casos de congestión venosa por separado. A pesar de esto, creemos un acierto el agrupar todas las complicaciones relacionadas con la perfusión del colgajo, ya que existe un estrecha relación entre todos estos factores que en nuestra opinión no se puede desligar sin incurrir en conclusiones erróneas.

- También habría resultado interesante realizar una medida intraoperatoria del calibre de cada perforante y relacionar este valor con otras variables circulatorias y las complicaciones revisadas. Aunque no se estudió este parámetro en términos absolutos, siempre se consideró el grosor de la perforante seleccionada de forma relativa con respecto a otras perforantes.

- Sería interesante realizar un estudio más pormenorizado de la anatomía circulatoria del sistema venoso superficial, la relación de las conexiones entre ambos sistemas venoso y la línea de la perforante y otros factores de interés. Creemos sin embargo, que todo ello sobrepasa con creces la dimensiones de este estudio y puede ser por si mismo trabajo como para desarrollar futuras líneas de investigación que ayuden a dotar de una mayor seguridad nuestras intervenciones. 


\section{CONCLUSIONES}



- La reconstrucción mamaria con el colgajo DIEP es una técnica altamente compleja que hace recomendable que el cirujano plástico participe activamente en su planificación preoperatoria.

- El software OsiriX es una aplicación sencilla al alcance de cualquier cirujano plástico que permite hacer una adecuada planificación del colgajo DIEP.

- El tabaquismo activo se asocia con un aumento de las complicaciones circulatorias en el colgajo DIEP.

- El antecedente de cirugía abdominal no se relaciona en nuestro trabajo con la aparición de problemas circulatorios en el colgajo o complicaciones en la zona donante.

- La radioterapia no se asoció a la aparición de complicaciones circulatorias en el colgajo DIEP en nuestro estudio. Sin embargo sería recomendable llevar a cabo futuros estudios que analizasen de manera individualizada el efecto de la radioterapia sobre los vasorreceptores.

- La realización de una segunda vena de drenaje mediante técnica de microsutura clásica supone un incremento significativo en la duración de la intervención.

- La aparición de necrosis grasa esta asociada a la selección de perforantes con un origen en la línea lateral o que no presentan conexiones con el sistema venoso superficial. También se observa una tendencia a la aparición de esta complicación en aquellas perforantes que no presentan ramificaciones en el interior del colgajo, siendo recomendable estudiar estos parámetros en futuros estudios con una muestra mayor.

- La aparición de problemas circulatorios en el colgajo esta asociada a la selección de perforantes sin conexión con el sistema venoso superficial o que no presentan ramificaciones en el interior del colgajo. 
- A medida que aumenta la lateralidad de entrada de la perforante en el colgajo, aumenta el riesgo de aparición de problemas circulatorios en el colgajo. En cambio, no hay una relación entre la entrada de la perforante en el eje vertical y la aparición de esta complicación.

- La elección de la mejor perforante del colgajo en términos de calibre, conexión al sistema venoso superficial y ramificación se asocia a una menor aparición de necrosis grasa y complicaciones circulatorias en general.

- En nuestro estudio no se comprobó un efecto protector de la realización de un segundo drenaje venoso con respecto a la formación de necrosis grasa en el colgajo. Sin embargo, en base a nuestras observaciones y a la bibliografía publicada, es necesario realizar futuros estudios adecuadamente conducidos para obtener conclusiones sólidas. 
ANEXO 



\section{PROTOCOLO DE ACTUACIÓN PARA LAS PACIENTES INTERVENIDAS DE RECONSTRUCCIÓN MAMARIA CON COLGAJO DIEP}

\section{CONSULTAS EXTERNAS:}

Informar a la paciente de la necesidad de acudir en el momento del ingreso con la faja y el sujetador necesarios durante el postoperatorio inmediato.

\section{INGRESO EN PLANTA:}

\section{Día del ingreso}

1. Confirmar la presencia en la historia de los consentimientos informados y el preoperatorio en regla.

2. Comprobar que la paciente acude con la faja y el sujetador requeridos.

\section{Día de la intervención quirúrgica}

1. Preparación quirúrgica según el protocolo hospitalario.

2. Rasurado de pubis y axilas.

3. Aseptizar la zona quirúrgica con povidona yodada y cubrir con paño estéril.

4. Instauración de las medias elásticas.

- Quirófano:

1. Colocación de manta de aire caliente para evitar la vasoconstricción periférica.

2. Protocolo quirúrgico de enfermería de anestesia.

3. Canalización de vías venosas.

4. Administración de la profilaxis $\mathrm{AB}$ (Cefazolina $2 \mathrm{~g}$ endovenoso. En alérgicos a $\beta$-Lactámicos emplear Vancomicina 1g endovenoso).

5. Sondaje vesical.

6. Inicio de la profilaxis antitrombótica con la administración de la $1^{\mathrm{a}}$ dosis de HBPM durante la anastomosis vascular.

7. Testado del colgajo en el área de despertar. 


\section{POSTOPERATORIO EN LA PLANTA:}

\section{Día de la intervención quirúrgica}

1. Recepción del paciente (constatar medicación administrada,...).

2. Testado del colgajo (caliente, relleno lento, normocoloración).

3. Comprobar estado de los redones (presencia de vacío y volúmenes recogidos).

4. Dieta absoluta.

5. Reposo absoluto.

\section{$1^{\circ}$ día postoperatorio}

1. Inicio de la tolerancia oral tras la visita siguiendo ordenes médicas.

2. Analgesia y profilaxis $\mathrm{AB}$ endovenoso según ordenes médicas.

3. Higiene de paciente en cama.

4. Cura de las heridas quirúrgicas.

5. Se mantienen las medias elásticas.

6. Retirada de sonda vesical.

7. Reposo absoluto.

8. Profilaxis antitrombótica con HBPM a las $18 \mathrm{~h}$.

\section{$\underline{2^{\circ} \text { día postoperatorio }}$}

1. Analgesia y profilaxis $\mathrm{AB}$ vía oral si correcta tolerancia el día anterior.

2. Higiene de paciente en cama.

3. Inicio de la sedestación.

4. Colocación de faja y sujetador (mantener las $24 \mathrm{~h}$ del día).

5. Cura de las heridas quirúrgicas y recambio de los apósitos y esparadrapo.

6. Mantener medias elásticas.

7. Profilaxis antitrombótica con HBPM a las $18 \mathrm{~h}$. 


\section{$\underline{3^{0}}$ día postoperatorio}

1. Mantener faja y sujetador (mantener las $24 \mathrm{~h}$ del día)

2. Inicio de la deambulación.

3. Higiene diaria habitual incluyendo lavado de heridas.

4. Cura de las heridas quirúrgicas y recambio de los apósitos y esparadrapo.

5. Mantener medias elásticas.

6. Profilaxis antitrombótica con HBPM a las $18 \mathrm{~h}$.

\section{$\underline{4^{0} \text { día postoperatorio }}$}

1. Mantener faja y sujetador las 24 h del día

2. Deambulación.

3. Higiene diaria habitual incluyendo lavado de heridas.

4. Cura de las heridas quirúrgicas y recambio de los apósitos y esparadrapo.

5. Mantener medias elásticas.

6. Profilaxis antitrombótica con HBPM a las $18 \mathrm{~h}$.

\section{$\underline{5^{0}}$ día postoperatorio}

1. Mantener faja y sujetador.

2. Deambulación.

3. Higiene diaria habitual incluyendo lavado de heridas.

4. Cura de las heridas quirúrgicas y recambio de los apósitos y esparadrapo.

5. Retirada de medias elásticas.

6. Suspensión de la profilaxis con HBPM.

7. Alta hospitalaria

8. Cita en consultas externas 



\section{PROTOCOLO DE ANESTESIA PARA LAS PACIENTES INTERVENIDAS DE RECONSTRUCCIÓN MAMARIA CON COLGAJO DIEP}

\section{RECEPCIÓN DE LA PACIENTE EN QUIRÓFANO:}

1. Marcaje y fotografiado de la paciente en bipedestación.

2. Colocación de la paciente en la mesa operatoria en posición de decúbito supino con los brazos a lo largo del cuerpo. El campo quirúrgico comprende el tronco y el abdomen desde la región clavicular hasta el pubis y raíz de muslos. Los electrodos se colocan en la espalda y la placa del bisturí en el muslo.

3. Calentar a la paciente con la manta térmica (la vasoconstricción periférica ocasionada por el frío dificulta la detección de los vasos perforantes con el doppler).

\section{INDUCCIÓN ANESTÉSICA:}

1. Protocolo básico de anestesia (canalización de vía venosa, relajación e intubación, canalizaciones de vía central y arterial, sondaje del paciente,....).

2. Exploración con el Doppler bidireccional del colgajo durante la canalización de la vía central.

\section{Factores anestésicos involucrados en la cirugía de los colgajos libres:}

1. Hipotensiones mantenidas con tensión sistólica $<90 \mathrm{~mm} \mathrm{Hg}$ son desaconsejadas por riesgo de comprometer la perfusión del colgajo. 
2. El empleo de drogas vasoactivas (efedrina p.e.) deberá ser ponderado con sus potenciales efectos adversos: fracaso de la reconstrucción y pérdida del colgajo por vasoespasmo del vaso perforante o de la microanastomosis

\section{REANIMACIÓN:}

Es aconsejable una estancia de $12 \mathrm{~h}$ en el área de reanimación postquirúrgica donde se atenderán las siguientes recomendaciones:

1. Dieta absoluta.

2. Colocación de la paciente en decúbito supino con las rodillas semiflexionadas.

3. Control de la TA, evitando hipotensiones mantenidas.

4. Control del vacío y los volúmenes de los drenajes aspirativos.

5. Testado del colgajo cada $2 \mathrm{~h}$, observando que se encuentre caliente, normocoloreado y con relleno lento.

6. Evitar cualquier maniobra que pueda comprimir el colgajo (vendajes o apósitos,..). 


\section{RECONSTRUCCIÓN MAMARIA POSTMASTECTOMÍA MEDIANTE COLGAJO DIEP}

Nombre:

\section{№ Historia Clínica:}

\section{¿QUE ES Y EN QUE CONSISTE LA INTERVENCIÓN?}

La reconstrucción de la mama tras su extirpación por un tumor es un procedimiento quirúrgico incluido en el tratamiento del cáncer de mama, que ayuda a la recuperación de la enfermedad y a una mayor reinserción laboral y familiar de las mujeres. Para la mayoría de las pacientes mastectomizadas (extirpación quirúrgica de la mama), la reconstrucción supone una mejoría de su imagen absoluta, proporcionando además un equilibrio psicológico que en muchas ocasiones se había perdido, volviendo a verse un cuerpo completo. El objetivo de la reconstrucción postmastectomía es recrear una mama de aspecto natural, incluyendo, si así lo desea la paciente, la areola y el pezón. Eliminar la necesidad de llevar prótesis de relleno, posibilitando llevar prendas de vestir que no serían posibles sin reconstrucción (bañadores, escotes, etc.), rellenar el hueco y la deformidad que queda en el tórax, restaurar la imagen corporal, mejorar la calidad de vida y proporcionar satisfacción a la paciente.

Existen diversos tipos de operación para reconstruir la mama. En su caso, el equipo médico que la atiende considera la Reconstrucción mediante colgajo DIEP como la más adecuada. Las técnicas que emplean tejidos propios para crear una mama natural, consisten en la movilización o el trasplante de tejidos de otras zonas del cuerpo como el abdomen (técnicas denominadas autólogas o colgajos). En su caso se utilizará la piel y la grasa del abdomen, que se trasplantan al tórax para formar una nueva mama. Mediante técnicas de microcirugía los vasos sanguíneos del trasplante se unen a los vasos sanguíneos del tórax. Esta técnica es más compleja y necesita mayor tiempo de quirófano (alrededor de 6-7 horas) que las que emplean expansión cutánea. Además, deja más cicatriz y el periodo de recuperación es mayor que para los implantes. Sin embargo, sólo suele precisarse una intervención y no existen los problemas relacionados con el uso de implantes (formación de cápsula, infección del implante,...). Cuando se moviliza tejido del abdomen, existe el beneficio añadido de la mejoría del contorno abdominal. Esta técnica se realiza bajo anestesia general, con una estancia hospitalaria entre 3 y 7 días.

¿CUALES SON LOS RIESGOS?

Prácticamente toda mujer que ha sido mastectomizada puede someterse a una reconstrucción mamaria. No obstante pueden existir ciertos riesgos que deben ser conocidos antes de someterse a esta intervención. Estos riesgos serían los propios de cualquier cirugía, como hematomas, cicatrices patológicas, seromas, infección de la herida quirúrgica, necrosis parcial o total del colgajo, que puede obligar a una nueva intervención quirúrgica. En la reconstrucción con colgajo DIEP se evitan las hernias o debilidad de la pared anterior del abdomen, asociadas al TRAM. Así mismo, las mujeres fumadoras deben saber, que el tabaco puede ocasionar problemas de cicatrización y tener un periodo de recuperación más prolongado.

El Servicio de Anestesia le informará de la técnica empleada en su caso y de las complicaciones asociadas.

Debe quedar claro que la reconstrucción no tiene efecto en la recurrencia de la enfermedad de la mama, ni interfiere con el tratamiento de quimioterapia o radioterapia, aunque la enfermedad recidive. Tampoco interfiere con los estudios posteriores que puedan ser necesarios en las revisiones.

En algunos casos la mama reconstruida puede tener un aspecto más firme y parecer más redonda que la otra mama. Puede que 


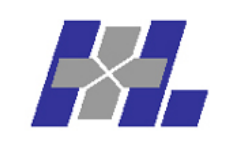

Complejo Asistencial de León

Altos de Nava s/n. 24071 LEÓN. Tel. 987237400 Fax. 987233322

zel art. 10 de la Ley 41/2002 Básica Reguladora de la Autonomía del Paciente y de los derechos y obligaciones en materia de información y documentación clínica. 
el contorno no sea exactamente igual que antes de la mastectomía, y pueden existir algunas diferencias de simetría con la mama no intervenida

Algunos de estos riesgos son más frecuentes en determinadas condiciones del paciente, por lo que usted debe exponer todos los datos de su historial médico y antecedentes clínico-quirúrgicos, especialmente los referidos a alergias y enfermedades o riesgos personales (ser fumador....).

En el curso de la operación pueden surgir condiciones no previstas, que hagan necesario un cambio en lo planeado, siendo necesarios otros tratamientos o la realización de procedimientos como biopsias, radiografías, transfusiones de sangre, etc. Para su realización puede ser necesaria la ayuda de otros especialistas.

El cirujano le dará las instrucciones que debe seguir antes, durante y después de la operación; así mismo, si su cirujano lo cree preciso, la intervención puede retrasarse o suspenderse.

Además de los riesgos anteriormente citados por la/s enfermedad/es que padece puede presentar otras complicaciones

Por este documento solicitamos su autorización para realizarle la intervención, y usar imágenes e información de su Historia Clínica con fines docentes o científicos debiendo saber a este respecto, que ello no supondrá un riesgo adicional para la salud4.

He comprendido las explicaciones que se me han facilitado y el facultativo que me ha atendido me ha contestado las dudas que he planteado.

También comprendo que en cualquier momento y sin necesidad de dar ninguna explicación, puedo revocar el consentimiento que ahora prestos.

Y en tales condiciones CONSIENTO que se me realice la reconstrucción postmastectomía mediante colgajo DIEP.

León, a............de.........................de 20.....

Fdo.: Paciente o representante legal

Fdo.: Médico

\section{REVOCACIÓN}

\section{Nombre:}

REVOCO el consentimiento prestado en fecha....................... no deseo proseguir el tratamiento propuesto. Habiendo sido informado y comprendiendo los riesgos y consecuencias de esta decisión, doy con esta fecha por finalizado el mismo. 



\section{ABREVIATURAS}

$\mathbf{A}$

$\mathrm{AB}$

Antibiótico

ACIS

Arteria circunfleja ilíaca superficial

AEIP

Arteria epigástrica inferior profunda

AEIS

Arteria epigástrica inferior superficial

AESP

Arteria epigástrica superior profunda

AESS

Arteria epigástrica superior superficial

AMI

Arteria mamaria interna

B

BRCA

Breasts cancer susceptibility protein

BSGC

Biopsia selectiva de ganglio centinela

C

CAP

Complejo areola-pezón

CDI

Carcinoma ductal infiltrante

CDIS

Carcinoma ductal in situ

CLI

Carcinoma lobulillar infiltrante

CLIS

Carcinoma lobulillar in situ

CLUT

Tabla de colores (Color look up table)

COLS.

Colaboradores

D

DIEP

Colgajo de perforante de arteria epigástrica inferior profunda

F

FDA

Food an Drug Administration

FIG.

Figura

G

GAP

Gluteal artery perforator

H

HBPM

Heparina de bajo peso molecular

HTA

Hipertensión arterial

HU

Unidades Hounsfield (Hounsfield units)

I

IC

Intervalo de confianza 
IGAP

IHQ

IMC

L

LD

M

MIP

MPR

MRM

MS

O

OSNA

$\mathbf{P}$

PAP

Q

QT

$\mathbf{R}$

$\mathrm{RH}$

$\mathrm{RM}$

RMD

RMI

RNM

RR

RT

$\mathbf{S}$

SIEA

SGAP

$\mathbf{T}$

TC

TCMD

TMG

TRAM

V

VEGF

VEIP

VEIS

VMI
Inferior gluteal artery perforator

Inmunohistoquímica

Índice de masa corporal

Latissimus dorsi (dorsal ancho)

Proyección de máxima intensidad

Reconstrucción multiplanar (multiplanar reformation)

Mastectomía radical modificada

Ahorrador de músculo (Muscle sparing)

One step nucleic acid amplification

Colgajo perforante de arteria femoral profunda

Quimioterapia

Receptores hormonales

Reconstrucción mamaria

Reconstrucción mamaria diferida

Reconstrucción mamaria inmediata

Resonancia nuclear magnética

Riesgo relativo

Radioterapia

Colgajo de perforante de arteria epigástrica inferior superficial Superior Gluteal artery perforator

Tomografía computerizada

Tomografía computerizada por multidetectores

Colgajo transverso miocutáneo de gracillis

Colgajo musculocutáneo transverso de recto abdominal

Vascular endotelial growth factor

Vena epigástrica inferior profunda

Vena epigástrica inferior superficial

Vena mamaria interna 
VR

VRAM

W

WL

WW
Renderizado volumétrico (volumen rendering)

Colgajo musculocutáneo vertical de recto abdominal

Nivel de ventana (Windows level)

Amplitud de ventana (Windows width) 

BIBLIOGRAFÍA 

1. Bostwick III J. Tratado de mamaplastia. Caracas, Venezuela: Amolca; 2002.

2. Pedreño Guerao F. Tram versus Diep e implicación de los vasos receptores en la viabilidad del colgajo [Tesis doctoral]. [Córdoba]: Universidad de Córdoba; 2006.

3. Cancer de mama: prevencion y control [Internet]. Recuperado a partir de: http://www.who.int/cancer/detection/breastcancer/es/

4. DeSantis C, Siegel R, Bandi P, Jemal A. Breast cancer statistics, 2011. CA Cancer J Clin. 2011;61(6):409-18.

5. Cabanes Domenech A, Pérez-Gómez B, Aragonés N, Pollán M, López-Abente G. La situación del cáncer en España, 1975-2006. Madrid: Centro Nacional de Epidemiología. Instituto de Salud Carlos III. Ministerio de Ciencia e Innovación; 2009.

6. Lopez-Abente O, Pollán Santamaria M, Aragonés N, Pérez-Gómez B, Hernández Barrera V, Lope Carvajal V. La situación del cáncer en España. Madrid: Centro Nacional de Epidemiología. Ministerio de Sanidad y Consumo, Centro de Publicaciones; 2005. 191 p.

7. Martín M, Llombart-Cussac A, Lluch A, Alba E, Munárriz B, Tusquets I, et al. Estudio epidemiológico del grupo GEICAM sobre el cáncer de mama en España (1990-1993): proyecto «El Álamo». Med Clin Barc. 2004;122(1):12-7.

8. Casanova Gomez F, Diez Andres A, González González MS. Programa de Detección Precoz de Cáncer de Mama en Castilla y León. Dirección General de Salud Pública y Consumo de Castillay León. Servicio de promoción de la salud y programas preventivos; 2005.

9. Apesteguía Ciriza L, Pina LJ. Manual de Práctica Clínica en Senología 2012. 2a ed. Fundación Sociedad de Senología y Patología mamaria; 2013.

10. Petracci E, Decarli A, Schairer C, Pfeiffer RM, Pee D, Masala G, et al. Risk factor modification and projections of absolute breast cancer risk. J Natl Cancer Inst. 2011;103(13):1037-48.

11. Hamajima N, Hirose K, Tajima K, Rohan T, Calle EE, Heath CW, et al. Alcohol, tobacco and breast cancer--collaborative reanalysis of individual data from 53 epidemiological studies, including 58,515 women with breast cancer and 95,067 women without the disease. Br J Cancer. 2002;87(11):1234-45. 
12. Bhatti P, Struewing JP, Alexander BH, Hauptmann M, Bowen L, Mateus-Pereira $\mathrm{LH}$, et al. Polymorphisms in DNA repair genes, ionizing radiation exposure and risk of breast cancer in U.S. Radiologic technologists. Int $\mathbf{J}$ Cancer $\mathbf{J}$ Int Cancer. 2008;122(1):177-82.

13. Pollán M, Pastor-Barriuso R, Ardanaz E, Argüelles M, Martos C, Galcerán J, et al. Recent changes in breast cancer incidence in Spain, 1980-2004. J Natl Cancer Inst. 2009;101(22):1584-91.

14. Brown WJ, Burton NW, Rowan PJ. Updating the evidence on physical activity and health in women. Am J Prev Med. 2007;33(5):404-11.

15. Schmidt ME, Chang-Claude J, Slanger T, Obi N, Flesch-Janys D, Steindorf K. Physical activity and postmenopausal breast cancer: effect modification by other breast cancer risk factors. Methods Inf Med. 2009;48(5):444-50.

16. Schmidt ME, Steindorf K, Mutschelknauss E, Slanger T, Kropp S, Obi N, et al. Physical activity and postmenopausal breast cancer: effect modification by breast cancer subtypes and effective periods in life. Cancer Epidemiol Biomark Prev Publ Am Assoc Cancer Res Cosponsored Am Soc Prev Oncol. 2008;17(12):3402-10.

17. Masala G, Assedi M, Bendinelli B, Ermini I, Sieri S, Grioni S, et al. Fruit and vegetables consumption and breast cancer risk: the EPIC Italy study. Breast Cancer Res Treat. 2012;132(3):1127-36.

18. La Vecchia C, Negri E, Franceschi S, Decarli A, Giacosa A, Lipworth L. Olive oil, other dietary fats, and the risk of breast cancer (Italy). Cancer Causes Control CCC. 1995;6(6):545-50.

19. Wang Z, Butt K, Wang L, Liu H. The effect of seal oil on paclitaxel induced cytotoxicity and apoptosis in breast carcinoma MCF-7 and MDA-MB-231 cell lines. Nutr Cancer. 2007;58(2):230-8.

20. Dos Santos Silva I, Mangtani P, McCormack V, Bhakta D, McMichael AJ, Sevak L. Phyto-oestrogen intake and breast cancer risk in South Asian women in England: findings from a population-based case-control study. Cancer Causes Control CCC. 2004;15(8):805-18.

21. Rosenberg L, Zhang Y, Coogan PF, Strom BL, Palmer JR. A case-control study of oral contraceptive use and incident breast cancer. Am J Epidemiol. 2009;169(4):4739. 
22. Burkman R, Schlesselman JJ, Zieman M. Safety concerns and health benefits associated with oral contraception. Am J Obstet Gynecol. 2004;190(4 Suppl):S5-22.

23. Reeves GK, Pirie K, Green J, Bull D, Beral V, Million Women Study Collaborators. Reproductive factors and specific histological types of breast cancer: prospective study and meta-analysis. Br J Cancer. 2009;100(3):538-44.

24. Collaborative Group on Hormonal Factors in Breast Cancer. Breast cancer and breastfeeding: collaborative reanalysis of individual data from 47 epidemiological studies in 30 countries, including 50302 women with breast cancer and 96973 women without the disease. Lancet. 2002;360(9328):187-95.

25. Andrieu N, Goldgar DE, Easton DF, Rookus M, Brohet R, Antoniou AC, et al. Pregnancies, breast-feeding, and breast cancer risk in the International BRCA1/2 Carrier Cohort Study (IBCCS). J Natl Cancer Inst. 2006;98(8):535-44.

26. Cullinane CA, Lubinski J, Neuhausen SL, Ghadirian P, Lynch HT, Isaacs C, et al. Effect of pregnancy as a risk factor for breast cancer in BRCA1/BRCA2 mutation carriers. Int J Cancer J Int Cancer. 2005;117(6):988-91.

27. Michels KB, Xue F, Colditz GA, Willett WC. Induced and spontaneous abortion and incidence of breast cancer among young women: a prospective cohort study. Arch Intern Med. 2007;167(8):814-20.

28. Clark GM. Prognostic and predictive factors. En: Diseases of the breast. Segunda edicion. Philadelpia: Lippincott Williams \& Wilkins; 2000. p. 489-514.

29. Francisco M, Francisco T, Antonio S. Protocolo unificado en el Cáncer de mama. Sección de Patología Mamaria. España. Asociación Española de Cirujanos; 2009.

30. Wooster R, Neuhausen SL, Mangion J, Quirk Y, Ford D, Collins N, et al. Localization of a breast cancer susceptibility gene, BRCA2, to chromosome 13q1213. Science. 1994;265(5181):2088-90.

31. Metcalfe KA, Semple JL, Narod SA. Time to reconsider subcutaneous mastectomy for breast-cancer prevention? Lancet Oncol. 2005;6(6):431-4.

32. Spear SL, Carter ME, Schwarz K. Prophylactic mastectomy: indications, options, and reconstructive alternatives. Plast Reconstr Surg. 2005;115(3):891-909.

33. Kurman RJ, International Agency for Research on Cancer, World Health Organization, editores. WHO classification of tumours of female reproductive 
organs. 4th ed. Lyon: International Agency for Research on Cancer; 2014. 307 p.

34. Lum YW, Jacobs L. Primary breast sarcoma. Surg Clin North Am. 2008;88(3):55970.

35. Carter M, Purpura J. Anaplastic Large Cell Lymphoma Occurring in Women with Breast Implants: Analysis of 173 Cases, and Breast Implant-Associated Anaplastic Large Cell Lymphoma: A Systematic Review. Plast Reconstr Surg. 2015;136(1):106e.

36. Edge SB, American Joint Committee on Cancer, editores. AJCC cancer staging manual. 7th ed. New York: Springer; 2010.648 p.

37. Veronesi U, Saccozzi R, Del Vecchio M, Banfi A, Clemente C, De Lena M, et al. Comparing radical mastectomy with quadrantectomy, axillary dissection, and radiotherapy in patients with small cancers of the breast. $\mathrm{N}$ Engl $\mathrm{J}$ Med. 1981;305(1):6-11.

38. Veronesi U, Salvadori B, Luini A, Greco M, Saccozzi R, del Vecchio M, et al. Breast conservation is a safe method in patients with small cancer of the breast. Long-term results of three randomised trials on 1,973 patients. Eur J Cancer Oxf Engl 1990. 1995;31A(10):1574-9.

39. La calidad del tratamiento integral a las mujeres afectadas por cáncer de mama: estudio nacional de la Sociedad Española de Cirugía Plástica, Reparadora y Estética. SEPCRE; 2012. 107 p.

40. Audretsch W, Rezai M, Kolotas C, Zamboglou N, Schnabel T, Bojar H. Onco-plastic surgery: «target» volumen reduction (BCT-mastopexy), lumpectomy reconstruction (BCT-reconstruction) and flapp-supported operability in breast cancer. En Vienna, Austria; 1994. p. 139-57.

41. Audretsch W, Rezai M, Kolotas C, Zamboglou N, Schnabel T, Bojar H. Tumorspecific immediate reconstruction in breast cancer patients. Perspect Plast Surg. 1998;11:71-106.

42. Naik AM, Fey J, Gemignani M, Heerdt A, Montgomery L, Petrek J, et al. The risk of axillary relapse after sentinel lymph node biopsy for breast cancer is comparable with that of axillary lymph node dissection: a follow-up study of 4008 procedures. Ann Surg. septiembre de 2004;240(3):462-8.

43. Veronesi U, Galimberti V, Mariani L, Gatti G, Paganelli G, Viale G, et al. Sentinel 
node biopsy in breast cancer: early results in 953 patients with negative sentinel node biopsy and no axillary dissection. Eur J Cancer. 2005;41(2):231-7.

44. Albertini JJ, Lyman GH, Cox C, Yeatman T, Balducci L, Ku N, et al. Lymphatic mapping and sentinel node biopsy in the patient with breast cancer. JAMA. 1996;276(22):1818-22.

45. Tsujimoto M, Nakabayashi K, Yoshidome K, Kaneko T, Iwase T, Akiyama F, et al. One-step nucleic acid amplification for intraoperative detection of lymph node metastasis in breast cancer patients. Clin Cancer Res Off J Am Assoc Cancer Res. 2007;13(16):4807-16.

46. Goldhirsch A, Wood WC, Coates AS, Gelber RD, Thürlimann B, Senn H-J, et al. Strategies for subtypes--dealing with the diversity of breast cancer: highlights of the St. Gallen International Expert Consensus on the Primary Therapy of Early Breast Cancer 2011. Ann Oncol. 2011;22(8):1736-47.

47. Perou CM, Sørlie T, Eisen MB, van de Rijn M, Jeffrey SS, Rees CA, et al. Molecular portraits of human breast tumours. Nature. 2000;406(6797):747-52.

48. Cheang MCU, Chia SK, Voduc D, Gao D, Leung S, Snider J, et al. Ki67 index, HER2 status, and prognosis of patients with luminal B breast cancer. J Natl Cancer Inst. 2009;101(10):736-50.

49. Paik S, Shak S, Tang G, Kim C, Baker J, Cronin M, et al. A multigene assay to predict recurrence of tamoxifen-treated, node-negative breast cancer. N Engl J Med. 2004;351(27):2817-26.

50. Romond EH, Perez EA, Bryant J, Suman VJ, Geyer CE, Davidson NE, et al. Trastuzumab plus adjuvant chemotherapy for operable HER2-positive breast cancer. N Engl J Med. 2005;353(16):1673-84.

51. Martín M, Llombart-Cussac A, Lluch A, Alba E, Munárriz B, Tusquets I, et al. The«Alamo»project (1990-1997): two consecutive hospital-based studies of breast cancer outcomes in Spain. Clin Trans Oncol. 2006;8(7):508-18.

52. Polgár C, Van Limbergen E, Pötter R, Kovács G, Polo A, Lyczek J, et al. Patient selection for accelerated partial-breast irradiation (APBI) after breast-conserving surgery: recommendations of the Groupe Européen de Curiethérapie-European Society for Therapeutic Radiology and Oncology (GEC-ESTRO) breast cancer working group based on clinical evidence (2009). Radiother Oncol J Eur Soc Ther Radiol Oncol. 2010;94(3):264-73. 
53. Giménez-Climent MJ, Piñero A, Merck B, Vázquez C. Documento de consenso sobre la reconstrucción postmastectomía. Madrid: Sociedad Española de Senología y Patología Mamaria; 2008. 157 p.

54. Early Breast Cancer Trialists' Collaborative Group (EBCTCG). Effects of chemotherapy and hormonal therapy for early breast cancer on recurrence and 15year survival: an overview of the randomised trials. Lancet Lond Engl. 2005;365(9472):1687-717.

55. García Palomo A, Nieto Palacios A, Cuezva Guzmán JF, Rodriguez de Nieto Y, Fenández Rojo F, Valles Casado LM, et al. Cáncer de mama: guía para la gestión integrada de procesos asistenciales relacionados con el cáncer: «Proyecto oncoguías» [Internet]. Junta de Castilla y León. Consejería de Sanidad. 2005. 266 p. Recuperado a partir de: http://www.saludcastillayleon.es/institucion/es/publicacionesconsejeria/buscador/cancer-mama-guia-gestion-integrada-procesos-asistencialesr.ficheros/328156-Cáncer\%20Mama.pdf

56. Fobair P, Stewart SL, Chang S, D’Onofrio C, Banks PJ, Bloom JR. Body image and sexual problems in young women with breast cancer. Psychooncology. 2006;15(7):579-94.

57. Lewis FM, Bloom JR. Psychosocial adjustment to breast cancer: a review of selected literature. Int J Psychiatry Med. 1979 de 1978;9(1):1-17.

58. Muñoz M. Quality of life during treatment in young women with breast cancer. Breast Cancer Res Treat. 2010;123 Suppl 1:75-7.

59. Cassileth BR. The aim of psychotherapeutic intervention in cancer patients. Support Care Cancer Off J Multinatl Assoc Support Care Cancer. 1995;3(4):267-9.

60. Snyderman RK, Guthrie RH. Reconstruction of the female breast following radical mastectomy. Plast Reconstr Surg. 1971;47(6):565-7.

61. Gruber RP, Kahn RA, Lash H, Maser MR, Apfelberg DB, Laub DR. Breast reconstruction following mastectomy: a comparison of submuscular and subcutaneous techniques. Plast Reconstr Surg. 1981;67(3):312-7.

62. Asplund O. Capsular contracture in silicone gel and saline-filled breast implants after reconstruction. Plast Reconstr Surg. 1984;73(2):270-5.

63. Gylbert L, Asplund O, Jurell G. Capsular contracture after breast reconstruction with 
silicone-gel and saline-filled implants: a 6-year follow-up. Plast Reconstr Surg. 1990;85(3):373-7.

64. Hester TR, Nahai F, Bostwick J, Cukic J. A 5-year experience with polyurethanecovered mammary prostheses for treatment of capsular contracture, primary augmentation mammoplasty, and breast reconstruction. Clin Plast Surg. 1988;15(4):569-85.

65. Radovan C. Breast reconstruction after mastectomy using the temporary expander. Plast Reconstr Surg. 1982;69(2):195-208.

66. Gibney J. The long-term results of tissue expansion for breast reconstruction. Clin Plast Surg. 1987;14(3):509-18.

67. Slavin SA, Colen SR. Sixty consecutive breast reconstructions with the inflatable expander: a critical appraisal. Plast Reconstr Surg. 1990;86(5):910-9.

68. Maxwell GP, Falcone PA. Eighty-four consecutive breast reconstructions using a textured silicone tissue expander. Plast Reconstr Surg. 1992;89(6):1022-34.

69. Pennisi VR. Making a definite inframammary fold under a reconstructed breast. Plast Reconstr Surg. 1977;60(4):523-5.

70. Ryan JJ. A lower thoracic advancement flap in breast reconstruction after mastectomy. Plast Reconstr Surg. 1982;70(2):153-60.

71. Baroudi R, Pinotti JA, Keppke EM. A transverse thoracoabdominal skin flap for closure after radical mastectomy. Plast Reconstr Surg. 1978;61(4):547-54.

72. Versaci AD. Reconstruction of a pendulous breast utilizing a tissue expander. Clin Plast Surg. 1987;14(3):499-508.

73. Schneider WJ, Hill HL, Brown RG. Latissimus dorsi myocutaneous flap for breast reconstruction. Br J Plast Surg. 1977;30(4):277-81.

74. Maxwell GP. Iginio Tansini and the origin of the latissimus dorsi musculocutaneous flap. Plast Reconstr Surg. 1980;65(5):686-92.

75. Bostwick J, Scheflan M. The latissimus dorsi musculocutaneous flap: a one-stage breast reconstruction. Clin Plast Surg. 1980;7(1):71-8.

76. Hokin JA, Silfverskiold KL. Breast reconstruction without an implant: results and 
complications using an extended latissimus dorsi flap. Plast Reconstr Surg. 1987;79(1):58-66.

77. McCraw JB, Maxwell GP. Early and late capsular «deformation» as a cause of unsatisfactory results in the latissimus dorsi breast reconstruction. Clin Plast Surg. 1988;15(4):717-26.

78. Robbins TH. Rectus abdominis myocutaneous flap for breast reconstruction. Aust N Z J Surg. 1979;49(5):527-30.

79. Dinner MI, Dowden RV. The L-shaped combined vertical and transverse abdominal island flap for breast reconstruction. Plast Reconstr Surg. 1983;72(6):894-8.

80. Hartrampf CR, Scheflan M, Black PW. Breast reconstruction with a transverse abdominal island flap. Plast Reconstr Surg. 1982;69(2):216-25.

81. Scheflan M, Dinner MI. The transverse abdominal island flap: part I. Indications, contraindications, results, and complications. Ann Plast Surg. 1983;10(1):24-35.

82. Scheflan M, Dinner MI. The transverse abdominal island flap: Part II. Surgical technique. Ann Plast Surg. 1983;10(2):120-9.

83. Hartrampf CR. The transverse abdominal island flap for breast reconstruction. A 7year experience. Clin Plast Surg. 1988;15(4):703-16.

84. Boyd JB, Taylor GI, Corlett R. The vascular territories of the superior epigastric and the deep inferior epigastric systems. Plast Reconstr Surg. 1984;73(1):1-16.

85. Bircoll M. Cosmetic breast augmentation utilizing autologous fat and liposuction techniques. Plast Reconstr Surg. 1987;79(2):267-71.

86. Montañana Vizcaino J, Baena Montilla P, Benito Ruiz J. Complications of autografting fat obtained by liposuction. Plast Reconstr Surg. 1990;85(4):638-9.

87. Coleman SR. Facial recontouring with lipostructure. Clin Plast Surg. 1997;24(2):347-67.

88. Coleman SR, Saboeiro AP. Fat grafting to the breast revisited: safety and efficacy. Plast Reconstr Surg. 2007;119(3):775-85; discussion 786-7.

89. Taylor GI, Palmer JH. The vascular territories (angiosomes) of the body: experimental study and clinical applications. Br J Plast Surg. 1987;40(2):113-41. 
90. Koshima I, Soeda S. Inferior epigastric artery skin flaps without rectus abdominis muscle. Br J Plast Surg. 1989;42(6):645-8.

91. Allen RJ, Treece P. Deep inferior epigastric perforator flap for breast reconstruction. Ann Plast Surg. 1994;32(1):32-8.

92. Blondeel PN, Boeckx WD. Refinements in free flap breast reconstruction: the free bilateral deep inferior epigastric perforator flap anastomosed to the internal mammary artery. Br J Plast Surg. 1994;47(7):495-501.

93. Allen RJ, Haddock NT, Ahn CY, Sadeghi A. Breast reconstruction with the profunda artery perforator flap. Plast Reconstr Surg. 2012;129(1):16e - 23e.

94. Koshima I, Inagawa K, Etoh K, Moriguchi T. Supramicrosurgical lymphaticovenular anastomosis for the treatment of lymphedema in the extremities. Nihon Geka Gakkai Zasshi. 1999;100(9):551-6.

95. Khoo A, Kroll SS, Reece GP, Miller MJ, Evans GR, Robb GL, et al. A comparison of resource costs of immediate and delayed breast reconstruction. Plast Reconstr Surg. 1998;101(4):964-8; discussion 969-70.

96. Alderman AK, Wilkins EG, Kim HM, Lowery JC. Complications in postmastectomy breast reconstruction: two-year results of the Michigan Breast Reconstruction Outcome Study. Plast Reconstr Surg. 2002;109(7):2265-74.

97. Sullivan SR, Fletcher DRD, Isom CD, Isik FF. True incidence of all complications following immediate and delayed breast reconstruction. Plast Reconstr Surg. 2008;122(1):19-28.

98. Andrada Aragones E, Reza Goyanes M, Blasco Amaro JA. Reconstrucción mamaria inmediata. Revisión sistemática y evaluación de resultados en una unidad de RMI de la Comunidad de Madrid. Madrid: Consejería de Sanidad - Direccion General de Planificación, Investigación y Formación; 2005 p. 65.

99. Kronowitz SJ, Kuerer HM. Advances and surgical decision-making for breast reconstruction. Cancer. 2006;107(5):893-907.

100. Kelley BP, Ahmed R, Kidwell KM, Kozlow JH, Chung KC, Momoh AO. A systematic review of morbidity associated with autologous breast reconstruction before and after exposure to radiotherapy: are current practices ideal? Ann Surg Oncol. 2014;21(5):1732-8. 
101. Duarte D. Reconstrucción mamaria con expansores. En: Cirugía Plástica Mamaria Ponencia oficial del XXXVIII Congreso de la Sociedad Española de Cirugía Plástica, Reparadora y Estética. SECPRE. Barcelona: MIC; 2003. p. 231-48.

102. Hokin JA. Mastectomy reconstruction without a prosthetic implant. Plast Reconstr Surg. 1983;72(6):810-8.

103. Saint-Cyr M, Nagarkar P, Schaverien M, Dauwe P, Wong C, Rohrich RJ. The pedicled descending branch muscle-sparing latissimus dorsi flap for breast reconstruction. Plast Reconstr Surg. 2009;123(1):13-24.

104. Sinna R, Delay E, Garson S, Delaporte T, Toussoun G. Breast fat grafting (lipomodelling) after extended latissimus dorsi flap breast reconstruction: a preliminary report of 200 consecutive cases. J Plast Reconstr Aesthet Surg. 2010;63(11):1769-77.

105. Veber M, Guerin AN, Faure C, Delay E, Mojallal A. Breast reconstruction using muscle sparing latissimus dorsi flap and fat grafting. Ann Chir Plast Esthét. 2012;57(4):366-72.

106. Watterson PA, Bostwick J, Hester TR, Bried JT, Taylor GI. TRAM flap anatomy correlated with a 10-year clinical experience with 556 patients. Plast Reconstr Surg. 1995;95(7):1185-94.

107. Kroll SS, Schusterman MA, Reece GP, Miller MJ, Robb G, Evans G. Abdominal wall strength, bulging, and hernia after TRAM flap breast reconstruction. Plast Reconstr Surg. 1995;96(3):616-9.

108. Correa D, García H, Lorduy Márquez C, Rodriguez JP, Terán DF, Torres T, et al. Colgajos perforantes. Principios básicos y aplicaciones clínicas. Rev Fac Med. 2012;20:42-51.

109. Geddes CR, Morris SF, Neligan PC. Perforator flaps: evolution, classification, and applications. Ann Plast Surg. 2003;50(1):90-9.

110. Granzow JW, Levine JL, Chiu ES, Allen RJ. Breast reconstruction with the deep inferior epigastric perforator flap: history and an update on current technique. J Plast Reconstr Aesthet Surg. 2006;59(6):571-9.

111. Grotting JC. The free abdominoplasty flap for immediate breast reconstruction. Ann Plast Surg. 1991;27(4):351-4. 
112. Taylor GI, Daniel RK. The anatomy of several free flap donor sites. Plast Reconstr Surg. 1975;56(3):243-53.

113. Arnez ZM, Khan U, Pogorelec D, Planinsek F. Breast reconstruction using the free superficial inferior epigastric artery (SIEA) flap. Br J Plast Surg. 1999;52(4):276-9.

114. Holm C, Mayr M, Höfter E, Ninkovic M. The versatility of the SIEA flap: a clinical assessment of the vascular territory of the superficial epigastric inferior artery. J Plast Reconstr Aesthet Surg. 2007;60(8):946-51.

115. Schoeller T, Huemer GM, Wechselberger G. The transverse musculocutaneous gracilis flap for breast reconstruction: guidelines for flap and patient selection. Plast Reconstr Surg. 2008;122(1):29-38.

116. Adams WM. Free transplantation of the nipples and areola. Surgery. 1944;15:186.

117. Mathes SJ, Hentz VR, editores. Plastic surgery. 2. ed. Philadelphia, Pa: Saunders Elsevier; 2006. 791-818 p.

118. Jones G, Bostwick III J. Nipple-areolar reconstruction. Oper Tech Plast Reconstr Surg. 1994;1:35.

119. Little JW. Nipple-areola reconstruction. Clin Plast Surg. 1984;11(2):351-64.

120. Kroll SS, Reece GP, Miller MJ, Evans GR, Robb GL, Baldwin BJ, et al. Comparison of nipple projection with the modified double-opposing tab and star flaps. Plast Reconstr Surg. 1997;99(6):1602-5.

121. Moore KL, Agur AMR, Dalley AF. Anatomía con orientación clínica. $7^{\mathrm{a}}$ ed. Barcelona: Wolters Kluwer, Lippincott Williams \& Wilkins; 2010. 1164 p.

122. Gagnon AR, Blondeel PN. Colgajos de perforantes de las arterias epigástricas inferiores profunda y superficial. Cir Plástica Ibero-Latinoam. 2006;32(4):243-58.

123. Milloy FJ, Anson BJ, Mcafee DK. The rectus abdominis muscle and the epigastric arteries. Surg Gynecol Obstet. 1960;110:293-302.

124. Moon HK, Taylor GI. The vascular anatomy of rectus abdominis musculocutaneous flaps based on the deep superior epigastric system. Plast Reconstr Surg. 1988;82(5):815-32.

125. Rozen WM, Ashton MW, Grinsell D. The branching pattern of the deep inferior 
epigastric artery revisited in-vivo: a new classification based on CT angiography. Clin Anat N Y N. 2010;23(1):87-92.

126. Itoh $\mathrm{Y}$, Arai $\mathrm{K}$. The deep inferior epigastric artery free skin flap: anatomic study and clinical application. Plast Reconstr Surg. 1993;91(5):853-63; discussion 864.

127. Blondeel PN, Beyens G, Verhaeghe R, Van Landuyt K, Tonnard P, Monstrey SJ, et al. Doppler flowmetry in the planning of perforator flaps. Br J Plast Surg. 1998;51(3):202-9.

128. Imanishi $\mathrm{N}$, Nakajima $\mathrm{H}$, Minabe $\mathrm{T}$, Chang $\mathrm{H}$, Aiso S. Anatomical relationship between arteries and veins in the paraumbilical region. $\mathrm{Br} \mathrm{J}$ Plast Surg. 2003;56(6):552-6.

129. Carramenha e Costa MA, Carriquiry C, Vasconez LO, Grotting JC, Herrera RH, Windle BH. An anatomic study of the venous drainage of the transverse rectus abdominis musculocutaneous flap. Plast Reconstr Surg. 1987;79(2):208-17.

130. Heitmann C, Felmerer G, Durmus C, Matejic B, Ingianni G. Anatomical features of perforator blood vessels in the deep inferior epigastric perforator flap. Br J Plast Surg. 2000;53(3):205-8.

131. Tregaskiss AP, Goodwin AN, Acland RD. The cutaneous arteries of the anterior abdominal wall: a three-dimensional study. Plast Reconstr Surg. 2007;120(2):44250 .

132. Rozen WM, Kapila S, Donahoe S. Why there are two rows of deep inferior epigastric artery perforators despite variability in the number of deep inferior epigastric artery trunks: An anatomical and embryological argument. Clin Anat. 2011;24(6):786-8.

133. Dinner MI, Dowden RV, Scheflan M. Refinements in the use of the transverse abdominal island flap for postmastectomy reconstruction. Ann Plast Surg. 1983;11(5):362-72.

134. Holm C, Mayr M, Höfter E, Ninkovic M. Perfusion zones of the DIEP flap revisited: a clinical study. Plast Reconstr Surg. 2006;117(1):37-43.

135. Wong C, Saint-Cyr M, Mojallal A, Schaub T, Bailey SH, Myers S, et al. Perforasomes of the DIEP flap: vascular anatomy of the lateral versus medial row perforators and clinical implications. Plast Reconstr Surg. 2010;125(3):772-82. 
136. Blondeel PN, Arnstein M, Verstraete K, Depuydt K, Van Landuyt KH, Monstrey SJ, et al. Venous congestion and blood flow in free transverse rectus abdominis myocutaneous and deep inferior epigastric perforator flaps. Plast Reconstr Surg. 2000;106(6):1295-9.

137. Dhar SC, Taylor GI. The delay phenomenon: the story unfolds. Plast Reconstr Surg. 1999;104(7):2079-91.

138. Ochoa O, Pisano S, Chrysopoulo M, Ledoux P, Arishita G, Nastala C. Salvage of Intraoperative Deep Inferior Epigastric Perforator Flap Venous Congestion with Augmentation of Venous Outflow: Flap Morbidity and Review of the Literature. Plast Reconstr Surg Glob Open. 2013;1(7):e52.

139. Santanelli di Pompeo F, Longo B, Laporta R, Pagnoni M, Cavalieri E. The use of the serratus anterior muscle vascular pedicle as recipient site in DIEP flap transfer for breast reconstruction. J Plast Reconstr Aesthet Surg. 2014;67(4):456-60.

140. Hivelin M, Heusse JL, Matar N, Lepage C, Lantieri L. Fibrin sealant decreases postoperative drainage in immediate breast reconstruction by deep inferior epigastric perforator flap after mastectomy with axillary dissection. Microsurgery. 2011;31(1):18-25.

141. Fernandez Aramburu J, Villegas L, Froján D, Gaillard J, Loccisano M. Mostración anatómica de la arteria torácica interna y su implicancia en la cirugía de revascularizacion miocárdica. Rev Arg Anat Onl. 2012;3:86-91.

142. Arnez ZM, Valdatta L, Tyler MP, Planinsek F. Anatomy of the internal mammary veins and their use in free TRAM flap breast reconstruction. Br J Plast Surg. 1995;48(8):540-5.

143. Darcy CM, Smit JM, Audolfsson T, Acosta R. Surgical technique: The intercostal space approach to the internal mammary vessels in 463 microvascular breast reconstructions. J Plast Reconstr Aesthet Surg. 2011;64(1):58-62.

144. Sacks JM, Chang DW. Rib-sparing internal mammary vessel harvest for microvascular breast reconstruction in 100 consecutive cases. Plast Reconstr Surg. 2009;123(5):1403-7.

145. Kim H, Lim S-Y, Pyon J-K, Bang S-I, Oh KS, Mun G-H. Preoperative computed tomographic angiography of both donor and recipient sites for microsurgical breast reconstruction. Plast Reconstr Surg. 2012;130(1):11e - 20e. 
146. Tejerina Botella C, Márquez Cañada JM, García Andrés E, Masiá Ayala J, Arpino A, Elia I. Estudio preoperatorio de vasos receptores en reconstrucción mamaria con colgajo DIEP. Cir Plástica Ibero-Latinoam. 2011;37(3):233-8.

147. McGregor IA, Morgan G. Axial and random pattern flaps. Br J Plast Surg. 1973;26(3):202-13.

148. Saint-Cyr M, Wong C, Schaverien M, Mojallal A, Rohrich RJ. The perforasome theory: vascular anatomy and clinical implications. Plast Reconstr Surg. 2009;124(5):1529-44.

149. Masià J, Clavero JA, Carrera A. Planificación preoperatoria de los colgajos de perforantes. Cir Plástica Ibero-Latinoam. 2006;32(4):237-42.

150. Hallock GG. Doppler sonography and color duplex imaging for planning a perforator flap. Clin Plast Surg. 2003;30(3):347-57.

151. Masiá Ayala J. Planificación preoperatoria de los colgajos de perforantes de la arteria epigástrica inferior profunda (DIEP) mediante el estudio con el TAC de multidetectores [Tesis doctoral]. [Barcelona]: Universitat Autònoma de Barcelona; 2008.

152. Rozen WM, Garcia-Tutor E, Alonso-Burgos A, Acosta R, Stillaert F, Zubieta JL, et al. Planning and optimising DIEP flaps with virtual surgery: the Navarra experience. J Plast Reconstr Aesthet Surg. 2010;63(2):289-97.

153. Castro García J, García-Tutor E, Alonso A, Pina L, De Luis E. Análisis de perforantes de la epigástrica inferior profunda con Angio TC 3D, Eco Doppler color y Doppler simple de ultrasonidos en colgajo DIEP: resultados preliminares. Cir Plástica Ibero-Latinoam. 2008;34(3):223-34.

154. Casares Santiago M. Optimización de la planificación quirúrgica de los colgajos DIEP usando angiografía TC multicorte [Tesis doctoral]. [Madrid]: Universidad Rey Juan Carlos; 2014.

155. Calzado A, Geleijns J. Tomografía computarizada. Evolución, principios técnicos y aplicaciones. Rev Física Médica. 2010;11(3):163-80.

156. Rozen WM, Stella DL, Bowden J, Taylor GI, Ashton MW. Advances in the preoperative planning of deep inferior epigastric artery perforator flaps: magnetic resonance angiography. Microsurgery. 2009;29(2):119-23. 
157. Cina A, Barone-Adesi L, Rinaldi P, Cipriani A, Salgarello M, Masetti R, et al. Planning deep inferior epigastric perforator flaps for breast reconstruction: a comparison between multidetector computed tomography and magnetic resonance angiography. Eur Radiol. 2013;23(8):2333-43.

158. Broome DR, Girguis MS, Baron PW, Cottrell AC, Kjellin I, Kirk GA. Gadodiamideassociated nephrogenic systemic fibrosis: why radiologists should be concerned. AJR Am J Roentgenol. 2007;188(2):586-92.

159. Rielo Arias F. II Curso de OsiriX para cirujanos vasculares. Sociedad Española de Angiología y Cirugía Vascular; 2012.

160. Rosset A, Spadola L, Ratib O. OsiriX: an open-source software for navigating in multidimensional DICOM images. J Digit Imaging. 2004;17(3):205-16.

161. Rodríguez-Vegas M, Martín Hervás C, Bartolomé Villar A. Angiotomografía computerizada, colgajos de perforante, cirujano y OsiriX. Cir Plástica IberoLatinoam. 2013;39(1):35-46.

162. Phillips TJ, Stella DL, Rozen WM, Ashton M, Taylor GI. Abdominal wall CT angiography: a detailed account of a newly established preoperative imaging technique. Radiology. 2008;249(1):32-44.

163. Clavero JA, Masia J, Larrañaga J, Monill JM, Pons G, Siurana S, et al. MDCT in the preoperative planning of abdominal perforator surgery for postmastectomy breast reconstruction. AJR Am J Roentgenol. 2008;191(3):670-6.

164. Prasad KN, Cole WC, Haase GM. Radiation protection in humans: extending the concept of as low as reasonably achievable (ALARA) from dose to biological damage. Br J Radiol. 2004;77(914):97-9.

165. Acosta R, Smit JM, Audolfsson T, Darcy CM, Enajat M, Kildal M, et al. A clinical review of 9 years of free perforator flap breast reconstructions: an analysis of 675 flaps and the influence of new techniques on clinical practice. J Reconstr Microsurg. 2011;27(2):91-8.

166. Blondeel PN, Morris SF, Hallock GG, Neligan PC. Perforator flaps: anatomy, technique \& clinical applications. 2nd ed. St. Louis, Mo: Quality Medical Pub; 2013. $1096 \mathrm{p}$.

167. Blondeel PN, Hijjawi J, Depypere H, Roche N, Van Landuyt K. Shaping the breast in aesthetic and reconstructive breast surgery: an easy three-step principle. Plast 
Reconstr Surg. 2009;123(2):455-62.

168. Blondeel PN, Hijjawi J, Depypere H, Roche N, Van Landuyt K. Shaping the breast in aesthetic and reconstructive breast surgery: an easy three-step principle. Part II-Breast reconstruction after total mastectomy. Plast Reconstr Surg. 2009;123(3):794805.

169. Heusse J-L, Hivelin M, Lepage C, Santini C, Lantieri L. Fibrin sealant significantly decrease postoperative drainage in breast reconstruction by deep inferior epigastric perforator (DIEP) flap. Ann Chir Plast Esthét. 2012;57(1):50-8.

170. Ochoa O, Chrysopoulo M, Nastala C, Ledoux P, Pisano S. Abdominal wall stability and flap complications after deep inferior epigastric perforator flap breast reconstruction: does body mass index make a difference? Analysis of 418 patients and 639 flaps. Plast Reconstr Surg. 2012;130(1):21e - 33e.

171. Lie KH, Barker AS, Ashton MW. A Classification System for Partial and Complete DIEP Flap Necrosis Based on a Review of 17,096 DIEP Flaps in 693 Articles Including Analysis of 152 Total Flap Failures: Plast Reconstr Surg. 2013;132(6):1401-8.

172. Hofer SOP, Damen THC, Mureau MAM, Rakhorst HA, Roche NA. A critical review of perioperative complications in 175 free deep inferior epigastric perforator flap breast reconstructions. Ann Plast Surg. 2007;59(2):137-42.

173. Thorarinsson A, Fröjd V, Kölby L, Lewin R, Molinder N, Lundberg J, et al. A retrospective review of the incidence of various complications in different delayed breast reconstruction methods. J Plast Surg Hand Surg. 2015;1-10.

174. Hu ES, Pusic AL, Waljee JF, Kuhn L, Hawley ST, Wilkins E, et al. Patient-Reported Aesthetic Satisfaction with Breast Reconstruction during the Long-Term Survivorship Perio: Plast Reconstr Surg. 2009;124(1):1-8.

175. Cabrera Sánchez E, Redondo Camacho A, Dean Ferrer A, Benítez i Gomá JR, Torre Beltrami C, De Piero Belmonte G, et al. Satisfacción en pacientes con reconstrucción mamaria con colgajo D.I.E.P. Cir Plástica Ibero-Latinoam. 2006;32(3):169-79.

176. Alderman AK, Kuhn LE, Lowery JC, Wilkins EG. Does patient satisfaction with breast reconstruction change over time? Two-year results of the Michigan Breast Reconstruction Outcomes Study. J Am Coll Surg. enero de 2007;204(1):7-12.

177. Kronowitz SJ, Robb GL. Breast reconstruction with postmastectomy radiation 
therapy: current issues. Plast Reconstr Surg. 2004;114(4):950-60.

178. Krueger EA, Wilkins EG, Strawderman M, Cederna P, Goldfarb S, Vicini FA, et al. Complications and patient satisfaction following expander/implant breast reconstruction with and without radiotherapy. Int J Radiat Oncol Biol Phys. 2001;49(3):713-21.

179. Visser NJ, Damen THC, Timman R, Hofer SOP, Mureau MAM. Surgical results, aesthetic outcome, and patient satisfaction after microsurgical autologous breast reconstruction following failed implant reconstruction. Plast Reconstr Surg. 2010;126(1):26-36.

180. Benditte-Klepetko HC, Lutgendorff F, Kästenbauer T, Deutinger M, van der Horst $\mathrm{CM}$ a. M. Analysis of patient satisfaction and donor-site morbidity after different types of breast reconstruction. Scand J Surg SJS Off Organ Finn Surg Soc Scand Surg Soc. 2014;103(4):249-55.

181. Momoh AO, Colakoglu S, Westvik TS, Curtis MS, Yueh JH, de Blacam C, et al. Analysis of complications and patient satisfaction in pedicled transverse rectus abdominis myocutaneous and deep inferior epigastric perforator flap breast reconstruction. Ann Plast Surg. 2012;69(1):19-23.

182. Casado Sánchez C, Cabrera Sánchez E, Redondo Camacho A, Rioja Torrejón LF. Análisis de controversias en reconstrucción mamaria con colgajo DIEP. Cir Plástica Ibero-Latinoam. 2008;34(4):267-75.

183. Enajat M, Rozen WM, Whitaker IS, Smit JM, Acosta R. A single center comparison of one versus two venous anastomoses in 564 consecutive DIEP flaps: investigating the effect on venous congestion and flap survival. Microsurgery. 2010;30(3):185-91.

184. Santanelli F, Longo B, Cagli B, Pugliese P, Sorotos M, Paolini G. Predictive and protective factors for partial necrosis in DIEP flap breast reconstruction: does nulliparity bias flap viability? Ann Plast Surg. 2015;74(1):47-51.

185. Al-Dhamin A, Bissell MB, Prasad V, Morris SF. The use of retrograde limb of internal mammary vein in autologous breast reconstruction with DIEAP flap: anatomical and clinical study. Ann Plast Surg. 2014;72(3):281-4.

186. Lee K-T, Mun G-H. Benefits of superdrainage using SIEV in DIEP flap breast reconstruction: A systematic review and meta-analysis. Microsurgery [Internet]. 2015 [citado 17 de octubre de 2015]; Recuperado a partir de: http://onlinelibrary.wiley.com/doi/10.1002/micr.22420/abstract 
187. Xin Q, Luan J, Mu H, Mu L. Augmentation of Venous Drainage in Deep Inferior Epigastric Perforator Flap Breast Reconstruction: Efficacy and Advancement. J Reconstr Microsurg. 2012;28(05):313-8.

188. Kroll SS. Fat necrosis in free transverse rectus abdominis myocutaneous and deep inferior epigastric perforator flaps. Plast Reconstr Surg. 2000;106(3):576-83.

189. Nahabedian MY, Dooley W, Singh N, Manson PN. Contour abnormalities of the abdomen after breast reconstruction with abdominal flaps: the role of muscle preservation. Plast Reconstr Surg. 2002;109(1):91-101.

190. Scheer AS, Novak CB, Neligan PC, Lipa JE. Complications associated with breast reconstruction using a perforator flap compared with a free TRAM flap. Ann Plast Surg. 2006;56(4):355-8.

191. Gill PS, Hunt JP, Guerra AB, Dellacroce FJ, Sullivan SK, Boraski J, et al. A 10-year retrospective review of 758 DIEP flaps for breast reconstruction. Plast Reconstr Surg. 2004;113(4):1153-60.

192. Peeters WJ, Nanhekhan L, Van Ongeval C, Fabré G, Vandevoort M. Fat Necrosis in Deep Inferior Epigastric Perforator Flaps: An Ultrasound-Based Review of 202 Cases: Plast Reconstr Surg. 2009;124(6):1754-8.

193. Man L-X, Selber JC, Serletti JM. Abdominal Wall following Free TRAM or DIEP Flap Reconstruction: A Meta-Analysis and Critical Review: Plast Reconstr Surg. 2009;124(3):752-64.

194. Lee K-T, Lee JE, Nam SJ, Mun G-H. Ischaemic time and fat necrosis in breast reconstruction with a free deep inferior epigastric perforator flap. J Plast Reconstr Aesthet Surg. 2013;66(2):174-81.

195. Baumann DP, Lin HY, Chevray PM. Perforator Number Predicts Fat Necrosis in a Prospective Analysis of Breast Reconstruction with Free TRAM, DIEP, and SIEA Flaps: Plast Reconstr Surg. 2010;125(5):1335-41.

196. Bozikov K, Arnez T, Hertl K, Arnez ZM. Fat necrosis in free DIEAP flaps: incidence, risk, and predictor factors. Ann Plast Surg. 2009;63(2):138-42.

197. Landin L, Bolado P, Casado-Sanchez C, Bonastre J, Garcia-Redondo M, Zharbakhsh $\mathrm{S}$, et al. Safety of Salvaging Impending Flap Congestion in Breast Reconstruction by Venous Supercharging of the Cephalic Vein: Ann Plast Surg. 2015;74(1):52-6. 
198. Rothenberger J, Amr A, Schiefer J, Schaller H-E, Rahmanian-Schwarz A. A quantitative analysis of the venous outflow of the deep inferior epigastric flap (DIEP) based on the perforator veins and the efficiency of superficial inferior epigastric vein (SIEV) supercharging. J Plast Reconstr Aesthet Surg. 2013;66(1):67-72.

199. Rozen WM, Ashton MW. The venous anatomy of the abdominal wall for Deep Inferior Epigastric Artery (DIEP) flaps in breast reconstruction. Gland Surg. 2012;1(2):92-110.

200. Sbitany H, Mirzabeigi MN, Kovach SJ, Wu LC, Serletti JM. Strategies for recognizing and managing intraoperative venous congestion in abdominally based autologous breast reconstruction. Plast Reconstr Surg. 2012;129(4):809-15.

201. Garvey PB, Buchel EW, Pockaj BA, Casey WJ, Gray RJ, Hernández JL, et al. DIEP and pedicled TRAM flaps: a comparison of outcomes. Plast Reconstr Surg. 2006;117(6):1711-9; discussion 1720-1.

202. Galla TJ, Lukas B, Feller AM. Pedicled versus free TRAM flap for breast reconstruction. Handchir Mikrochir Plast Chir Organ Deutschsprachigen Arbeitsgemeinschaft Für Handchir Organ Deutschsprachigen Arbeitsgemeinschaft Für Mikrochir Peripher Nerven Gefässe Organ Ver Dtsch Plast Chir. 1999;31(2):126-33.

203. Schusterman MA, Kroll SS, Weldon ME. Immediate breast reconstruction: why the free TRAM over the conventional TRAM flap? Plast Reconstr Surg. 1992;90(2):25561 ; discussion 262.

204. Kroll SS, Marchi M. Comparison of strategies for preventing abdominal-wall weakness after TRAM flap breast reconstruction. Plast Reconstr Surg. 1992;89(6):1045-51; discussion 1052-3.

205. Wang X-L, Liu L-B, Song F-M, Wang Q-Y. Meta-analysis of the safety and factors contributing to complications of MS-TRAM, DIEP, and SIEA flaps for breast reconstruction. Aesthetic Plast Surg. 2014;38(4):681-91.

206. Nahabedian MY, Momen B. Lower abdominal bulge after deep inferior epigastric perforator flap (DIEP) breast reconstruction. Ann Plast Surg. 2005;54(2):124-9.

207. Arnez ZM, Khan U, Pogorelec D, Planinsek F. Rational selection of flaps from the abdomen in breast reconstruction to reduce donor site morbidity. Br J Plast Surg. 1999;52(5):351-4. 
208. Blondeel N, Vanderstraeten GG, Monstrey SJ, Van Landuyt K, Tonnard P, Lysens $\mathrm{R}$, et al. The donor site morbidity of free DIEP flaps and free TRAM flaps for breast reconstruction. Br J Plast Surg. 1997;50(5):322-30.

209. Garvey PB, Salavati S, Feng L, Butler CE. Abdominal donor-site outcomes for medial versus lateral deep inferior epigastric artery branch perforator harvest. Plast Reconstr Surg. 2011;127(6):2198-205.

210. Roostaeian J, Yoon AP, Sanchez IS, Rahgozar P, Galanis C, Herrera F, et al. The effect of prior abdominal surgery on abdominally based free flaps in breast reconstruction. Plast Reconstr Surg. 2014;133(3):247e - 255e.

211. Jokuszies A, Radtke C, Betzler C, Branski L, Krämer R, Vogt PM. Is tamoxifen associated with an increased risk for thromboembolic complications in patients undergoing microvascular breast reconstruction? Ger Med Sci. 2013;11:Doc05.

212. Pannucci CJ, Chang EY, Wilkins EG. Venous thromboembolic disease in autogenous breast reconstruction. Ann Plast Surg. 2009;63(1):34-8.

213. Schneider DS, McClain L, Robb PK, Rosenthal EL, Wax MK. Use of internal mammary vessels in head and neck microvascular reconstruction. Arch Otolaryngol Head Neck Surg. 2012;138(2):172-6.

214. Matros E, Albornoz CR, Razdan SN, Mehrara BJ, Macadam SA, Ro T, et al. Costeffectiveness analysis of implants versus autologous perforator flaps using the BREAST-Q. Plast Reconstr Surg. 2015;135(4):937-46.

215. Kantak NA, Koolen PGL, Martin C, Tobias AM, Lee BT, Lin SJ. Are patients with low body mass index candidates for deep inferior epigastric perforator flaps for unilateral breast reconstruction?: Unilateral DIEP Flap Breast Reconstruction in Low BMI Patients. Microsurgery. 2015;35(6):421-7.

216. Grover R, Nelson JA, Fischer JP, Kovach SJ, Serletti JM, Wu LC. The impact of perforator number on deep inferior epigastric perforator flap breast reconstruction. Arch Plast Surg. 2014;41(1):63-70.

217. Nahabedian MY, Momen B, Manson PN. Factors associated with anastomotic failure after microvascular reconstruction of the breast. Plast Reconstr Surg. 2004;114(1):74-82.

218. Padubidri AN, Yetman R, Browne E, Lucas A, Papay F, Larive B, et al. Complications of postmastectomy breast reconstructions in smokers, ex-smokers, 
and nonsmokers. Plast Reconstr Surg. 2001;107(2):342-9; discussion 350-1.

219. Park YJ, Kim EK, Yun JY, Eom JS, Lee TJ. The influence of Pfannenstiel incision scarring on deep inferior epigastric perforator. Arch Plast Surg. 2014;41(5):542-7.

220. Farid M, Nicholson S, Kotwal A, Akali A. DIEP breast reconstruction following multiple abdominal liposuction procedures. Eplasty. 2014;14:e47.

221. Rozen WM, Acosta R. Successful DIEP flap for breast reconstruction in a patient with prior abdominoplasty. Plast Reconstr Surg. 2012;130(5):751e - 752e.

222. Santanelli F, Paolini G, Renzi L. Preliminary experience in breast reconstruction with the free vertical deep inferior epigastric perforator flap. Scand J Plast Reconstr Surg Hand Surg Nord Plast Foren Nord Klubb Handkirurgi. 2008;42(1):23-7.

223. Rozen WM, Ashton MW. Radiotherapy and breast reconstruction: oncology, cosmesis and complications. Gland Surg. 2012;1(2):119-27.

224. Rogers NE, Allen RJ. Radiation effects on breast reconstruction with the deep inferior epigastric perforator flap. Plast Reconstr Surg. 2002;109(6):1919-24; discussion 1925-6.

225. Kronowitz SJ, Robb GL. Radiation therapy and breast reconstruction: a critical review of the literature. Plast Reconstr Surg. 2009;124(2):395-408.

226. Kronowitz SJ, Hunt KK, Kuerer HM, Babiera G, McNeese MD, Buchholz TA, et al. Delayed-immediate breast reconstruction. Plast Reconstr Surg. 2004;113(6):1617-28.

227. Fernández García A, Fernández Pascual C, Moreno Villalba RA, Gerrero Navarro L. Drenaje suplementario del sistema venoso superficial en colgajos pediculados. Cir Plástica Ibero-Latinoam. 2012;38(2):125-35.

228. Schwabegger AH, Gschnitzer C, Ninkovic MM. Contour deformity at the internal mammary recipient site. Br J Plast Surg. 1999;52(8):674.

229. Kavouni A, Shibu M. Problems associated with the use of internal mammary vessels as recipients for free flap breast reconstruction. Br J Plast Surg. 1999;52(7):597.

230. Zweifel-Schlatter M, Darhouse N, Roblin P, Ross D, Zweifel M, Farhadi J. Immediate microvascular breast reconstruction after neoadjuvant chemotherapy: complication rates and effect on start of adjuvant treatment. Ann Surg Oncol. noviembre de 2010;17(11):2945-50. 
231. Kelley BP, Valero V, Yi M, Kronowitz SJ. Tamoxifen Increases the Risk of Microvascular Flap Complications in Patients Undergoing Microvascular Breast Reconstruction. Plast Reconstr Surg. 2012;129(2):305-14.

232. Ninković M, Anderl H, Hefel L, Schwabegger A, Wechselberger G. Internal mammary vessels: a reliable recipient system for free flaps in breast reconstruction. Br J Plast Surg. 1995;48(8):533-9.

233. Dupin CL, Allen RJ, Glass CA, Bunch R. The internal mammary artery and vein as a recipient site for free-flap breast reconstruction: a report of 110 consecutive cases. Plast Reconstr Surg. 1996;98(4):685-9; discussion 690-2.

234. Hallock GG. Evaluation of fasciocutaneous perforators using color duplex imaging. Plast Reconstr Surg. 1994;94(5):644-51.

235. De Frene B, Van Landuyt K, Hamdi M, Blondeel P, Roche N, Voet D, et al. Free DIEAP and SGAP flap breast reconstruction after abdominal/gluteal liposuction. J Plast Reconstr Aesthet Surg. 2006;59(10):1031-6.

236. Masia J, Clavero JA, Larrañaga JR, Alomar X, Pons G, Serret P. Multidetector-row computed tomography in the planning of abdominal perforator flaps. J Plast Reconstr Aesthet Surg. 2006;59(6):594-9.

237. Rozen WM, Phillips TJ, Ashton MW, Stella DL, Gibson RN, Taylor GI. Preoperative Imaging for DIEA Perforator Flaps: A Comparative Study of Computed Tomographic Angiography and Doppler Ultrasound: Plast Reconstr Surg. 2008;121(MOC-PS CME Coll):1-8.

238. Uppal RS, Casaer B, Van Landuyt K, Blondeel P. The efficacy of preoperative mapping of perforators in reducing operative times and complications in perforator flap breast reconstruction. J Plast Reconstr Aesthet Surg. 2009;62(7):859-64.

239. Alonso-Burgos A, García-Tutor E, Bastarrika G, Cano D, Martínez-Cuesta A, Pina LJ. Preoperative planning of deep inferior epigastric artery perforator flap reconstruction with multislice-CT angiography: imaging findings and initial experience. J Plast Reconstr Aesthet Surg. 2006;59(6):585-93.

240. Smit JM, Dimopoulou A, Liss AG, Zeebregts CJ, Kildal M, Whitaker IS, et al. Preoperative CT angiography reduces surgery time in perforator flap reconstruction. J Plast Reconstr Aesthet Surg. 2009;62(9):1112-7.

241. Gacto-Sánchez P, Sicilia-Castro D, Gómez-Cía T, Lagares A, Collell T, Suárez C, 
et al. Computed tomographic angiography with VirSSPA three-dimensional software for perforator navigation improves perioperative outcomes in DIEP flap breast reconstruction. Plast Reconstr Surg. 2010;125(1):24-31.

242. Minqiang X, Lanhua M, Jie L, Dali M, Jinguo L. The value of multidetector-row CT angiography for pre-operative planning of breast reconstruction with deep inferior epigastric arterial perforator flaps. Br J Radiol. 2010;83(985):40-3.

243. Casey WJ, Chew RT, Rebecca AM, Smith AA, Collins JM, Pockaj BA. Advantages of preoperative computed tomography in deep inferior epigastric artery perforator flap breast reconstruction. Plast Reconstr Surg. 2009;123(4):1148-55.

244. Teunis T, Heerma van Voss MR, Kon M, van Maurik JFMM. CT-angiography prior to DIEP flap breast reconstruction: a systematic review and meta-analysis. Microsurgery. 2013;33(6):496-502.

245. Casares Santiago M, García-Tutor E, Rodríguez Caravaca G, Del Cerro González J, Klein LM, Alonso-Burgos A. Optimising the preoperative planning of deep inferior epigastric perforator flaps for breast reconstruction. Eur Radiol. 2014;24(9):2097108.

246. Rozen W, Ashton M, Stella D, Phillips TJ, Taylor G. Magnetic Resonance Angiography and Computed Tomographic Angiography for Free Fibular Flap Transfer. J Reconstr Microsurg. 2008;24(06):457-8.

247. Suffee T, Pigneur F, Rahmouni A, Bosc R. Best choice of perforator vessel in autologous breast reconstruction: Virtual reality navigation vs radiologist analysis. A prospective study. J Plast Surg Hand Surg. 2015;1-6.

248. Smit JM, Klein S, Werker PMN. An overview of methods for vascular mapping in the planning of free flaps. J Plast Reconstr Aesthet Surg. 2010;63(9):e674-82.

249. Masia J, Larrañaga J, Clavero JA, Vives L, Pons G, Pons JM. The value of the multidetector row computed tomography for the preoperative planning of deep inferior epigastric artery perforator flap: our experience in 162 cases. Ann Plast Surg. 2008;60(1):29-36.

250. Yu P, Youssef A. Efficacy of the handheld Doppler in preoperative identification of the cutaneous perforators in the anterolateral thigh flap. Plast Reconstr Surg. 2006;118(4):928-33; discussion 934-5.

251. Khan UD, Miller JG. Reliability of handheld Doppler in planning local perforator- 
based flaps for extremities. Aesthetic Plast Surg. 2007;31(5):521-5.

252. Giunta RE, Geisweid A, Feller AM. The value of preoperative Doppler sonography for planning free perforator flaps. Plast Reconstr Surg. 2000;105(7):2381-6.

253. Rozen WM, Palmer KP, Suami H, Pan WR, Ashton MW, Corlett RJ, et al. The DIEA Branching Pattern and Its Relationship to Perforators: The Importance of Preoperative Computed Tomographic Angiography for DIEA Perforator Flaps: Plast Reconstr Surg. 2008;121(2):367-73.

254. Rozen WM, Ashton MW, Grinsell D. The Type 4 DIEA: A Newly Identified Branching Pattern of the Deep Inferior Epigastric Artery: Plast Reconstr Surg. 2010;126(2):86e - 87e.

255. Munhoz AM, Ishida LH, Sturtz GP, Cunha MS, Montag E, Saito FL, et al. Importance of lateral row perforator vessels in deep inferior epigastric perforator flap harvesting. Plast Reconstr Surg. 2004;113(2):517-24.

256. Rahmanian-Schwarz A, Rothenberger J, Hirt B, Luz O, Schaller H-E. A combined anatomical and clinical study for quantitative analysis of the microcirculation in the classic perfusion zones of the deep inferior epigastric artery perforator flap. Plast Reconstr Surg. 2011;127(2):505-13.

257. Wong C, Saint-Cyr M, Arbique G, Becker S, Brown S, Myers S, et al. Three- and four-dimensional computed tomography angiographic studies of commonly used abdominal flaps in breast reconstruction. Plast Reconstr Surg. 2009;124(1):18-27.

258. Rozen WM, Ashton MW, Stella DL, Phillips TJ, Grinsell D, Taylor GI. The Accuracy of Computed Tomographic Angiography for Mapping the Perforators of the Deep Inferior Epigastric Artery: A Blinded, Prospective Cohort Study: Plast Reconstr Surg. 2008;122(4):1003-9.

259. Rozen WM, Phillips TJ, Stella DL, Ashton MW. Preoperative Computed Tomographic Angiography for Deep Inferior Epigastric Artery Perforator Flaps: Important Information for the Reporting Radiologist: Plast Reconstr Surg. 2010;125(2):70e - 72e.

260. Rozen WM, Stella DL, Phillips TJ, Ashton MW, Corlett RJ, Taylor GI. Magnetic Resonance Angiography in the Preoperative Planning of DIEA Perforator Flaps: Plast Reconstr Surg. 2008;122(6):222e - 223e.

261. Rozen WM, Ashton MW, Stella DL, Ferris S, White DC, Phillips TJ, et al. 
Developments in perforator imaging for the anterolateral thigh flap: CT angiography and CT-guided stereotaxy. Microsurgery. 2008;28(4):227-32.

262. Rozen WM, Ashton MW, Murray ACA, Taylor GI. Avoiding denervation of rectus abdominis in DIEP flap harvest: the importance of medial row perforators. Plast Reconstr Surg. 2008;122(3):710-6.

263. Vandevoort M, Vranckx JJ, Fabre G. Perforator topography of the deep inferior epigastric perforator flap in 100 cases of breast reconstruction. Plast Reconstr Surg. 2002;109(6):1912-8.

264. Schaverien M, Saint-Cyr M, Arbique G, Brown SA. Arterial and venous anatomies of the deep inferior epigastric perforator and superficial inferior epigastric artery flaps. Plast Reconstr Surg. 2008;121(6):1909-19.

265. Rozen WM, Ashton MW, Le Roux CM, Pan W-R, Corlett RJ. The perforator angiosome: A new concept in the design of deep inferior epigastric artery perforator flaps for breast reconstruction. Microsurgery. 2010;30:1-7.

266. Tregaskiss A. Perfusion zones of the DIEP flap revisited: a clinical study. Plast Reconstr Surg. 2006;118(3):816.

267. Hallock GG. Perforasomes, Venosomes, and Perfusion Zones of the DIEAP Flap. Plast Reconstr Surg. 2010;126(6):2282-4; author reply 2284-6.

268. Keller A. Perfusion zones of the DIEP flap revisited: a clinical study. Plast Reconstr Surg. 2006;118(4):1076-7.

269. Nahabedian MY, Tsangaris T, Momen B. Breast reconstruction with the DIEP flap or the muscle-sparing (MS-2) free TRAM flap: is there a difference? Plast Reconstr Surg. 2005;115(2):436-44.

270. Schaverien MV, Ludman CN, Neil-Dwyer J, Perks AGB, Raurell A, Rasheed T, et al. Relationship between venous congestion and intraflap venous anatomy in DIEP flaps using contrast-enhanced magnetic resonance angiography. Plast Reconstr Surg. 2010;126(2):385-92.

271. El-Mrakby HH, Milner RH. The vascular anatomy of the lower anterior abdominal wall: a microdissection study on the deep inferior epigastric vessels and the perforator branches. Plast Reconstr Surg. 2002;109(2):539-43; discussion 544-7.

272. Rozen WM, Murray ACA, Ashton MW, Bloom RJ, Stella DL, Phillips TJ, et al. The 
cutaneous course of deep inferior epigastric perforators: implications for flap thinning. J Plast Reconstr Aesthet Surg. 2009;62(8):986-90.

273. Tran NV, Buchel EW, Convery PA. Microvascular complications of DIEP flaps. Plast Reconstr Surg. 2007;119(5):1397-405; discussion 1406-8.

274. Ayhan S, Oktar SO, Tuncer S, Yucel C, Kandal S, Demirtas Y. Correlation between vessel diameters of superficial and deep inferior epigastric systems: Doppler ultrasound assessment. J Plast Reconstr Aesthet Surg. 2009;62(9):1140-7.

275. Wechselberger G, Schoeller T, Bauer T, Ninkovic M, Otto A, Ninkovic M. Venous superdrainage in deep inferior epigastric perforator flap breast reconstruction. Plast Reconstr Surg. 2001;108(1):162-6.

276. Ali R, Bernier C, Lin YT, Ching W-C, Rodriguez EP, Cardenas-Mejia A, et al. Surgical Strategies to Salvage the Venous Compromised Deep Inferior Epigastric Perforator Flap: Ann Plast Surg. octubre de 2010;65(4):398-406.

277. Villafane O, Gahankari D, Webster M. Superficial inferior epigastric vein (SIEV): «lifeboat» for DIEP/TRAM flaps. Br J Plast Surg. 1999;52(7):599.

278. Barnett GR, Carlisle IR, Gianoutsos MP. The cephalic vein: an aid in free TRAM flap breast reconstruction. Report of 12 cases. Plast Reconstr Surg. 1996;97(1):71-6; discussion 77-8.

279. Tutor EG, Auba C, Benito A, Rábago G, Kreutler W. Easy venous superdrainage in DIEP flap breast reconstruction through the intercostal branch. J Reconstr Microsurg. 2002;18(7):595-8.

280. Shamsian N, Sassoon E, Haywood R. Salvage of a congested DIEP flap: a new technique. Plast Reconstr Surg. 2008;122(1):41e - 42e.

281. Cohn AB, Walton RL. Immediate autologous breast reconstruction using musclesparing TRAM flaps with superficial epigastric system turbocharging: a salvage option. J Reconstr Microsurg. 2006;22(3):153-6.

282. Minqiang X, Jie L, Dali M, Lanhua M. Hemodynamic effect of different kinds of venous augmentation in a pig transmidline flap model of DIEP flap. J Reconstr Microsurg. 2013;29(6):379-86.

283. Hallock GG, Rice DC. Efficacy of venous supercharging of the deep inferior epigastric perforator flap in a rat model. Plast Reconstr Surg. 2005;116(2):551-5; 
discussion 556.

284. Fidalgo Rodríguez F, Redondo Camacho A, Dean Ferrer A, Rioja Torrejón LF. Remodelación de los colgajos TRAM libres y DIEP. Cir Plástica Ibero-Latinoam. 2007;33(1):37-48. 